\title{
Results of Waste Transfer and Back-Dilution in Tanks 241-SY-101 and 241-SY-102
}

\author{
LA Mahoney \\ ZI Antoniak \\ WB Barton ${ }^{(a)}$ \\ JM Conner ${ }^{(a)}$ \\ NW Kirch ${ }^{(a)}$ \\ CW Stewart \\ BE Wells
}

July 2000

Prepared for

the U.S. Department of Energy

under Contract DE-AC06-76RLO 1830

Pacific Northwest National Laboratory

Richland, Washington

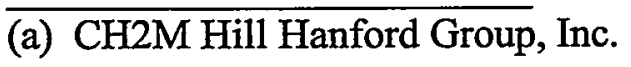




\section{DISCLAIMER}

This report was prepared as an account of work sponsored by an agency of the United States Government. Neither the United States Government nor any agency thereof, nor any of their employees, make any warranty, express or implied, or assumes any legal liability or responsibility for the accuracy, completeness, or usefulness of any information, apparatus, product, or process disclosed, or represents that its use would not infringe privately owned rights. Reference herein to any specific commercial product, process, or service by trade name, trademark, manufacturer, or otherwise does not necessarily constitute or imply its endorsement, recommendation, or favoring by the United States Government or any agency thereof. The views and opinions of authors expressed herein do not necessarily state or reflect those of the United States Government or any agency thereof. 


\section{DISCLAIMER}

Portions of this document may be illegible in electronic image products. Images are produced from the best available original document. 


\section{Abstract}

This report chronicles the process of remediation of the flammable gas hazard in Tank 241-SY-101 (SY-101) by waste transfer and back-dilution from December 18, 1999 through April 2, 2000. A brief history is given of the development of the flammable gas retention and release hazard in this tank, and the transfer and dilution systems are outlined. A detailed narrative of each of the three transfer and dilution campaigns is given to provide structure for the balance of the report. Details of the behavior of specific data are then described, including the effect of transfer and dilution on the waste levels in Tanks SY-101 and SY-102, data from strain gauges on equipment suspended from the tank dome, changes in waste configuration as inferred from neutron and gamma logs, headspace gas concentrations, waste temperatures, and the mixer pump operating performance. Operating data and performance of the transfer pump in SY-101 are also discussed. 


\section{Summary}

This report chronicles the process of remediation of the flammable gas hazard in Tank 241-SY-101 (SY-101) by waste transfer and back dilution from December 18, 1999 through April 2, 2000. The periodic gas releases from SY-101 that began shortly after it was first filled in 1980 led to the creation of the Flammable Gas Watch List of tanks considered to be potentially hazardous and placement of flammable gas administrative controls on all tanks. A mixer pump was installed in July 1993 that prevented the large gas releases. However, over the next seven years, growth of the floating crust layer caused an accelerating waste level rise that reached 434 inches in February 1999, three feet above its post-mitigation level of 398 inches.

To reverse these effects, sequences of waste removal and water back-dilution were initiated with the objective of dissolving most of the soluble solids to prevent significant gas retention. Based on laboratory dilution studies and analyses, this required a 1:1 dilution ratio, or a 500,000 gallon transfer with approximately equal back-dilution. The transfer and dilution system consisted of a transfer pump, an overground, encased transfer line, and a drop-leg connection with an anti-siphon break at Tank SY-102. The system also included a pressurized, heated water supply for in-line dilution of the waste being removed from SY-101. The drop leg in SY-102 was used to minimize ammonia and volatile organic compounds within the SY-Farm ventilation system.

Three campaigns of transfers followed by back dilutions were accomplished. The first campaign, from December 18 to December19, 1999, mitigated the immediate level concern by dissolving a large fraction of the original freeboard. The second transfer and top back-dilution, January 25 to 27,2000 , removed the major hazard of level rise by dissolving the crust and releasing most of its stored gas. The subsequent low back-dilution, from February 21 to February 23, dissolved most of the soluble solids in the mixed slurry and the remaining crust remnants. The third transfer was performed February 27 to March 2, 2000, and the final back dilution was completed on March 15, 2000, bringing the tank to the planned end state. Table S-1 provides a summary of the transfer and back-dilution volumes.

Table S-1. SY-101 Transfer and Dilution Volumes (gallons)

\begin{tabular}{|l|l|l|l|l|}
\hline & Transfer & $\begin{array}{l}\text { Top Back } \\
\text { Dilution }\end{array}$ & $\begin{array}{l}\text { Bottom Back } \\
\text { Dilution }\end{array}$ & $\begin{array}{l}\text { Total Back } \\
\text { Dilution }\end{array}$ \\
\hline Campaign \#1 & 89,500 & 26,000 & 36,000 & 62,000 \\
\hline Campaign \#2 & 240,500 & 89,500 & 150,000 & 239,500 \\
\hline Campaign \#3 & 286,000 & 36,500 & 187,000 & 223,500 \\
\hline Cumulative & 616,000 & 152,000 & 373,000 & 525,000 \\
\hline
\end{tabular}


Because the second and third transfers also removed of some of the dilution water added earlier, not all of the total back-dilution volume can be counted in the dilution ratio. Based on a detailed cumulative mass balance, a total of 434,000 gallons of water were left in the tank out of the 525,000 total dilution. Of the total 973,000 gallons in the tank after the three campaigns, 539,000 gallons were undiluted original waste. This gives a final dilution ratio of $0.8: 1$.

Figure S-1 shows the changes in waste level during the three transfer and back-dilution operations by way of a summary of the entire process. The level changes corresponded closely to the combined effects of waste transfer, water addition, and gas release. The thick crust layer rose and fell smoothly and uniformly in response dilution and transfer without evidence of major hang-up or distortion. However a ring of waste up to a meter thick in places remained attached to the wall during the first and second transfers.

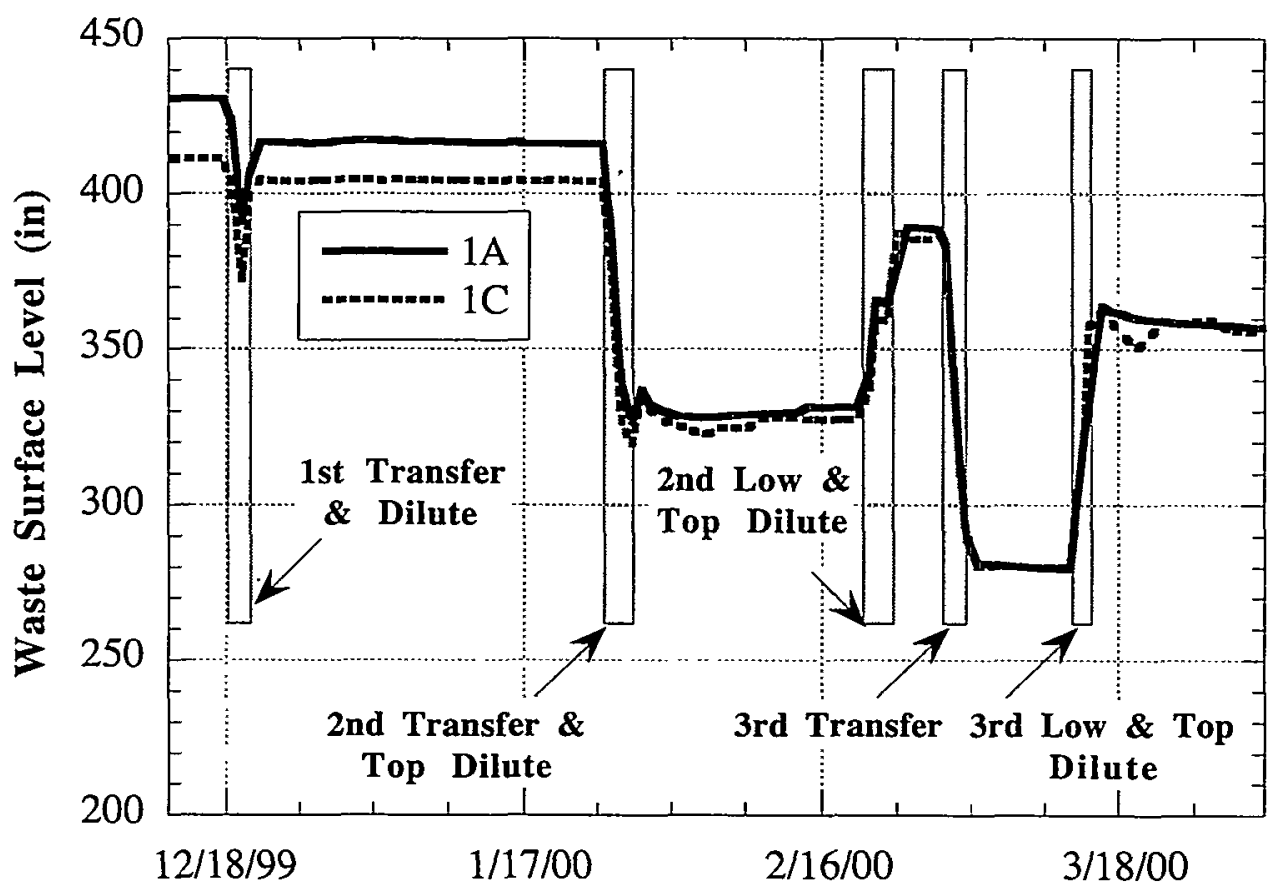

Figure S-1. Waste Level History During Remediation

Retained gas was released from the crust layer during dissolution, and the ammonia concentration increased after the crust was dissolved as expected. Releases were largest during and after the second top dilution when the bulk of the crust dissolved. Local bubble slurry flows, crust capsize and sinking, and "landslides" of waste from the tank walls were observed during this period. The dome space hydrogen concentration peaked at about 3,000 ppm during the crust dissolution in the second top dilution. The ammonia concentration remained under $1,000 \mathrm{ppm}$ in SY-101 but approached 8,000 ppm in SY-102 during the third transfer. The ammonia concentration at the SY-farm exhaust stack remained below 2,000 ppm. 
Mixer pump operations between the various stages of transfer and dilution showed reduced motor power and volute and nozzle pressures consistent with reduced density and viscosity resulting from dilution. There was no evidence of performance degradation due to gas or solids ingestion as the base of the crust layer descended close to the inlet. The transfer pump performed flawlessly throughout. The operators were able to control both the transfer and in-line dilution flow precisely.

At the completion of the three campaigns, neutron probe data showed a uniform count rate over the majority of the waste depth. No crust was noted from these examinations. Visually a thin, mobile layer of a light-colored foamy material or "scum" covered most of the surface with small pools of liquid surface occasionally visible. However, the three-meter-thick crust existing before remediation no longer exists nor is it expected to reform. Since the second and third back dilutions added cold water to the tank, the average waste temperature was reduced from $120^{\circ} \mathrm{F}$ to approximately $95^{\circ} \mathrm{F}$ after the third campaign, which was close to the estimated steady-state temperature.

The waste conditions are being monitored and evaluated during the summer of 2000 to provide confirmatory data for removing the tank from the Flammable Gas Watch List and returning it to normal service. Based on evidence collected to date, there is little doubt that these goals will be achieved. 


\section{Contents}

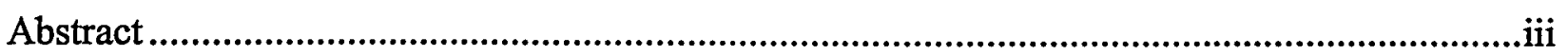

Summary

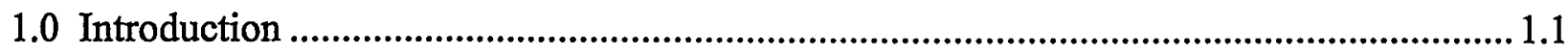

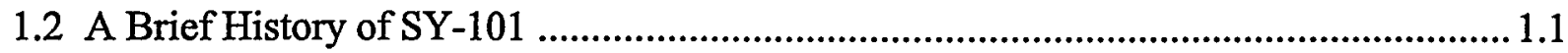

1.2 Summary of Transfer and Back-Dilution Campaigns .................................................. 1.2

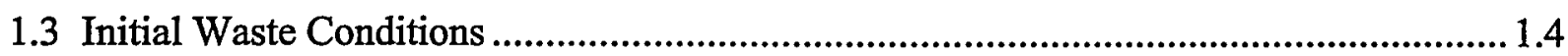

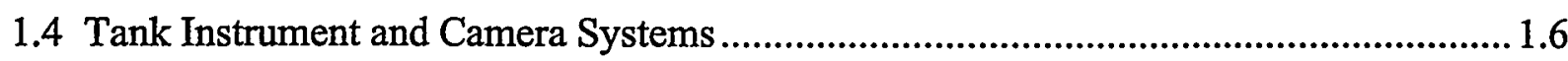

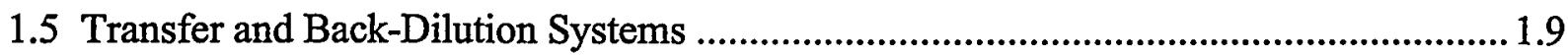

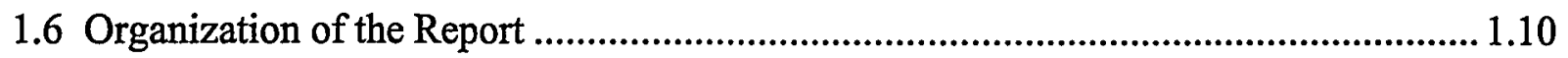

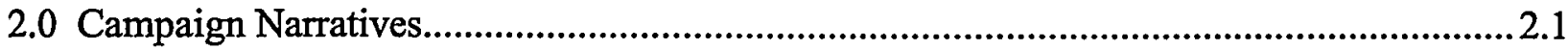

2.1 Narrative of Events During the First Campaign ........................................................... 2.1

2.2 Narrative of Events During the Second Campaign ........................................................ 2.9

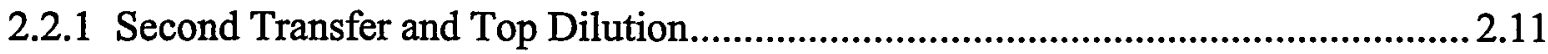

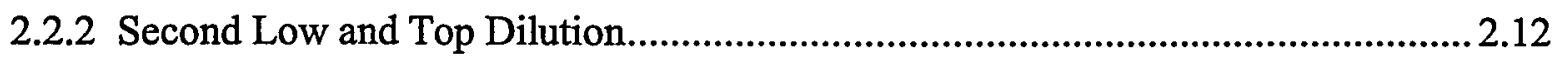

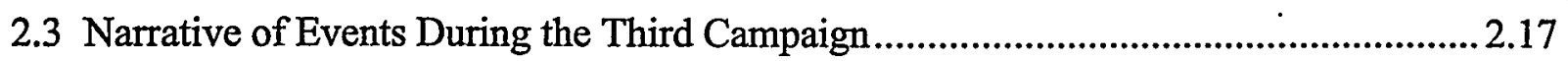

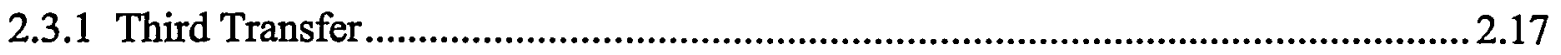

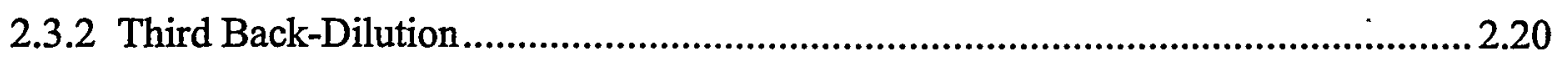

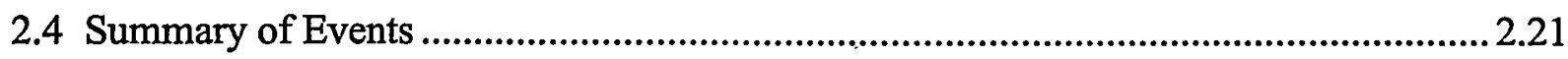

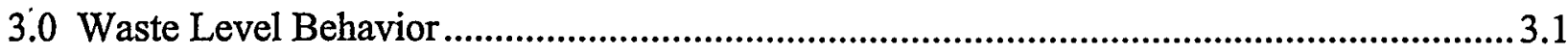

3.1 Visual Determination of Local Waste Level Drop ..................................................... 3.1

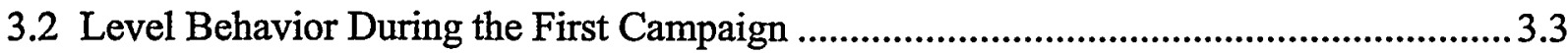

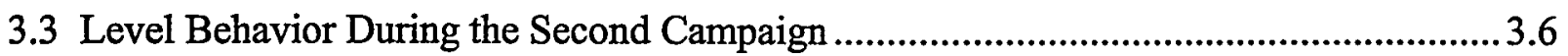

3.4 Level Behavior During the Third Campaign............................................................... 3.10

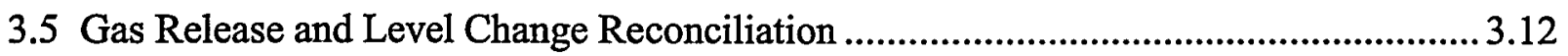

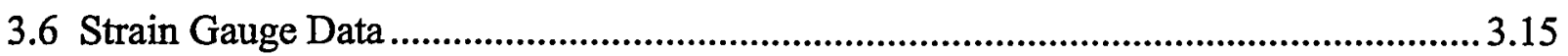

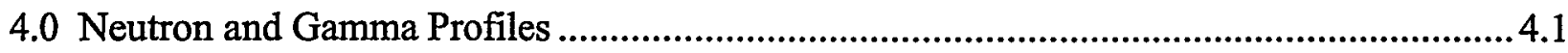

4.1 Neutron and Gamma Profiles During the First Campaign .............................................. 4.1

4.2 Neutron and Gamma Profiles During the Second Campaign.......................................... 4.3

4.3 Neutron and Gamma Profiles During the Third Campaign........................................... 4.11

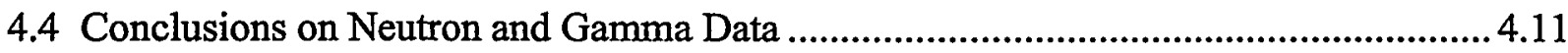




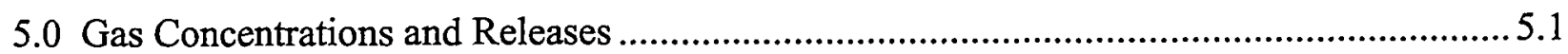

5.1 Gas Release During the First Campaign ......................................................... 5.3

5.2 Gas Release During the Second Campaign .......................................................5.6

5.2.2 Second Transfer and Top Dilution ............................................................. 5.6

5.2 .2 Second Low Dilution............................................................................. 5.9

5.3 Gas Releases During the Third Campaign ...................................................... 5.11

5.4 Summary of Gas Release Behavior ............................................................... 5.13

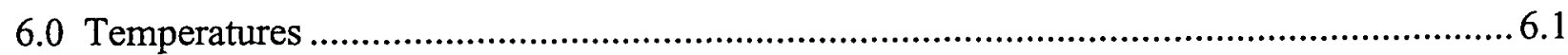

6.1 Temperature Behavior During the First Campaign...............................................6.1

6.2 Temperature Behavior During the Second Campaign ........................................... 6.7

6.2.1 Second Transfer and Top Dilution........................................................... 6.7

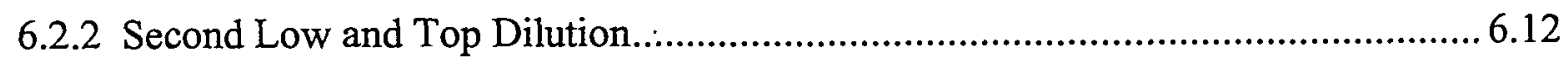

6.3 Temperature Behavior During the Third Campaign .............................................6.14

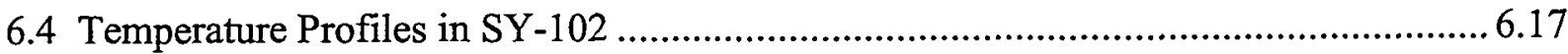

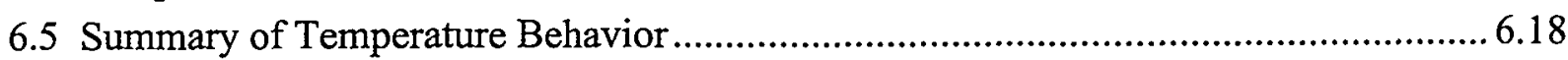

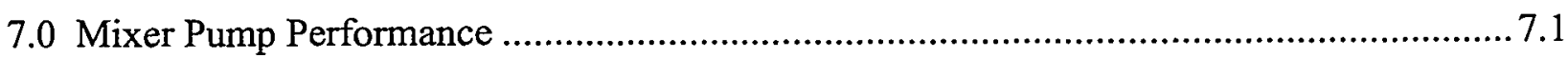

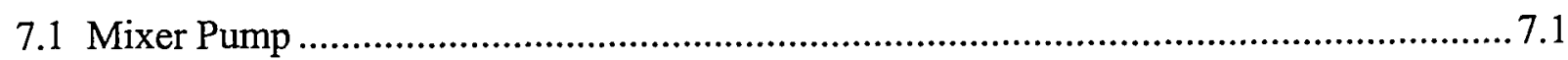

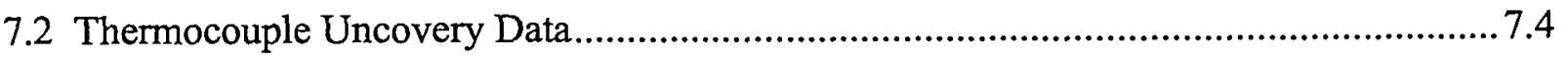

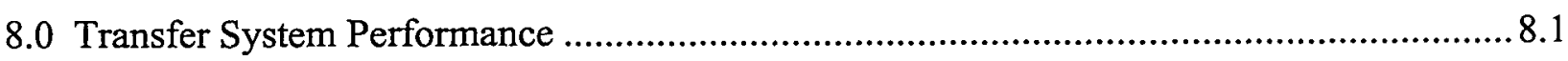

9.0 Summary and Conclusion ...............................................................................

9.1 Summary of Observations Versus Predictions and Expectations ...............................9.1

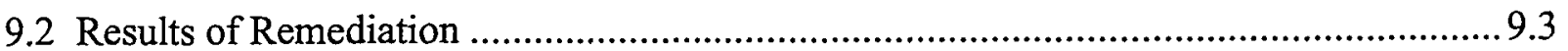

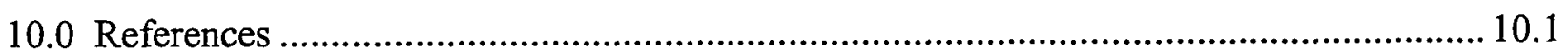




\section{Figures}

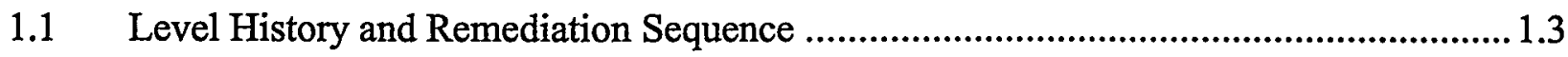

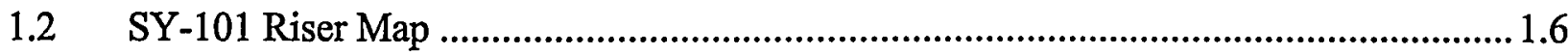

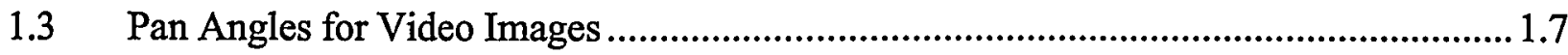

1.4 View of Transfer Pump from Portable Camera in Riser 4A ............................................. 1.8

1.5 View of Mixer Pump Column from the "Fisheye" Camera in Riser 5A .......................... 1.8

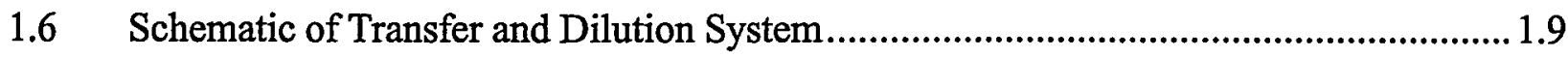

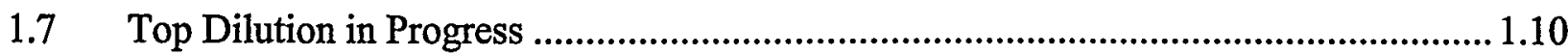

2.1 Waste Attachment to Tank Wall During Transfer 1a ........................................................ 2.3

2.2 Waste Surface Around the Mixer Pump During Transfer 1a ........................................... 2.4

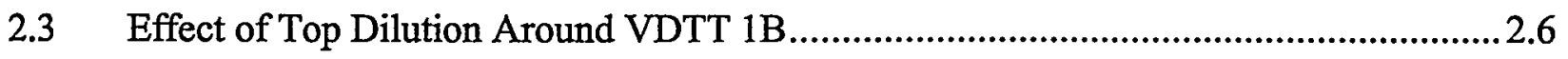

2.4 Result of Top Dilution 1b Around the Mixer Pump ........................................................ 2.7

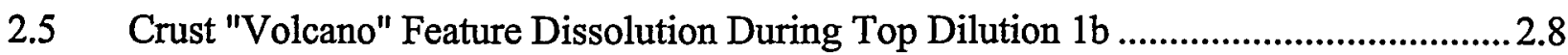

2.6 Slurry Flows Around the VDTTs After the First Campaign ............................................ 2.9

2.7 Waste Layer Attached to Tank Wall After Transfer 2a ................................................... 2.11

2.8 "Landslide" from Tank Wall During Top Dilution 2b................................................... 2.13

$2.9 \quad$ Bubble Slurry Flow During Top Dilution $2 b$................................................................ 2.14

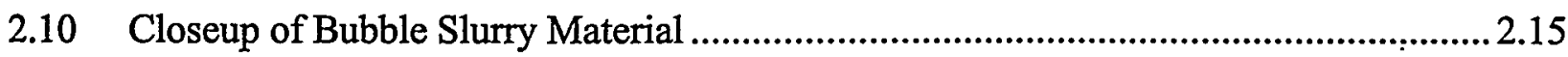

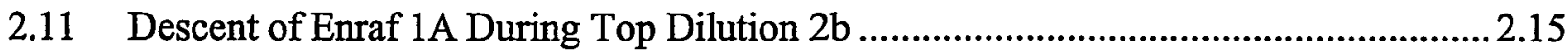

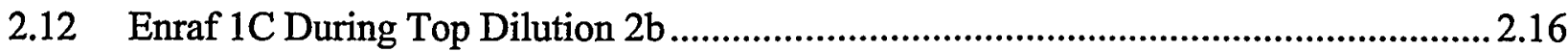

2.13 Waste Attached to the Tank Wall After Transfer 3b .....................................................19

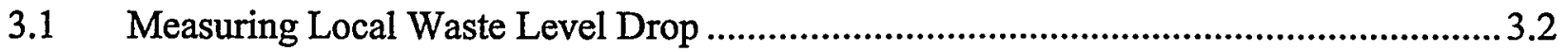

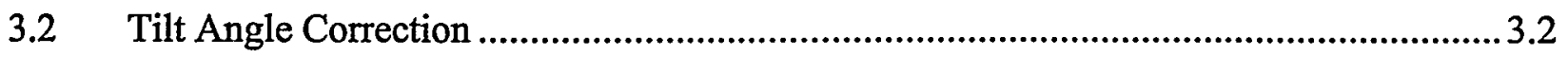

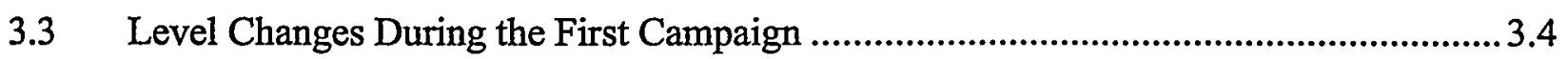

3.4 Level Changes After the First Campaign ................................................................... 3.5

3.5 Observed Waste Level Drops During the First Transfer 1a .............................................. 3.5

3.6 Level Changes During Transfer 2a and Top Dilution 2b...............................................

3.7 Level Changes Between Top Dilution $2 b$ and Low Dilution 2c..................................... 3.8

3.8 Level Changes During Low Dilutions 2c-d and Top Dilution 2e......................................

3.9 Observed Level Changes During Transfer 2a .................................................................. 3.9

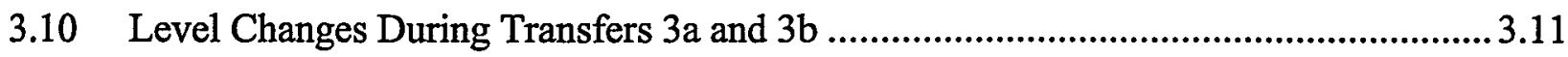

3.11 Level Changes During Back-Dilutions 3c-f ................................................................

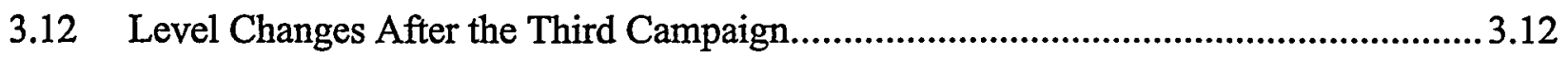

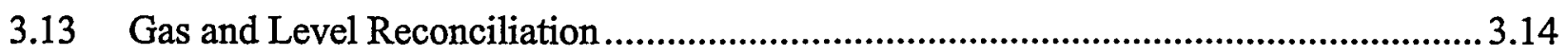

3.14 Pump Column Strains During the First Transfer and Dilution.....................................15 
3.15 Riser 17C Strains During the First Transfer and Dilution.............................................16

3.16 Pump Column Strains During Transfer 2a and Top Dilution 2b.................................... 3.16

4.1 Neutron Profiles at 17B Before and After the First Campaign ..................................... 4.2

4.2 Neutron Profiles at 17C Before and After the First Campaign ....................................... 4.2

4.3 Neutron Profiles at 17B Between the First and Second Campaigns................................4.3

4.4 Neutron Profiles at 17C Between the First and Second Campaigns................................4.4

4.5 Neutron Profiles at 17B Before and After Transfer 2a and Top Dilution 2b .................. 4.4

4.6 Gamma Profiles at 17B Before and After Transfer 2a and Top Dilution 2b ...................4.5

4.7 Neutron Profiles at 17C Before and After Transfer 2a and Top Dilution 2b ...................4.5

4.8 Gamma Profiles at 17C Before and After Transfer 2a and Top Dilution 2b .................. 4.6

4.9 Neutron Profiles at 17B Between Top Dilution $2 b$ and Low Dilution 2c....................... 4.7

4.10 Gamma Profiles at 17B Between Top Dilution $2 b$ and Low Dilution $2 c$.......................4.8

4.11 Neutron Profiles at $17 \mathrm{C}$ Between Top Dilution $2 \mathrm{~b}$ and Low Dilution $2 \mathrm{c}$.......................... 4.8

4.12 Gamma Profiles at 17C Between Top Dilution $2 b$ and Low Dilution $2 c$....................... 4.9

4.13 Neutron Profiles at 17B Before and After Dilutions 2c-e.............................................. 4.9

4.14 Gamma Profiles at 17B Before and After Dilutions 2c-e .......................................... 4.10

4.15 Neutron Profiles at 17C Before and After Dilutions 2c-e .............................................10

4.16 Gamma Profiles at 17B Before and After Dilutions 2c-e ........................................... 4.11

4.17 Neutron Profiles at 17B Before and After Transfers 3a-b............................................12

4.18 Gamma Profiles at 17B Before and After Transfers 3a-b ............................................12

4.19 Neutron Profiles at 17C Before and After Transfers 3a-b............................................13

4.20 Gamma Profiles at 17C Before and After Transfers 3a-b ............................................ 4.13

4.21 Neutron Profiles at 17B Before and After Dilutions 3c-f ............................................14

4.22 Gamma Profiles at 17B Before and After Dilutions 3c-f............................................. 4.14

4.23 Neutron Profiles at 17C Before and After Dilutions 3c-f ........................................... 4.15

4.24 Gamma Profiles at 17C Before and After Dilutions 3c-f............................................ 4.15

4.25 Neutron Profiles at 17B After the Third Campaign...................................................16

4.26 Neutron Profiles at 17C After the Third Campaign .................................................... 4.16

5.1 SY-101 Headspace Concentrations During First Campaign ............................................5.3

5.2 Hydrogen/Nitrous Oxide Ratio During the First Campaign.......................................... 5.4

5.3 SY-101 Hydrogen and Ammonia Between the First and Second Campaigns .................5.5

5.4 SY-102 Headspace Gas Concentrations During First Campaign ...................................5.6

5.5 SY-101 Headspace Gas Concentrations During Transfer 2a and Top Dilute 2b .............5.7

5.6 Hydrogen/Nitrous Oxide Ratio During Transfer $2 \mathrm{a}$ and Top Dilute $2 \mathrm{~b}$........................... 5.8

5.7 SY-102 Headspace Concentrations During Second Campaign ....................................5.8

5.8 SY-101 Gas Concentration and $\mathrm{H}_{2} / \mathrm{N}_{2} \mathrm{O}$ Ratio After the Second Campaign ...................5.9 
5.9 SY-101 Gas Concentrations During Dilutions 2c-e..................................................10

$5.10 \mathrm{SY}-101 \mathrm{H}_{2} / \mathrm{N}_{2} \mathrm{O}$ Ratio During Dilution 2c-e .........................................................

5.11 SY-101 Gas Concentrations and $\mathrm{H}_{2} / \mathrm{N}_{2} \mathrm{O}$ Ratio During Transfers 3a-b ..................... 5.12

5.12 SY-102 Gas Concentrations During the Third Transfer .......................................... 5.12

5.13 SY-101 Gas Concentrations and $\mathrm{H}_{2} / \mathrm{N}_{2} \mathrm{O}$ Ratio During Dilutions $3 \mathrm{c}-\mathrm{f}$........................ 5.13

5.14 SY-101 Gas Concentrations and $\mathrm{H}_{2} / \mathrm{N}_{2} \mathrm{O}$ Ratio After the Third Campaign................... 5.14

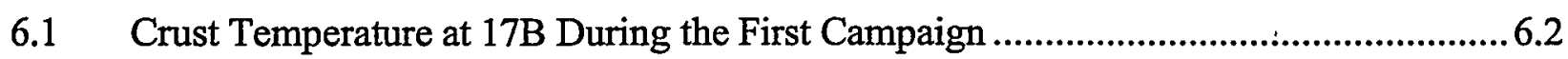

6.2 Crust Temperature at 17C During the First Campaign ...................................................6.3

6.3 Mixed Slurry Temperature at 17B During the First Campaign ......................................... 6.4

6.4 Mixed Slurry Temperature at 17C During the First Campaign .......................................6.5

6.5 Temperature Profile History at 17B During the First Campaign.......................................6.6

6.6 Temperature Profile History at 17C During the First Campaign.....................................6.6

6.7 Upper Temperatures at 17B During Transfer 2a and Top Dilution 2b............................6.8

6.8 Upper Temperature at 17C During Transfer 2a and Top Dilution $2 \mathrm{~b}$..............................6.8

6.9 Lower Temperatures at 17C During Transfer 2a and Top Dilution 2b..........................6.9

6.10 Temperature Profile at 17B During Transfer 2a and Top Dilution 2b..........................6.10

6.11 Temperature Profile at 17C During Transfer 2a and Top Dilution 2b.............................10

6.12 Temperature Profiles at 17B During and After Top Dilution 2b................................6.11

6.13 Temperature Profile at 17C During and After Top Dilution 2b .......................................11

6.14 Crust Temperatures at 17B During Dilutions 2c-e .....................................................12

6.15 Crust Temperatures at 17C During Dilutions 2c-e ....................................................13

6.16 Mixed Slurry Temperatures at 17B During Dilutions 2c-e...........................................13

6.17 Mixed Slurry Temperatures at 17C During Dilutions 2c-e .........................................14

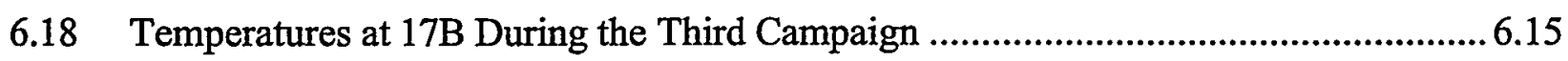

6.19 Temperatures at 17C During the Third Campaign ......................................................6.16

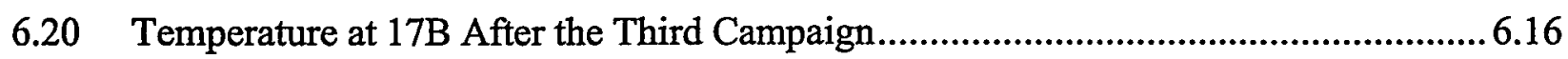

6.21 Temperatures at 17C After the Third Campaign ............................................................... 6.17

6.22 SY-102 Temperature Profiles ............................................................................... 6.18

7.1 Run-Average Power and Volute Pressure for All Campaigns......................................... 7.2

7.2 Run-Average Discharge Line Pressure Drop and Inlet Waste Temperature..................... 7.2

7.3 Pump Oil Temperature Transients Through All Remediation Campaigns .......................7.4

7.4 Thermocouple Uncovery Transient at 17B December 26, 1999 .........................................5

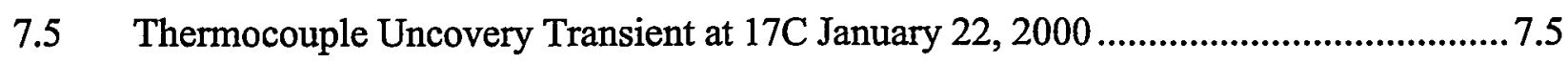

7.6 Thermocouple Uncovery Transient at 17C, February 24, 2000 ...................................... 7.6

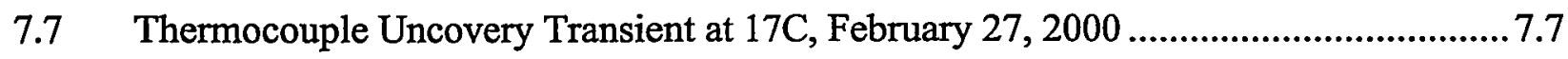

7.8 Thermocouple Uncovery Transient at 17B, March 17, 2000 ............................................ 7.7 
7.9 Thermocouple Uncovery Transient at 17C, March 17, 2000 f......................................... 7.8

7.10 Thermocouple Uncovery Transient at 17B, March 24, 2000 .......................................... 7.9

7.11 Thermocouple Uncovery Transient at 17C, April 1, 2000 ............................................. 7.9

8.1 Waste Flow, Water Flow, and Dilution Ratio for the First Transfer .............................. 8.1

8.2 Waste Flow, Water Flow, and Dilution Ratio for the Second Transfer........................... 8.2

8.3 Waste Flow, Water Flow, and Dilution Ratio for Transfer 3a ...................................... 8.2

8.4 Waste Flow, Water Flow, and Dilution Ratio for Transfer 3b ...................................... 8.3

8.5 Transfer Pump Performance During Transfer 3a.......................................................... 8.5

8.6 Comparison of Transfer Pump Performance Between Transfers 1a and 3a .................... 8.6

8.7 Transfer Flow Versus Percent Speed for Transfer 3a .................................................... 8.6

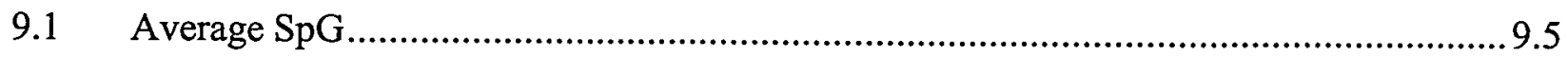

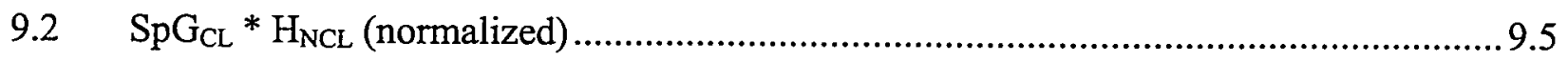

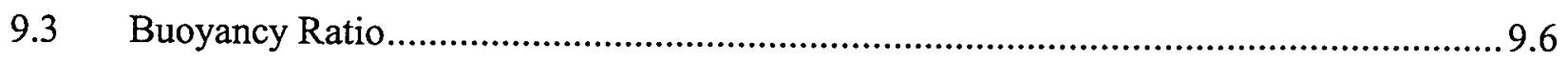




\section{Tables}

1.1 Transfer and Back-Dilution Event Summary .................................................................. 1.2

1.2 Net Results of Transfer and Dilution for Each Campaign ................................................. 1.5

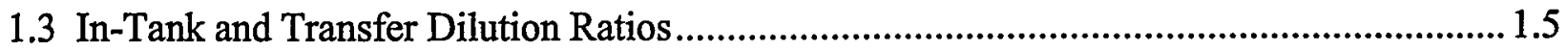

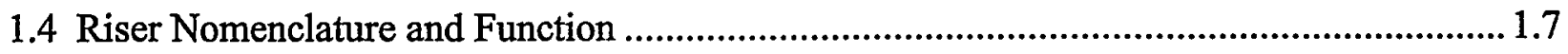

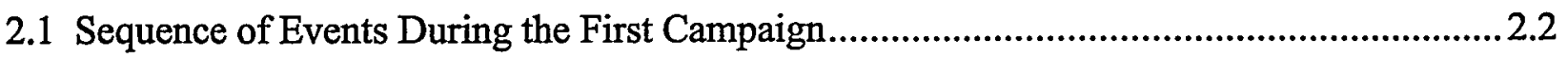

2.2 Sequence of Events During the Second Campaign ........................................................... 2.10

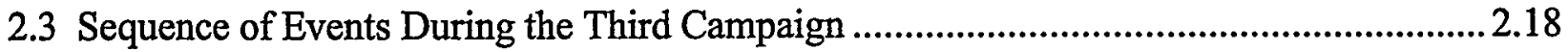

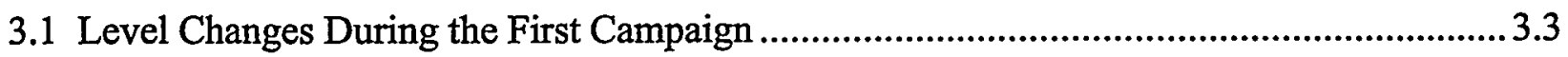

3.2 Level Changes During the Second Campaign ......................................................................... 3.6

3.3 Level Changes During the Third Campaign........................................................................10

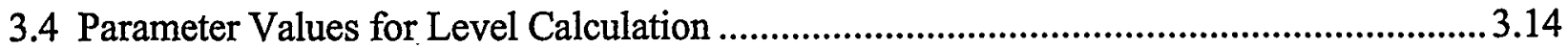

5.1 Gas Release Volumes During Remediation Campaigns...................................................... 5.2

7.1 Remediation Campaigns' Effects on Mixer Pump Parameters ............................................... 7.3

8.1 Transfer Flows and Dilution Ratio Summary ....................................................................... 8.4

9.1 Effect of Transfer and Back-Dilution on SY-101 Waste Configuration ..............................9.5 


\subsection{Introduction}

This report chronicles the process of remediation of the flammable gas hazard in Tank 241-SY-101 (SY-101) by waste transfer and back-dilution from December 18, 1999, through April 2, 2000. This is the last in a long series of efforts that began over a decade ago to understand and tame this tank. As a result of these accomplishments, SY-101 is expected to be removed from the Flammable Gas Watch List (FGWL) and returned to normal service in the fall of 2000.

Section 1.1 briefly describes the history of the gas retention and release hazard, and Section 1.2 summarizes the steps in the transfer and dilution process. Section 1.3 describes the waste conditions prior to the first transfer, Section 1.4 introduces the tank instrumentation and camera system by which the process was recorded, and Section 1.5 describes the transfer and backdilution system. Section 1.6 outlines the balance of the report.

\subsection{A Brief History of SY-101}

SY-101 began gaining notoriety shortly after it was first filled in 1980, when the waste level began showing the characteristic "sawtooth" pattern of gradual, linear rises punctuated by sudden drops that were later recognized as the results of buoyant displacement (BD) gas release events (GREs). In the late 1980s, gas monitoring data showed that some of these gas releases made gas concentrations flammable in the headspace for a brief period. This spawned a period of intense study of and debate about gas release in general and SY-101 in particular that led to the creation of the FGWL of tanks considered to be potentially hazardous and placement of flammable gas administrative controls on all tanks. At the same time, a high-priority project was initiated to mitigate BD GREs in SY-101.

A BD GRE occurs when a portion of the nonconvective layer retains enough gas to become buoyant, rises to the waste surface, breaks up, and releases some of its stored gas. Five other double-shell tanks (DSTs) exhibit buoyant displacements, but those occurring in SY-101, especially during 1989-1992, were an order of magnitude bigger and faster and about three times as frequent (Meyer et al. 1997).

The installation of a mixer pump in July 1993 successfully mitigated gas retention in the settled solids layer in SY-101 and prevented BD GREs, as intended. However, mixer pump operation over the next seven years allowed gas retention in and growth of the floating crust layer, which caused an accelerating waste level rise. By early 1999 the crust thickness had grown to $3 \mathrm{~m}$ (120 inches), and the waste level had risen to 434 inches, three feet above its postmitigation level of 398 inches (Rassat et al. 2000). The waste had accumulated as much gas in the crust as it had released during some of its larger historic GREs. To reverse these effects, sequences of waste removal and water back-dilution were initiated in December 1999 with the objective of dissolving most of the soluble solids to prevent significant gas retention (Barton 1999). Section 1.2 summarizes this final remediation program, which, when confirmed successful, will have permanently cured the flammable gas problem in this most hazardous of Hanford tanks. 


\subsection{Summary of Transfer and Back-Dilution Campaigns}

Three sequences of transfers and back-dilutions (remediation campaigns) were conducted. The specific transfer and back-dilution events are listed for each campaign in Table 1.1 and shown with a plot of the waste level history in Figure 1.1. The "Action" column is included to aid in identifying specific operations in each campaign throughout the report. For example, the second stage of the low back-dilution in the second campaign that occurred February 23 would be identified as " $2 \mathrm{~d} . "$

The first transfer and back-dilution campaign occurred December 18-20, 1999. After an 89,500-gallon transfer (1a) to Tank 241-SY-102 (SY-102), 26,000 gallons of water was added on top of the crust ( $1 \mathrm{~b}$ ) followed by an addition of 36,000 gallons (1c) at the transfer pump inlet (96 inches above the tank bottom). The initial part of the second transfer and back-dilution campaign, January 25-28, 2000, removed 240,500 gallons of waste from SY-101 (2a) and added 78,500 gallons of water on the waste surface (2b) to dissolve most of the crust and release its stored gas. Up to this point, heated dilution water was supplied through the water skid. In-line

Table 1.1. Transfer and Back-Dilution Event Summary

\begin{tabular}{|c|c|c|c|c|c|c|}
\hline Campaign & Action & $\begin{array}{c}\text { Start Date and } \\
\text { Time }\end{array}$ & $\begin{array}{c}\text { End Date and } \\
\text { Time }\end{array}$ & $\begin{array}{l}\text { Transfer to } \\
\text { SY-102 } \\
\text { (gal) }\end{array}$ & $\begin{array}{l}\text { Top Back- } \\
\text { Dilution } \\
\text { (gal) }\end{array}$ & $\begin{array}{l}\text { Bottom Back- } \\
\text { Dilution } \\
\text { (gal) }\end{array}$ \\
\hline \multirow[t]{3}{*}{1} & $\mathrm{a}$ & $12 / 18 \quad 0645$ & $12 / 19 \quad 0545$ & $89,500^{(\mathrm{a})}$ & & \\
\hline & $\mathrm{b}$ & $\begin{array}{ll}12 / 19 & 1834 \\
\end{array}$ & $12 / 20 \quad 0430$ & & $26,000^{(\text {a) }}$ & \\
\hline & c & $12 / 20 \quad 0445$ & $\begin{array}{ll}12 / 20 & 1458 \\
\end{array}$ & & & $36,000^{(\mathrm{a})}$ \\
\hline \multirow[t]{5}{*}{2} & $\mathrm{a}$ & $1 / 25 \quad 1622$ & $1 / 27 \quad 2207$ & $240,500^{(\mathrm{a})}$ & & \\
\hline & $\mathrm{b}$ & 0143 & 2219 & & $78,500^{(\mathrm{a})}$ & \\
\hline & $\mathrm{c}$ & 0240 & 2232 & & & $99,500^{(\text {b) }}$ \\
\hline & $\mathrm{d}$ & 1037 & 2053 & & & $50,500^{(\mathrm{c})}$ \\
\hline & $\mathrm{e}$ & 2057 & 2330 & & 11,000 & \\
\hline Totals \#2 & & & & 240,500 & 89,500 & 150,000 \\
\hline \multirow[t]{6}{*}{3} & a & 0635 & 0523 & $160,500^{(\mathrm{d})}$ & & \\
\hline & b & 1418 & 1326 & 125,500 & & \\
\hline & c & 1126 & 1300 & & & 127,000 \\
\hline & $\mathrm{d}$ & 1300 & 2030 & & 22,000 & \\
\hline & $\mathrm{e}$ & $3 / 14 \quad 2030$ & 1030 & & & 60,000 \\
\hline & $\mathrm{f}$ & 1030 & 1500 & & 14,500 & \\
\hline Totals \#3 & & & & 286,000 & 36,500 & 187,000 \\
\hline Total & & & & 616,000 & 152,000 & 373,000 \\
\hline \multicolumn{7}{|c|}{$\begin{array}{l}\text { (a) Heated water supplied through the water skid, } \sim 80^{\circ} \mathrm{F} \text { for top dilution, } \sim 120^{\circ} \mathrm{F} \text { for in-line and low } \\
\text { dilution. Raw water at } \sim 50^{\circ} \mathrm{F} \text { was used for dilution after January } 28,2000 \text {. } \\
\text { (b) Low dilution delayed three weeks to allow maximum crust dissolution. } \\
\text { (c) Low dilution suspended due to staffing constraints. } \\
\text { (d) Transfer halted to stay within WDOE permit limit of } 100 \mathrm{lbm} / \text { day ammonia release. }\end{array}$} \\
\hline
\end{tabular}




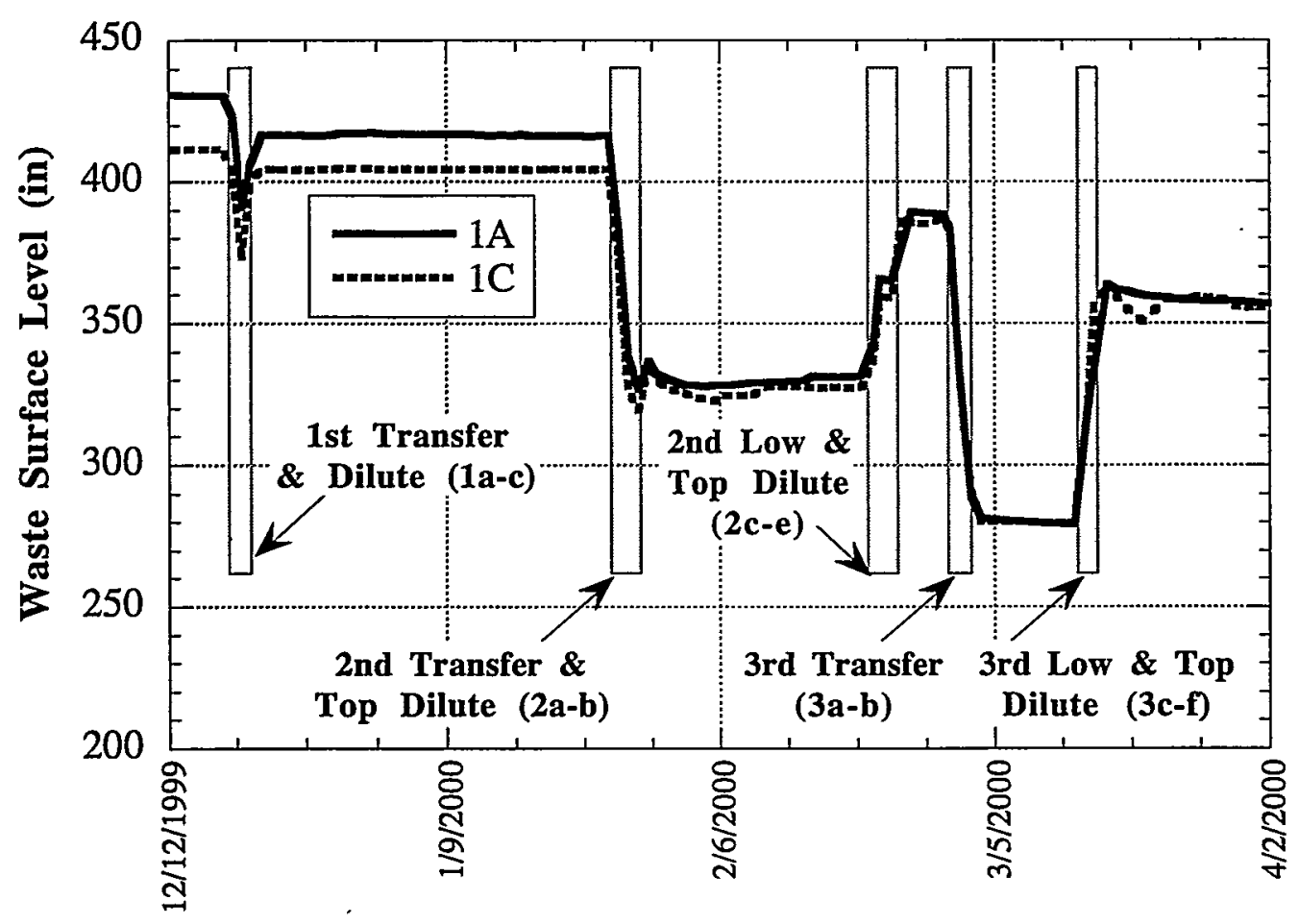

Figure 1.1. Level History and Remediation Sequence

and low dilution used $\sim 120^{\circ} \mathrm{F}$ water to match the waste temperature, and top dilutions were $\sim 80^{\circ} \mathrm{F}$ to prevent fog formation. Subsequent dilutions used raw water at $\sim 50^{\circ} \mathrm{F}$, bypassing the water skid.

After a three-week wait to allow maximum dissolution, 150,000 gallons of water were added (2c and 2d) at the transfer pump inlet February 21-23, 2000, and another 11,000 gallons were placed on top (2e) to dissolve some remaining crust debris. The third and final campaign was also performed in two stages. A 286,000 gallon transfer ( $3 a$ and $3 b$ ) was performed between February 29 and March 2, 2000, and 223,500 gallons of back-dilution (3c-f) was accomplished March 13-15, 2000. Of this, 187,000 gallons was added at the transfer pump inlet (3c and 3e) and 36,500 gallons placed on top of the waste ( $3 \mathrm{~d}$ and $3 \mathrm{f}$ ) to ensure that all remaining soluble material would dissolve as quickly as possible.

Volumes of waste and in-line dilution water transferred were calculated based on flow totalizer values. Water skid flow totalizer volumes were used for back-dilutions routed through the water skid. Volumes for the back-dilutions on February 21-23 (2c-e) and March 13-15 (3c-f), which used the SY-farm raw water supply and bypassed the water skid, were taken from the SY-farm raw water totalizer. This gauge was found to be less accurate than the water skid totalizer. For the low back-dilutions on February 21-23 (2c-e), the level change from Enraf 1A was taken to represent the dilution volume. For the third back-dilution, on March 13-15 (3c-f), the Enraf level change could not be used because of an apparent attached waste ring below 300 inches (see Sections 2.2 and 2.3). This ring reduced the effective diameter of the tank and caused a higher level rise than the water volume added. Therefore, for the third back-dilution 
(3c-f), the SY-farm raw water totalizer was adjusted by a factor of 0.862 , which is roughly equal to the offset between the Enraf and the raw water totalizer during the second low dilution (2c-d) on February 21-23 and part of the day on March 15 (3e-f) after the waste level rose above the waste ring.

Because transfers followed back-dilutions, some of the water added in the early stages was actually removed by later transfers, and the amount of original, undiluted SY-101 waste removed is less than the measured transfer volume. In order to correctly compute the actual dilution of the original SY-101 waste, a careful volume balance is necessary. The back-dilutions (1b-c) after the first transfer (1a) consisted of 26,000 gallons above the surface (1b) and 36,000 gallons below the surface (1c). Because little change was observed in the crust either visually or from the neutron scans (see Sections 2.1 and 3.1), the 26,000 gallons of water added on top of the crust was assumed to have no dilution effect below the crust. The 36,000 gallons of low addition affected the lower 300 inches of the tank (again based on neutron scans), or 825,000 gallons. So the fraction of original waste fraction removed by the second transfer (2a) was calculated as $(825-35) / 825$ or 0.956 .

The calculation for the third transfer (3a-b) was different because the crust broke up after the second top dilution (2b) and the waste became reasonably well mixed (see Section 2.2 and 3.2). A starting volume of 1,064,000 gallons (from the original 1980 fill) was used, and the "original waste" transferred in the first two campaigns was subtracted. The amount of dilution water added back to the tank (less what went out in the second transfer) was calculated, and a fraction of original waste transferred was computed as 0.719 for the third transfer $(3 a-b)$.

Table 1.2 shows the net results of each campaign in terms of original, undiluted SY-101 waste and water remaining in the tank. ${ }^{(a)}$ Referring to the last row of the table, the 616,000 gallons total waste removed from SY-101 consisted of 525,000 gallons of original waste plus 91,000 gallons of water. Remaining in the tank are 539,000 gallons of original, undiluted waste. Though 525,000 gallons of water were added, only 434,000 gallons remain in the tank. The resulting dilution ratios are summarized in Table 1.3. The final dilution ratio (volume of water to volume of original waste) is $0.8: 1$ (434/539:1). The dilution ratios after the first and second campaigns were $0.06: 1$ and $0.39: 1$, respectively. The in-line dilution ratios for the three transfers were $0.9: 1,0.80: 1$, and $0.34: 1$, respectively. Including the initial in-tank dilution, the overall dilution ratio of the waste entering SY-102 was almost constant at $0.9: 1$. The actual ratios were $0.9: 1,0.91: 1$, and $0.86: 1$, respectively, for the three transfers.

\subsection{Initial Waste Conditions}

Knowledge of the configuration and properties of the waste, especially the crust layer, was important to planning the remediation strategy and predicting how the waste would respond. This knowledge developed cumulatively from a series of studies and observations made over several years. The detailed temperature profiles provided by the validation probe provided a

(a) Letter from CHGI Process Control to RE Raymond, Tank 241-SY-101 Final Calculated Transfer and Dilution Volumes for Level Growth Remediation, 74B50-00-030, March 23, 2000. 
Table 1.2. Net Results of Transfer and Dilution for Each Campaign

\begin{tabular}{|c|c|c|c|c|c|c|}
\hline & $\begin{array}{c}\text { Total Mixed } \\
\text { Waste } \\
\text { Removed } \\
\text { (gal) }\end{array}$ & $\begin{array}{c}\text { Original } \\
\text { Waste } \\
\text { Removed } \\
\text { (gal) }\end{array}$ & $\begin{array}{c}\text { Original } \\
\text { Waste } \\
\text { Remaining } \\
\text { (gal) }\end{array}$ & $\begin{array}{c}\text { Dilution } \\
\text { Water } \\
\text { Removed } \\
\text { (gal) }\end{array}$ & $\begin{array}{c}\text { Dilution } \\
\text { Water } \\
\text { Added } \\
\text { (gal) }\end{array}$ & $\begin{array}{c}\text { Dilution } \\
\text { Water } \\
\text { Remaining } \\
\text { (gal) }\end{array}$ \\
\hline 1 & 89,500 & 89,500 & 974,500 & & 62,000 & 62,000 \\
\hline 2 & 240,500 & 230,000 & 744,500 & 10,500 & 239,500 & 291,000 \\
\hline 3 & 286,000 & 205,500 & 539,000 & 80,500 & 223,500 & 434,000 \\
\hline Total & 616,000 & 525,000 & 539,000 & 91,000 & 525,000 & 434,000 \\
\hline
\end{tabular}

Table 1.3. In-Tank and Transfer Dilution Ratios

\begin{tabular}{|l|c|c|c|}
\hline Transfer & $\begin{array}{c}\text { Initial In-tank } \\
\text { Dilution Ratio }\end{array}$ & $\begin{array}{c}\text { In-line Dilution } \\
\text { Ratio }\end{array}$ & $\begin{array}{c}\text { Overall Dilution } \\
\text { Ratio into SY-102 }\end{array}$ \\
\hline 1a & $0: 1$ & $0.9: 1$ & $0.9: 1$ \\
\hline 2a & $0.06: 1$ & $0.80: 1$ & $0.91: 1$ \\
\hline 3a-b & $0.39: 1$ & $0.34: 1$ & $0.86: 1$ \\
\hline End Result & $0.80: 1$ & & \\
\hline
\end{tabular}

measure of the thickness of the crust layer and the loosely settled solids on the bottom (Conner and Koreski 1998, 1999). In the summer and fall of 1998, the void fraction instrument (VFI) and retained gas sampler (RGS) provided detailed information on the distribution and volume of gas contained in the crust and the mixed slurry below (Stewart et al. 1998; Mahoney et al. 1999). The resistance to rotation of the VFI and of the mechanical mitigation arm that was deployed in the crust in May 1999 gave a qualitative measure of the strength of the waste. Beginning in February 1999, data from the small-bore neutron and gamma probes allowed us to see some of the detailed structure of the crust layer and how its thickness increased that spring. All of these data and observations were used to develop a crust model based on Archimedes' principle of buoyancy that predicted the changes in crust structure, waste level, liquid level, gas content, and crust base elevation resulting from the various transfer and dilution scenarios (Stewart et al. 1999). The picture of the crust that developed from this model and the observations that went into it is summarized below.

Before the first transfer and dilution campaign in December 1999, the waste in SY-101 was arranged in three layers: a floating crust, a mixed-slurry suspension of solid particles and small bubbles in liquid, and a thin layer of loosely settled solids on the bottom (Rassat et al. 2000). The crust consisted of four distinguishable sublayers. At the top was a 20-inch freeboard of porous broken material above the liquid level. While this layer had no strength as a unit, individual fragments might have had a yield strength in excess of $10,000 \mathrm{~Pa}$. Below that was 12 inches of "wet clay," with a low gas volume fraction estimated from neutron logs at 0.08 and a yield strength assumed greater than 3,000 $\mathrm{Pa}$. Below that lay 80 inches of "paste" with a moderate gas volume fraction (averaging 0.2 ) that decreased with increasing elevation and had a yield strength of 400 to $3,000 \mathrm{~Pa}$. At the bottom of the crust was about 8 inches of a "bubble slurry," high in gas (volume fraction possibly as great as 0.6 ) and low in yield strength (less than $100 \mathrm{~Pa}$ ). 
The mixed slurry was a fluid, based on its uniform temperature profile, the ability of the mixer pump to pump it, and the observation that bubbles and particles could move in it. Its gas volume fraction was estimated from earlier measurements and mixer pump operation parameters at about 0.03 , and its solid volume fraction was about 0.15 . The gas and solids were believed to exist in suspension as bubble-particle agglomerates as well as separate bubbles and particles.

The loosely settled solids layer was easily mobilized by the mixer pump jet, based on temperature response at the multifunction instrument trees (MITs) in risers $17 \mathrm{~B}$ and $17 \mathrm{C}$ during pump runs aimed at these risers. Gas fraction measurements made in 1998 and 1999 indicated that this layer retained about the same amount of gas as the slurry layer. Core sample analyses showed that its composition was the same as elsewhere in the tank.

\subsection{Tank Instrument and Camera Systems}

Figure 1.2 is a map of the SY-101 tank, showing all of the pertinent risers. The figure and the rest of this report use the "old" riser numbers to be consistent with historical data. Table 1.4 lists "old" and "new" riser numbers. The angles are stated with reference to the mixer pump nozzle orientation (approximately). Figure 1.3 shows the pan angles associated with the main video camera in riser $5 \mathrm{~A}$ to show the orientation of views to be shown in later sections. All video frames shown are from this camera unless noted otherwise. Note that the mixer pump column blocks the view of the transfer pump column by the camera. However, a portable camera was installed in riser 4A with a fixed wide-angle view of the transfer pump column and waste surface on the east side of the tank. Figure 1.4 is a sample of the view from this camera. A second fixed camera with a 180-degree "fisheye" lens is mounted with the main camera in riser 5A and aimed at the mixer pump. The view from this camera is shown in Figure 1.5.

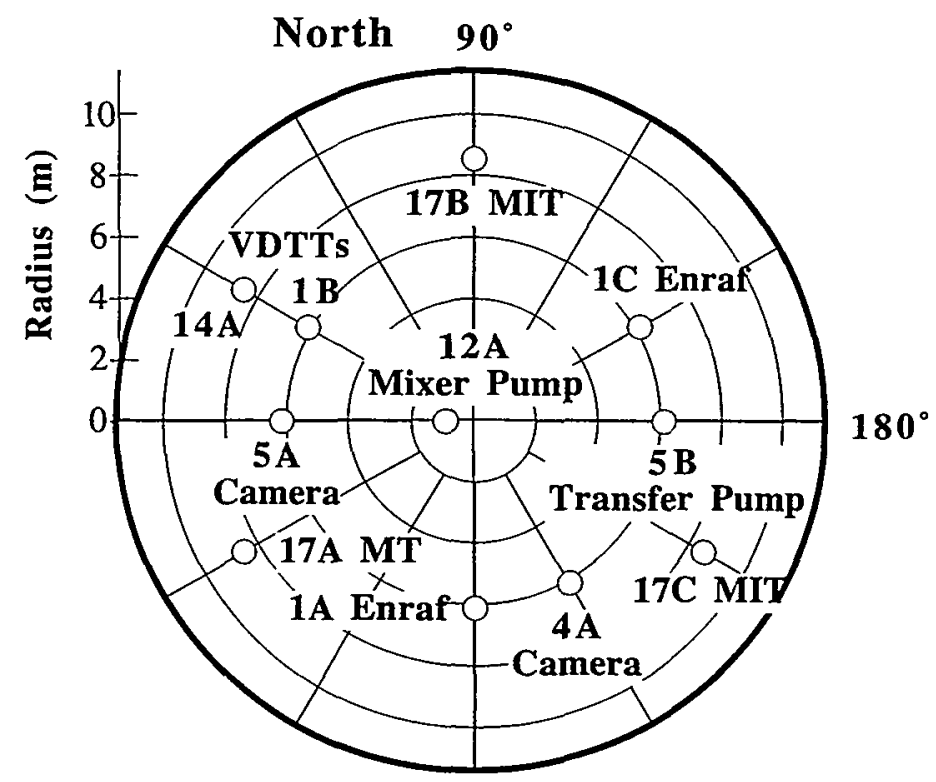

Figure 1.2. SY-101 Riser Map 
Table 1.4. Riser Nomenclature and Function

\begin{tabular}{|l|l|l|}
\hline “Old" Riser & "New" Riser & Function \\
\hline 1 A & 002 & Enraf surface level \\
\hline 1 C & 001 & Enraf surface level \\
\hline 14A & 015 & VDTT \\
\hline 17 A & 020 & Manual tape surface level \\
\hline 17 B & 018 & MTT temperature, neutron/gamma \\
\hline 17 C & 019 & MIT temperature, neutron/gamma \\
\hline 1B & 003 & VDTT \\
\hline 4A & 006 & Portable wide angle camera \\
\hline 5 A & 008 & Color video camera and "fisheye" camera \\
\hline 5B & 007 & PPP, transfer pump and back-dilution \\
\hline 12A & 013 & Mixer pump \\
\hline
\end{tabular}

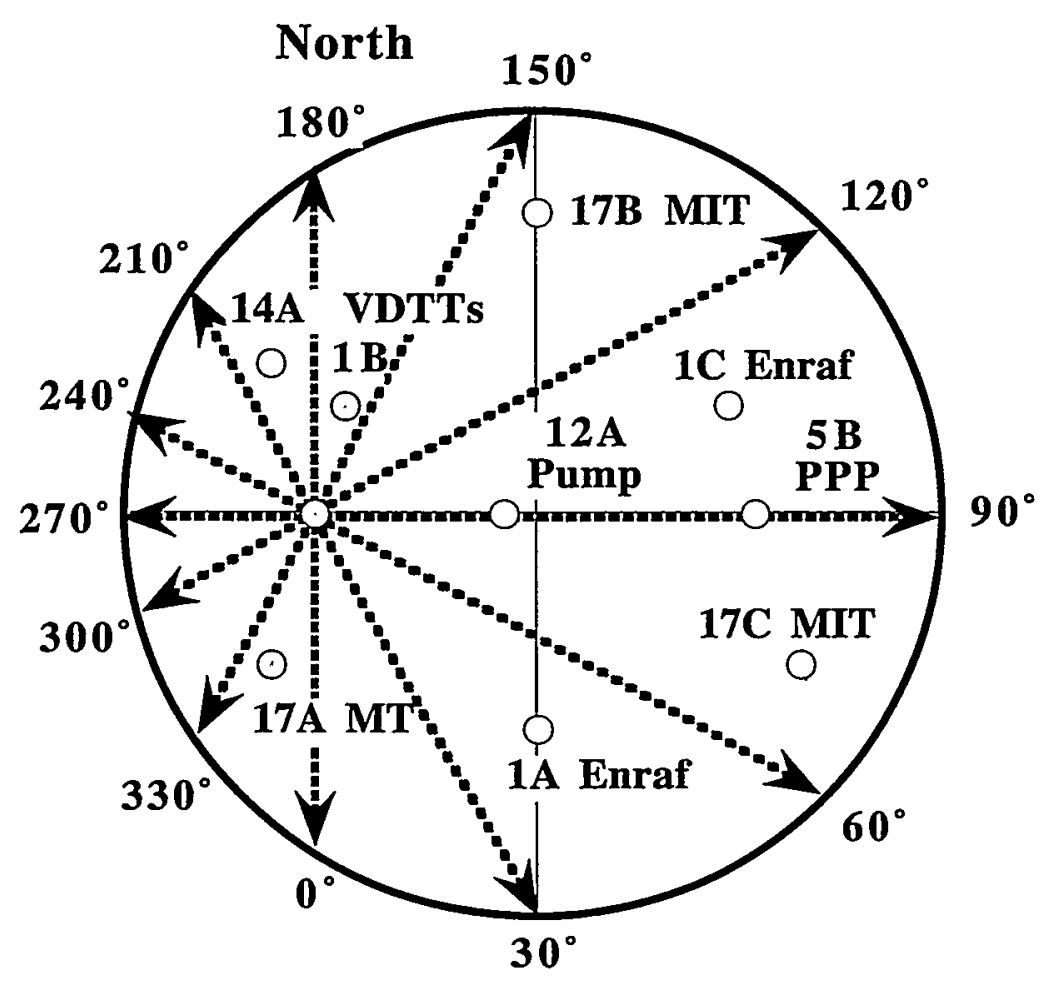

Figure 1.3. Pan Angles for Video Images 


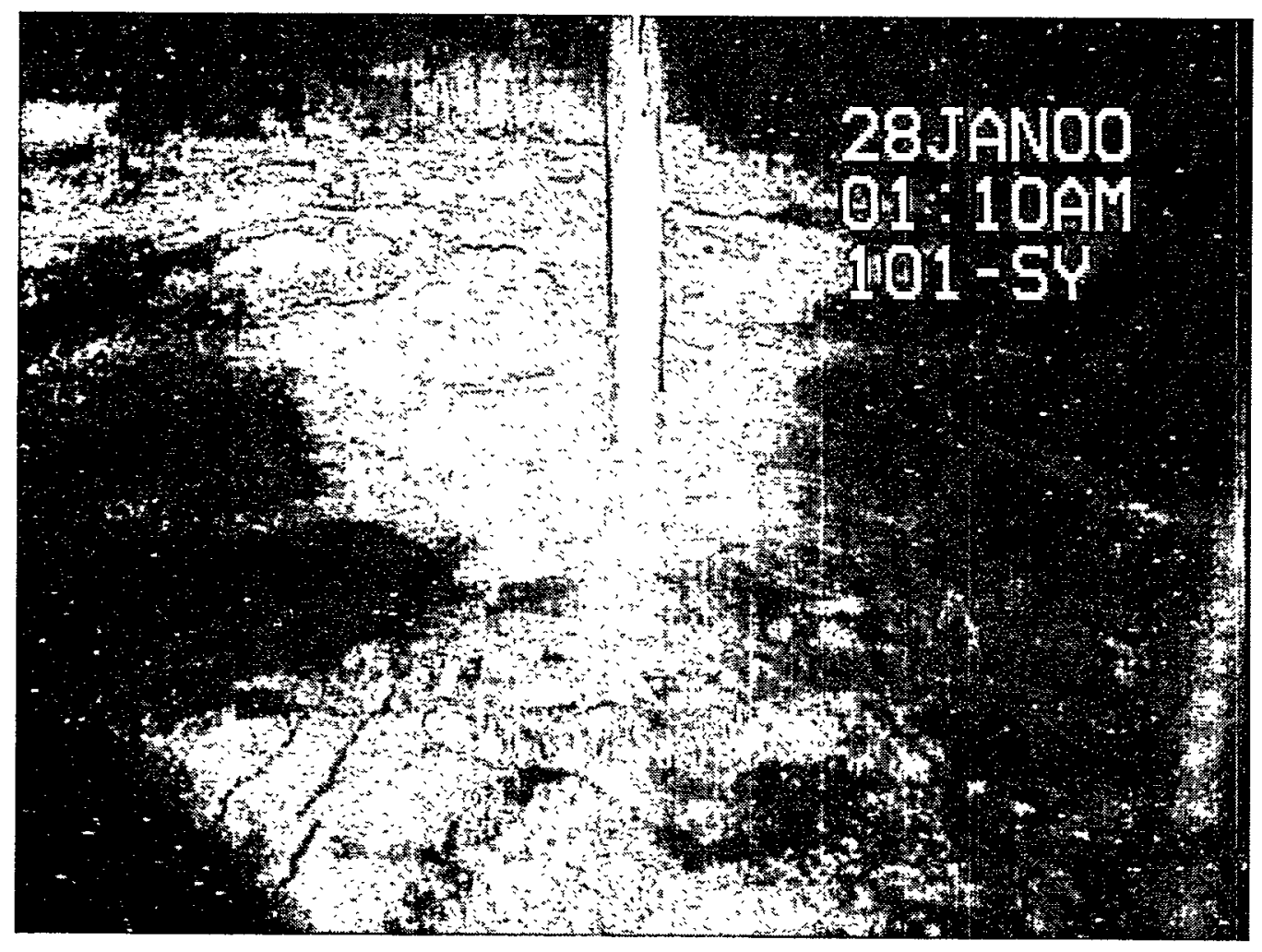

Figure 1.4. View of Transfer Pump from Portable Camera in Riser 4A

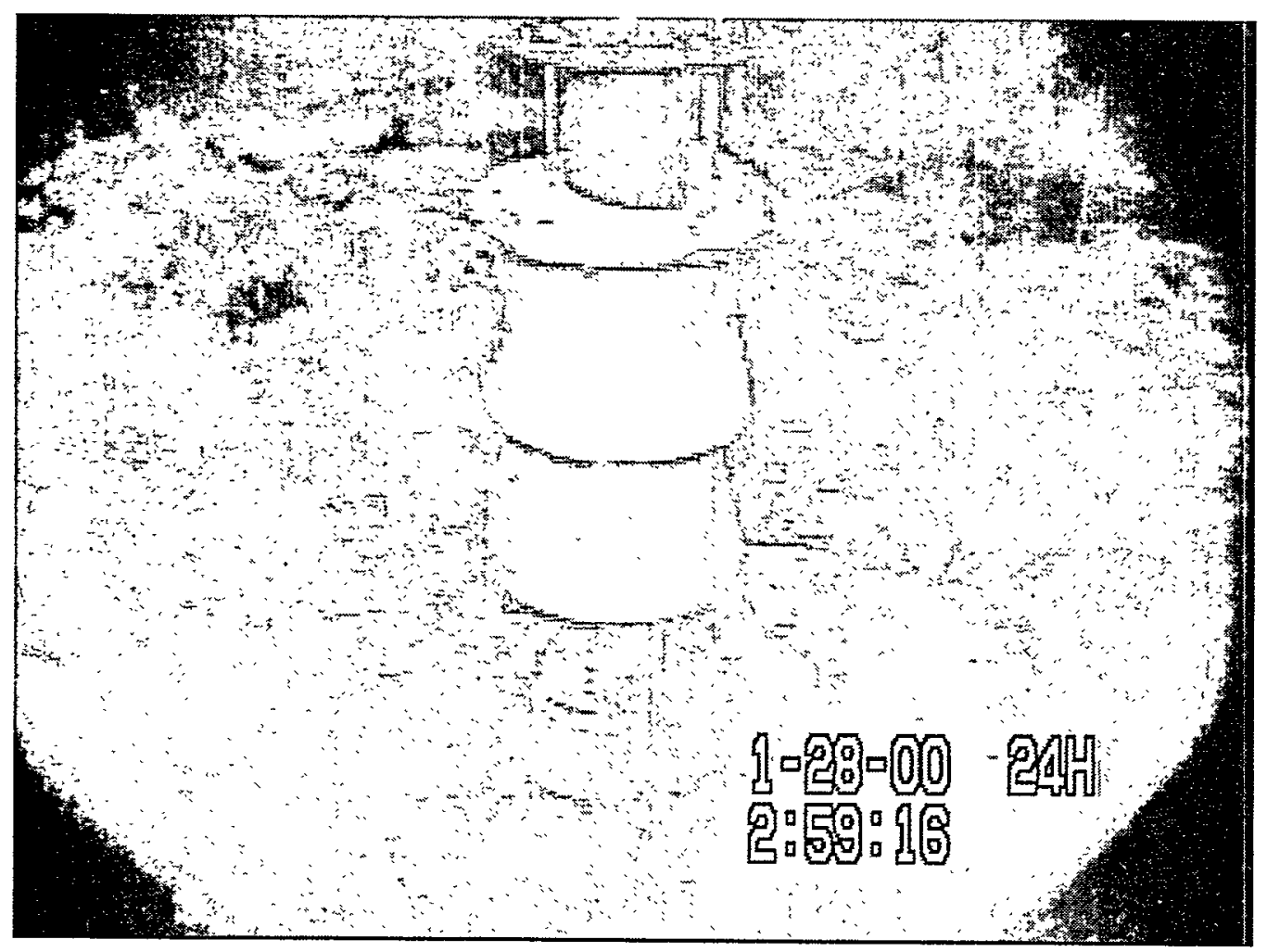

Figure 1.5. View of Mixer Pump Column from the "Fisheye" Camera in Riser 5A 


\subsection{Transfer and Back-Dilution Systems}

The complete details of the transfer and back-dilution systems are given in the Process Control Plan (Estey 2000). A very simplified schematic is given in Figure 1.6. In its simplest form, the system consisted of the prefabricated pump pit (PPP), water supply skid, the transfer pump in SY-101, and the overground transfer line to SY-102.

The PPP contained all the pipes, valves, and instrumentation that operate the transfer and dilution system. A data logger continuously recorded flow rates of dilution water and mixed waste and water as well, waste and water temperature and pressure, and the transfer pump current. Top dilution was accomplished through the flush spray ring at the base of the PPP in the riser at dome elevation. Top dilution water fell on the waste as large droplets over a fairly large area, as shown in Figure 1.7. Much of the water actually flowed down the outside surface of the transfer pump column.

The new generation transfer pump was a $60 \mathrm{hp}(67 \mathrm{~kW})$, vertical two-stage centrifugal pump capable of up to $200 \mathrm{gpm}$ total flow including in-line dilution of up to about $60 \mathrm{gpm}$. In-line dilution water was sprayed directly into the transfer pump inlet at 96 inches elevation. Low back-dilution water was injected at the base of the transfer pump through this line. The wastewater mixture flowed through a 125-ft, 2-inch-diameter, flexible overground transfer line to SY-102. This was the first application of this hose-in-hose system at Hanford. Waste entered SY-102 at the 160-inch elevation through a drop-leg slurry distributor. A siphon break in the drop leg prevented tank-to-tank flow when the transfer pump was not running.

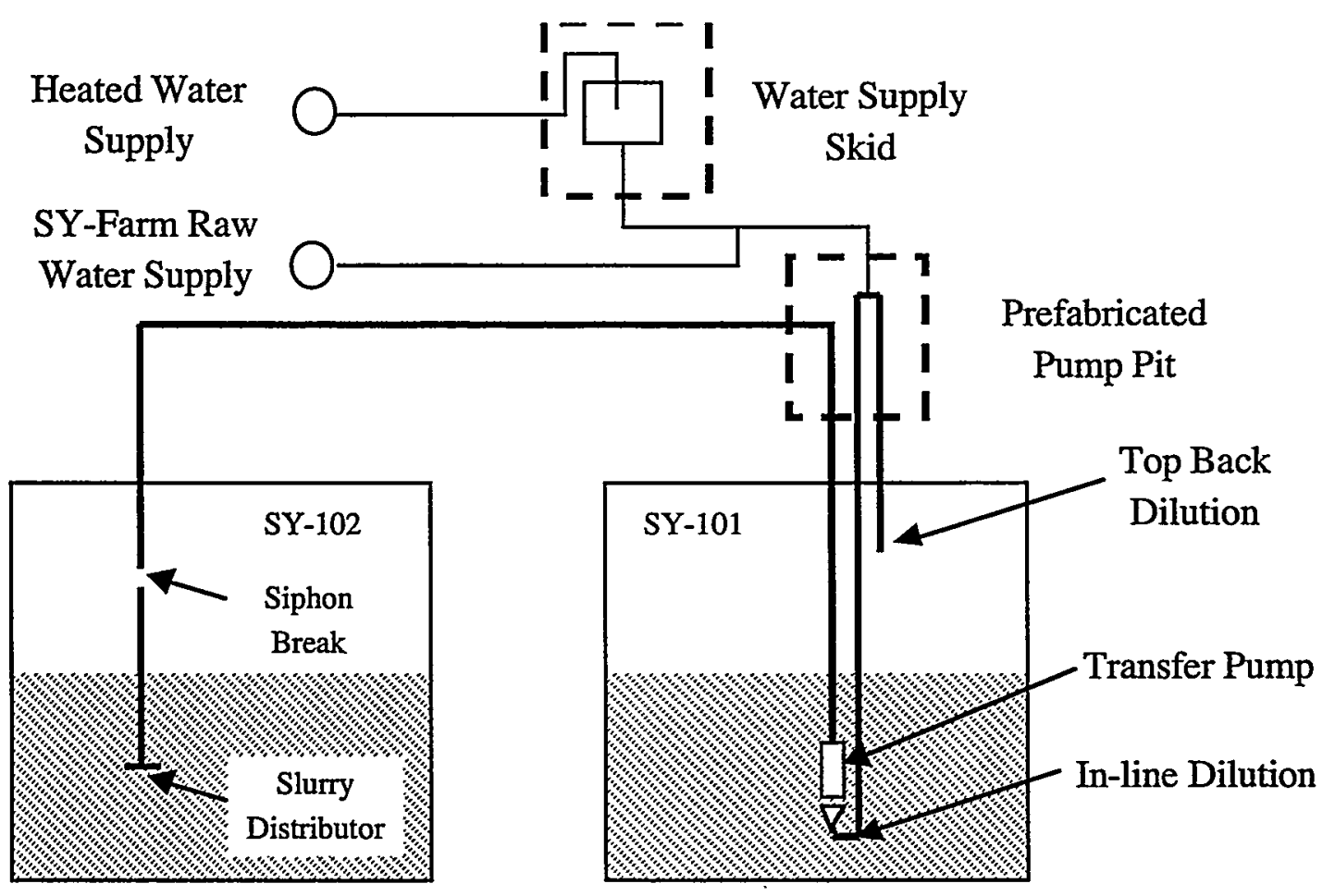

Figure 1.6. Schematic of Transfer and Dilution System 


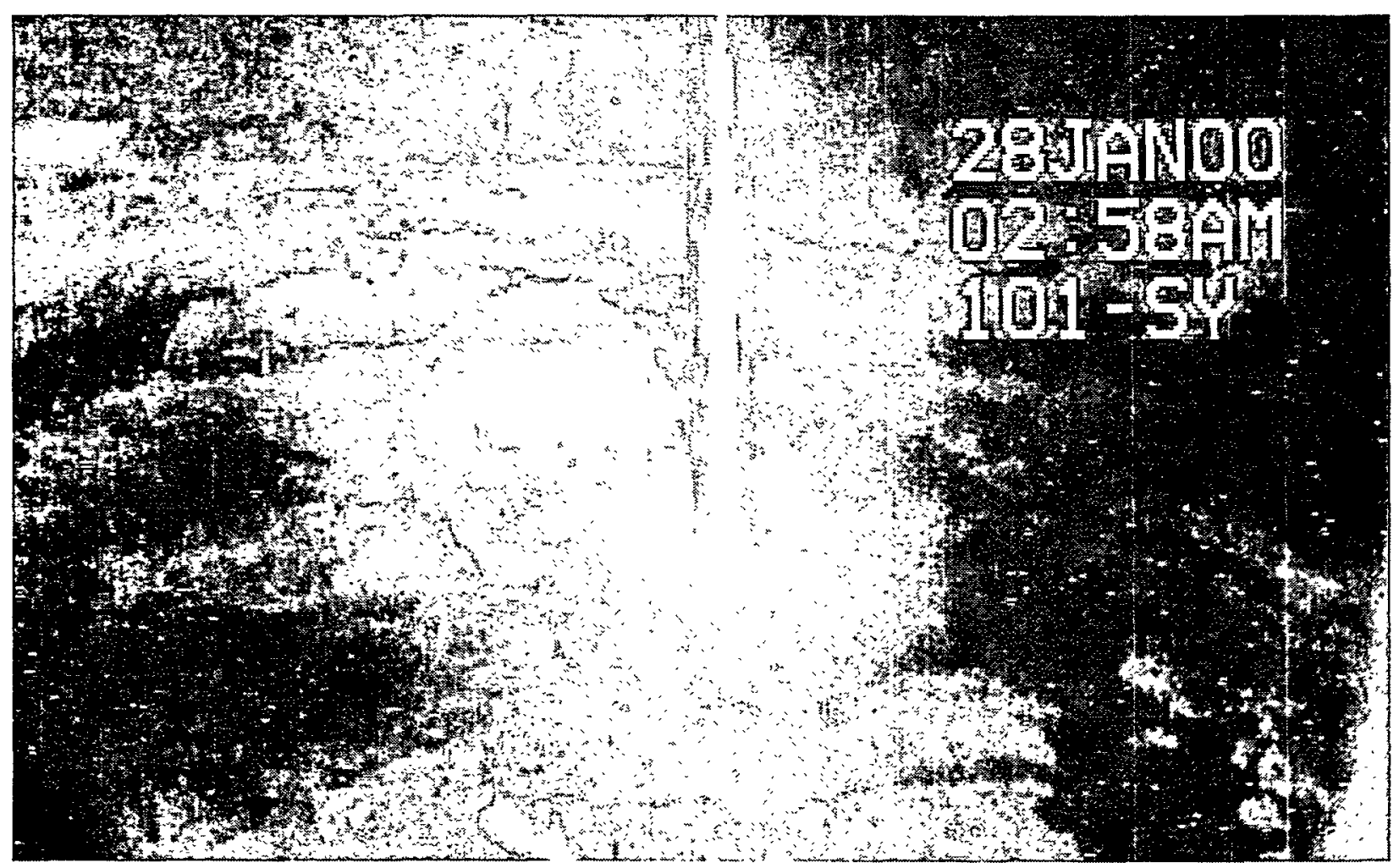

Figure 1.7. Top Dilution in Progress

The water supply skid was designed with two 20 -hp supply pumps and a 2,000-gallon supply tank to supply pressurized hot water at up to $130^{\circ} \mathrm{F}$ to the PPP for dilution and flushes. It was used for the first campaign and the second transfer and top back-dilution. For the second low dilution and third dilution heated water was not considered necessary, and raw water at about $50^{\circ} \mathrm{F}$ was piped directly to the PPP from the SY tank farm water supply. Low or top dilution could be supplied at up to $60 \mathrm{gpm}$ through the water skid or $80 \mathrm{gpm}$ from the raw water supply.

\subsection{Organization of the Report}

The report is organized into two main divisions: Section 2 provides a detailed narrative of the three transfer and dilution campaigns; the later sections provide detailed discussions of specific data for which the narratives are intended to set the stage. Section 3 describes the effect of transfer and dilution on the waste levels in Tanks SY-101 and SY-102 and strain gauge data. Section 4 traces the changes in waste configuration as evidenced by neutron and gamma logs. Sections 5, 6, and 7 discuss (respectively) headspace gas concentrations and releases, waste temperatures, and mixer pump operating performance. Section 8 describes transfer pump operating data and performance. Section 9 is a summary and conclusions. References are listed in Section 10. A CD is enclosed in the back cover of this report. It contains the data used in this report, video frames captured during the campaigns, some pertinent reports that provide more details on the analysis and planning of the remediation effort, and SY-101 historical DACS data from 1993. A table of contents is included separately on the CD. 


\subsection{Campaign Narratives}

Observing the actual transfer and back-dilution events that were introduced in Section 1 was a very exciting and satisfying time for the project team. There were many unknowns before the first campaign and high interest about what would happen. A visitor center was set up with live data and video monitoring, and a team of engineers manned the SY-101 Data Acquisition and Control System (DACS) trailer and video shack. It was gratifying to see the waste behave consistently with predictions and the operations completed without any significant delays or problems. In this section, narratives are given for each of the three campaigns to introduce the details presented in later sections.

\subsection{Narrative of Events During the First Campaign}

The objectives of the first transfer were two-fold. The first objective was to dissolve a large fraction of the existing crust freeboard above the liquid level to remove the immediate hazard of cumulative level growth. Removal of this "dead weight" would also make the rest of the crust less prone to sink during future dissolution. The second objective was to confirm that the crust dissolution behavior would be as predicted. No large gas releases or disruption of the existing crust structure were expected. Table 2.1 shows the sequence of events associated with the first transfer and dilution campaign.

The first transfer (1a) started at 6:45 AM on December 18, 1999. The initial flow rate of inline dilution water was $59.8 \mathrm{gpm}$ at $112^{\circ}$ to $122^{\circ} \mathrm{F}$, and the total waste flow was $121.6 \mathrm{gpm}$ into SY-102. This means $61.8 \mathrm{gpm}$ of SY-101 waste were being transferred with a dilution ratio of 0.97:1. At about 2 PM on December 18 (nine hours from the start) the slurry transfer flow rate was increased slightly to $129 \mathrm{gpm}$ with a water flow of $59.9 \mathrm{gpm}$. This represents a dilution ratio of 0.87 with $69 \mathrm{gpm}$ of SY-101 waste being transferred to SY-102. The transfer was completed at 5:44 AM on December 19, after 23 hours. The average in-line dilution ratio was 0.9:1.

After about two hours, a drop in the crust around the pump column was visible. The crust generally descended smoothly, with no large cracks, "tilts," or large waste "hangups" on the walls or "lollipops" on suspended hardware. The appearance of the crust surface did not change during transfer except near the tank wall, where some waste remained attached to the wall. An example on the south side of the tank is shown in Figure 2.1.

Over the course of about 10 hours, the hydrogen concentration in the SY-101 headspace rose from $50 \mathrm{ppm}$ to $380 \mathrm{ppm}$ and remained there for the rest of the transfer. Nitrous oxide and ammonia in SY-101 also rose rapidly in the first 10 hours but continued to increase at lesser rates after that time (while hydrogen was approximately constant). The SY-102 headspace ammonia concentration continued to increase almost linearly throughout the transfer, peaking at almost $2,000 \mathrm{ppm}$. Hydrogen, nitrous oxide, and ammonia concentrations in the SY-101 headspace dropped rapidly once the transfer stopped, as did the ammonia concentration in SY-102. 
Table 2.1. Sequence of Events During the First Campaign

\begin{tabular}{|l|c|c|}
\hline Event & Date and Time \\
\hline End of 25-minute pump run at 168 degrees & $12 / 16 / 99$ & $22: 00$ \\
\hline First Transfer 1a & & \\
\hline Transfer 1a start & $12 / 18 / 99$ & $06: 45$ \\
\hline Transfer 1a end & $12 / 19 / 99$ & $05: 45$ \\
\hline Neutron probe runs in 17B and 17C & $12 / 19 / 99$ & $12: 00$ \\
\hline End of 5-min pump run at 30 degrees & $12 / 19 / 99$ & $13: 48$ \\
\hline First Dilution 1b-c & & \\
\hline Top-dilution 1b start & $12 / 19 / 99$ & $18: 24$ \\
\hline Temperature of top-dilution water slowly reduced & $12 / 19 / 99$ & $20: 00$ \\
\hline 13-minute interruption due to spurious FTIR ${ }^{(a)} \mathrm{NH}_{3}$ and $\mathrm{N}_{2} \mathrm{O}$ & $12 / 19 / 99$ & $22: 38$ \\
\hline Dilution flow increased to 63 gpm & $12 / 20 / 99$ & $00: 40$ \\
\hline Water observed across whole tank surface except for islands & $12 / 20 / 99$ & $01: 00$ \\
\hline Top-dilution 1b end & $12 / 20 / 99$ & $04: 30$ \\
\hline Low-dilution 1c start & $12 / 20 / 99$ & $04: 45$ \\
\hline Low-dilution 1c end & $12 / 20 / 99$ & $14: 58$ \\
\hline Post-Campaign & & \\
\hline End of 25-minute pump run at 30 degrees & $12 / 21 / 99$ & $11: 14$ \\
\hline End of 25-minute pump run at 63 degrees & $12 / 23 / 99$ & $14: 37$ \\
\hline End of 25-minute pump run at 95 degrees & $12 / 26 / 99$ & $09: 54$ \\
\hline Neutron probe runs in 17B and 17C & $12 / 28 / 99$ & $22: 26$ \\
\hline Largest of several post-campaign slurry flow events & $1 / 7 / 00$ & $18: 42$ \\
\hline (a) Fourier transform infrared spectrometer. & & \\
\hline
\end{tabular}

A level increase of 62.7 in. was measured in SY-102 over the course of the transfer (before the salt-well pumping from Tanks S-106 and SX-106 into SY-102 resumed at 1:00 AM on December 20). The transfer alone produced a 40-inch level drop at riser 1A and a 38.7-inch drop at riser 1C. The area around the mixer pump and the southeast quadrant of SY-101 appeared to descend more than the average. The waste surrounding the mixer pump, shown in Figure 2.2, dropped about six inches more than at riser 1A. A comparison of the rate of level drop to the transfer flow rate implied that a ring of waste about one meter thick had adhered to the wall. This was not expected, but the thickness was consistent with that predicted from the estimated crust strength. ${ }^{(a)}$

Neutron probes were run in risers $17 \mathrm{~B}$ and $17 \mathrm{C}$ about five hours after the end of the transfer. The neutron profiles showed that the waste top and bubble slurry layer had moved down by about the same amount at risers $17 \mathrm{~B}$ and $17 \mathrm{C}$ as the waste level had fallen at risers $1 \mathrm{~A}$ and $1 \mathrm{C}$. However, there was virtually no change in the shape of the neutron profile or crust thickness, as expected.

(a) Stewart CW, G Terrones, PA Meyer, ML Grigsby, RE Raymond, RE Bauer, BK Hampton, and GD Johnson. October 1999. Assessment of SY-101 Crust Structural Issues During Transfer and BackDilution. PNNL Letter Report TWS99.51 Rev. 1. 

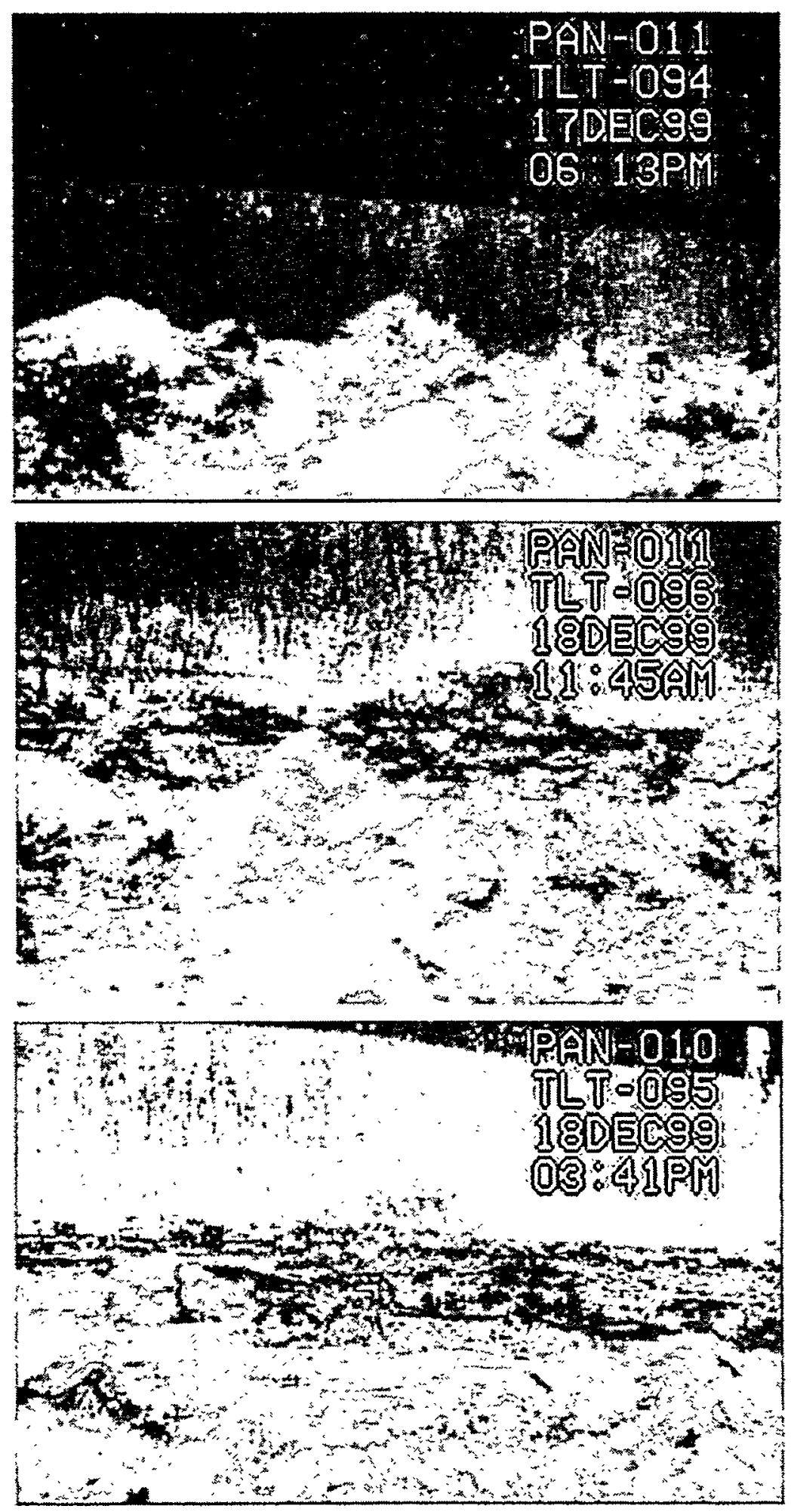

Figure 2.1. Waste Attachment to Tank Wall During Transfer 1a 


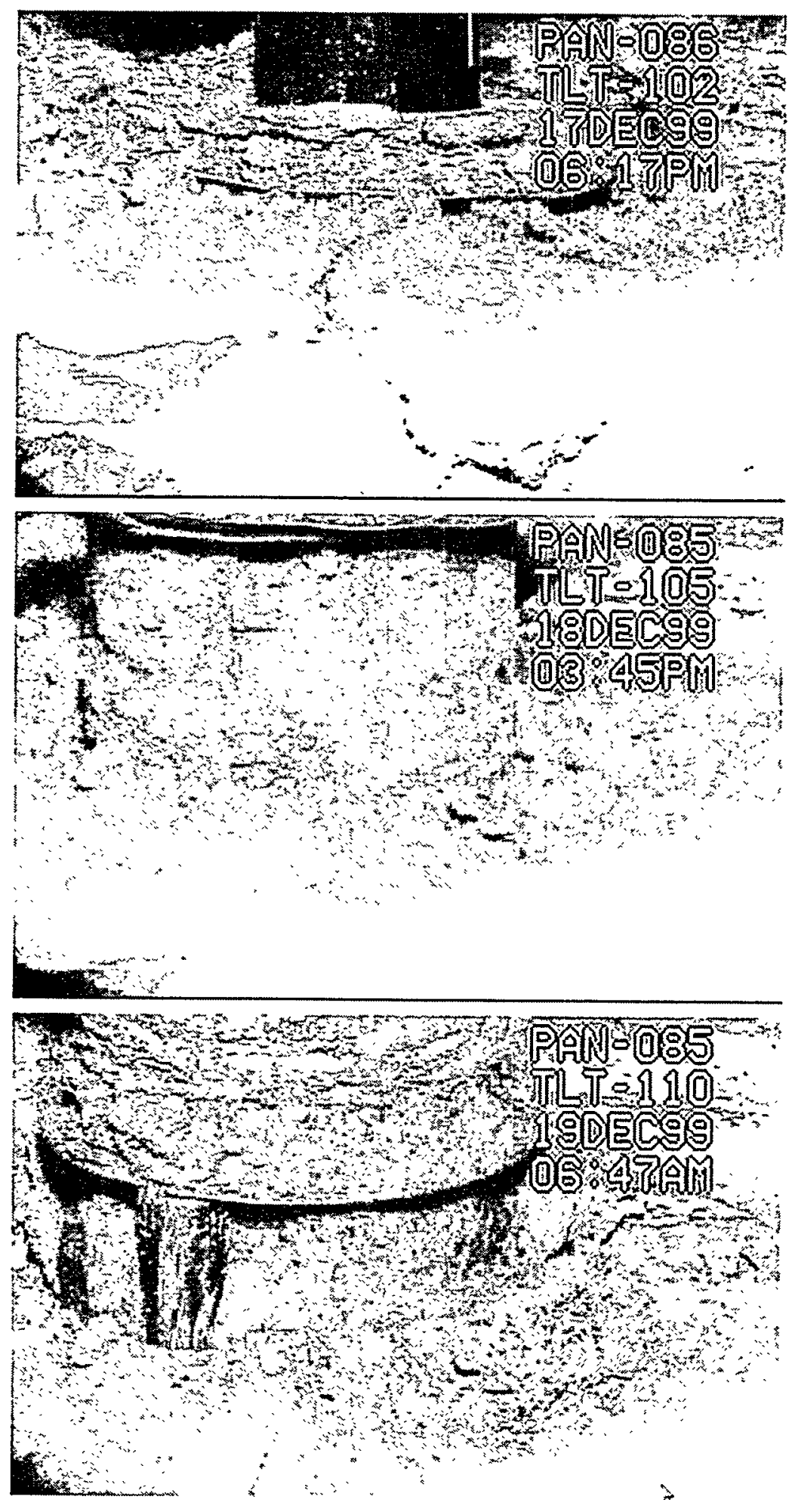

Figure 2.2. Waste Surface Around the Mixer Pump During Transfer 1a 
A mixer pump run began about nine hours after the end of the transfer but was aborted after five minutes because the reduced hydrostatic pressure was outside the range set for the volute pressure transducer. The pump power, however, indicated no abnormalities. (Later, as the level rose during dilution, the hydrostatic pressure recovered and brought the volute pressure back within range.)

Top dilution (1b) began at 6:34 PM on December 19, 1999. Initially, the water was added at $20 \mathrm{gpm}$ and a temperature of $112^{\circ} \mathrm{F}$. Over the course of two hours, the flow rate was increased to $40 \mathrm{gpm}$ while the temperature was reduced, eventually to $80^{\circ} \mathrm{F}$, to reduce the high humidity that had caused mist to form. There was concern that the ventilation filters might plug with water, though no increase was observed in the filter pressure drop. Top dilution was shut down briefly at 10:38 PM (after four hours) because the FTIR readings of ammonia and nitrous oxide were erratic, possibly because of the high humidity. The instruments recovered in about 13 minutes, and top dilution was restarted at 10:51 PM December 19. The flow was raised to 63 gpm by 12:40 AM on December 20 but reduced to $40 \mathrm{gpm}$ in the last hour. Top dilution was shut off at 4:30 AM on December 20, having lasted 10 hours.

The hydrogen concentration in the headspace began to rise after about two hours of dilution but remained much lower than during the transfer. The ammonia concentrations fell sharply due to the scrubbing effect of water falling through the dome. After two hours, hydrogen and ammonia both leveled off.

Within the first half-hour of top dilution (1b), the depression beneath the transfer pump was filled with moving water. This pool gradually enlarged, but most of the water being added was apparently flowing outward beneath the top surface. By the third hour of dilution, pools began to appear on the surface at various points in the tank. Some small subsidence events and cracks were also observed. Even after water covered most of the surface, a number of islands remained, showing that the final effect on the surface level would be uneven. After top dilution ended, the liquid quickly found its way beneath the crust, and surface pools disappeared within a few hours.

The effect of top dilution on the crust surface is illustrated in Figures 2.3 through 2.5. Figure 2.3 shows the surface around VDTT 1B during dilution. Figure 2.4 shows the region around the pump column after about seven hours of top dilution. The liquid surface is clearly visible, though some of the surface is covered by small bits of waste and perhaps by a thin scum. Figure 2.5 shows the dissolution of a volcano-like mound in the center of the upper left frame. The three frames on the left show the effect of the first transfer, and the three on the right show the progression of top dilution. The white object on the right is the Enraf $1 \mathrm{C} \mathrm{bob}$.

The low dilution (1c) began at 4:45 AM December 20, 1999, shortly after top dilution ended. The low dilution water flow rate varied from 50 to $64 \mathrm{gpm}$ over the course of the process, and the water temperature from $114^{\circ}$ to $124^{\circ} \mathrm{F}$. Headspace hydrogen actually decreased slightly during low dilution, while the ammonia increased slightly (both concentrations changing by 40 to $50 \mathrm{ppm}$ ). Low dilution was completed at 2:58 PM on December 20, after about 10 hours.

The SY-101 waste level at riser $1 \mathrm{~A}$ rose by $25.1 \mathrm{in}$. as a result of top and low dilution (1b-c), while the level at riser $1 \mathrm{C}$ rose by $32.0 \mathrm{in}$. in the same period. Overall, the waste at riser $1 \mathrm{~A}$ fell 

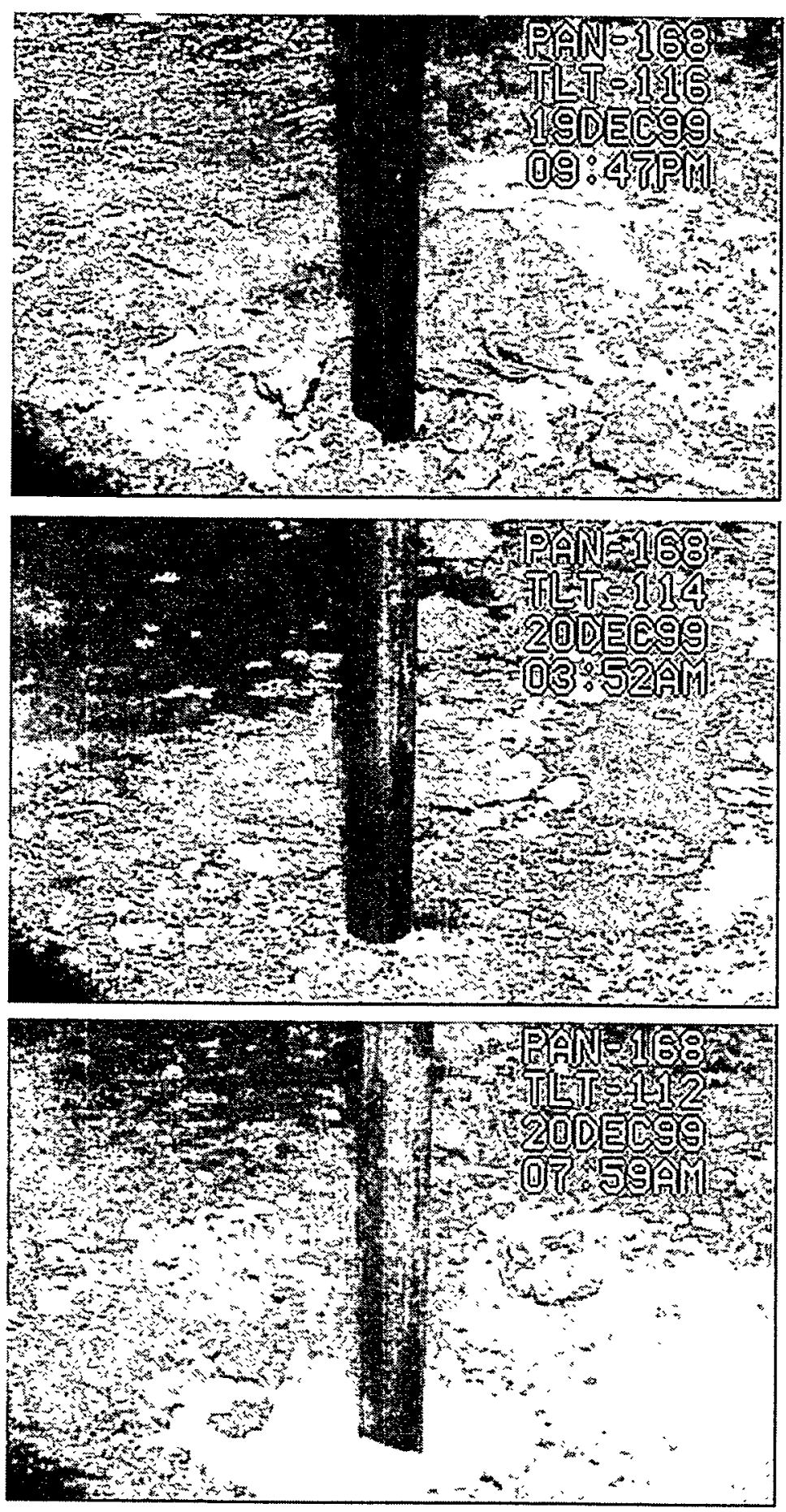

Figure 2.3. Effect of Top Dilution 1b Around VDTT 1B

by 8 inches more than the waste at riser $1 \mathrm{C}$, probably due to dissolution of a portion of the shelf of waste on which the $1 \mathrm{~A}$ Enraf bob had rested. The level rose at approximately the same rate for both top and low dilution, as expected. 

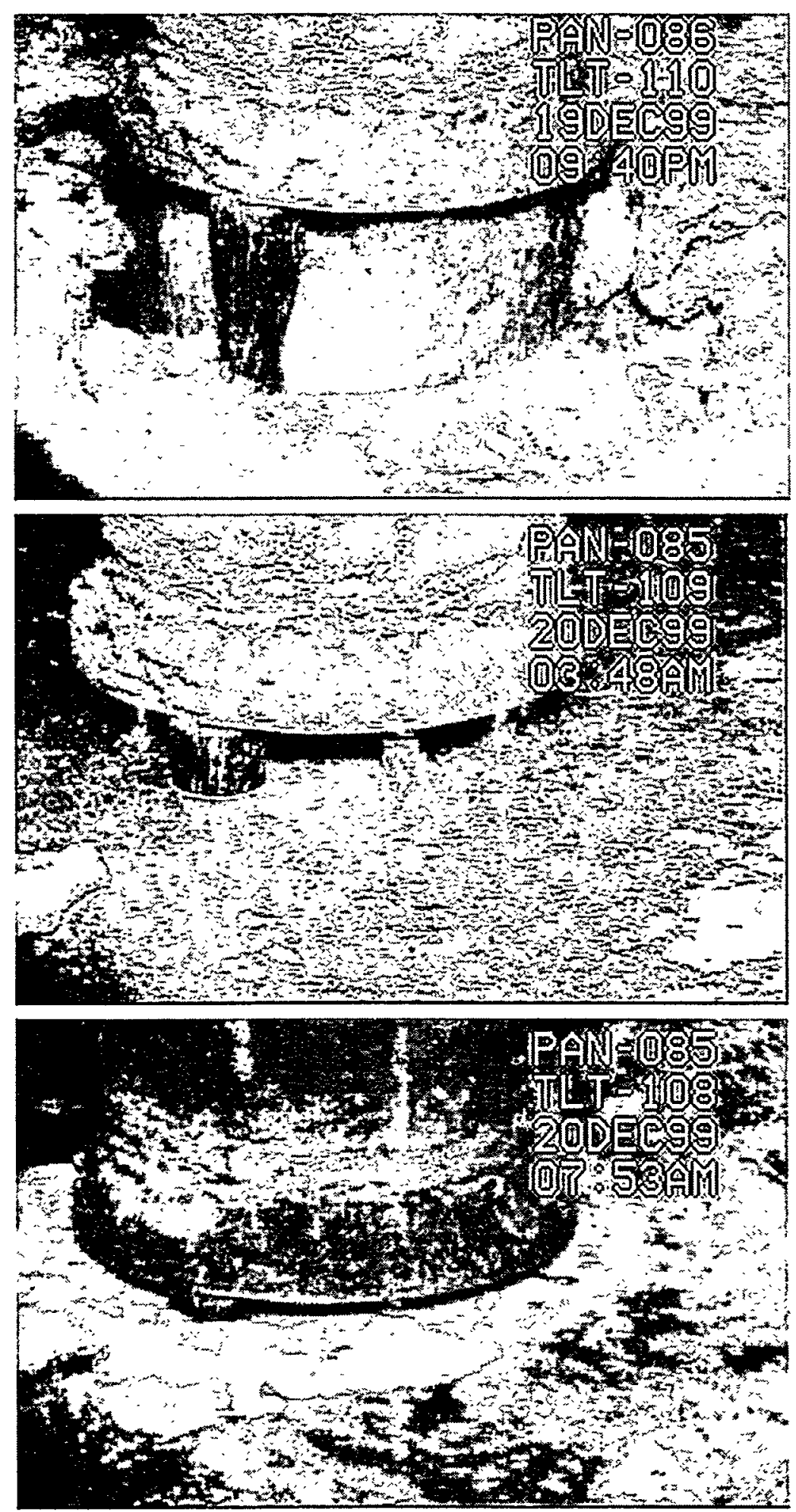

Figure 2.4. Result of Top Dilution 1b Around the Mixer Pump 

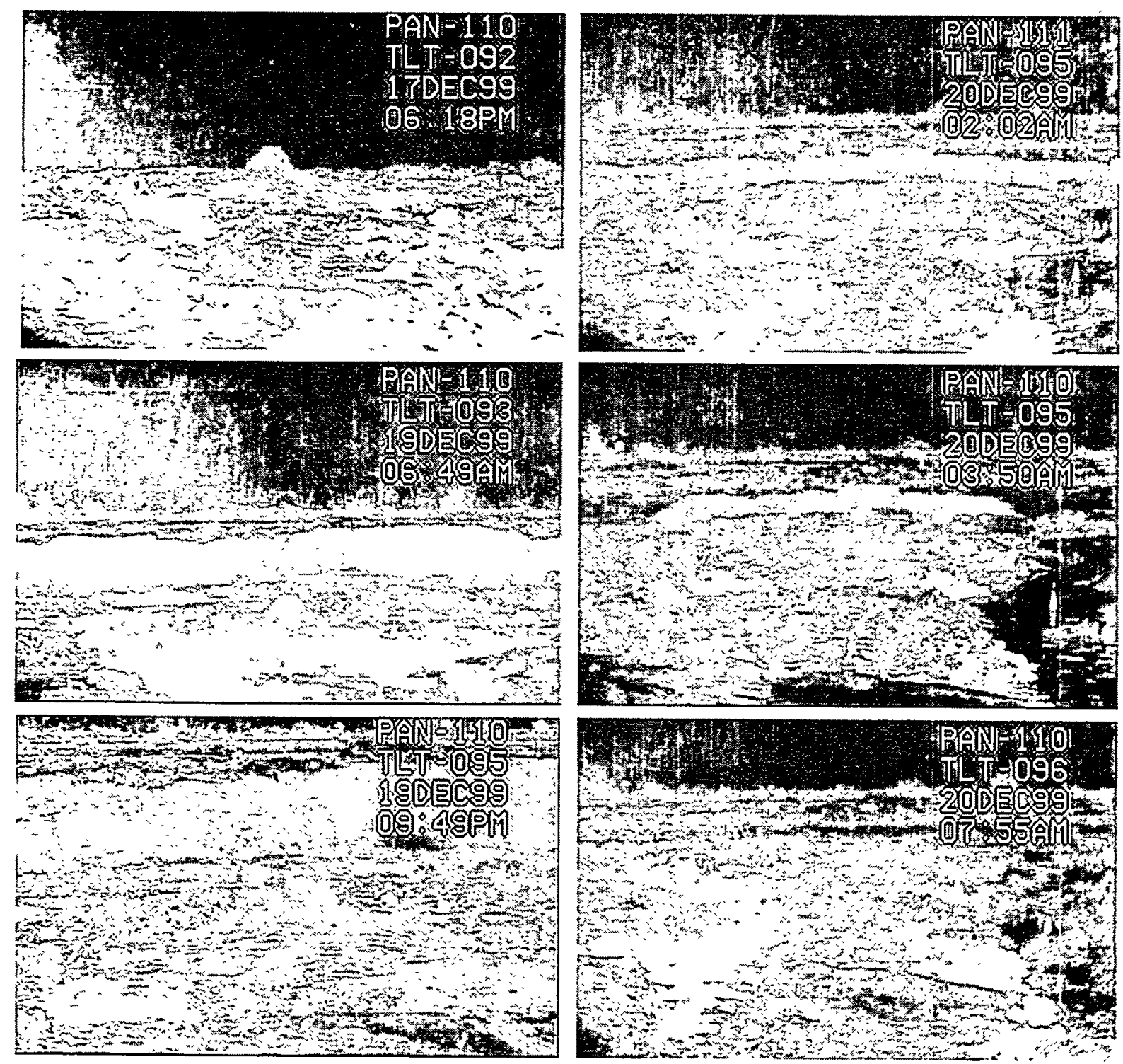

Figure 2.5. Crust "Volcano" Feature Dissolution During the Top Dilution $1 \mathrm{~b}$

Several slurry flows (resembling mud flows) occurred after the first campaign ended on December 21, apparently because the top dilution had softened and opened passages through the crust. The largest flow occurred at 6:42 PM on January 7, 2000, as inferred from a spontaneous headspace hydrogen spike at that time and from in-tank camera images taken at 3:59 PM on January 7 and 1:45 PM on January 8. Based on a full-tank surface scan (January 10), the flow was estimated to cover 1-2\% of the tank area (Stewart et al. 2000). Part of this flow around the VDTTs is shown in Figure 2.6. 

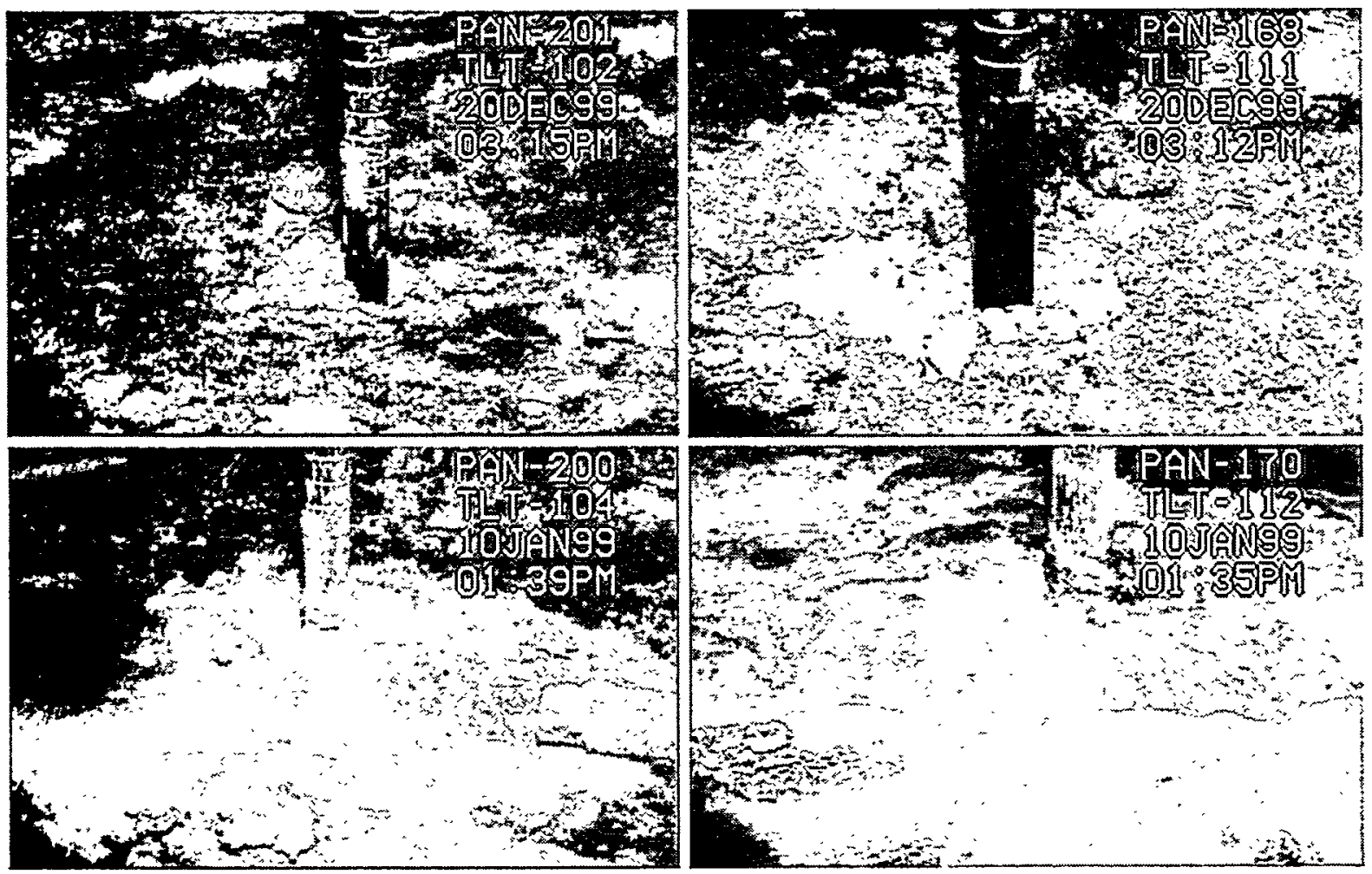

Figure 2.6. Slurry Flows Around the VDTTs after the First Campaign

The tank scan showed signs of five distinguishable flows since the transfer, none larger than $2 \%$ of the tank surface. Gas monitoring provided evidence of at least 10 spontaneous releases between the transfer and January 1, 2000, and of at least four more between January 1 and 10 . The gas releases and slurry flows are believed to be related, with many of the flows probably being concealed by overlapping or by being out of view of the camera.

Thirteen 25-minute mixer pump runs were made between the first and second campaigns. The slight decrease in fluid density and viscosity resulting from dilution decreased the average motor power and volute pressure initially by about $4 \%$, increasing back to $3 \%$ after the first few runs mixed the dilution water throughout the waste. The rate of motor oil temperature heating remained about the same after dilution, but the peak oil temperature was lower because the starting oil temperature was also lower.

\subsection{Narrative of Events During the Second Campaign}

The first campaign went forward without adverse incident, and the project team concluded that larger transfers and back-dilutions could be made safely. Accordingly, the primary goal of the second campaign was to remove the main hazard of crust growth by destroying the crust layer and dissolving a large fraction of the solids suspended in the slurry. The campaign was conducted in two stages. The first stage was a large (241,000 gallons) transfer (2a) and large top dilution ( $2 \mathrm{~b}, 79,000$ gallons). After about a three-week hiatus to allow the top dilution to have 
maximum effect, the second stage was performed. It comprised a large low dilution (2c-d, $151,000 \mathrm{gal})$ plus a small top dilution (2e, 11,000 gal) to dissolve crust remnants. The sequence of events associated with the second transfer and back-dilution campaign is given in Table 2.2.

Table 2.2. Sequence of Events During the Second Campaign

\begin{tabular}{|c|c|}
\hline Event & Date and Time \\
\hline End of 25 -minute pump run at 29 degrees & $1 / 22 / 00 \quad 10: 40$ \\
\hline \multicolumn{2}{|l|}{ Second Transfer (2a) and Top Dilution (2b) } \\
\hline Transfer 2a start & $1 / 25 / 00 \quad 16: 22$ \\
\hline Transfer $2 a$ end & $1 / 27 / 00 \quad 22: 07$ \\
\hline Top-dilution $2 \mathrm{~b}$ start & $1 / 28 / 00 \quad 01: 43$ \\
\hline Waste release from tank wall & $1 / 28 / 00 \quad 04: 52$ \\
\hline Waste release from tank wall & $1 / 28 / 00 \quad 05: 43$ \\
\hline Bubble slurry flow and gas release $\left(\mathrm{H}_{2} 1600 \mathrm{ppm}\right)$ & $1 / 28 / 00 \quad 09: 33$ \\
\hline Bubble slurry flow and gas release $\left(\mathrm{H}_{2} 1300 \mathrm{ppm}\right)$ & $1 / 28 / 00 \quad 10: 15$ \\
\hline Bubble slurry flow and gas release $\left(\mathrm{H}_{2} 1100 \mathrm{ppm}\right)$ & $1 / 28 / 00 \quad 12: 31$ \\
\hline Bubble slurry flow and gas release $\left(\mathrm{H}_{2} 1500 \mathrm{ppm}\right)$ & $1 / 28 / 00 \quad 17: 20$ \\
\hline Bubble slurry flow and gas release $\left(\mathrm{H}_{2} 2000 \mathrm{ppm}\right)$ & $1 / 28 / 00 \quad 18: 30$ \\
\hline Bubble slurry flow and gas release $\left(\mathrm{H}_{2} 2000 \mathrm{ppm}\right)$ & $1 / 28 / 00 \quad 21: 30$ \\
\hline Top-dilution $2 b$ end & $1 / 28 / 00 \quad 22: 19$ \\
\hline \multicolumn{2}{|l|}{ Inter-Campaign Hold } \\
\hline Neutron probes in $17 \mathrm{~B}$ and $17 \mathrm{C}$ & $1 / 29 / 00 \quad 12: 02$ \\
\hline Bubble slurry flow and gas release $\left(\mathrm{H}_{2} 2300 \mathrm{ppm}\right)$ & $1 / 29 / 00 \quad 18: 40$ \\
\hline Waste surface is primarily motionless, foamy solid & $1 / 29 / 00 \quad 21: 00$ \\
\hline Bubble slurry flow and gas release $\left(\mathrm{H}_{2} 1000 \mathrm{ppm}\right)$ & $1 / 30 / 00 \quad 08: 15$ \\
\hline End of 5-minute pump run at 95 degrees & $1 / 31 / 00 \quad 20: 26$ \\
\hline Neutron probes in $17 \mathrm{~B}$ and $17 \mathrm{C}$ & $2 / 1 / 00 \quad 19: 34$ \\
\hline End of 25 -minute pump run at 95 degrees & $2 / 2 / 00 \quad 17: 58$ \\
\hline Neutron probes in $17 \mathrm{~B}$ and $17 \mathrm{C}$ & $2 / 3 / 00 \quad 10: 23$ \\
\hline End of 25 -minute pump run at 29 degrees & $2 / 3 / 00 \quad 20: 40$ \\
\hline Seven 25 -minute pump runs & $2 / 5-2 / 18 / 00$ \\
\hline Neutron probes in $17 \mathrm{~B}$ and $17 \mathrm{C}$ & $2 / 10 / 00 \quad 10: 54$ \\
\hline Neutron probes in $17 \mathrm{~B}$ and $17 \mathrm{C}$ & $2 / 17 / 00 \quad 10: 59$ \\
\hline End of 25 -minute pump run at 30 degrees & $2 / 20 / 00 \quad 15: 43$ \\
\hline \multicolumn{2}{|l|}{ Low Dilution 2c-d and Top Dilution $2 \mathrm{e}$} \\
\hline Low dilution $2 \mathrm{c}$ start & $2 / 21 / 00 \quad 02: 40$ \\
\hline Low dilution $2 \mathrm{c}$ shutdown due to staffing limitations & $2 / 21 / 00 \quad 22: 32$ \\
\hline End of 25 -minute pump run at 63 degrees & $2 / 22 / 00 \quad 11: 49$ \\
\hline Low dilution $2 \mathrm{~d}$ restarted & $2 / 23 / 00 \quad 10: 37$ \\
\hline Low dilution $2 \mathrm{~d}$ shut down & $2 / 23 / 00 \quad 20: 53$ \\
\hline Small top dilution $2 \mathrm{e}$ start & $2 / 23 / 00 \quad 20: 57$ \\
\hline Small top dilution $2 \mathrm{e}$ end & $2 / 23 / 00 \quad 23: 30$ \\
\hline \multicolumn{2}{|l|}{ Post Campaign } \\
\hline Neutron probes in $17 \mathrm{~B}$ and $17 \mathrm{C}$ & $2 / 25 / 00 \quad 10: 04$ \\
\hline End of 25 -minute pump run at 30 degrees & $2 / 27 / 00 \quad 02: 08$ \\
\hline
\end{tabular}




\subsubsection{Second Transfer and Top Dilution}

The second waste transfer 2a started at 4:22 PM on January 25, 2000. The in-line dilution flow was $60 \mathrm{gpm}$, and the SY-101 waste flow was $75-78 \mathrm{gpm}$ for a dilution ratio of about 0.8:1. The transfer was completed at 10:07 PM on January 27, 2000, after almost 54 hours. The total level decrease during the transfer at Enraf $1 \mathrm{~A}$ was 98 inches. A waste level increase of 152 inches was recorded in SY-102.

The level drop was smooth and uniform, and there was no evidence of major crust "hangup" or "lollipops" on tank hardware. This time all areas of the waste surface descended at essentially the same rate. However, as in the first transfer, some waste material remained attached to the tank walls. Again, comparing transfer flow with the measured level drop, this material was estimated to be on the order of one foot to one meter thick and extended about 100 inches vertically. Figure 2.7 shows a section of tank wall with the thickness of the attached waste ring visible.

The gas concentrations during transfer $2 a$ behaved as in the first transfer (1a). Within the first hour after transfer started, the hydrogen concentration in SY-101 went from about $30 \mathrm{ppm}$ to $200 \mathrm{ppm}$ and averaged about $275 \mathrm{ppm}$ for the remainder of the transfer. Again, the hydrogen concentration began to decrease immediately after the transfer ended.

The ammonia concentration in SY-101 also responded to the transfer, with a linear increase to $422 \mathrm{ppm}$ early on January 27 , and $450 \mathrm{ppm}$ at the end of the transfer. The SY stack ammonia concentration followed the same trend as the ammonia concentration in SY-102 during the

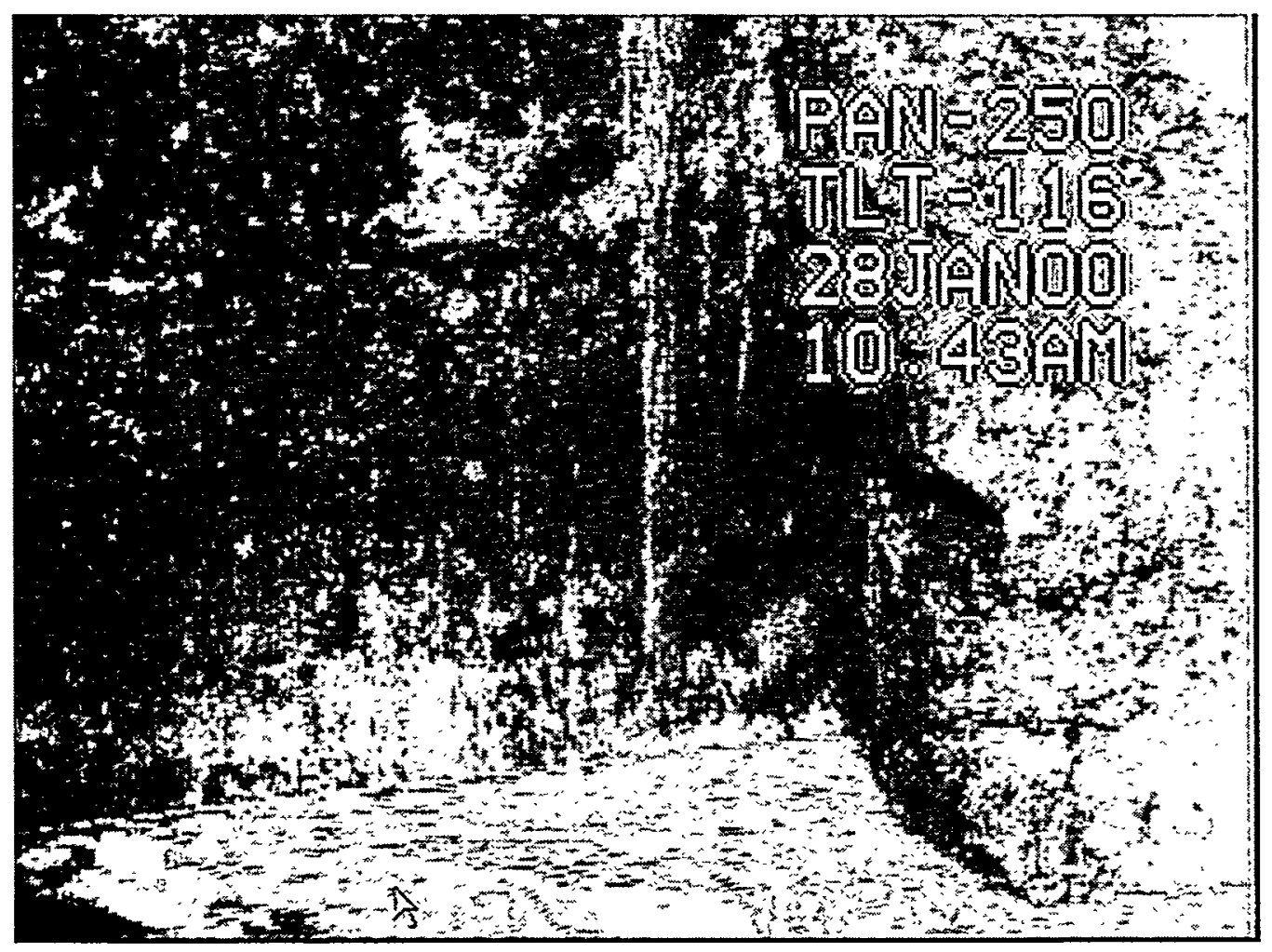

Figure 2.7. Waste Layer Attached to Tank Wall after Transfer 2a 
transfer, rising linearly from $150 \mathrm{ppm}$ to approximately $1000 \mathrm{ppm}$ by 1:00 AM on January 26 , when the rate of rise decreased so that the peak concentration reached $1775 \mathrm{ppm}$ at the end of the transfer. In SY-102, the ammonia concentration showed the same rapid initial increase and was about $5300 \mathrm{ppm}$ upon completion of the transfer, after which the ammonia concentration immediately started to decrease.

Top-dilution $2 \mathrm{~b}$ started at 1:43 AM on January 28,2000 . A total of 78,500 gallons of water was added at $63 \mathrm{gpm}$ and $80^{\circ} \mathrm{F}$. The entire waste surface was covered with liquid by about 2:00 PM. As the water covered the crust, the solid waste attached to the tank walls began to fall off. Large sections of this material were observed to fall from the southeast wall with a large splash at 4:52 AM and 5:43 AM on January 28. The temperatures near the tank bottom also suddenly dropped as cooler waste apparently flowed across the floor. Several other splashes and waves seen during the dilution are believed to be caused by these "landslides." A landslide on the northwest wall is illustrated in Figure 2.8. The waste on the wall in the top frame slid off and piled up on the submerged crust in the middle frame. However, the debris dissolved in the dilute liquid in only two hours, as shown in the bottom frame.

There were also numerous instances of apparent gas release from the submerged crust as it dissolved. These were evidenced by the sudden appearance of white, foamy "bubble slurry" on the waste surface, sometimes accompanied by small waves on the surface and a sharp rise in hydrogen concentration. The hydrogen concentration reached $2000 \mathrm{ppm}$ several times during these events. One of the larger bubble slurry flow events during dilution $2 b$ is shown in Figure 2.9. The flow originated on the east side of the tank. The upper frame shows a liquid surface with a few waste islands remaining. The white, foamy material in the middle frame appeared only minutes before the frame was captured. The hydrogen concentration peaked over $2000 \mathrm{ppm}$ at the same time. However, the foam dissolved in the dilute liquid in less than two hours, as indicated in the bottom frame. A closeup of the bubble slurry consistency from an earlier flow is shown in Figure 2.10.

The waste level rose by 32 inches, as indicated by Enraf $1 \mathrm{C}$ during top dilution $2 \mathrm{~b}$. The neutron logs taken in risers $17 \mathrm{~B}$ and $17 \mathrm{C}$ on January 29, 2000 indicated the same waste level and suggested that the upper 30 to 40 inches of waste had a very high water content. Subsequent neutron probes showed the gradual thinning of this dilute layer as the remaining crust dissolved and mixed with the waste below. During this top dilution, the two Enrafs began reading the same level. The shelf of waste supporting Enraf 1A dissolved, as shown in Figure 2.11 (the bob is hidden in a depression in the lower left frame). Enraf $1 \mathrm{C}$, however, remained essentially at the liquid surface, as shown in Figure 2.12. The level dropped several inches during the week after the second top dilution due to gas release from continuing crust dissolution.

\subsubsection{Second Low and Top Dilution}

After top dilution $2 \mathrm{~b}$, a new "crust" formed which (based on neutron and gamma profiles) was a 30-40-inch-thick "slush" of foam from bubble slurry flows and crust debris. Large slurry flows that added more foam and debris from beneath the surface were observed for several days. The new floating layer was much softer and more mobile than the thick pre-dilution crust, but it covered the entire surface and still held a moderate volume of solids and gas. 

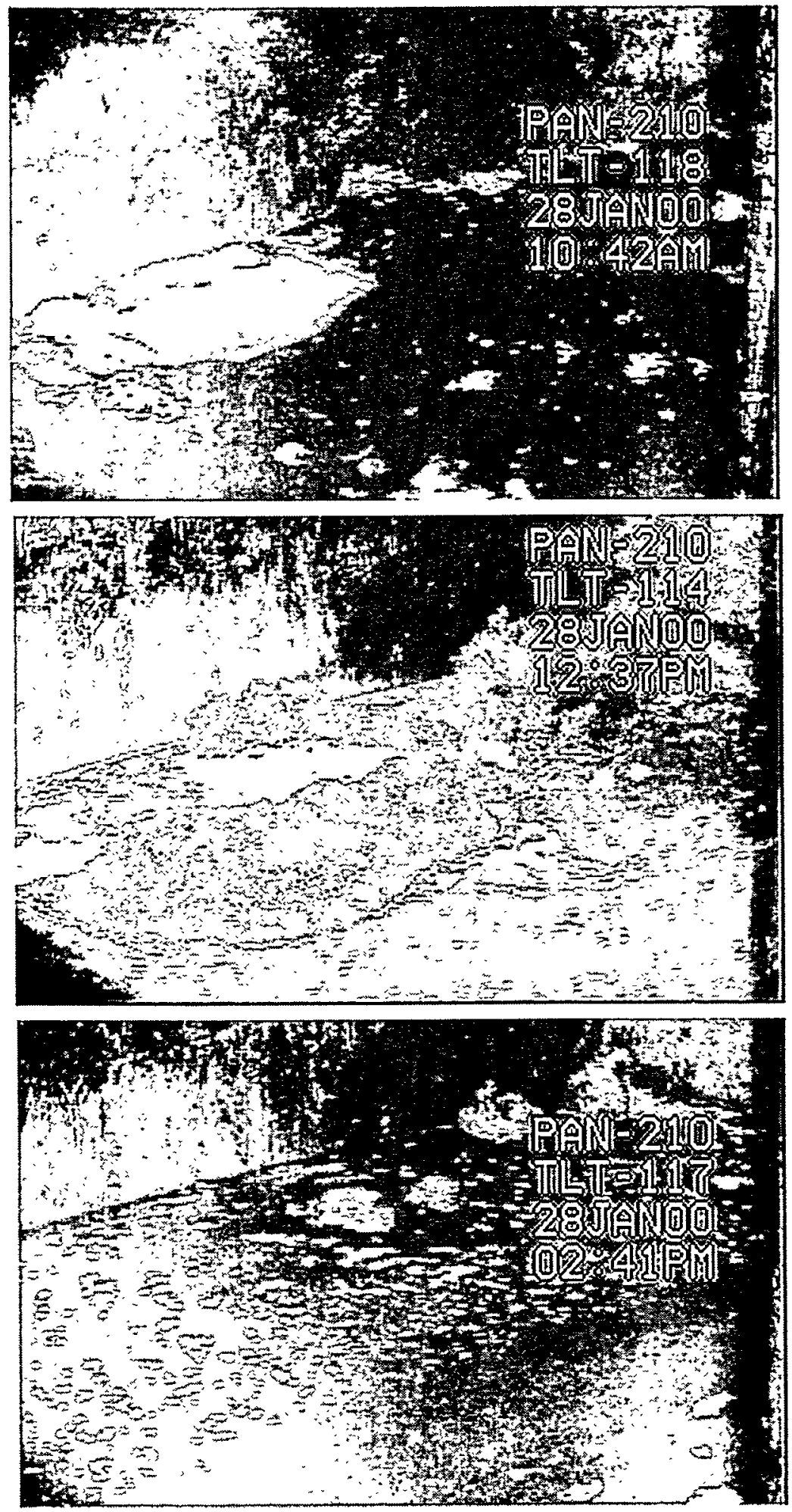

Figure 2.8. "Landslide" from Tank Wall During Top Dilution $2 b$ 

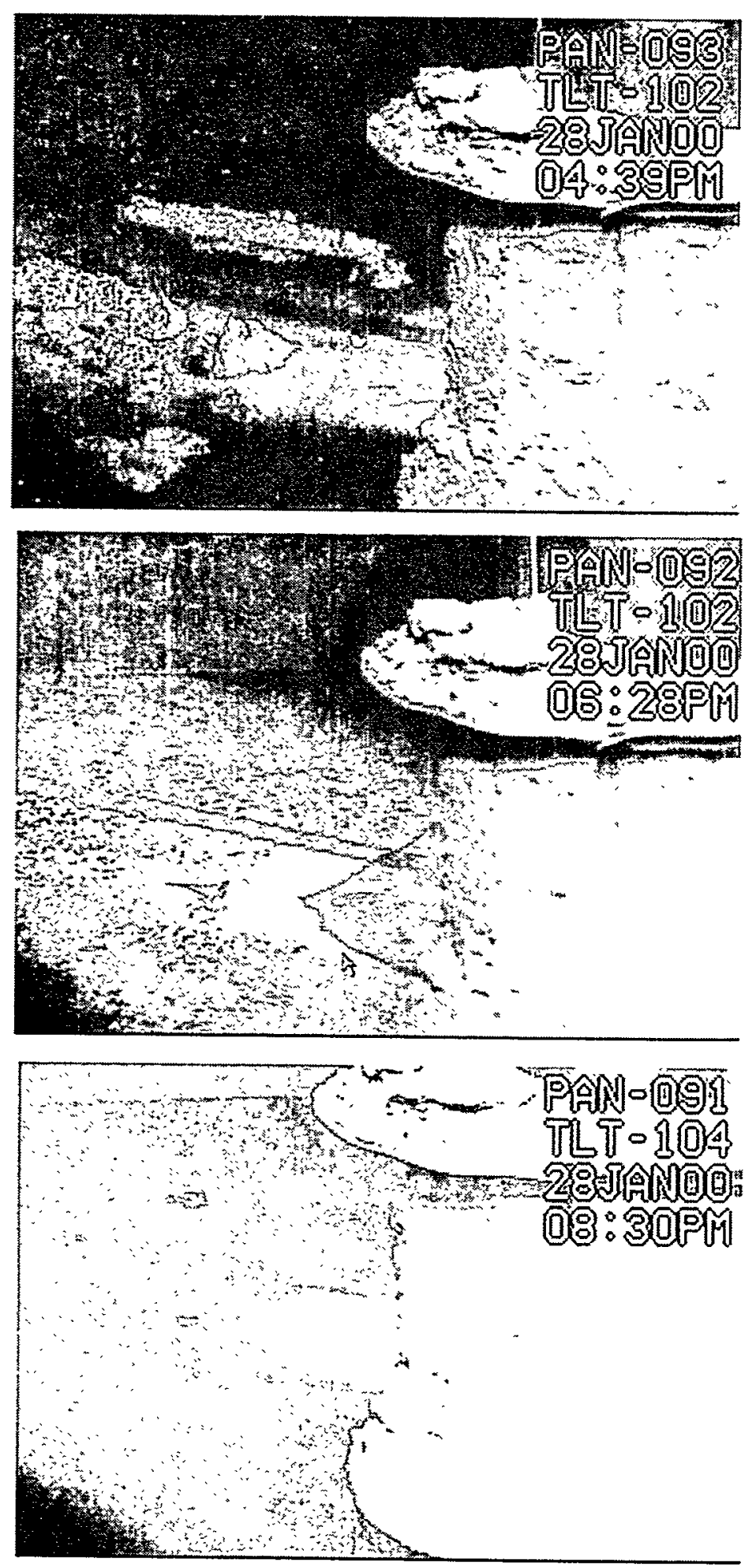

Figure 2.9. Bubble Slurry Flow During Top Dilution $2 b$ 


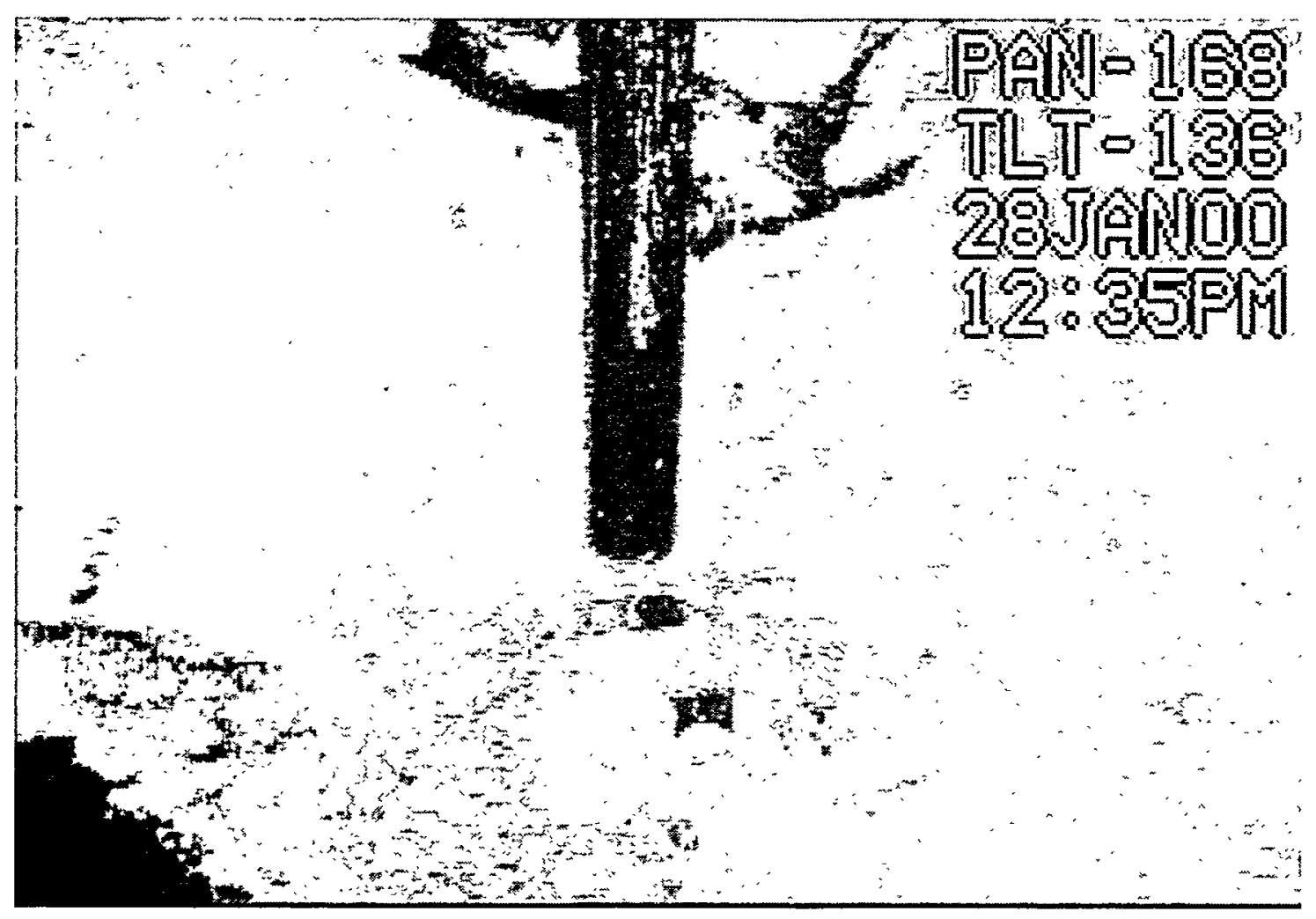

Figure 2.10. Closeup of Bubble Slurry Material
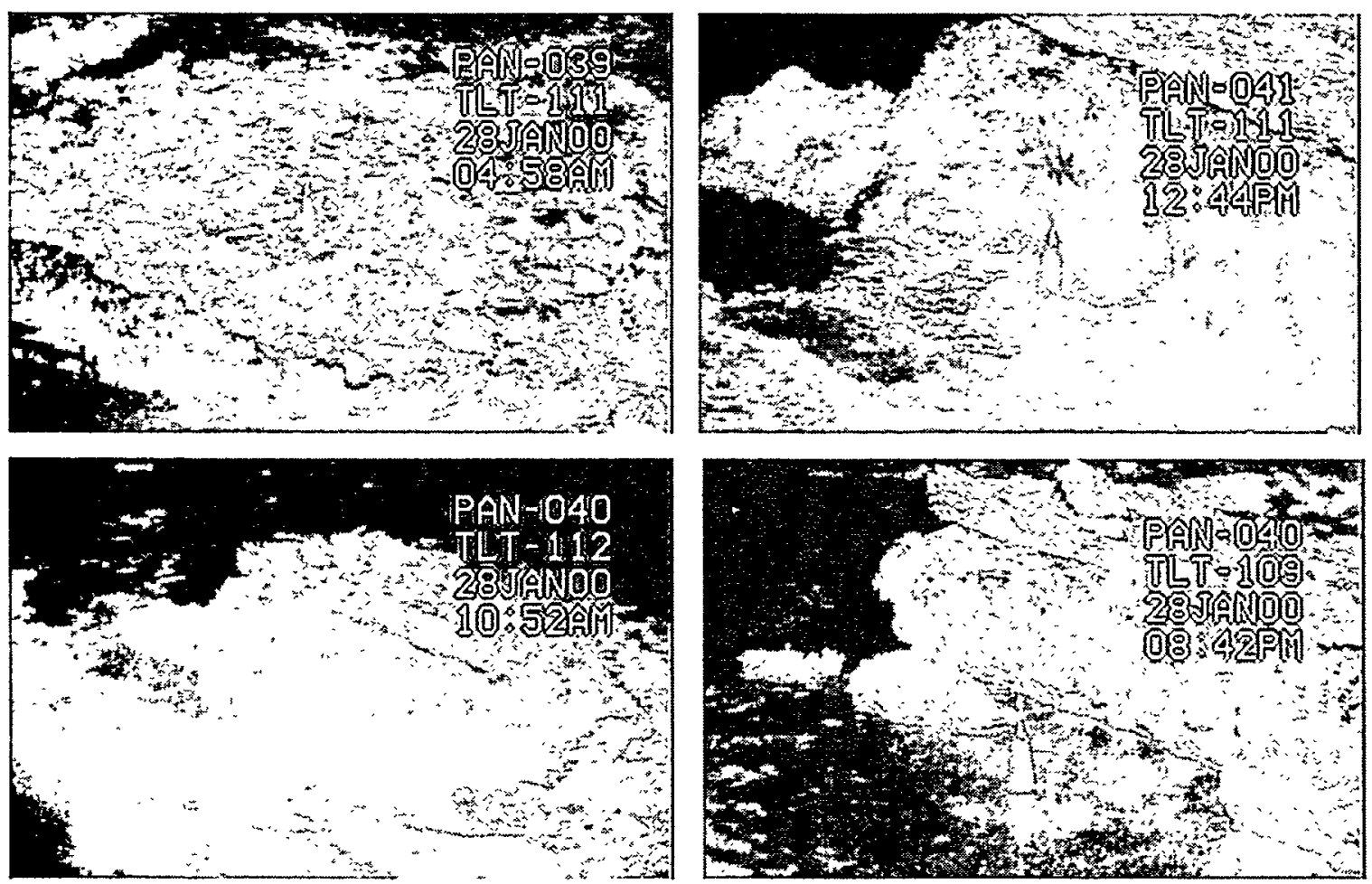

Figure 2.11. Descent of Enraf 1A During Top Dilution 2b 

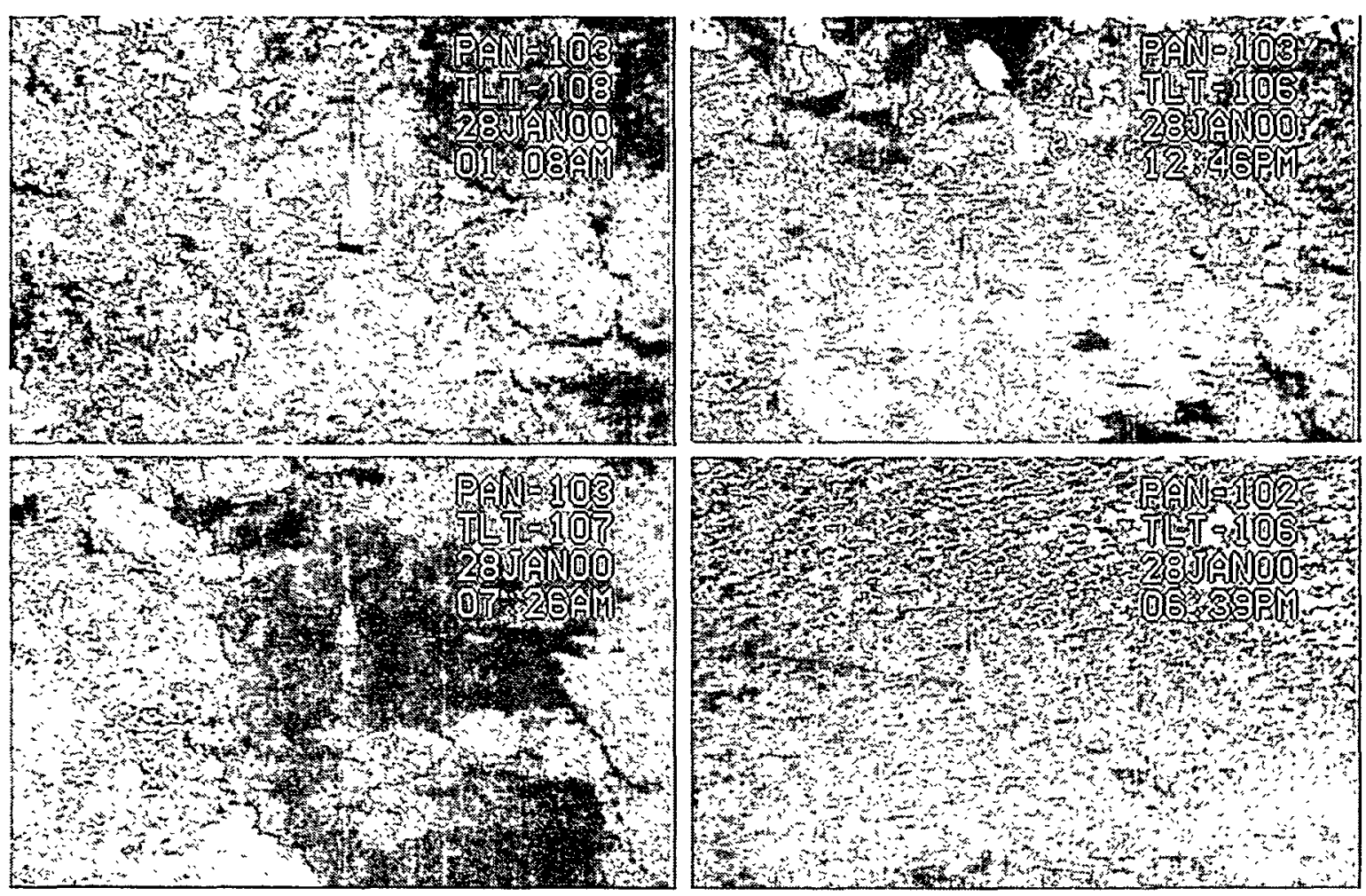

Figure 2.12. Enraf $1 C$ During Top Dilution $2 b$

The second low dilution, $2 c-d$, was performed in two stages due to staffing constraints. Low dilution $2 \mathrm{c}$ began at 2:40 AM February 21 and ended at 11:32 PM the same day. One mixer pump run was performed between stages on February 22. Low dilution $2 d$ started at 10:37 AM on February 23 and was completed at 8:53 PM that evening. A small top dilution, 2e, immediately followed $2 \mathrm{~d}$ and finished at 11:30 PM on February 23.

The progress of low and top dilutions 2c-e was uneventful. No video frames are shown because there are no significant changes in surface appearance to show. With much less crust remaining to dissolve and release gas, the levels at both risers $1 \mathrm{~A}$ and $1 \mathrm{C}$ responded positively to both low and top dilution. The top layer of floating crust debris was not submerged during top dilution. Based on neutron and gamma profiles, this 30-40 inch "slush" layer did not change very much during this last portion of the second campaign.

The SY-101 ammonia concentration increased almost linearly throughout both low dilutions $2 \mathrm{c}-\mathrm{d}$, peaking at just over $600 \mathrm{ppm}$ on the first and about $550 \mathrm{ppm}$ in low dilution $2 \mathrm{~d}$. After low dilution $2 \mathrm{c}$, the ammonia concentration decayed exponentially. The small top dilution, $2 \mathrm{e}$, very quickly scrubbed ammonia from the headspace, but the concentration recovered to $300 \mathrm{ppm}$ shortly afterward.

The hydrogen concentration peaked at $240 \mathrm{ppm}$ at the middle of low dilution $2 \mathrm{c}$ and reached $100 \mathrm{ppm}$ at the end of low dilution $2 \mathrm{~d}$, but it fell quickly to background between the two. The small top dilution, $2 \mathrm{e}$, caused a brief rise to about $210 \mathrm{ppm}$. Hydrogen quickly fell back to about $40 \mathrm{ppm}$ in the six hours after top dilution ended. The hydrogen release during these operations could be attributed either to dissolution of crust remnants or to small bubbles in the mixed slurry 
finally being released. Continued dissolution of crust remnants after the top dilution elevated hydrogen background concentration above $50 \mathrm{ppm}$ for several days.

Both the low and top dilution water was added at about $50^{\circ} \mathrm{F}$ with the goal of advancing the tank more quickly to its eventual cooler steady state. The relatively low temperature of the low dilution water was sufficient to overcome the heat of solution/dilution that increased temperatures during the first low dilution. The temperature above the transfer pump inlet at the 100 -inch level decreased from $116^{\circ}$ to $106^{\circ} \mathrm{F}$ during the two steps of the second low dilution. After several mixer pump runs, the average slurry temperature relaxed to about $108^{\circ} \mathrm{F}$ prior to the third campaign.

\subsection{Narrative of Events During the Third Campaign}

The third and last campaign was performed to finish dissolving the remaining crust debris floating on the surface and to dilute the remaining waste to the desired end state. The sequence of events during the third transfer and back-dilution campaign is given in Table 2.3, including mixer pump runs up to the beginning of an evaluation period without mixer pump operation.

The third campaign was performed in two stages. Transfers $3 \mathrm{a}-\mathrm{b}$ were accomplished on February 29-March 1, 2000, and back-dilutions 3c-f were performed about two weeks later, March 13-15, 2000. The transfers moved 286,000 gallons of waste to SY-102 and reduced the waste level in SY-101 to about 280 inches. The previous minimum was 305 inches after transfer 2a. The back-dilutions $3 \mathrm{c}-\mathrm{f}$ were alternating large low dilutions and smaller top dilutions. Low dilution $3 \mathrm{c}$ was 127,000 gallons, and top dilution $3 \mathrm{~d}$ was 22,000 gallons. Low dilution $3 \mathrm{e}$ was 60,000 gallons, and top dilution $3 \mathrm{f}$ was 145,000 gallons.

\subsubsection{Third Transfer}

Transfer 3a began at 9:43 PM on February 29 with a waste flow of $90 \mathrm{gpm}$ and an in-line dilution flow of $30 \mathrm{gpm}$ for a $0.33: 1$ dilution ratio. About fifteen hours later the flow was ramped up to $200 \mathrm{gpm}$ (150 gpm waste and $50 \mathrm{gpm}$ dilution), maintaining a 0.33:1 dilution ratio. Raw water at about $50^{\circ} \mathrm{F}$ was used for in-line dilution in this transfer. The permit issued by the Washington State Department of Ecology limited the amount of ammonia that an operation was allowed to release to the atmosphere to $100 \mathrm{lbm}$ in 24 hours. On the morning of March 1, it was determined that the ammonia release from the SY-farm stack was approaching the limit, and transfer 3a was shut down at 5:23 AM after 160,500 gallons had been pumped from SY-101.

Transfer $3 \mathrm{~b}$ started at 2:18 PM at the same flow rates as before. By 10:30 PM that evening, however, stack ammonia had reached $1,750 \mathrm{ppm}$, the concentration calculated to produce a $100 \mathrm{lbm}$ release in 24 hours at the prevailing exhaust flow rate. To reduce the ammonia concentration, the transfer rate was reduced to $103 \mathrm{gpm}$ ( $75 \mathrm{gpm}$ of waste and $28 \mathrm{gpm}$ of water) with a dilution ratio of $0.37: 1$. This maintained the stack ammonia concentration below 1,750 $\mathrm{ppm}$. The flow rate was raised to $130 \mathrm{gpm}(100 \mathrm{gpm}$ waste and $30 \mathrm{gpm}$ water, 0.3:1 dilution ratio) at 8:00 AM on March 2 and held there for the last five hours of transfer. This raised the stack ammonia concentration to almost $2,000 \mathrm{ppm}$ when transfer $3 \mathrm{~b}$ was shut down at 1:26 PM. A total of 125,500 gallons had been pumped, bringing the total for the third transfer, $3 a-b$, to 286,000 gallons. 
Table 2.3. Sequence of Events During the Third Campaign

\begin{tabular}{|l|cl|}
\hline Event & $\begin{array}{c}\text { Date and } \\
\text { Time }\end{array}$ \\
\hline Third Transfer & & \\
\hline Transfer 3a start at 120 gpm (90 gpm waste, 30 gpm water) & $2 / 29 / 00$ & $06: 35$ \\
\hline Transfer pump powered up to 200 gpm (150 gpm waste, 50 gpm water) & $2 / 29 / 00 \quad 21: 43$ \\
\hline SY102 ammonia 7160 ppm, SY stack at 2080 ppm & $3 / 1 / 00 \quad 03: 00$ \\
\hline Transfer 3a shut down due NH limit, 160,500 gallons pumped & $3 / 1 / 00 \quad 05: 23$ \\
\hline SY102 ammonia 3810 ppm, SY stack at 935 ppm & $3 / 1 / 00 \quad 13: 00$ \\
\hline Transfer 3b start & $3 / 1 / 00 \quad 14: 18$ \\
\hline SY stack at 1750 ppm, concern over 100 lb/24 hr NH3 limit & $3 / 1 / 00 \quad 22: 30$ \\
\hline Transfer reduced to 103 gpm (75 gpm waste, 28 gpm water) & $3 / 1 / 00 \quad 22: 50$ \\
\hline Transfer increased to 130 gpm (100 gpm waste, 30 gpm water) & $3 / 2 / 00 \quad 08: 00$ \\
\hline Transfer 3b shut down, total of 286,000 gallons transferred in \#3 & $3 / 2 / 00 \quad 13: 26$ \\
\hline Third Back Dilution & & \\
\hline Mixer pump run attempted, shut down due to spray after 5 min. & $3 / 6 / 00$ & $19: 52$ \\
\hline Low dilute 3c start (transfer pump inlet) & $3 / 13 / 00$ & $11: 26$ \\
\hline Low dilute 3c shut down, 127,000 gallons added & $3 / 14 / 00$ & $13: 00$ \\
\hline Top dilute 3d start & $3 / 14 / 00 \quad 13: 10$ \\
\hline Top dilute 3d shut down, 22,000 gallons water added & $3 / 14 / 00$ & $20: 30$ \\
\hline Low dilute 3e start (transfer pump inlet) & $3 / 14 / 00$ & $20: 40$ \\
\hline Low dilute 3e shut down, 60,000 gallons of water added & $3 / 15 / 00$ & $10: 30$ \\
\hline Top dilute 3f start & $3 / 15 / 00$ & $10: 40$ \\
\hline Top dilute 3f shut down, 14,500 gallons water added. & $3 / 15 / 00$ & $15: 00$ \\
\hline
\end{tabular}

Transfer 3a dropped the waste level in SY-101by 58.5 inches. This implies a volume of 160,875 gallons, which closely matches the measured transfer volume of 160,500 gallons. The close match of volumes suggests there was no waste attached to the wall between the initial level of 388 inches and the ending level of 330 inches. During transfer $3 b$, the level dropped 48.5 inches in SY-101 for an apparent volume of 133,375 gallons. Compared with the measured volume of 125,500 gallons, this implies a ring of attached waste of $1.1 \mathrm{ft}$ average thickness. If we assume that the second back-dilutions $2 \mathrm{~b}-\mathrm{e}$ cleared the tank walls above 305 inches, the minimum waste level after the second transfer $2 a$, the average attached waste ring between 305 inches and 281 inches would be about 2 feet, the same as derived for the second transfer $2 \mathrm{a}$. This thickness is consistent with the appearance of the tank wall after the third transfers, $3 a-b$, compared with the clean wall midway through the second top dilution $2 b$, as shown in Figure 2.13. The total level rise in SY-102 of 140.6 inches for the entire third transfer is consistent with the $0.34: 1$ in-line dilution ratio used in this transfer.

A mixer pump run was attempted on March 6 with the waste level at about 280 inches. The run was aborted at the five-minute check point because the small vent hole on the volute flush manifold was exposed, spraying waste into the headspace. The vent hole was designed to allow air to exit the volute and cooling jacket as the pump submerged in the waste during installation. The brief spray did not impact the exhaust filters, and no waste was released from the tank, but the event confirmed that the vent hole was not plugged, as had been postulated prior to remediation. No further mixer pump runs were performed until after the third back-dilution. 


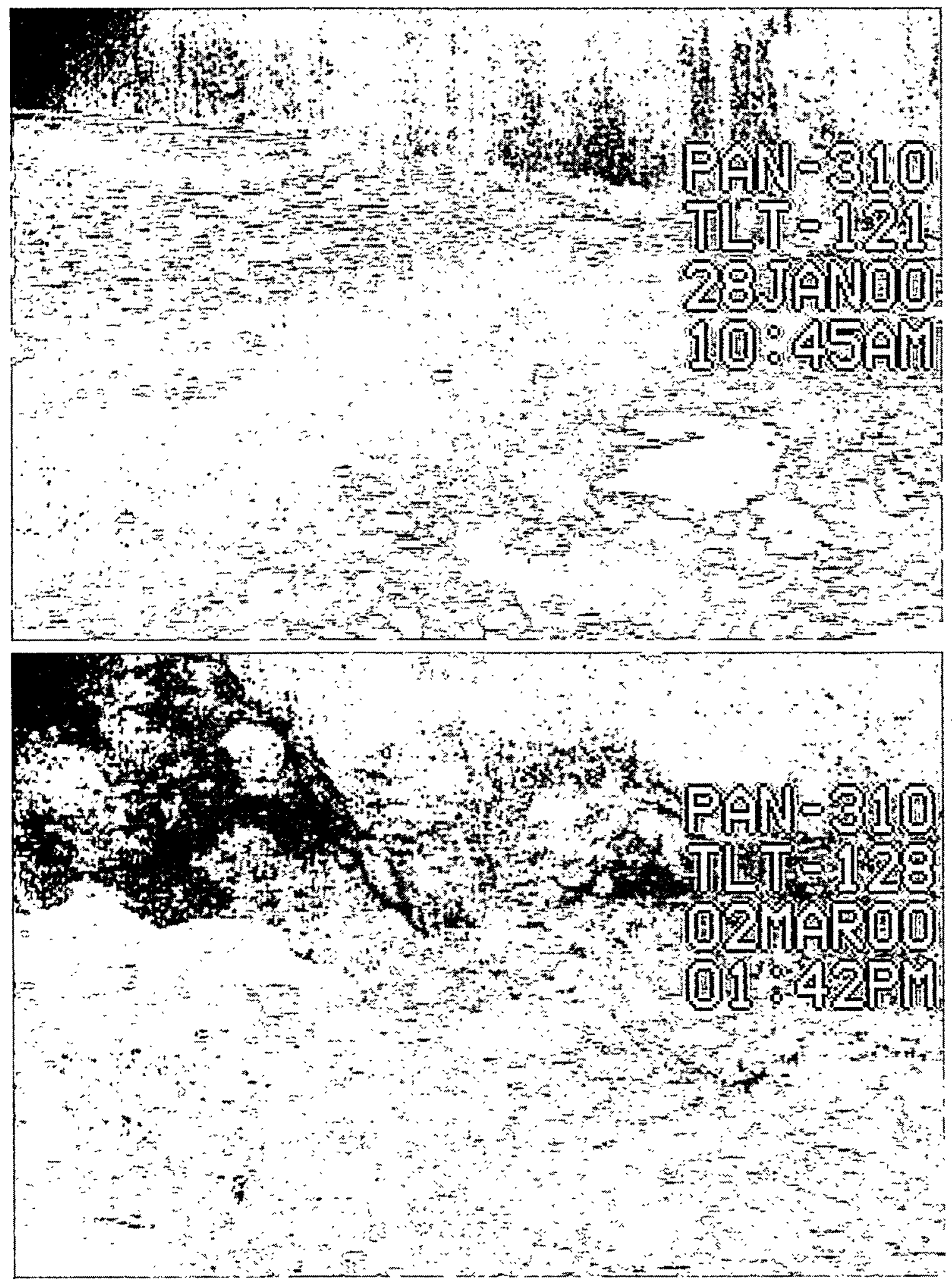

Figure 2.13. Waste Attached to the Tank Wall after Transfer $3 b$ 


\subsubsection{Third Back-Dilution}

The four back-dilutions, $3 \mathrm{c}-\mathrm{f}$, of the third campaign alternated a large low dilution followed by a smaller top dilution. The large low dilution 3c added 127,000 gallons from 11:26 AM on March 13 to 1:00 PM on March 14. Top dilution 3d began immediately and added 22,000 gallons by 8:30 PM on the same day. Low dilution 3e began immediately afterward and added 60,000 gallons by 10:30 AM on March 15. The 14,500-gallon top dilution $3 \mathrm{f}$ was completed at 3:00 PM the same day. The total back-dilution was 223,500 gallons, of which 187,000 was added at the transfer pump inlet and 36,500 on the waste surface.

The third back-dilution was uneventful. The top layer of floating crust debris stayed on the surface during both top dilutions ( $2 \mathrm{~d}$ and $\mathrm{f}$ ) but apparently began dissolving. By March 17 the neutron and gamma profiles showed a dilute layer about 30 inches deep at the surface, about half the 40-60 inches that had existed after the second campaign. By March 29, further dissolution and aggressive mixer pump operation had removed essentially all traces of a crust or dilute layer on top of the waste. However, the surface remained covered by a thin "scum" of white foamy material that has suppressed ammonia evaporation.

The SY-101 ammonia concentration increased steadily during low dilution 3c, peaking at about $270 \mathrm{ppm}$. However, the succeeding top dilutions $3 \mathrm{~d}$ and $3 \mathrm{f}$ brought the ammonia level back below $140 \mathrm{ppm}$. The background ammonia concentration gradually increased back to about $180 \mathrm{ppm}$ a week after the third campaign.

The hydrogen concentration also increased with each step of the process: about $100 \mathrm{ppm}$ after low dilution 3c, $160 \mathrm{ppm}$ after top dilution 3d, $240 \mathrm{ppm}$ after low dilution 3e, finally peaking at over $400 \mathrm{ppm}$ at the middle of the last top dilution, $3 \mathrm{f}$. Continued dissolution of crust remnants and solids after the last top dilution kept the hydrogen background concentration above $160 \mathrm{ppm}$ for several days. The high background release caused a level drop of several inches over this period.

Dilution water was again added at about $50^{\circ} \mathrm{F}$ as in low dilutions $2 \mathrm{c}-\mathrm{d}$. The temperature above the transfer pump inlet at the 100 -inch level decreased from $108^{\circ}$ to $92^{\circ} \mathrm{F}$ during backdilutions $3 \mathrm{c}-\mathrm{f}$. After several mixer pump runs, the average slurry temperature relaxed to about $96^{\circ} \mathrm{F}$.

After the third campaign, the mixer pump was run as aggressively as possible to mix the tank thoroughly in preparation for the mixer pump evaluation period. "Tank sweeps" of up to four mixer pump runs per day were made on March 17, 18 (three runs), 23, 24, 26, 28 (three runs), 30 and April 1. One run was made on March 21. Each run was performed at 1,000 rpm for 25 minutes. The 31 runs swept the entire tank in 30-degree increments five times during this period.

The fluid motion at the surface imparted by the mixer pump jet was able to move the foamy "crust" such that the Enraf bobs were pulled out of vertical alignment, especially at $1 \mathrm{C}$. The longer, non-vertical cable length made the level reading artificially low, and procedures were modified to lift the bobs off the waste surface periodically to keep the cables vertical. A pool of liquid was also observed to form temporarily on the surface above the vent hole in the volute flush manifold. 


\subsection{Summary of Events}

The three remediation campaigns performed from mid-December 1999 through mid-March 2000 achieved the intended goals. The first campaign reduced the waste surface level more than one foot and mitigated the immediate problem of level growth. It also confirmed (and slightly adjusted) our expectations of the behavior of the waste during transfer, top dilution, and low dilution and exercised all aspects of the transfer system. The second campaign destroyed the crust and released most of the tank's stored gas, removing the main hazard of crust growth. The third campaign dissolved the bulk of the remaining soluble solids and diluted the rest of the waste sufficiently, according to predictions, to prevent significant gas retention in the future.

Throughout the three campaigns, transfer and dilution procedures were accomplished safely, smoothly, and efficiently, without any major difficulties or discovery of new hazards. The transfer pump and dilution system performed flawlessly, and the mixer pump continued to operate normally except for a few minor complications that were easily corrected.

On April 2, 2000, SY-101 entered a period of observation without mixer pump operation to confirm that the desired end state had actually been achieved: a relatively shallow nonconvective layer with a much-reduced gas generation rate that does not retain a volume of gas that could lead to BD GREs. On the basis of the data collected during the observation period, the level growth unreviewed safety question (USQ) will be closed, and the tank will be removed from the FGWL. When these steps have been accomplished, the remediation process will have converted SY-101 from a potential hazard requiring constant attention and expense into a resource that can eventually be used for normal waste retrieval staging operations. 


\subsection{Waste Level Behavior}

Changes in the waste surface level gave the most direct information on the progress of waste transfer out of SY-101 into SY-102 and back-dilution in SY-101. Changes in level between transfer and dilution operations are also a measure of gas release. The difference between the measured level change and that inferred from transfer and dilution flows, including the effect of gas release, reveals changes in the surface topography due to crust deformation and/or dissolution and whether a significant thickness of waste was attached to the tank wall.

Data from strain gauges installed on suspended equipment also provided indications of crust deformation and movement during transfer and back-dilution. The strains at the mixer pump column and riser $17 \mathrm{C}$ indicated changes in loading during the first transfer and second top dilution; however, these strains quickly relaxed, and none represented significant loads. Strain data were not monitored during the second low dilution or the third campaign because the crust layer, which would have produced significant strains, no longer existed.

Measured surface levels from Tanks SY-101 and SY-102 along with data from dilution and waste flow totalizers were monitored during each campaign to provide data for mass balances and to follow the progress of the activity. However, only the SY-102 waste level was used in the mass balance because the nonuniform behavior and dissolution of the crust in SY-101 would have introduced considerable error if the SY-101 levels were used.

During transfers in the first and second campaigns, surface level changes at several other locations in SY-101 were estimated by observing surface motion relative to suspended hardware using in-tank video. Local level drops were measured this way at five points: the two velocitydensity-temperature trees (VDTTs) in risers 1B and 14A, the two MTTs in risers 17B and 17C, and the mixer pump support column. During transfer 1a, measurements were also attempted at several points on the tank wall, but, soon after transfer began, the initial reference points disappeared as the crust descended. Measurements were not practical during back-dilution because the waste surface changed constantly as it dissolved.

The method of determining the local level drop from video images is described in Section 3.1. The level behavior in the three campaigns is described in Sections 3.2, 3.3, and 3.4, respectively. Section 3.5 gives a summary with the overall reconciliation of level changes with gas releases and transfers and dilutions. Section 3.6 discusses strain gauge data that were gathered during the first and second campaigns.

\subsection{Visual Determination of Local Waste Level Drop}

The local level drop measured the apparent distance from a clearly visible reference point on the piece of hardware to the waste surface using photometric software on a captured video frame, as shown in Figure 3.1. The reference point had to be changed occasionally as the initial one rose out of view. The measured level drop is the measured distance calibrated to the known diameter of an MIT or VDTT (3.5 inches) or to some known dimension on the mixer pump column. The measured level drop is corrected for the camera tilt angle, as shown in Figure 3.2 using the following relation: 


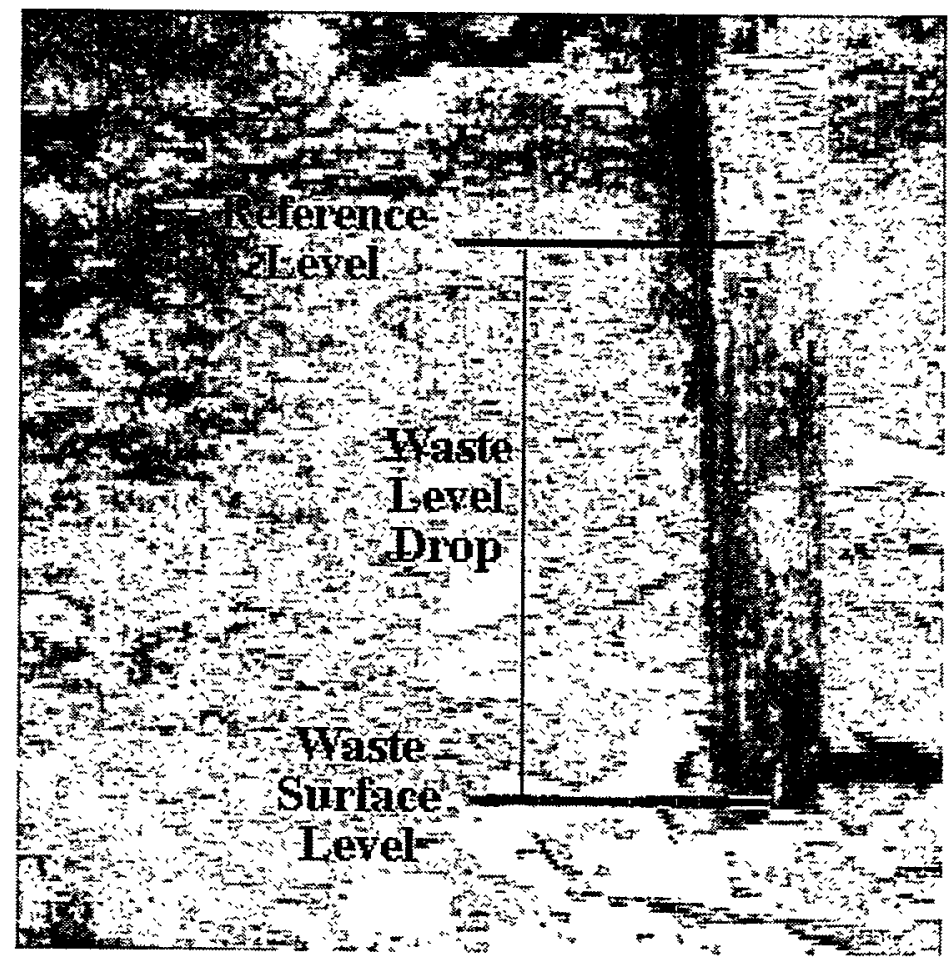

Figure 3.1. Measuring Local Waste Level Drop (VDTT at 14A)

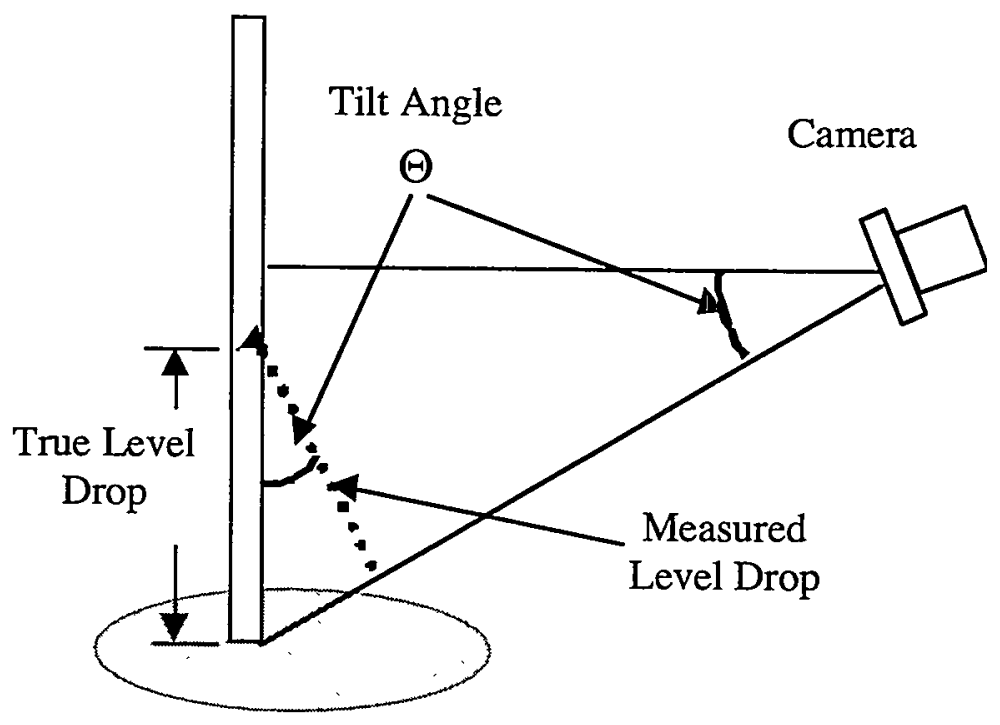

Figure 3.2. Tilt Angle Correction 


$$
\text { True Level Drop }=\frac{\text { Measured Drop }}{\operatorname{Cos} \Theta}
$$

where $\Theta$ is the tilt angle. Even with this correction, the error of the visually determined level drop increases at high angles, but the error was significant only in the measurement referenced to the VDTT in riser $1 \mathrm{~B}$, the point nearest the camera, at the end of the second transfer.

A parameter of interest during the first two campaigns was the difference between the level readings from the Enraf gauges in risers $1 \mathrm{~A}$ and $1 \mathrm{C}$, which stood at 20 inches prior to the first transfer. Because the waste around riser $1 \mathrm{C}$ had been flushed often with water since 1993 to allow the level gauge to operate properly, it was assumed to be an approximate measurement of the free liquid level. Enraf 1A had not been flushed and was assumed to measure the top surface of the crust. Thus the difference between the two was taken to be the "freeboard," that part of the buoyant crust floating above the liquid. As will be shown, the riser $1 \mathrm{~A}-1 \mathrm{C}$ level difference decreased after back-dilution $1 \mathrm{~b}$ and disappeared during back-dilution $2 \mathrm{~b}$ as the bulk of the crust layer dissolved.

\subsection{Level Behavior During the First Campaign}

The overall level changes in SY-101 and SY-102 during the first campaign are summarized in Table 3.1. The levels at risers $1 \mathrm{~A}$ and $1 \mathrm{C}$ dropped almost the same amount during the transfer but, because of dissolution, $1 \mathrm{~A}$ rose about 7 inches less than $1 \mathrm{C}$ during dilutions $1 \mathrm{~b}-\mathrm{c}$. The difference between the two levels ended up at about 11 inches, 9 inches less than the initial difference of 20 inches. The 62.7-inch level rise in SY-102 represents a 172,400 gallon volume of SY-101 waste plus in-line dilution water. This is consistent with 89,500 gallons of waste removed from SY-101 with a 0.9:1 in-line dilution.

Table 3.1. Level Changes During the First Campaign

\begin{tabular}{|l|c|c|c||}
\hline $\begin{array}{l}\text { Level } \\
\text { Measurement }\end{array}$ & $\begin{array}{c}\text { Transfer } \\
\text { 1a }\end{array}$ & $\begin{array}{c}\text { Dilutions } \\
\text { 1b-c }\end{array}$ & Net Change \\
\hline SY-101 1A & & & \\
\hline Start & 430.8 & 390.8 & \\
\hline End & 390.8 & 415.9 & \\
\hline Difference & -40.0 & +25.1 & -14.9 \\
\hline SY-101 1C & & & \\
\hline Start & 411.0 & 372.3 & \\
\hline End & 372.3 & 404.3 & \\
\hline Difference & -38.7 & +32.0 & -6.7 \\
\hline SY-102 & & & \\
\hline Start & 290.0 & & \\
\hline End & 352.7 & NA & \\
\hline Difference & +62.7 & & \\
\hline
\end{tabular}


The levels at 1A in SY-101 responded promptly and linearly to the first transfer, as shown in Figure 3.3. Levels measured at $1 \mathrm{C}$ are not recorded on the DACS, so only manual readings are available. The daily manual readings from the TWINS (Tank Waste Information Network System) database are shown in the figure. Top dilution $1 \mathrm{~b}$ also caused a steady level rise at $1 \mathrm{~A}$, but not until about an hour after top dilution started. The rise continued approximately proportional to the flow rate during low dilution $1 \mathrm{c}$ and stopped immediately when dilution was over. The slight rise in SY-102 level after December 21 is due to resumption of salt-well pumping.

Figure 3.4 shows the level behavior in the month after the first campaign. Both the SY-101 levels dropped about $1 / 2$ inch during this time and their difference remained at about 11 inches throughout. The SY-102 level continued to rise as a result of salt-well pumping prior to a crosssite transfer January 12 to prepare for the second campaign.

Although the rises and drops of the waste surface at riser $1 \mathrm{~A}$ generally matched those measured at $1 \mathrm{C}$ during transfer, local measurements with the video camera indicated that the waste's top surface descended unevenly. Figure 3.5 shows the level change at the five locations expressed as inches of level drop. The waste apparently dropped much farther around the mixer pump, ending a total of about eight inches lower than measured at $1 \mathrm{~A}$. The surface in the northwest quadrant, however, dropped 3-6 inches less than the measurement at $1 \mathrm{~A}$.

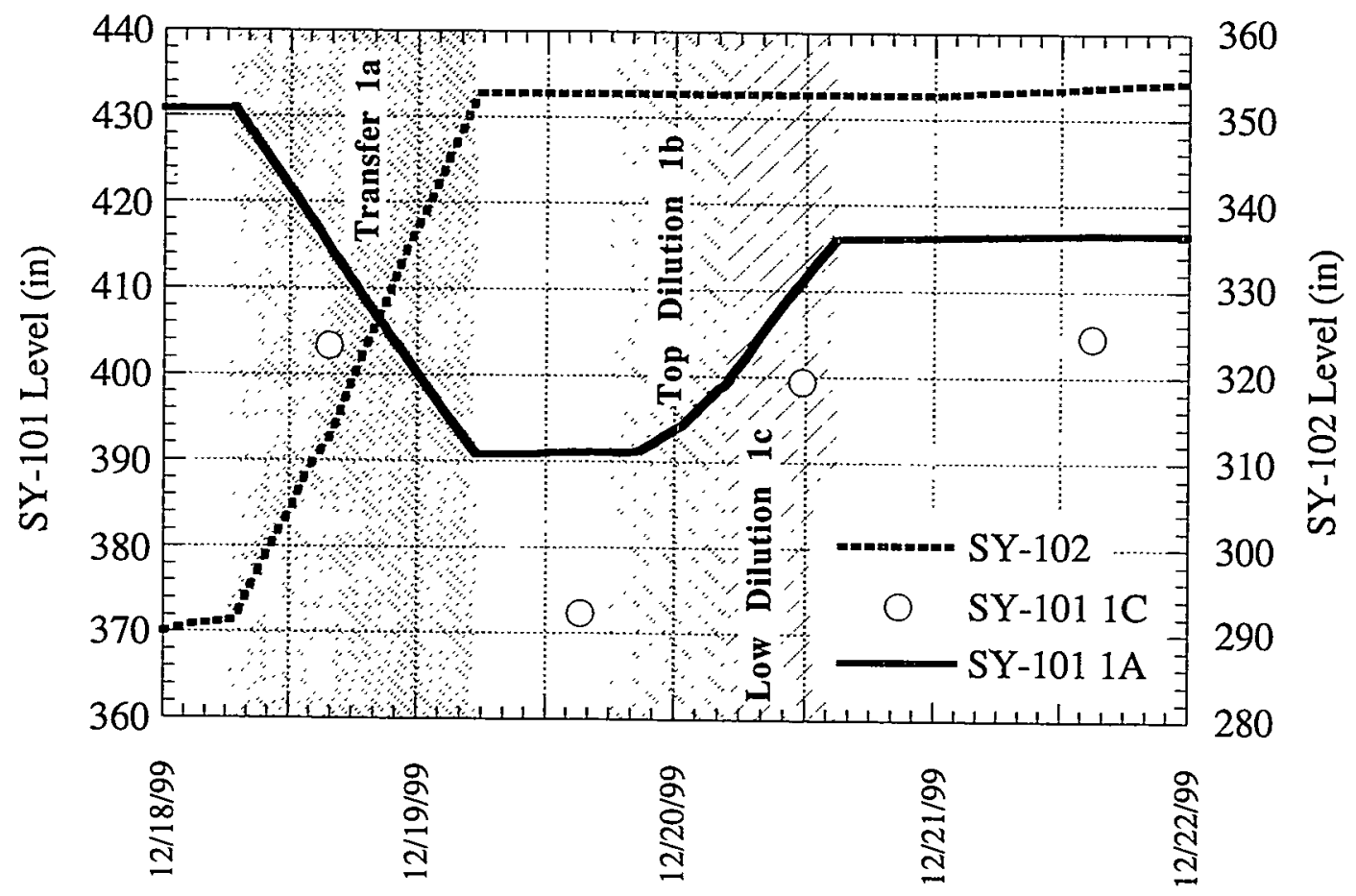

Figure 3.3. Level Changes During the First Campaign 


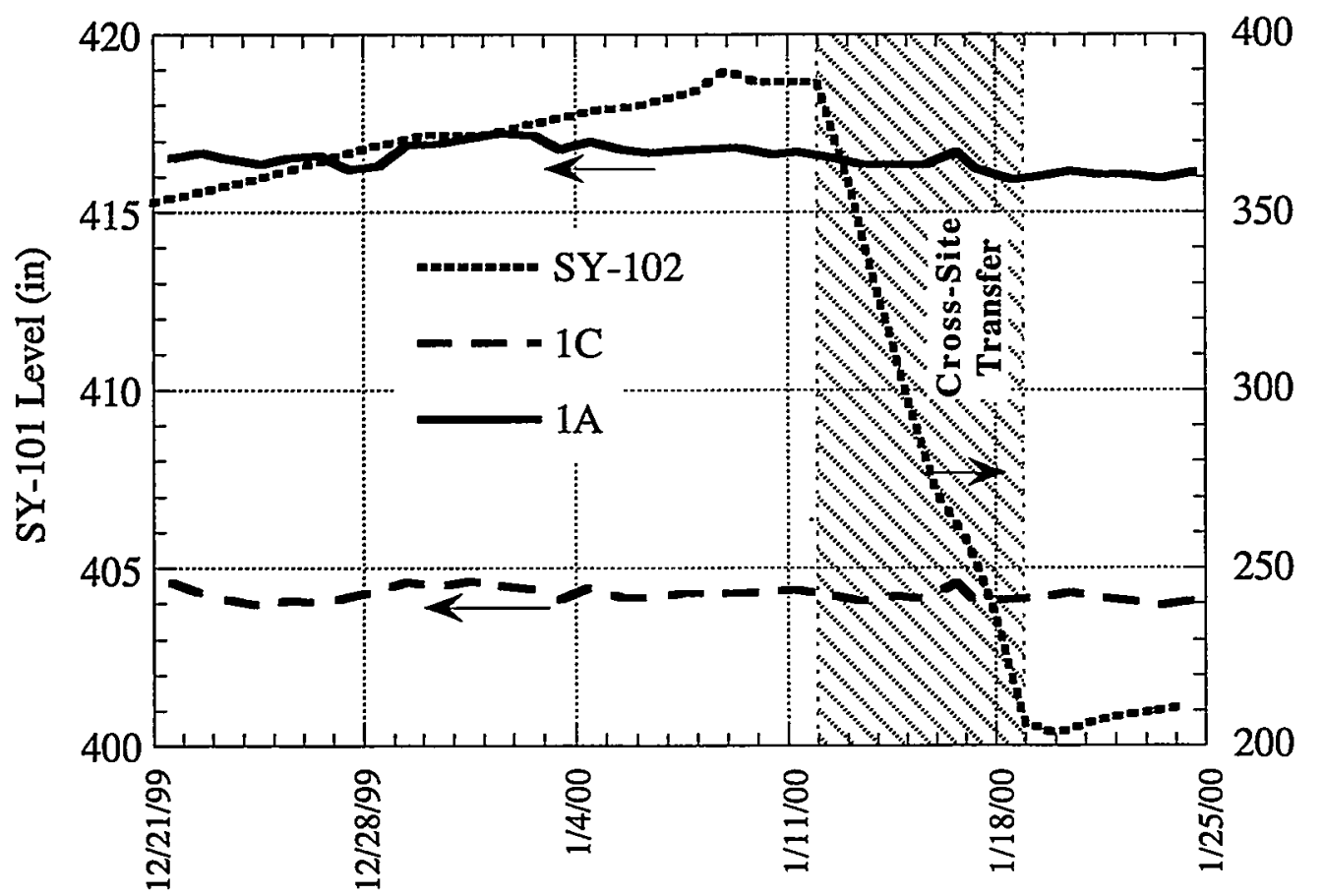

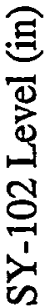

Figure 3.4. Level Changes After the First Campaign

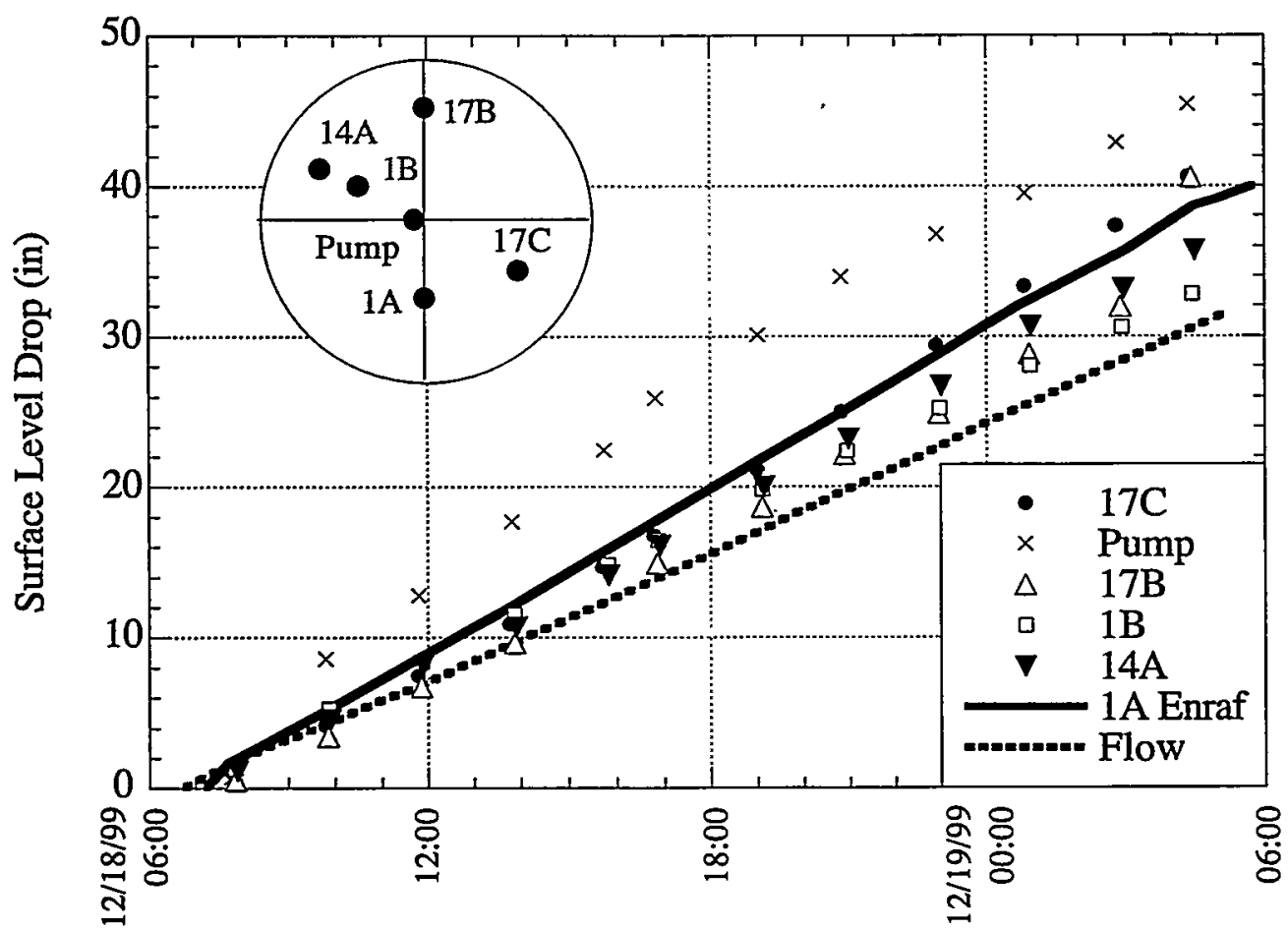

Figure 3.5. Observed Waste Level Drops During the First Transfer 1a 
At the same time, all five points on the surface as well as the riser 1A level dropped about eight inches more, on the average, than the change inferred from the transfer flow, shown as the dashed line in Figure 3.5. Low back-dilution also caused a faster level rise than the added volume would indicate. Gas release during the transfer accounts for less than three inches of the difference and is contrary to the excess level rise during dilution. However, the difference is consistent with the effect of a ring of waste one meter thick attached to the wall. Comparing the measured level changes with the later transfer and dilution flow volumes (not shown) implied that this attached ring survived through the first back-dilution and the second transfer.

\subsection{Level Behavior During the Second Campaign}

The second campaign was accomplished in two stages: the first was a large transfer, $2 \mathrm{a}$, and large top dilution, $2 \mathrm{~b}$. The second stage was a large low dilution, $2 \mathrm{c}-\mathrm{d}$, and small top dilution, $2 \mathrm{e}$. The main event during the entire campaign was the dissolution of most of the crust layer with the consequent release of several thousand cubic feet of gas during top dilution $2 \mathrm{~b}$. The waste behavior during the rest of the campaign was relatively uninteresting by comparison.

The overall level changes in SY-101 and SY-102 during the two stages of the second campaign are summarized in Table 3.2. As in the first campaign, the levels at $1 \mathrm{~A}$ and $1 \mathrm{C}$ dropped almost the same amount during transfer $2 \mathrm{a}$ but, because most of the crust dissolved, the $1 \mathrm{C}$ level rose over 12 inches more than the $1 \mathrm{~A}$ level during top dilution $2 \mathrm{~b}$. After dilution $2 \mathrm{~b}$, the levels at both $1 \mathrm{~A}$ and $1 \mathrm{C}$ remained within a few inches of each other. The 6-10-inch level drop after top dilution $2 \mathrm{~b}$ represents the large gas releases that occurred while the remainder of the crust layer dissolved.

The 152-inch level rise in SY-102 indicates a total transfer of waste plus water of 418,000 gallons. This means that the 240,500 gallons of waste removed from SY-101 had a

Table 3.2. Level Changes During the Second Campaign

\begin{tabular}{||c|c|c|c|c|c|}
\hline $\begin{array}{c}\text { Level } \\
\text { Measurement (in.) }\end{array}$ & $\begin{array}{c}\text { Transfer } \\
\text { 2a }\end{array}$ & $\begin{array}{c}\text { Dilution } \\
\mathbf{2 b}\end{array}$ & $\begin{array}{c}\text { Between } \\
\mathbf{2 b} \mathbf{~ \& ~ 2 c}\end{array}$ & $\begin{array}{c}\text { Dilutions } \\
\text { 2c-e }\end{array}$ & $\begin{array}{c}\text { Net } \\
\text { Change }\end{array}$ \\
\hline SY-101 1A & & & & & \\
\hline Start & 416.1 & 318.6 & 337.6 & 331.4 & \\
\hline End & 318.6 & 337.6 & 331.4 & 388.6 & \\
\hline Difference & -97.5 & +19.0 & -6.2 & +57.2 & -27.5 \\
\hline SY-101 1C & & & & & \\
\hline Start & 404.1 & 305.3 & 337.1 & 327.5 & \\
\hline End & 305.3 & 337.1 & 327.5 & 387.6 & \\
\hline Difference & -98.8 & +31.8 & -9.6 & +60.1 & -16.5 \\
\hline SY-102 & & & & & \\
\hline Start & 211.9 & & & & \\
\hline End & 363.9 & NA & NA & NA & NA \\
\hline Difference & +152.0 & & & & \\
\hline
\end{tabular}


0.75:1 in-line dilution. However, the measured total flow and water flow averaged $137 \mathrm{gpm}$ and $61 \mathrm{gpm}$, respectively, for an average dilution ratio of $0.8: 1$. Assuming the volume added to SY-102 is correct, the higher dilution ratio implies that 8,300 gallons (3.5\%) less waste, 232,200 gallons, was removed from SY-101 instead of 240,500 gallons. Alternately, a 0.8:1 dilution with 240,500 gallons of SY-101 waste would add 432,900 gallons to SY-102; 14,900 gallons more than the level change indicated. The SY-102 level should have increased 5.4 inches more, to 157 inches, to match this condition. Note that the apparent small in-line dilution bypass flow (see Section 5) would increase the volume of SY-101 waste transferred and cannot explain this discrepancy.

The riser $1 \mathrm{~A}$ and $1 \mathrm{C}$ levels in SY-101 responded promptly and linearly to transfer 2a, as shown in Figure 3.6. Manual readings of the $1 \mathrm{C}$ level, taken about every two hours during the transfer and top dilution, are shown. A prompt and steady level rise began with top dilution $2 \mathrm{~b}$. The rise rate was initially proportional to the flow rate but slowed as solids dissolution accelerated and larger gas releases began. The levels at $1 \mathrm{~A}$ and $1 \mathrm{C}$ became approximately equal midway through the top dilution, when the surface was covered with liquid, and both began dropping immediately when dilution was over and major gas releases continued. As in the first campaign, the SY-102 level began rising late on January 28 as salt-well pumping resumed.

Figure 3.7 shows the level behavior in the three weeks between the end of top dilution $2 b$ and the start of low dilution 2c. Both the SY-101 levels rose 2-3 inches as a foamy crust remnant formed at the surface. The SY-102 level continued to rise as a result of salt-well pumping prior to a cross-site transfer February 10.

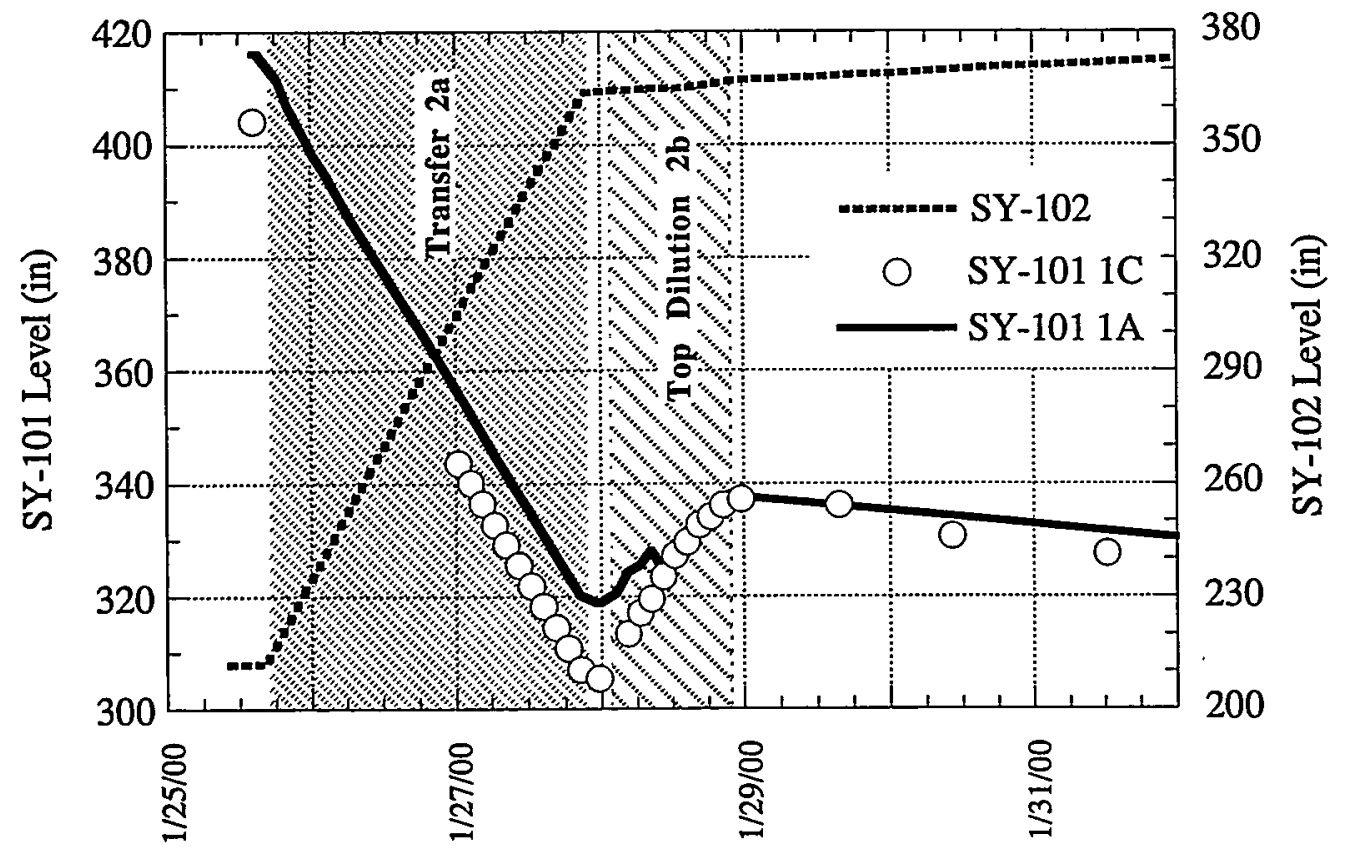

Figure 3.6. Level Changes During Transfer 2a and Top Dilution 2b 


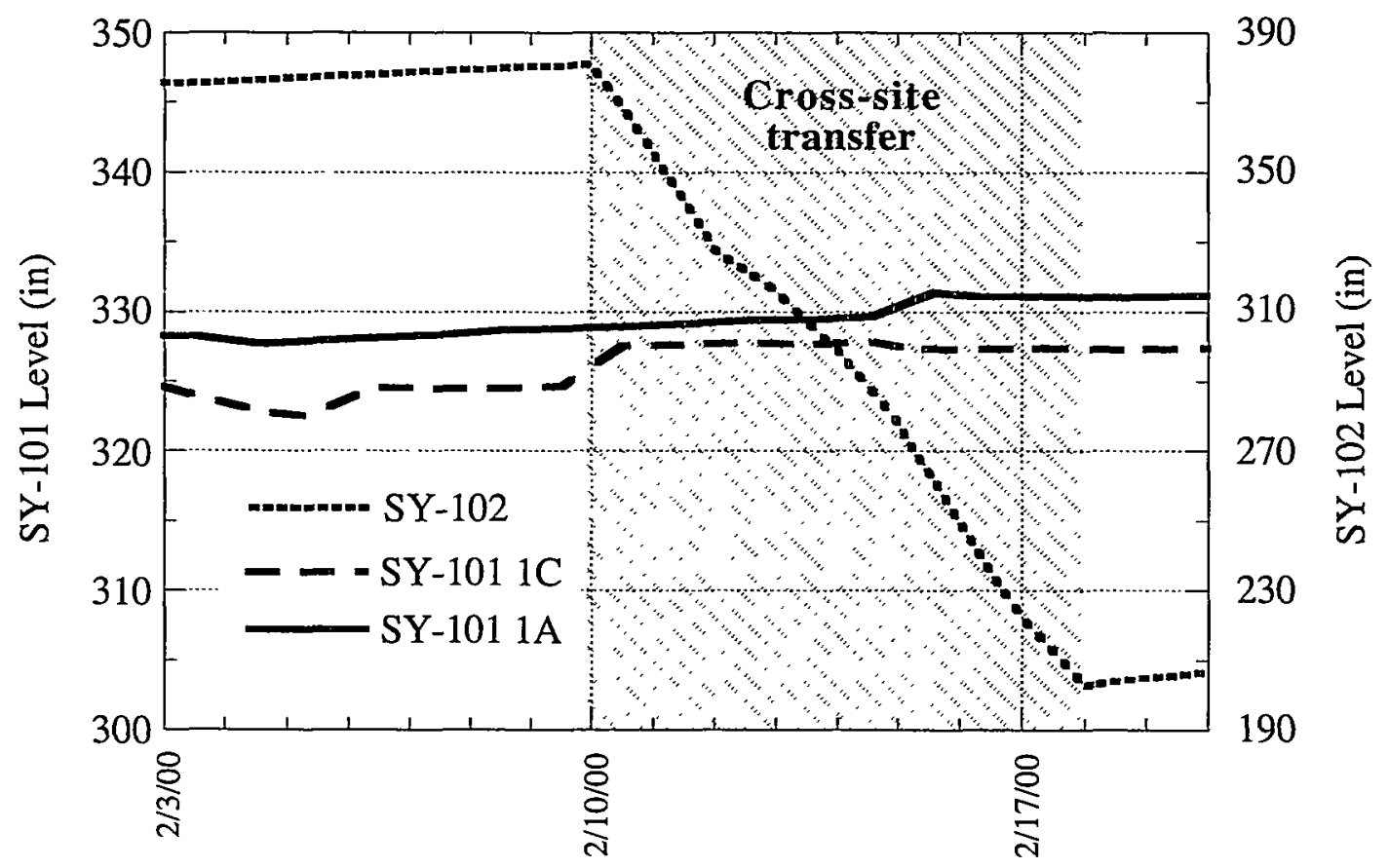

Figure 3.7. Level Changes Between Top Dilution $2 b$ and Low Dilution $2 c$

Figure 3.8 gives the level history during and a few days after low dilutions $2 \mathrm{c}-\mathrm{d}$ and small top dilution $2 \mathrm{e}$. With no significant crust remaining to dissolve and release gas, the levels at both $1 \mathrm{~A}$ and $1 \mathrm{C}$ responded positively to both low and top dilution. This time the thin layer of floating foamy material was not submerged during top dilution but remained floating. The level in SY-102 continued to rise with salt-well pumping.

As in the first campaign, local surface level measurements were made with the video camera during transfer 2a. The results, shown in Figure 3.9, indicate that the waste fell much more evenly than in December. Within the uncertainty of the method, the waste surface can be said to have descended uniformly. The departure of the level at VDTT 1B in the last few hours is due to the extreme tilt angle necessary to see the waste surface close to the camera.

Though the waste surface fell uniformly, it dropped faster than it would have had the entire area been affected. The surface dropped about 10 inches more than the 87.5 inches implied by a 240,500-gallon transfer, as shown by the dashed line in Figure 3.9. This difference is consistent with the effect of a ring of waste about $2 \mathrm{ft}$ thick attached to the wall, about half that implied by the results of the first transfer. The large transfer exposed attached waste at a few places along the wall (see Figure 2.7) that might have represented this ring. All of the attached material either dissolved or slid off the wall during the second top dilution, so all subsequent level changes were consistent with the combined effects of transfer, dilution, and gas releases. 


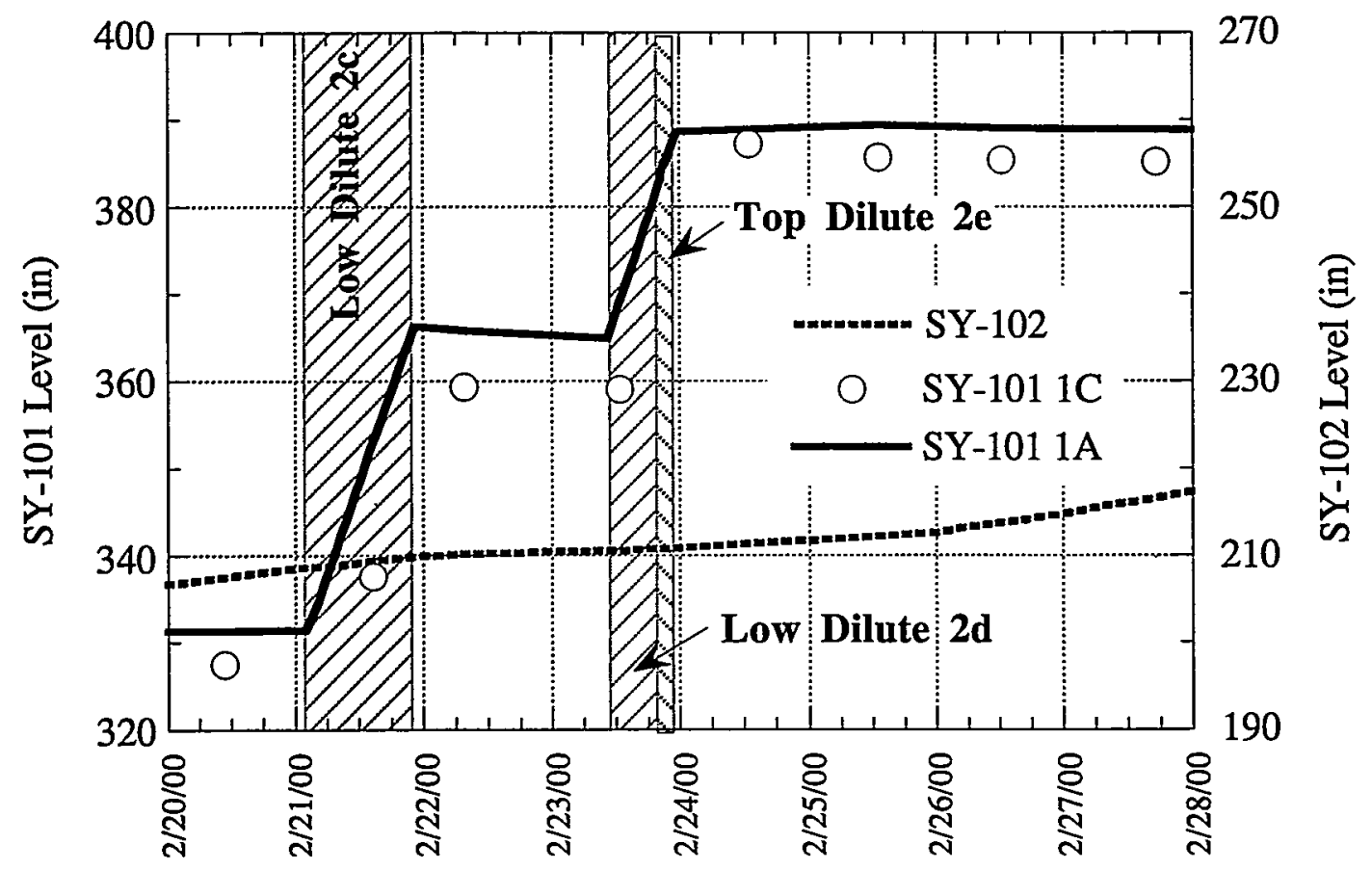

Figure 3.8. Level Changes During Low Dilutions $2 c-d$ and Top Dilution $2 e$

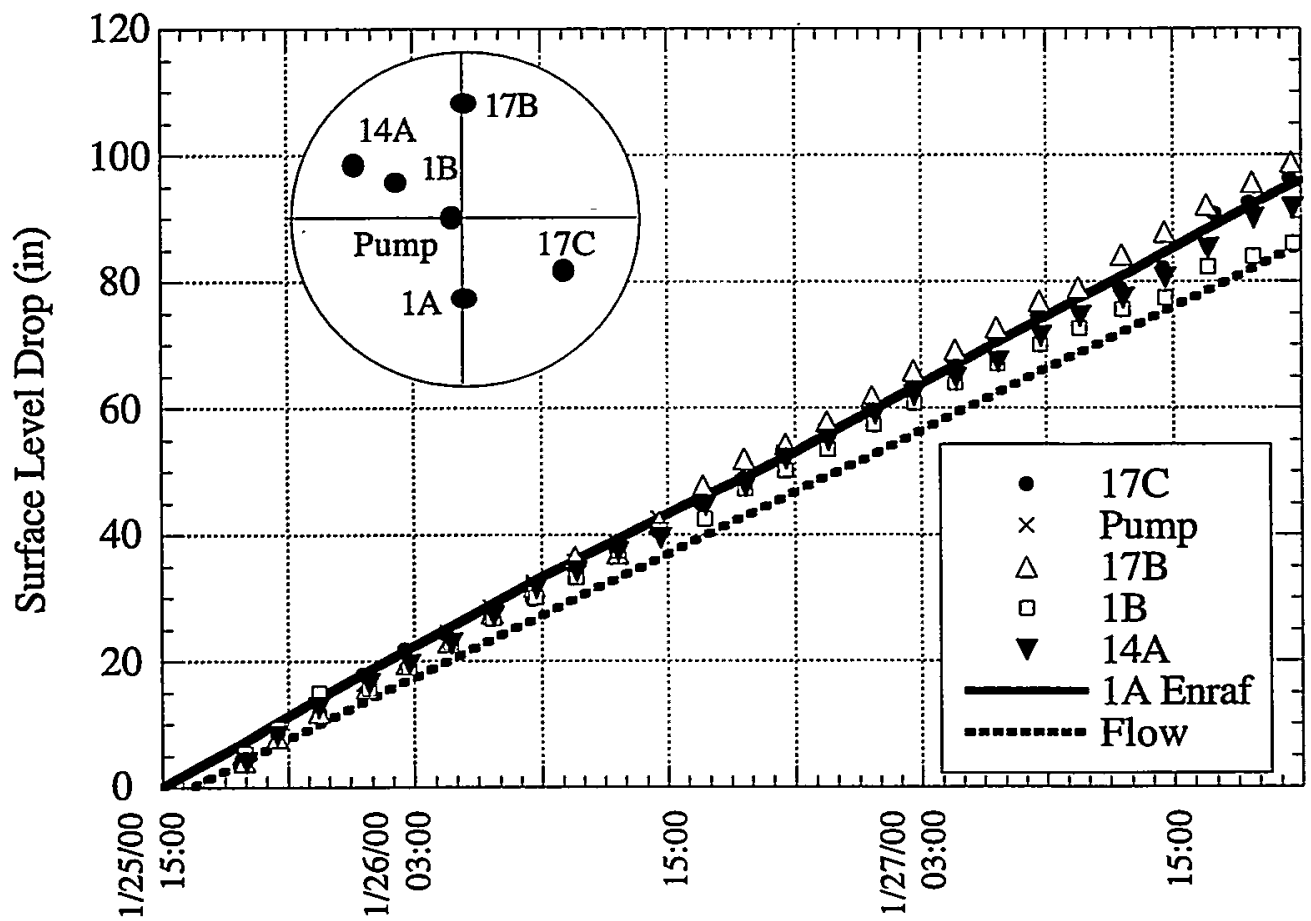

Figure 3.9. Observed Level Changes During Transfer 2a 


\subsection{Level Behavior During the Third Campaign}

The third transfer and back-dilution campaign was also accomplished in two stages: the first was a large transfer, $3 a-b$, and the second was a series of two sets of alternating large low dilutions ( $3 \mathrm{c}$ and $3 \mathrm{e}$ ) and smaller top dilutions ( $3 \mathrm{~d}$ and $3 \mathrm{f}$ ). Both stages were relatively uneventful as far as waste level and configuration are concerned. The main item of interest was the new ability of the mixer pump to move waste at the surface and pull both Enraf bobs with it. At times this gave artificially low readings until procedures were modified to regularly lift both bobs off the surface to allow them to return to vertical.

The overall level changes in SY-101 and SY-102 during the third campaign are summarized in Table 3.3. With no crust to complicate events, the levels at both $1 \mathrm{~A}$ and $1 \mathrm{C}$ remained within a few inches of each other throughout. In SY-102 the level rose 131 inches at the end of the transfer but kept rising for some hours and eventually reached 141 inches. The 141-inch level rise in SY-102 represents 386,700 gallons of waste plus dilution water. A total of 286,000 gallons of waste were removed from SY-101 with a $0.35: 1$ in-line dilution. The dilution ratio determined from the waste and water flowmeters averaged $0.34: 1$ during the third transfer, which indicates the 141-inch level rise in SY-102 is most likely correct.

The 1A levels in SY-101 responded promptly and linearly to transfers 3a-b, as shown in Figure 3.10. The small variations visible in the slope of the plot result from flow adjustments. The levels remained constant after the transfer. The slight rise in SY-102 level after dilution might be the result of foam formed during the transfer.

Figure 3.11 shows the level behavior during dilutions 3c-f. Both the SY-101 levels rose positively and promptly in response to both top and low dilutions. The level rise matched the dilution volume with no evidence of waste attached to the wall. The SY-102 level continued to rise as salt-well pumping resumed.

Table 3.3. Level Changes During the Third Campaign

\begin{tabular}{|l|c|c|c|c|}
\hline $\begin{array}{l}\text { Level } \\
\text { Measurement (in) }\end{array}$ & $\begin{array}{c}\text { Transfers } \\
\text { 3a-b }\end{array}$ & $\begin{array}{c}\text { Between } \\
\text { 3b \& 3c }\end{array}$ & $\begin{array}{c}\text { Dilutions } \\
\text { 3c-f }\end{array}$ & $\begin{array}{c}\text { Net } \\
\text { Change }\end{array}$ \\
\hline SY-101 1A & & & & \\
\hline Start & 388.5 & 281.3 & 279.6 & \\
\hline End & 281.3 & 279.6 & 364.4 & \\
\hline Difference & -107.2 & -1.7 & +84.8 & -24.1 \\
\hline SY-101 1C & & & & \\
\hline Start & 387.6 & 280.8 & 279.8 & \\
\hline End & 280.8 & 279.8 & 362.0 & \\
\hline Difference & -106.8 & -1.5 & +82.2 & -26.1 \\
\hline SY-102 & 220.0 & & & \\
\hline Start & $351.2^{\text {(a) }}$ & NA & NA & NA \\
\hline \multicolumn{2}{|l|}{$\begin{array}{l}\text { End } \\
\text { Difference }\end{array}$} & $+131.2^{\text {(a) }}$ & & \\
\hline $\begin{array}{l}\text { (a) The SY-102 level reached 360.6 inches shortly after the transfer was } \\
\text { completed, for a level difference of 140.6 inches. }\end{array}$ \\
\hline
\end{tabular}



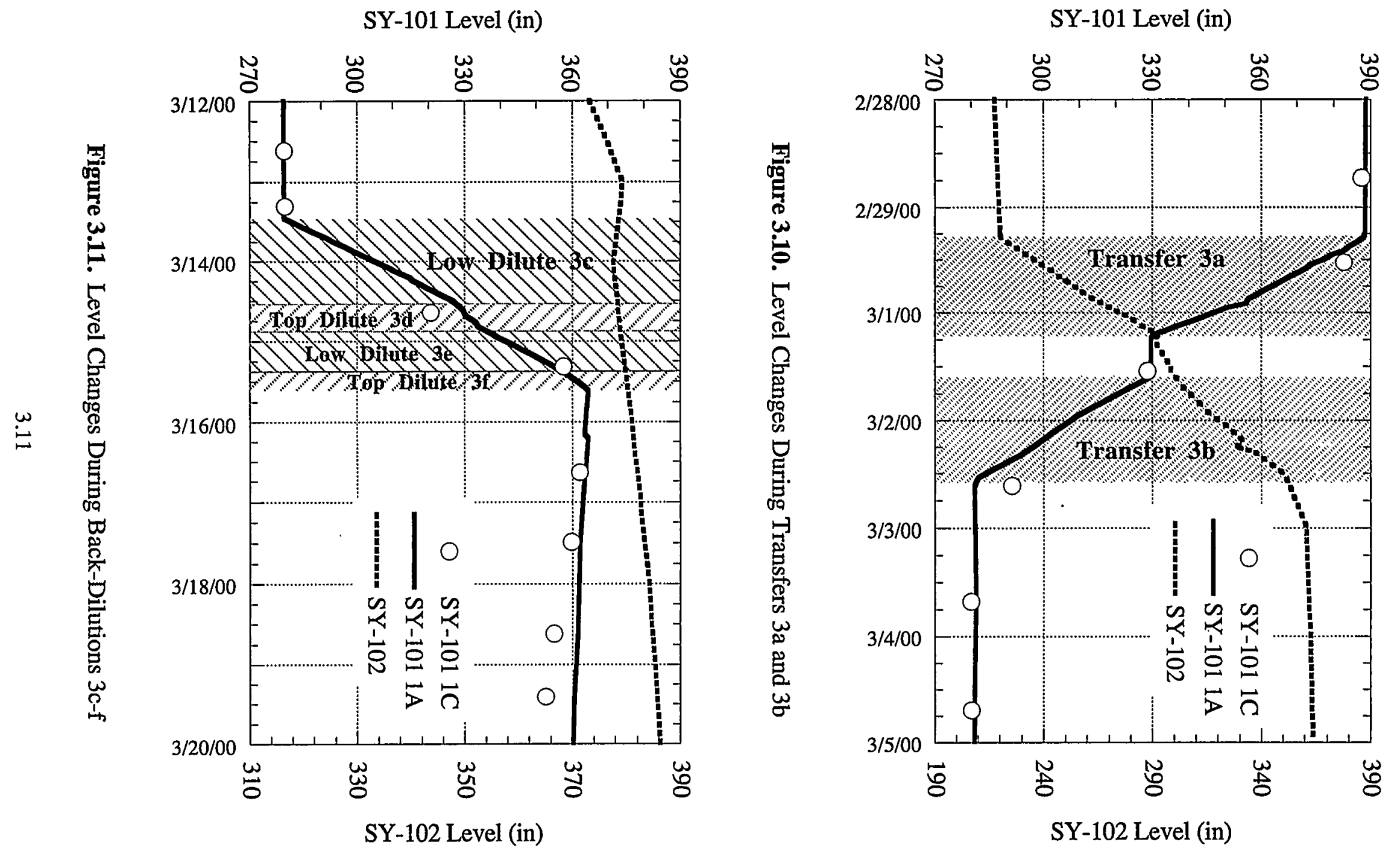
Figure 3.12 gives the level history during the period between the end of the third campaign and the mixer pump evaluation period that began April 3. Four mixer pump runs of 25 minutes were being performed at $1000 \mathrm{rpm}$ every few days during this period to prepare for the mixer pump evaluation period. The 10-inch drop in the riser $1 \mathrm{C}$ level is caused by the lateral offset due to crust motion induced by mixer pump runs. The waste level dropped about five inches from March 17 to April 2 as a result of the final bit of gas release from the aggressive mixing and the last dilution. As before, the SY-102 level increased steadily from salt-well pumping, which had been interrupted by the cross-site transfer March 22 .

\subsection{Gas Release and Level Change Reconciliation}

Tank waste levels change mainly as the result of waste removal (transfer), mass addition (dilution with water) and gas release. Changes in the buoyancy of the floating crust layer would also have a strong effect while it still existed, as did the apparent ring of waste attached to the tank wall. Other effects could include volume changes as solids dissolve or precipitate and the slight expansion or contraction as the bulk temperature changes. Transfer line flushes, Enraf flushes, and evaporation (after the waste became more dilute) could also be included. There was also evidence of a small in-line dilution water bypass or leakage during transfer. However, this would have been balanced by an increase in SY-101 waste flow at the flow meter.

Gas release as the solids in the crust and mixed slurry dissolved were the largest contributor to level change besides transfer and dilution. The estimated gas volume of 14,900 scf in the waste before the first transfer (Rassat et al. 2000) contributed 31 inches to the waste level at a pressure of $1.3 \mathrm{~atm}$. Compared to this, the other effects discussed above are not significant.

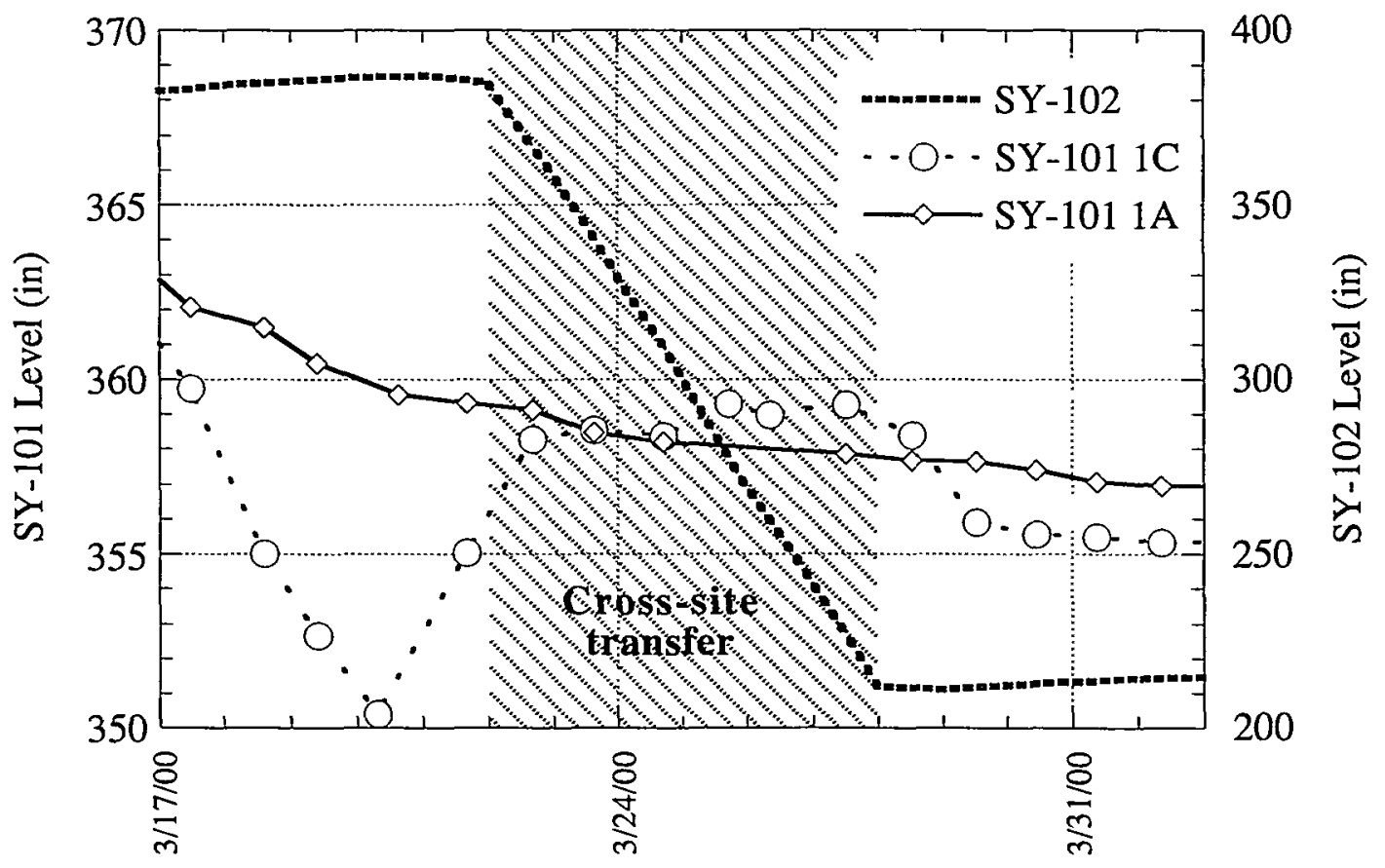

Figure 3.12. Level Changes After the Third Campaign 
To confirm this, the waste level was calculated based only on transfer and dilution volume and the calculated gas release and then compared with the measured level. The gas release volume was calculated by integrating the product of headspace hydrogen concentration and ventilation flow rate over time, dividing by the estimated hydrogen fraction in the released gas, and subtracting the estimated total gas generation rate. This integration is expressed as follows:

$$
\mathrm{V}_{\mathrm{REL}}(\mathrm{t})=\int_{0}^{\mathrm{t}}\left(\left[\mathrm{H}_{2}\right] \mathrm{Q}_{\mathrm{V}} / \chi_{\mathrm{H}_{2}}-\mathrm{G}(\mathrm{t})\right) \mathrm{dt}
$$

where $\left[\mathrm{H}_{2}\right]$ is the headspace hydrogen concentration, $Q_{V}$ is the ventilation flow rate, $G(t)$ is the gas generation rate, and $\chi_{\mathrm{H} 2}$ is the hydrogen fraction. All quantities are assumed to vary with time except the hydrogen fraction.

The gas generation rate is estimated by reducing the pre-transfer value in proportion to the cube of the fraction of original waste remaining. The cube is used to approximate the additional effect of temperature reduction and decreased concentration of various species influencing hydrogen generation. The hydrogen generation calculated after the third transfer and dilution using the empirical model developed by $\mathrm{Hu}$ (1999) was a factor of about 8 less than the initial value. This change corresponds to the cube of the fraction (one half) of the original waste remaining. The gas generation rate can therefore be approximated in terms of transfer volume as

$$
G(t)=G_{0}\left(1-\frac{V_{x f e r}(t)}{V_{w 0}}\right)^{3}
$$

where $\mathrm{G}_{0}$ is taken to be $90 \mathrm{scfd}, \mathrm{V}_{\text {wo }}$ is the original degassed waste volume (1064 kgal), and $V_{x f e r}(t)$ is the cumulative transfer volume.

The waste level was calculated in reverse from the known ending level by adding back the level drop due to gas release and transfer and subtracting the level rise from dilution. The level calculation is expressed as

$$
L(t)=L_{\text {end }}+\frac{1}{A}\left[\begin{array}{l}
\left(V_{R E L}\left(t_{\text {end }}\right)-V_{R E L}(t)\right) \frac{p_{0}}{p_{G}}+ \\
V_{x f e r}\left(t_{\text {end }}\right)-V_{x f e r}(t)-V_{\text {dil }}\left(t_{\text {end }}\right)+V_{\text {dil }}(t)
\end{array}\right]
$$

where $L_{\text {end }}$ is the waste level at time $t_{\text {end }}(4 / 2 / 2000)$ just before the start of the mixer pump evaluation period ( 356.2 inches, average of $1 \mathrm{~A}$ and $1 \mathrm{C}$ ), $\mathrm{A}$ is the tank area, $\mathrm{p}_{0}$ is atmospheric pressure, and $\mathrm{p}_{\mathrm{G}}$ is the average pressure at which the gas is stored.

The gas pressure and hydrogen fraction must be specified to solve Eq. (3.1) through (3.3). Table 3.4 shows the sets of values that give the maximum, best estimate, and minimum starting waste level. The hydrogen fraction of 0.29 has historically been used to calculate level from gas release in SY-101 and is given as the "best estimate" in the LANL Safety Assessment (Sullivan 1995). It also approximates the average hydrogen fraction below the crust in the mixed slurry layer measured by the retained gas sampler (RGS) in December 1998 (Mahoney et al. 1999). 
Table 3.4. Parameter Values for Level Calculation

\begin{tabular}{|l|c|c|c|}
\hline Parameter & Min. Gas Rel. & Best Estimate & Max. Gas Rel. \\
\hline Hydrogen Fraction & 0.38 & 0.34 & 0.29 \\
\hline Gas Pressure (atm) & 1.5 & 1.3 & 1.2 \\
\hline Calculated Starting Level (in.) & 412.5 & 420.3 & 429.8 \\
\hline
\end{tabular}

The maximum hydrogen fraction of 0.38 was measured in the crust layer in December 1998 with the RGS and 0.34 is the average of the two extremes. The pressure calculated at the base of the crust layer is $1.3 \mathrm{~atm}$, and the average pressure of all the gas in the waste prior to the first transfer is $1.5 \mathrm{~atm}$. The pressure of $1.1 \mathrm{~atm}$ represents a location approximately $1 \mathrm{~m}$ beneath the waste surface.

The last row in the table gives the starting waste level calculated from Eq. (3.1) through (3.3) with the selected parameters. The predicted levels are plotted along with the levels measured at risers $1 \mathrm{~A}$ and $1 \mathrm{C}$ in Figure 3.13. Note that the calculated maximum level of 429.8 inches is only one inch less than the starting $1 \mathrm{~A}$ level of 430.8 inches, and the calculated minimum level of 412.5 inches is very close to the starting $1 \mathrm{C}$ level of 411.3 inches. The best estimate value of 420.3 falls comfortably between the two. We conclude that, within the uncertainty of both level measurements and gas release calculations, the cumulative level changes are consistent with transfer/dilution volumes and gas releases, and there are no other significant effects. The total volume of gas released also matches the estimated initial retained gas volume within these uncertainties.

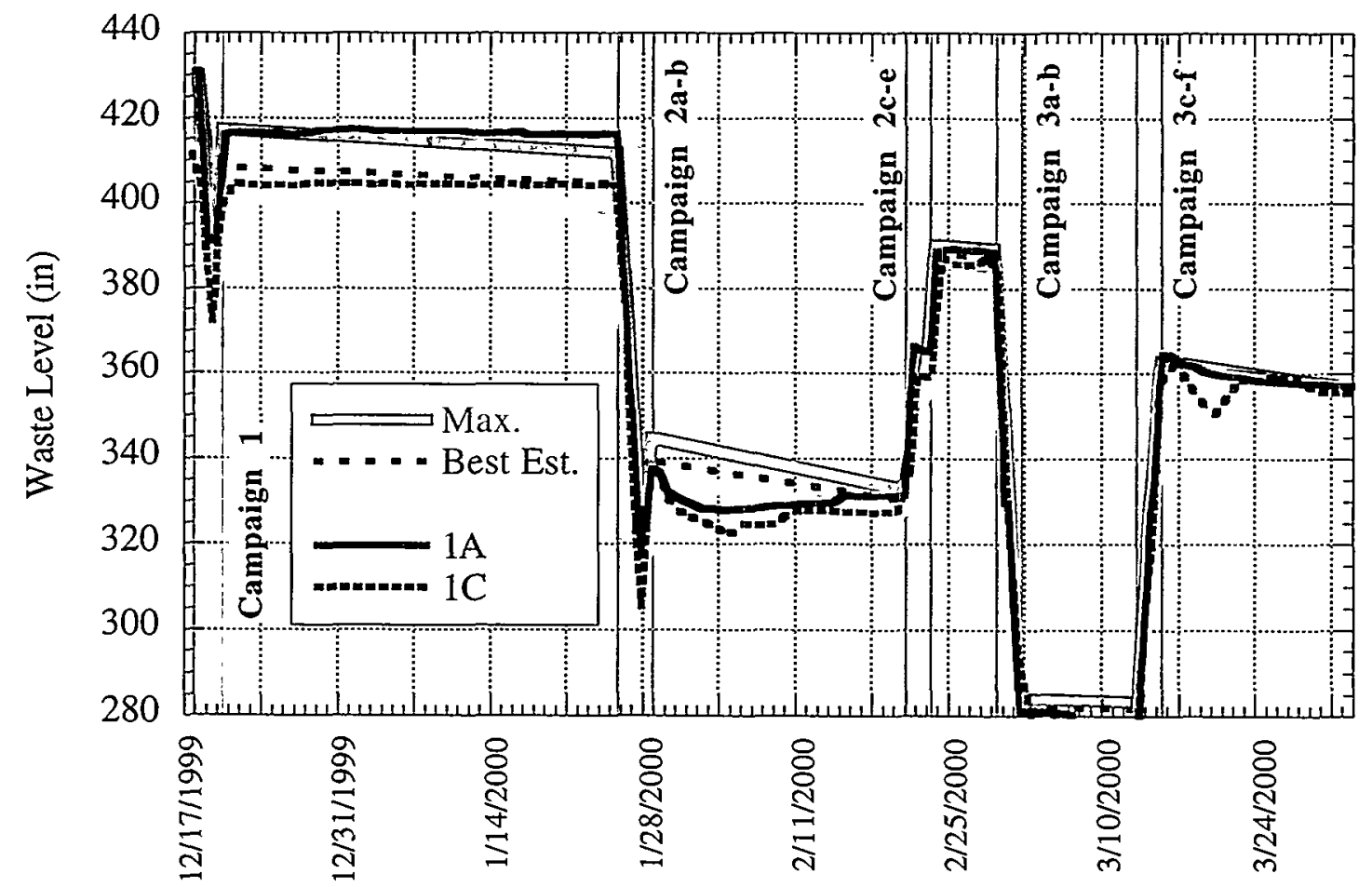

Figure 3.13. Gas and Level Reconciliation 


\subsection{Strain Gauge Data}

Strain data were measured on three pieces of hardware in SY-101 during the first campaign: the mixer pump column, riser 12A (two of four strain gauges operable), the MIT in riser $17 \mathrm{C}$ (two strain gauges), and the VDTT in riser 1B (two of three strain gauges operable). All but the two operable pump column strain gauges were disconnected from the data acquisition system January 20 , before the second campaign.

The strain data before and after the first transfer and dilution were compared to check for any load that the crust put on the apparatus as a result of the activity. No difference was seen during the first campaign in the data from the strain gauges on riser 1B; however, the pump column and $17 \mathrm{C}$ did show some changes, as illustrated in Figures 3.14 and 3.15. The pump column and riser $17 \mathrm{C}$ strain gauges both registered temporary increases during the first campaign. At the pump column, strain spikes were visible during the first transfer but relaxed during dilution, so the average strains were in the same range as before. At $17 \mathrm{C}$, the strains showed new trends. Gauge 1 went farther into compression than before the transfer, and gauge \#2 went into tension, suggesting an increasing load, until about January 13.

Strain changes were evident at the pump column during the second campaign, as shown in Figure 3.16. These were primarily during and after top dilution when the crust was dissolving. The strains were probably related to the crust motion caused by the sinking, capsize, and gas release events and by waste falling from the walls into the liquid. In no case did the strain readings indicate any appreciable load on the structure.

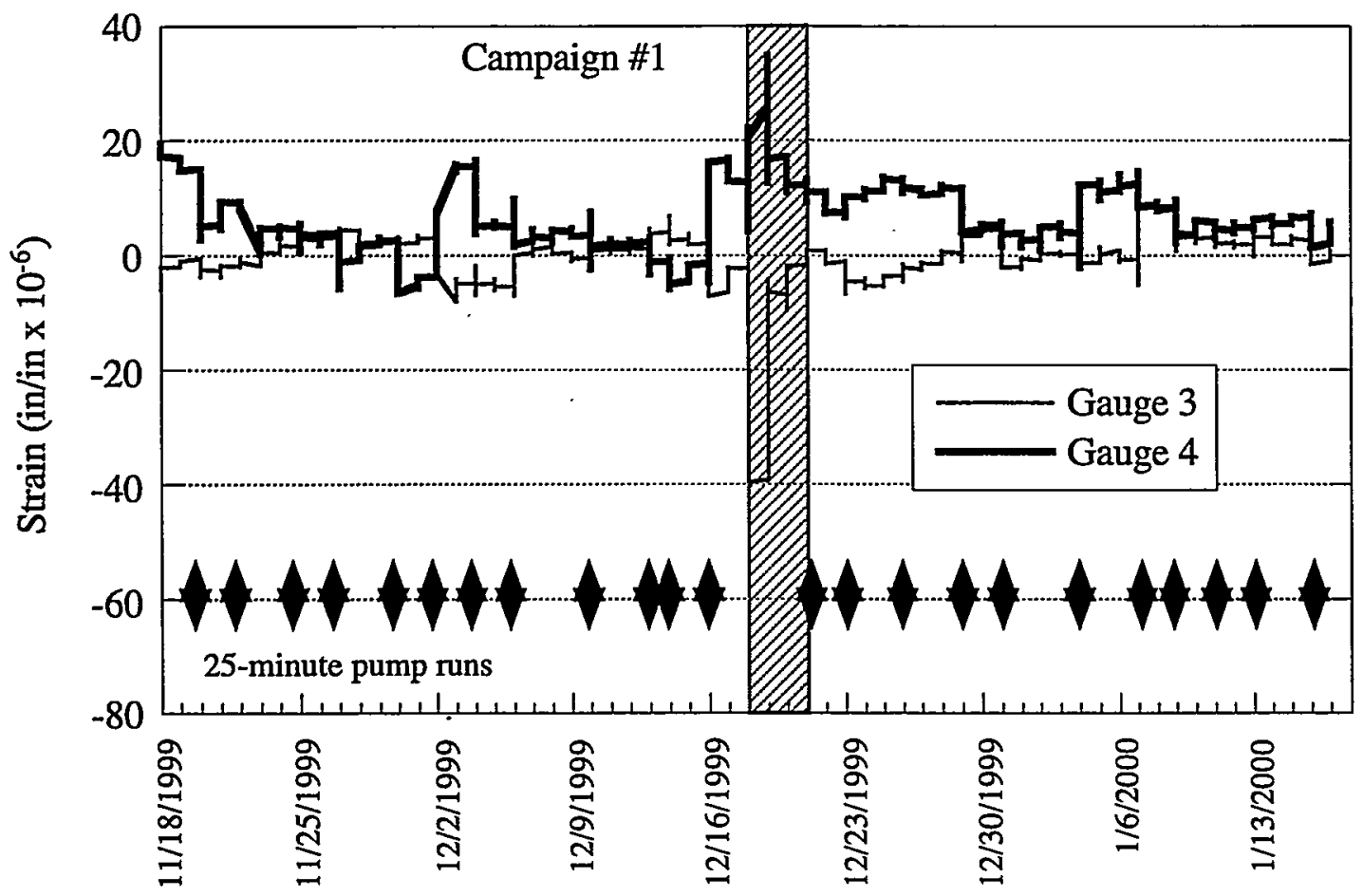

Figure 3.14. Pump Column Strains During the First Transfer and Dilution 


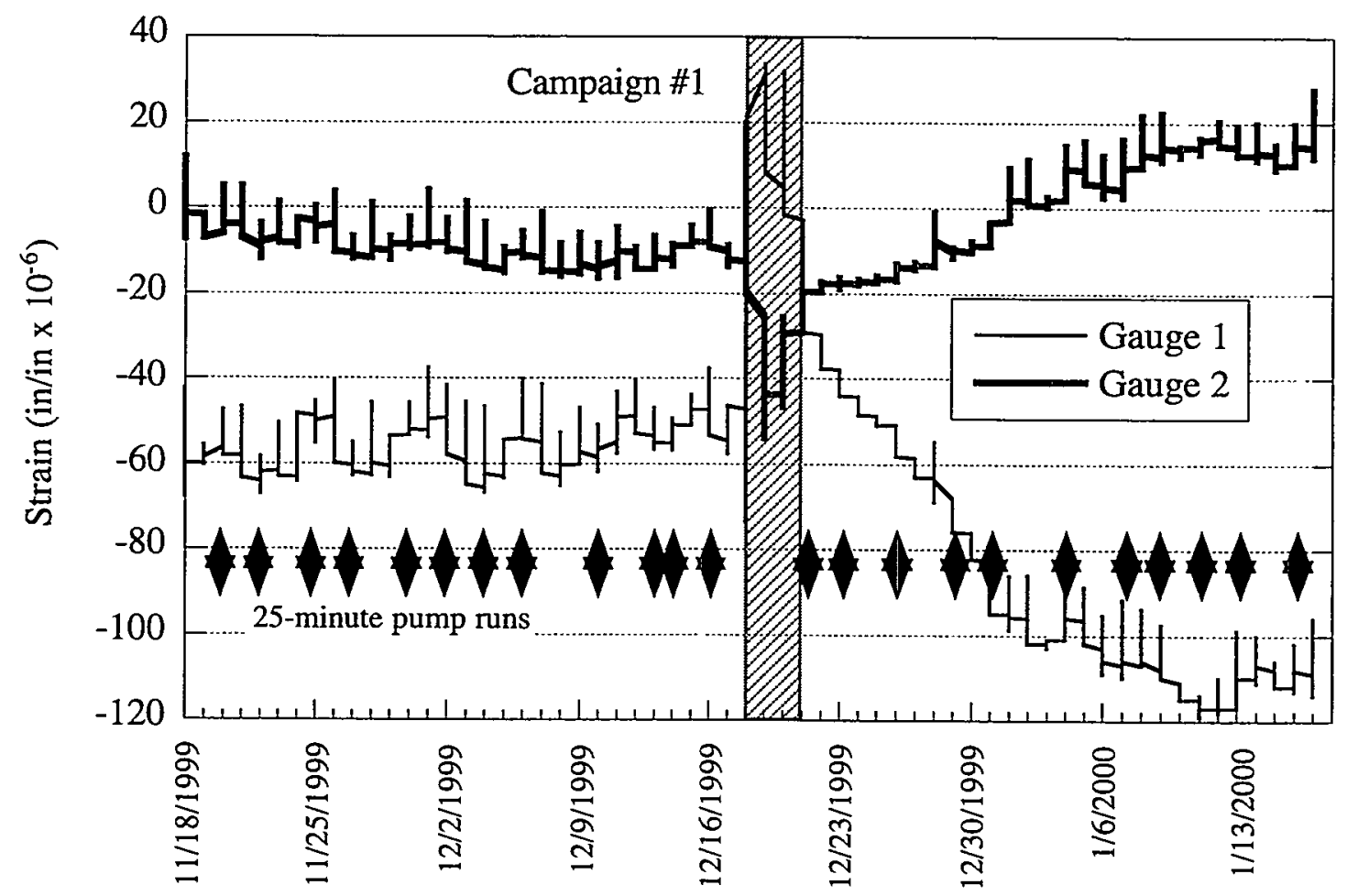

Figure 3.15. Riser 17C Strains During the First Transfer and Dilution

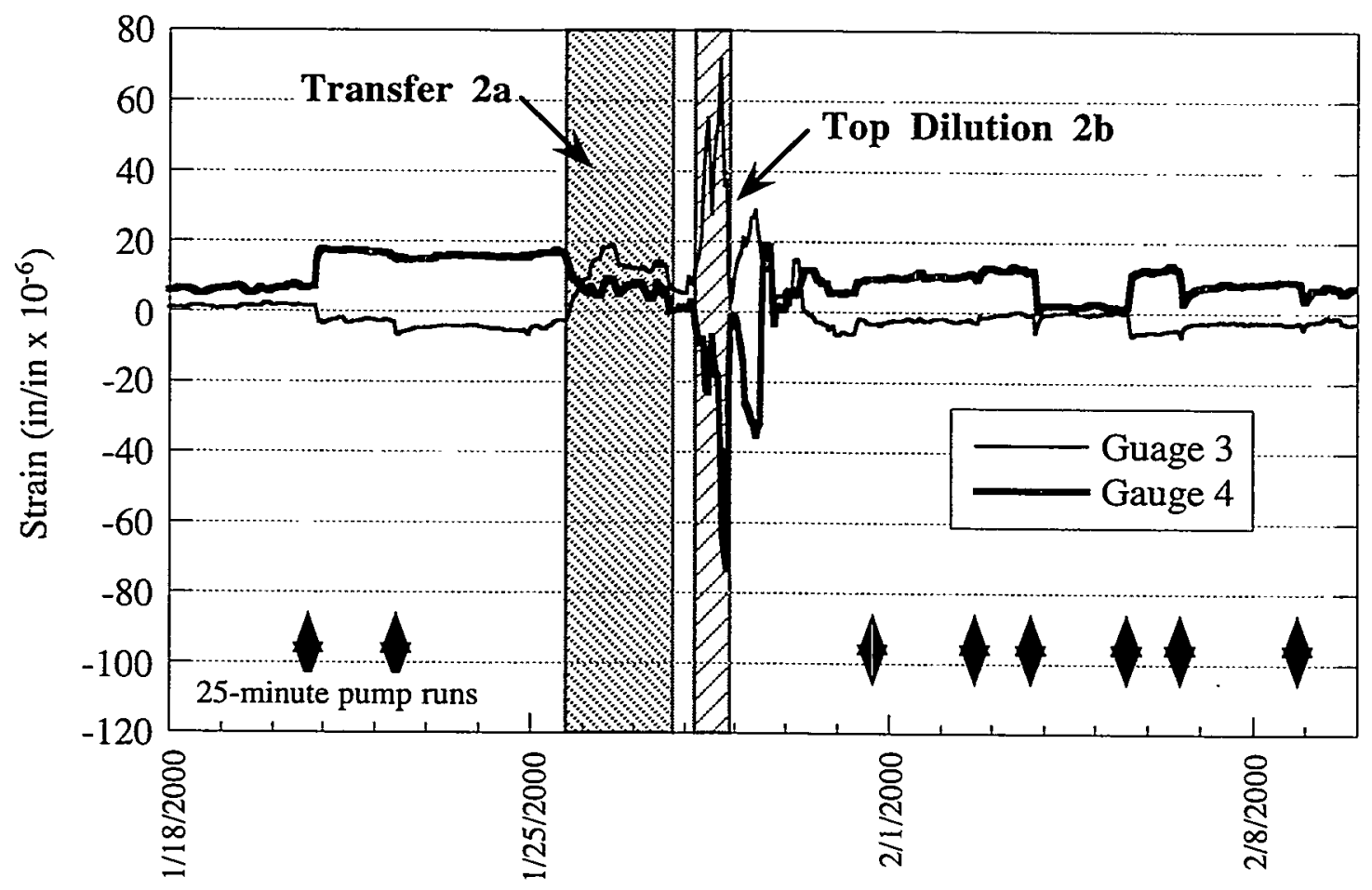

Figure 3.16. Pump Column Strains During Transfer 2a and Top Dilution $2 b$ 


\subsection{Neutron and Gamma Profiles}

The new, small-bore neutron and gamma probe that was developed to fit inside an MIT in the passage designed for the validation probe began operation in SY-101 in February 1999. The data immediately provided details on the structure and extent of the crust and clearly showed the progression of the "rearrangement event" that caused the crust to thicken by about a meter in April and May of 1999. During remediation, neutron and gamma logs were taken in risers 17B and $17 \mathrm{C}$ approximately every week, before and after each major operation where possible, to help assess the effects of transfer and dilution on the waste configuration.

The neutron count is proportional to the number of hydrogen atoms present. A high count indicates the presence of water and a lower count its absence (presence of solids or gas). The gamma count is proportional to the number of ${ }^{137} \mathrm{Cs}$ atoms present that exist mainly as dissolved solids in the liquid with some in the solids. Thus a high gamma count indicates a concentrated solution, and a low count shows a dilute solution or absence of waste. These data taken together show the top and bottom of the crust, the location of the bubble slurry layer, the presence of excess water after top dilution, and the effect of mixer pump runs on the undiluted waste left below the transfer pump inlet after low dilution.

This report shows neutron and gamma profiles taken before and after each transfer and dilution and describes the information that can be inferred from these data. Section 4.1 describes the neutron and gamma profiles obtained during the first campaign; Section 4.2 and 4.3 cover the second and third campaigns, respectively. Section 4.4 gives conclusions on the neutron and gamma data.

\subsection{Neutron and Gamma Profiles During the First Campaign}

About a week after the first campaign, neutron probe data from risers $17 \mathrm{~B}$ and $17 \mathrm{C}$ indicated that the average crust thickness was 95-102 inches with the base at 305-315 inches and the surface level about 408 inches, as shown in Figures 4.1 and 4.2, respectively. The top and base of the crust are taken as the midpoint of the long, near-linear transition seen on the neutron profile. This is consistent with the method used to find the interstitial liquid level in single-shell tank liquid observation wells. Gamma profiles were relatively unaffected by the small dilution and are not shown. At the same time, the waste level was 404 inches at riser $1 \mathrm{C}$ and 417 inches at riser $1 \mathrm{~A}$. The crust buoyancy and dissolution model described in Rassat et al. (2000) predicted a crust thickness of 95 inches, with the base at 314 inches and the surface at 408 inches.

After the relatively small top (1b) and low dilutions (1c) of the first campaign, the 10-inch bubble slurry layer at the crust base was still present but with increased neutron count, suggesting a decrease in the gas fraction. There was also a slightly higher count below the crust at $17 \mathrm{C}$, indicating a slightly more dilute fluid there. 


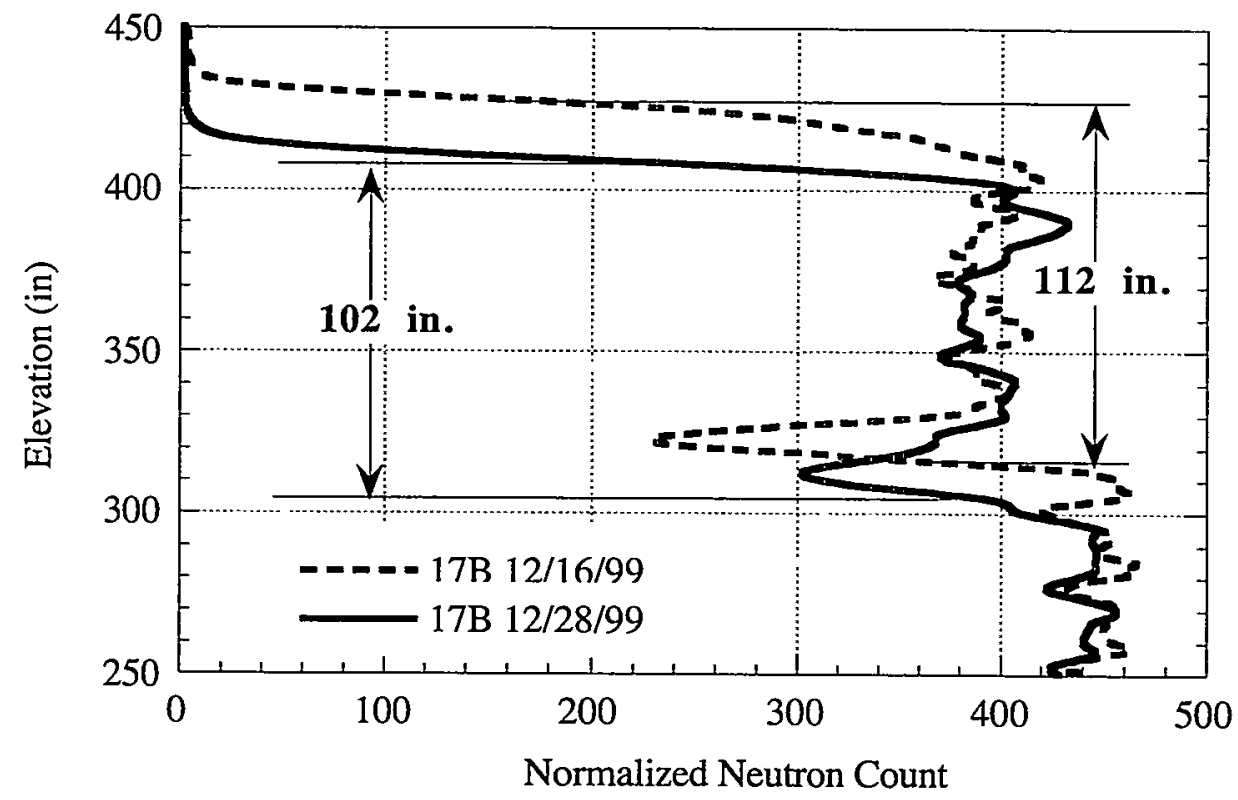

Figure 4.1. Neutron Profiles at 17B Before and After the First Campaign

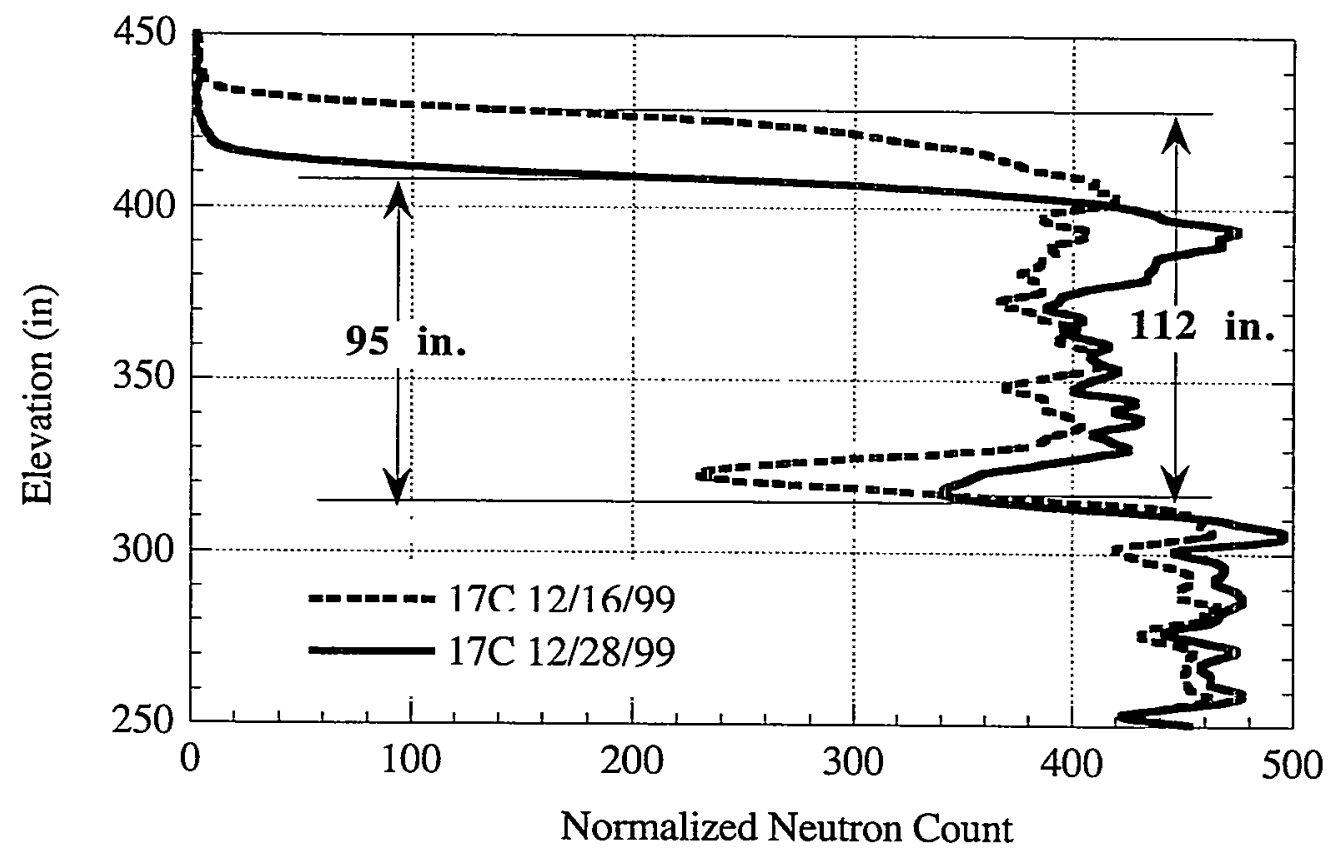

Figure 4.2. Neutron Profiles at $17 \mathrm{C}$ Before and After the First Campaign 
In the month after the first campaign there was little further change in the crust layer, as can be seen in Figures 4.3 and 4.4. The bubble slurry layer remained depleted in gas. Some further decrease in gas may have occurred at riser $17 \mathrm{C}$ after December 28, 1999. The January 20, 2000 profile shows less difference in counts between the bubble slurry and the crust or between the bubble slurry and the mixed slurry than was present in December, possibly as a result of slow solids dissolution re-concentrating the liquid.

\subsection{Neutron and Gamma Profiles During the Second Campaign}

Neutron and gamma profiles from risers $17 \mathrm{~B}$ and $17 \mathrm{C}$ that bracket the first stage of the second campaign are shown in Figures 4.5 through 4.8. The January 20 data (dashed line in the figures) shows essentially the original crust configuration. The neutron logs (Figures 4.5 and 4.7) show a somewhat lower neutron count from 300 to 400 inches, with a clearly visible "bubble slurry" layer between 300-340 inches and a wet layer left over from the first top dilution between $370-400$ inches.

The gamma profiles (Figures 4.6 and 4.8) are relatively uniform, though some correspondence can be seen with the features in the neutron profiles. The raw gamma counts plotted here are not normalized to maintain the same average count in the mixed slurry region as the smoothed neutron profiles are. Therefore, only the shape of the gamma profiles should be compared, not the absolute counts. The difference in count between dates below 250 inches in Figures 4.6 and 4.8 is not significant.

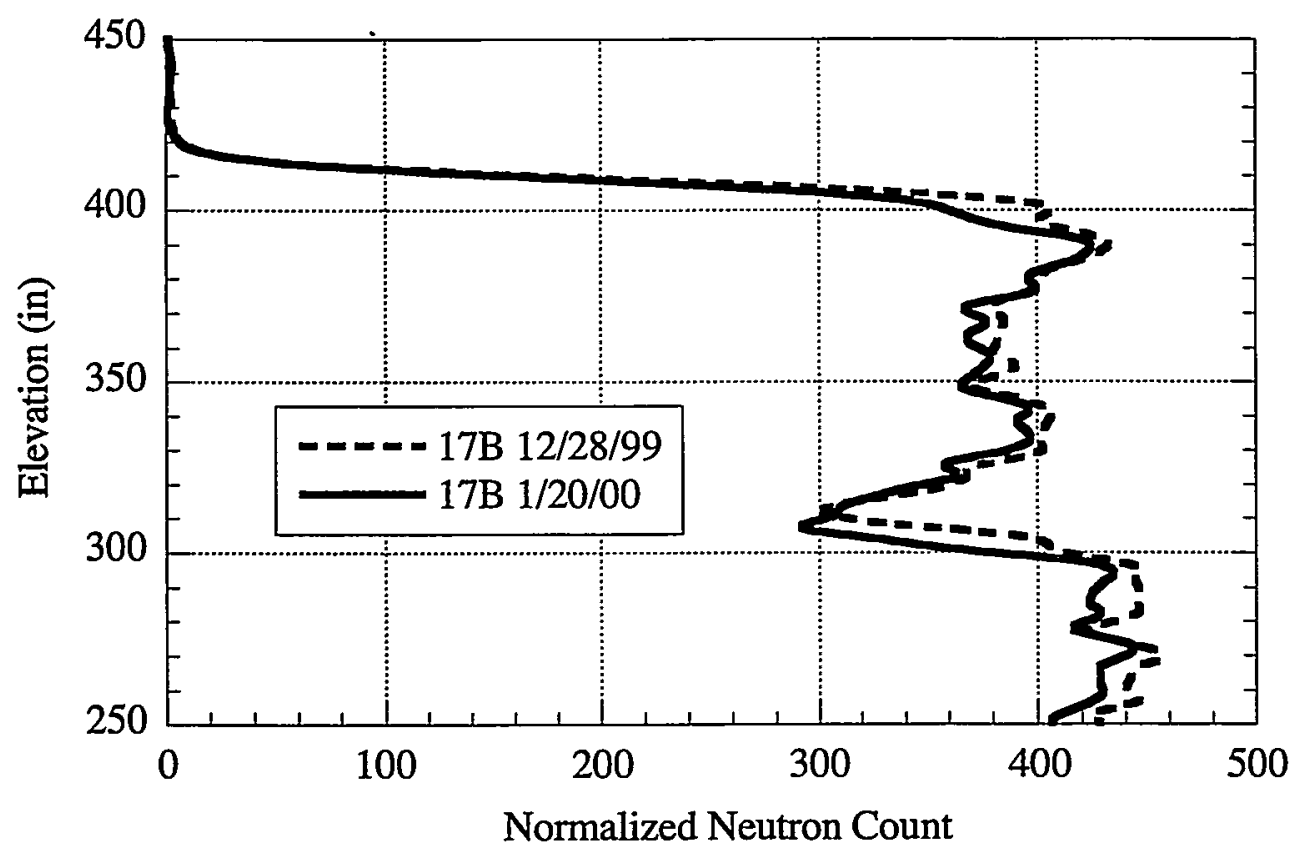

Figure 4.3. Neutron Profiles at 17B Between the First and Second Campaigns 


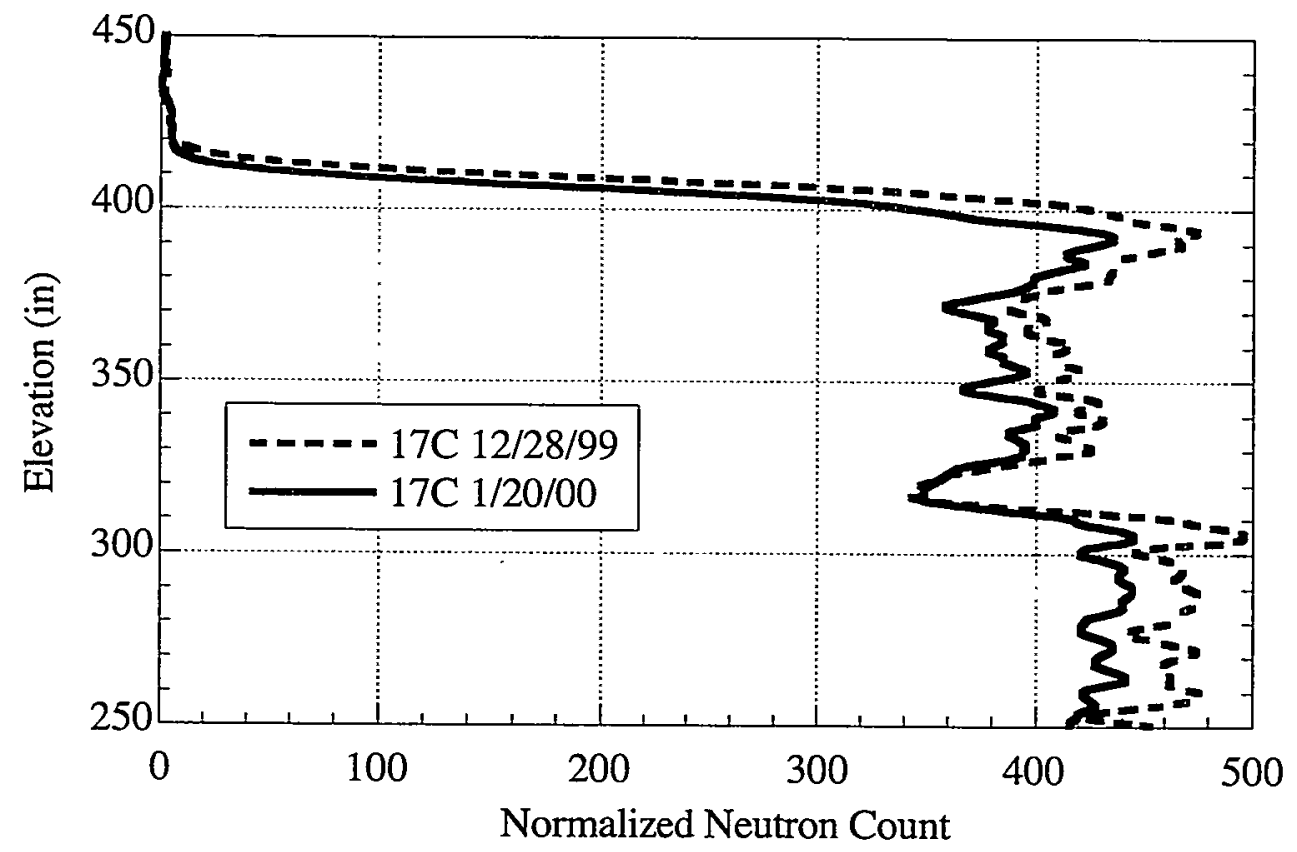

Figure 4.4. Neutron Profiles at $17 \mathrm{C}$ Between the First and Second Campaigns

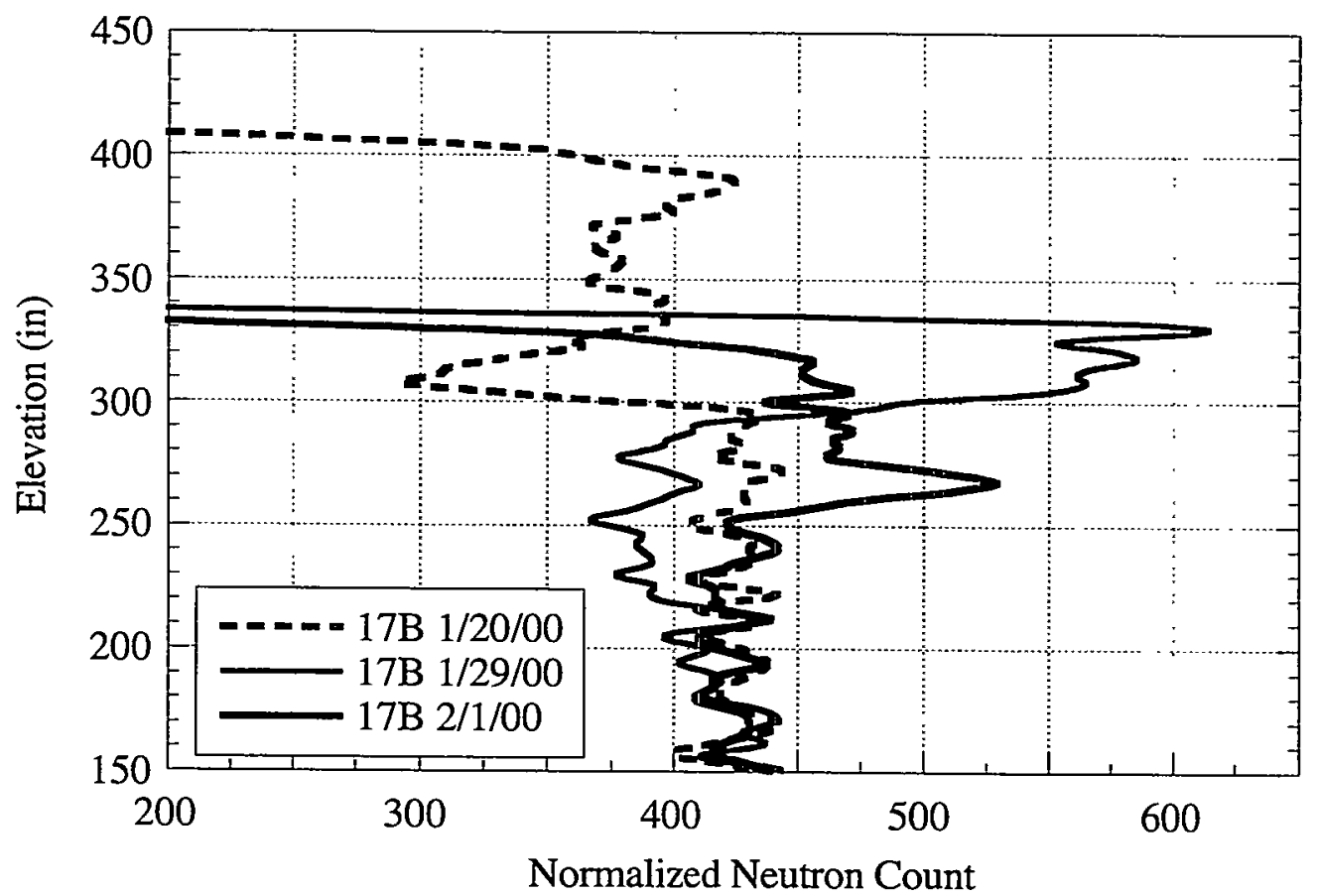

Figure 4.5. Neutron Profiles at 17B Before and After Transfer 2a and Top Dilution 2b 


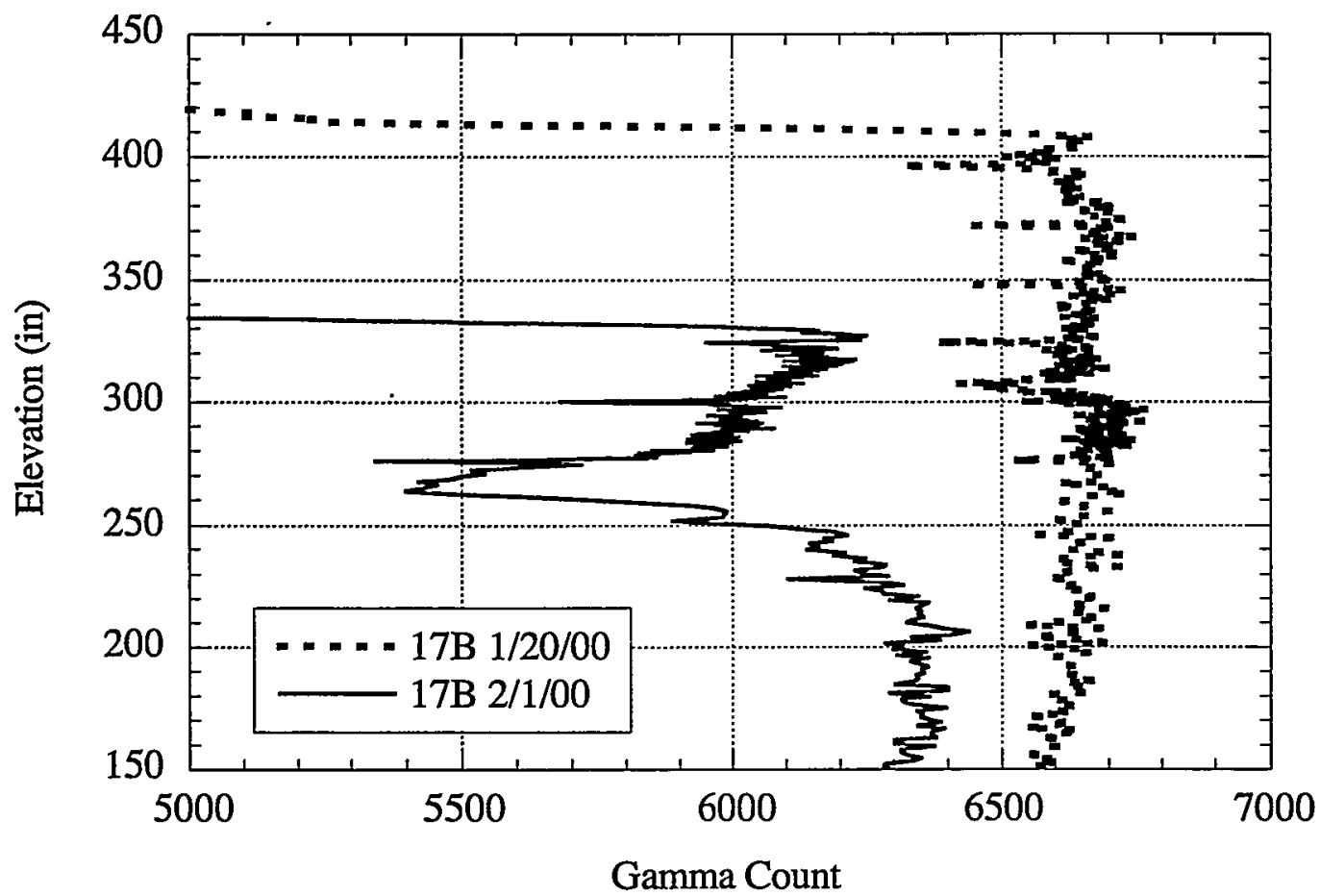

Figure 4.6. Gamma Profiles at 17B Before and After Transfer 2a and Top Dilution 2b

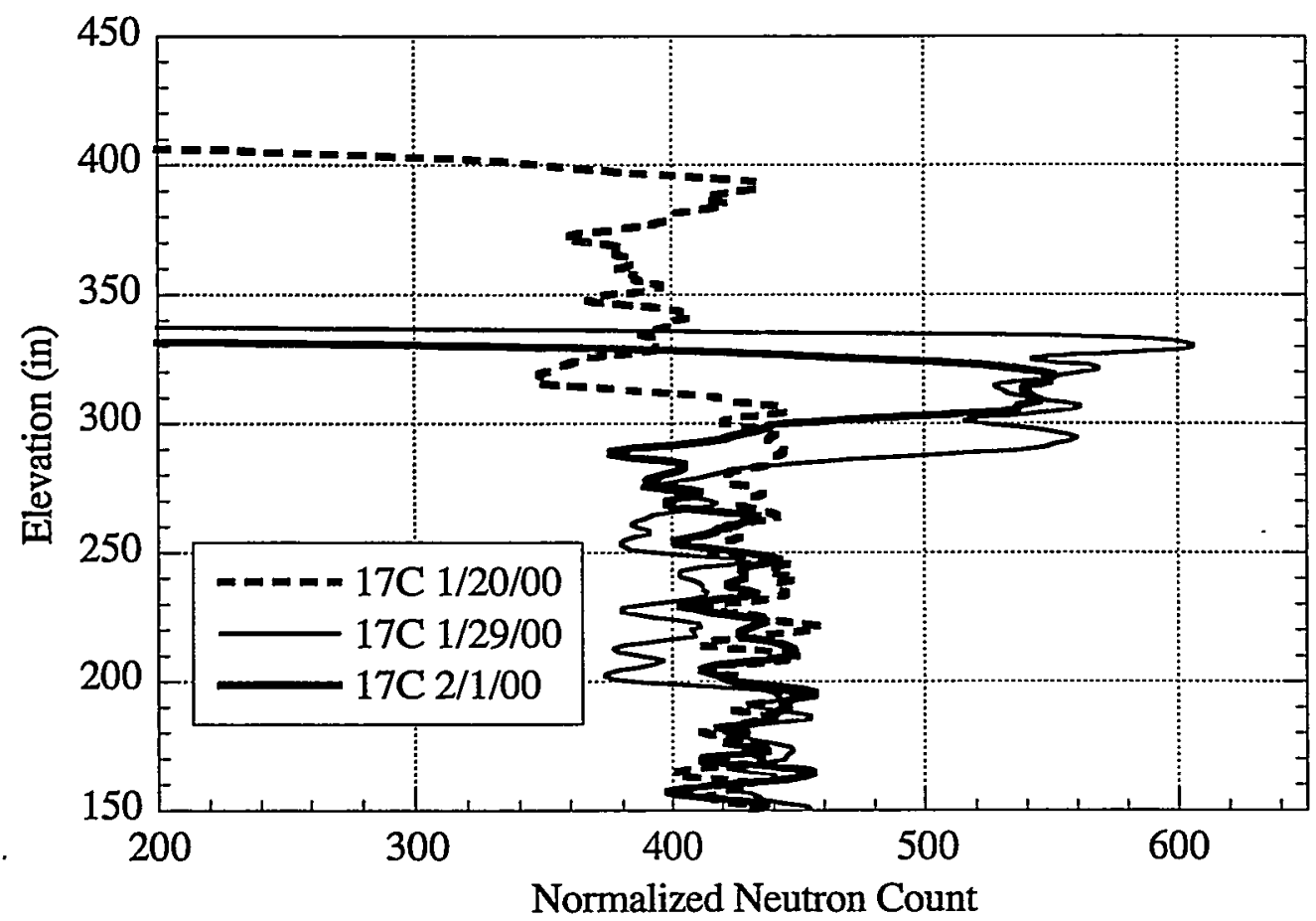

Figure 4.7. Neutron Profiles at $17 \mathrm{C}$ Before and After Transfer $2 a$ and Top Dilution $2 b$ 


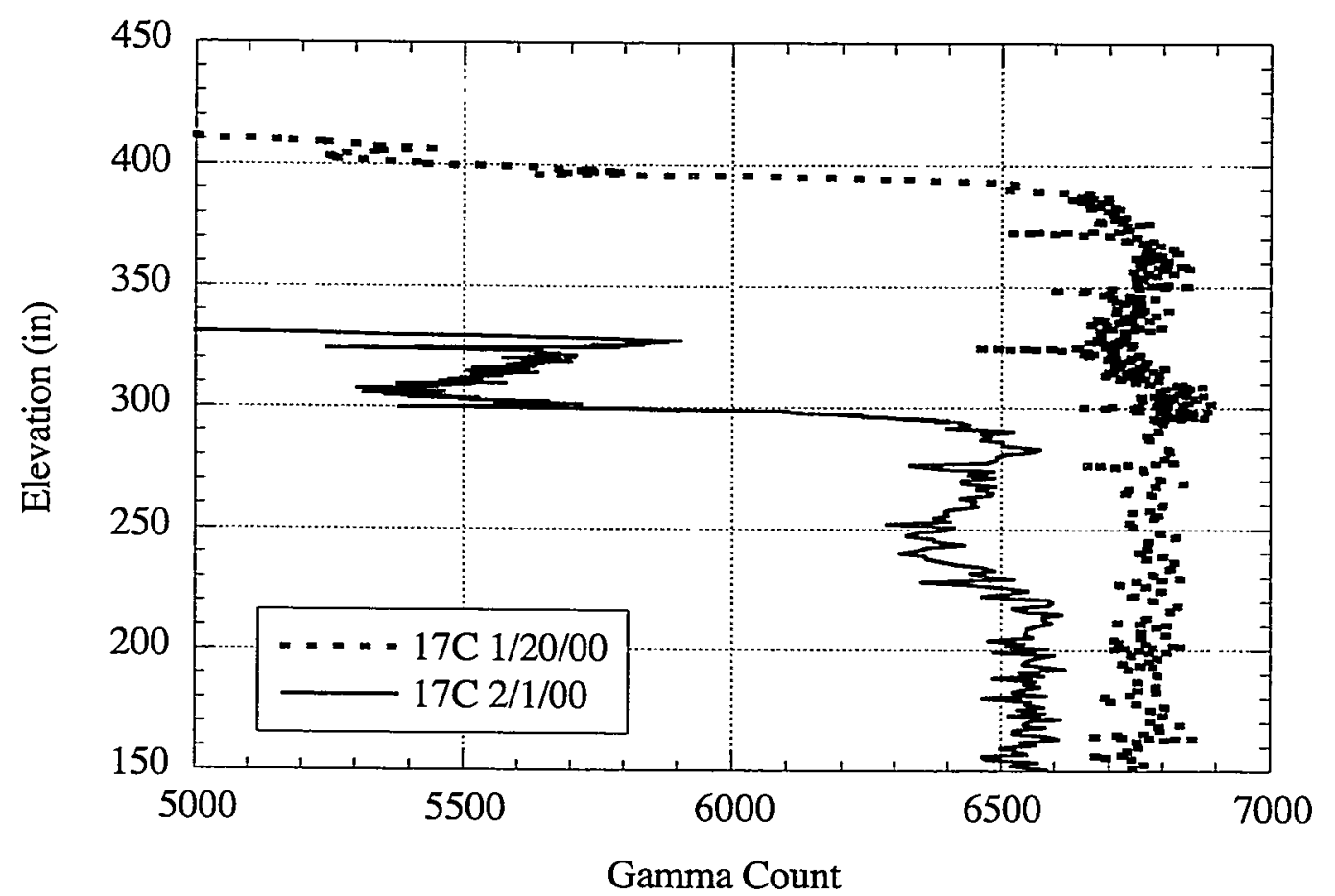

Figure 4.8. Gamma Profiles at 17C Before and After Transfer 2a and Top Dilution 2b

Shortly after top dilution $2 \mathrm{~b}$, the neutron data from January 29 (thin solid line on Figures 4.5 and 4.7) reveal a high water content (high neutron count) layer between 300-340 inches at 17B (Figure 4.5) and 280-340 inches at 17C (Figure 4.6). This layer overlays a low water content (lower neutron count) layer about 70 inches thick at both risers that probably represents submerged crust. This configuration, dissolving crust covered by dilute liquid, is consistent with the low ammonia releases (see Section 5) observed during this period because ammonia is strongly absorbed by the excess water.

The neutron data for February 1 (bold solid line on Figures 4.5 and 4.7) show a dramatic change in the configuration at $17 \mathrm{~B}$ and the effect of continued crust dissolution at $17 \mathrm{C}$. At $17 \mathrm{~B}$ the remains of the crust have risen to the surface and overlay about 20 inches of relatively dilute liquid. This is corroborated by the gamma profile for February 1 in Figure 4.6, where the low gamma count between 260-280 inches matches the high-neutron count in Figure 4.5. The appearance of a more concentrated solution on the surface apparently caused the dramatic increase in background ammonia concentration early on January 30 (see Section 5). At 17C the dilute layer has remained on the surface, but it is much thinner on February 1 than it was two days earlier. What appeared to be 70 inches of crust remnants between 200-270 inches on January 29 has shrunk to perhaps 20 inches between $270-290$ inches. As at 17B, the gamma profile (Figure 4.8) confirms the dilute layer between 300-340 inches.

The further evolution of the waste in the three weeks between top dilution $2 \mathrm{~b}$ and low dilution $2 \mathrm{c}$ is shown by the neutron and gamma profiles in Figures 4.9 through 4.12 . By February 17 the crust remnants at 17B floated as a 30 -inch-thick layer above about 20 inches of 
semi-dilute liquid (Figures 4.9 and 4.10). The combination of low neutron count and relatively high gamma count in the upper layer indicates a wet floating crust with a significant gas fraction. At $17 \mathrm{C}$ the crust remnants are not so clearly visible, with only a somewhat dilute layer between 270 and 330 inches (Figures 4.11 and 4.12).

The effects of the low dilution and small top dilution of the second stage of the second campaign are shown in Figures 4.13 and 4.16. The plots give the full neutron and gamma profiles from tank bottom to waste surface. The profiles from February 25 are essentially uniform below 340 inches except for the effect of the increased solids content in the loosely settled layer below 50 inches. One mixer pump run was performed between the two low backdilutions. Above 340 inches, the slightly higher neutron count (Figures 4.13 and 4.15 ) and markedly lower gamma count (Figures 4.14 and 4.16) are the result of the small, 11,000-gallon top dilution at the end of the second campaign. Little or no evidence remains of the 4-m-thick crust that existed in December.

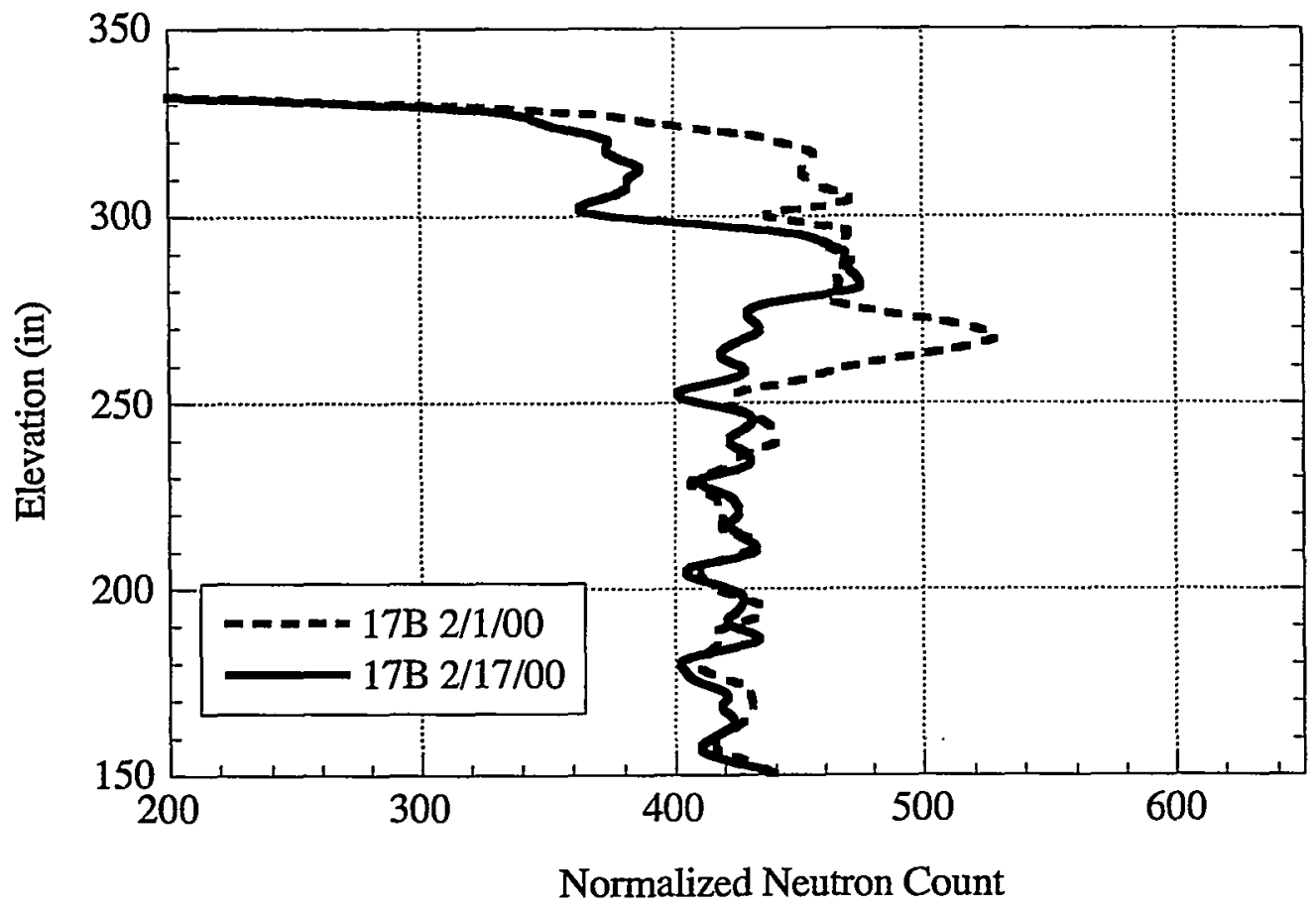

Figure 4.9. Neutron Profiles at 17B Between the Top Dilution 2b and Low Dilution 2c 


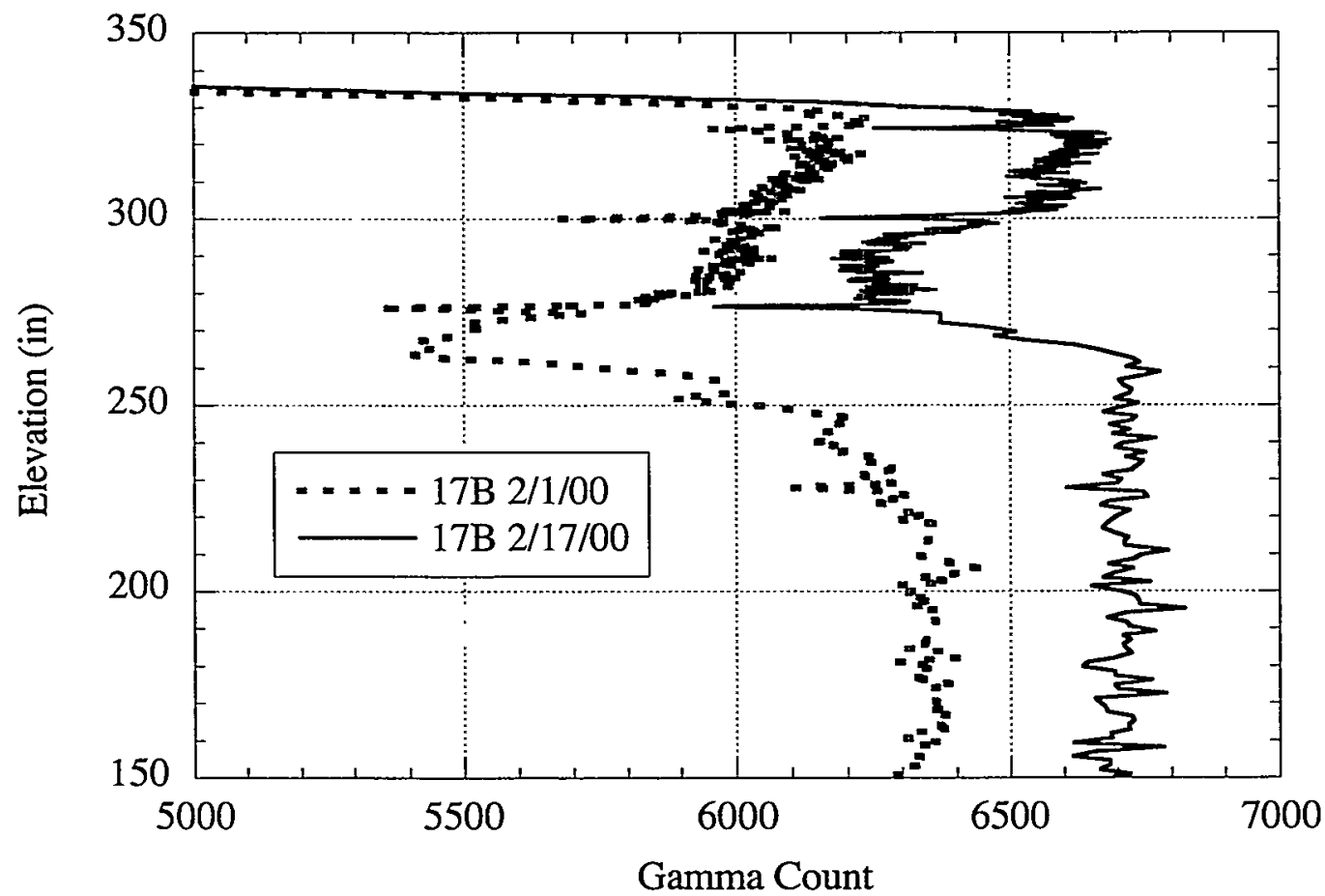

Figure 4.10. Gamma Profiles at 17B Between the Top Dilution $2 \mathrm{~b}$ and Low Dilution $2 \mathrm{c}$

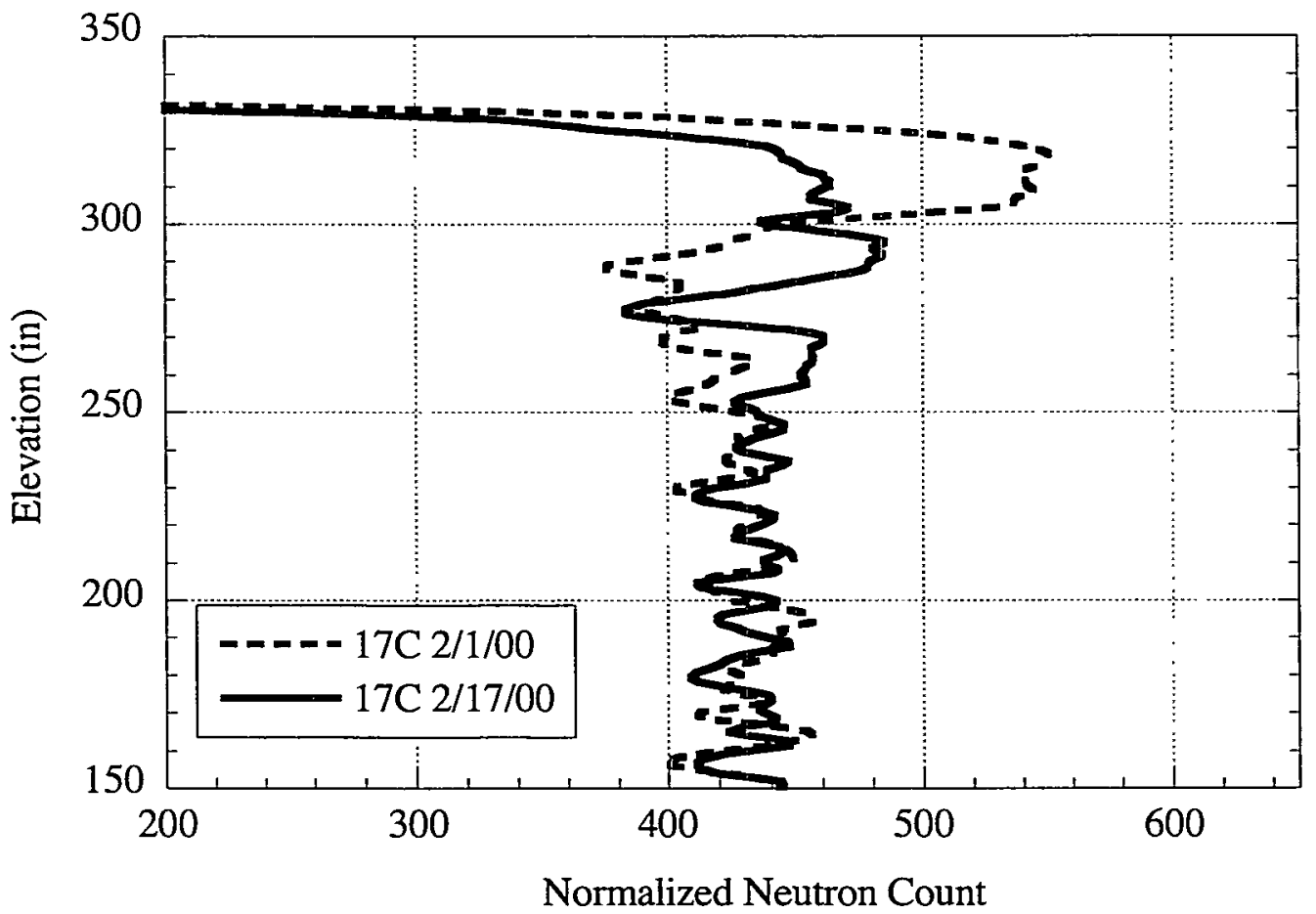

Figure 4.11. Neutron Profiles at $17 \mathrm{C}$ Between the Top Dilution $2 \mathrm{~b}$ and Low Dilution 2c 


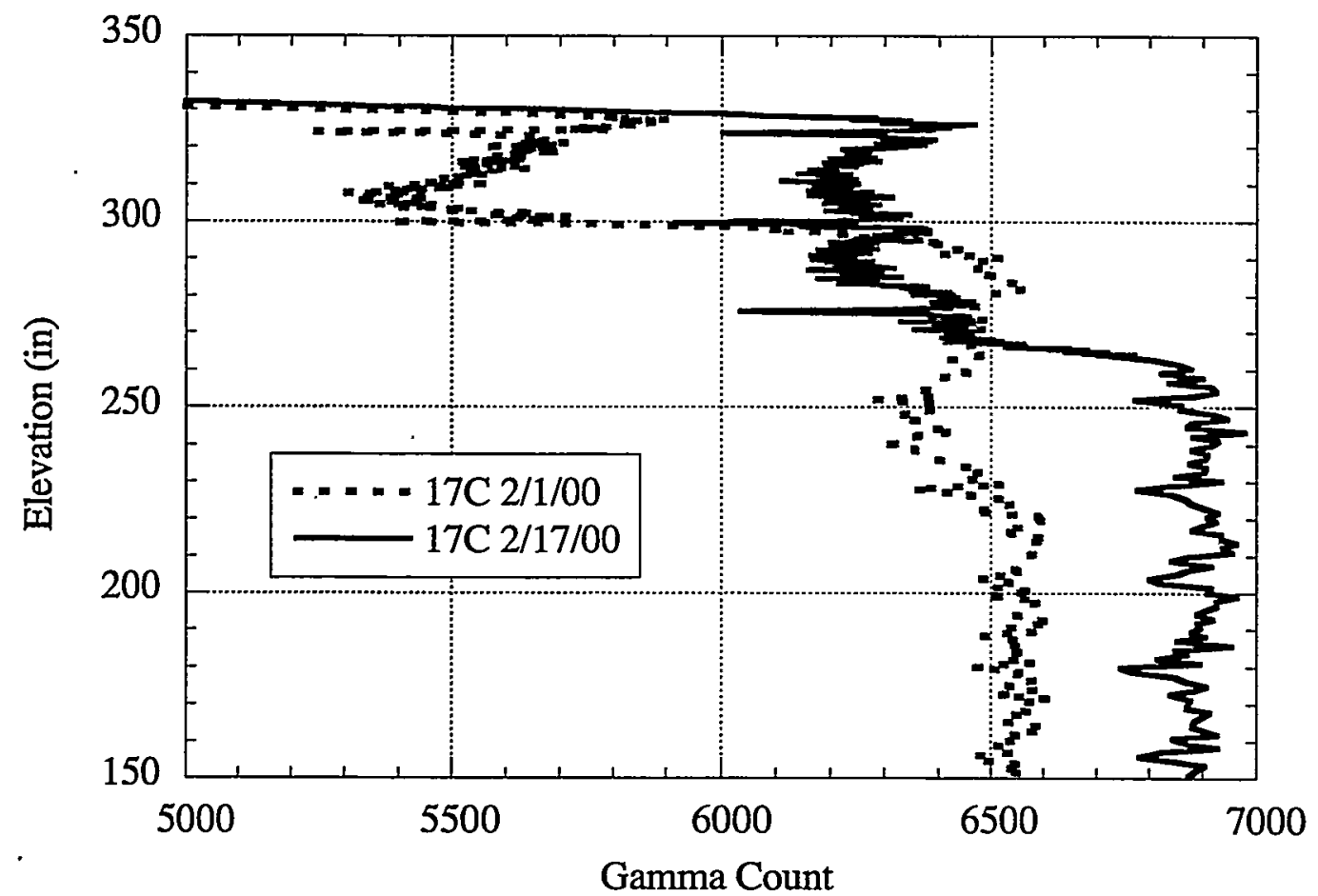

Figure 4.12. Gamma Profiles at 17C Between the Top Dilution 2b and Low Dilution 2c

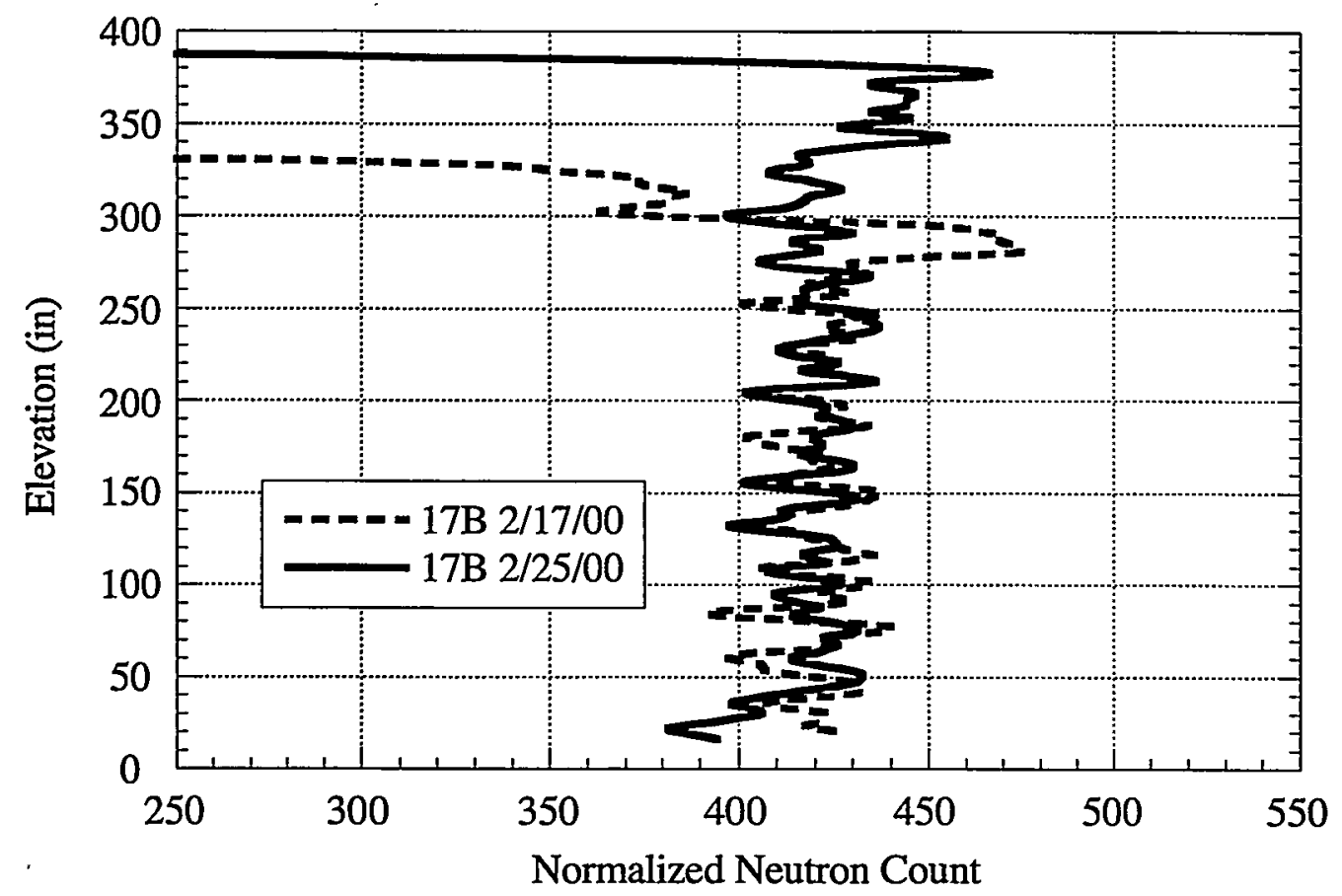

Figure 4.13. Neutron Profiles at 17B Before and After Dilutions 2c-e 


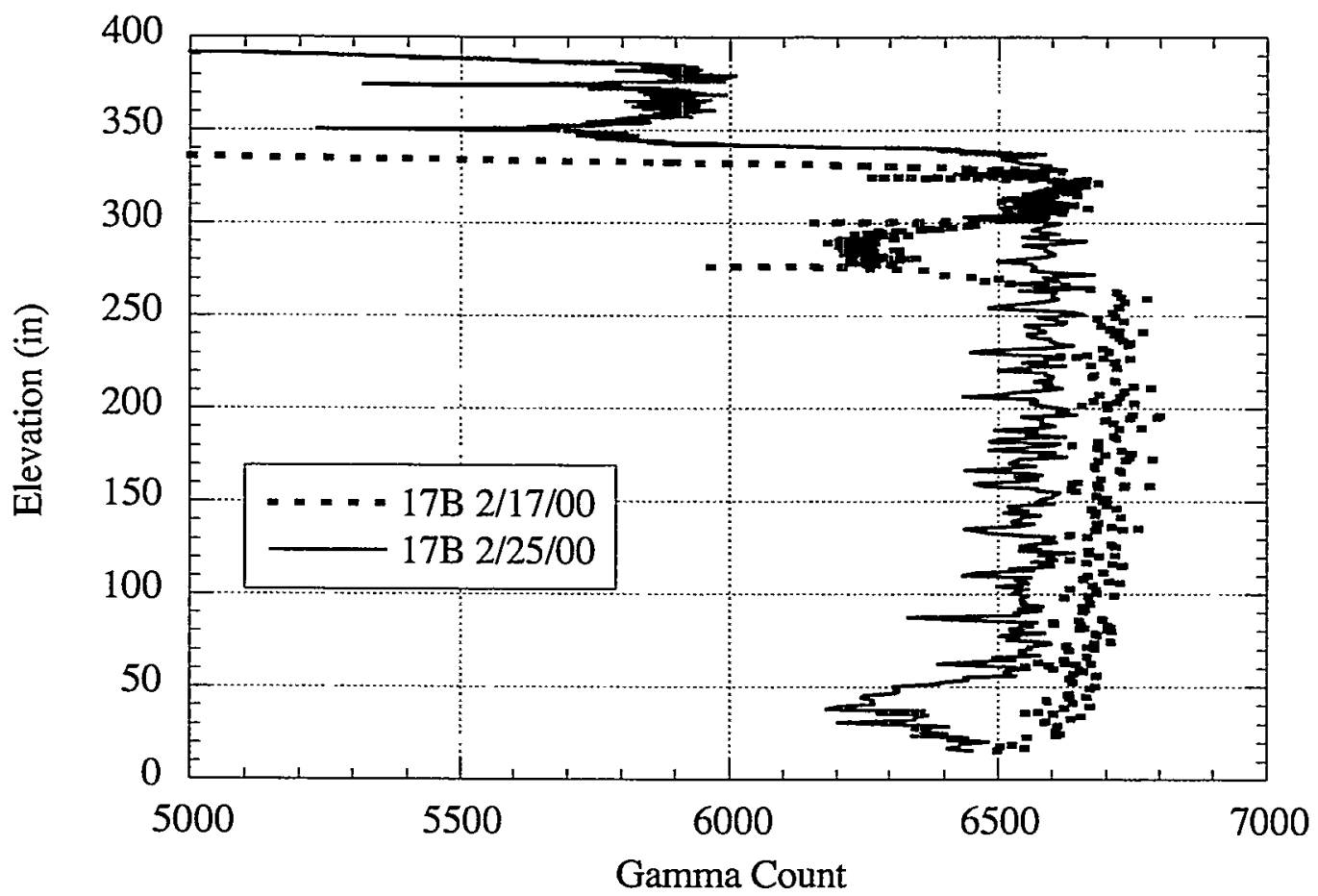

Figure 4.14. Gamma Profiles at 17B Before and After Dilutions 2c-e

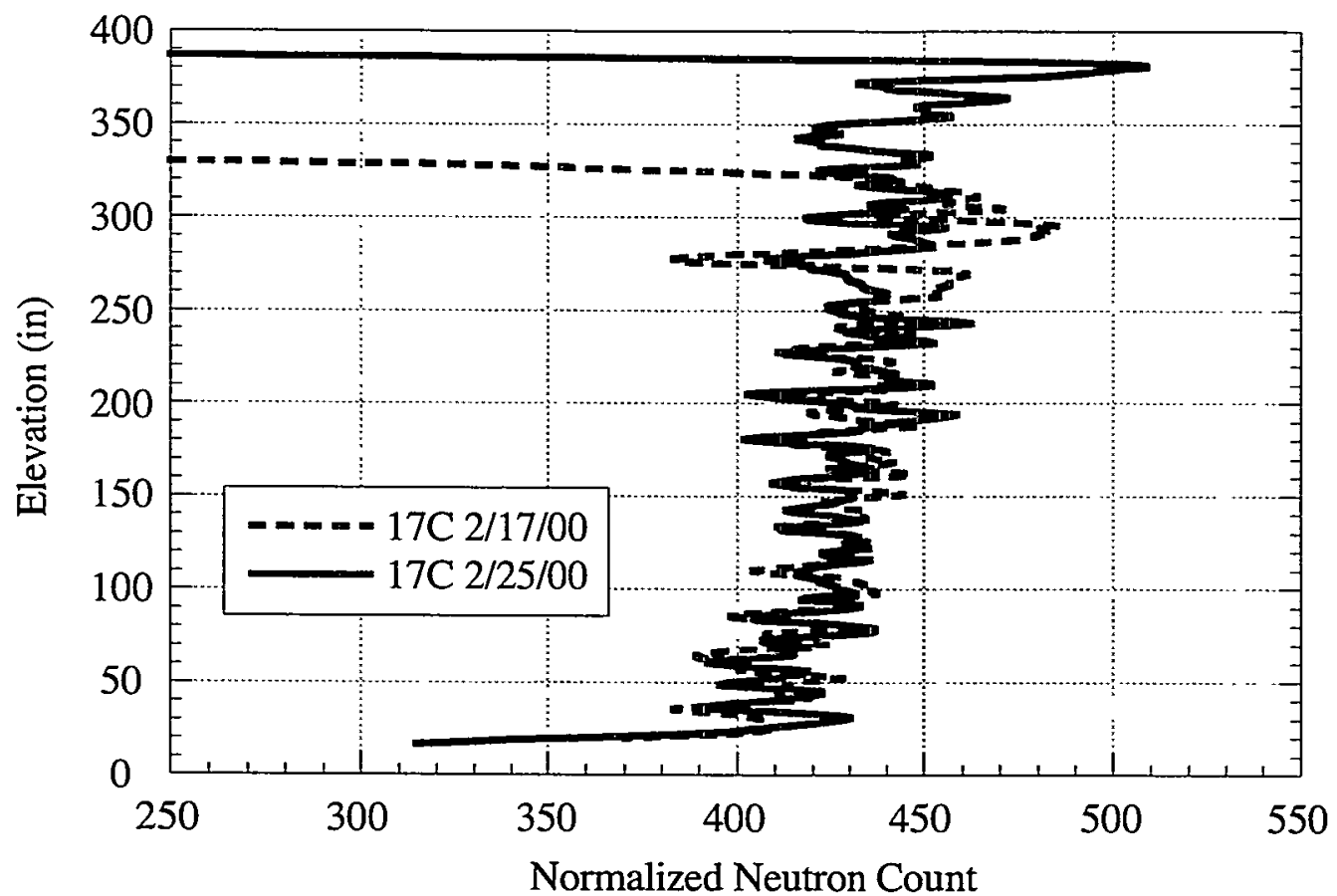

Figure 4.15. Neutron Profiles at 17C Before and After Dilutions 2c-e 


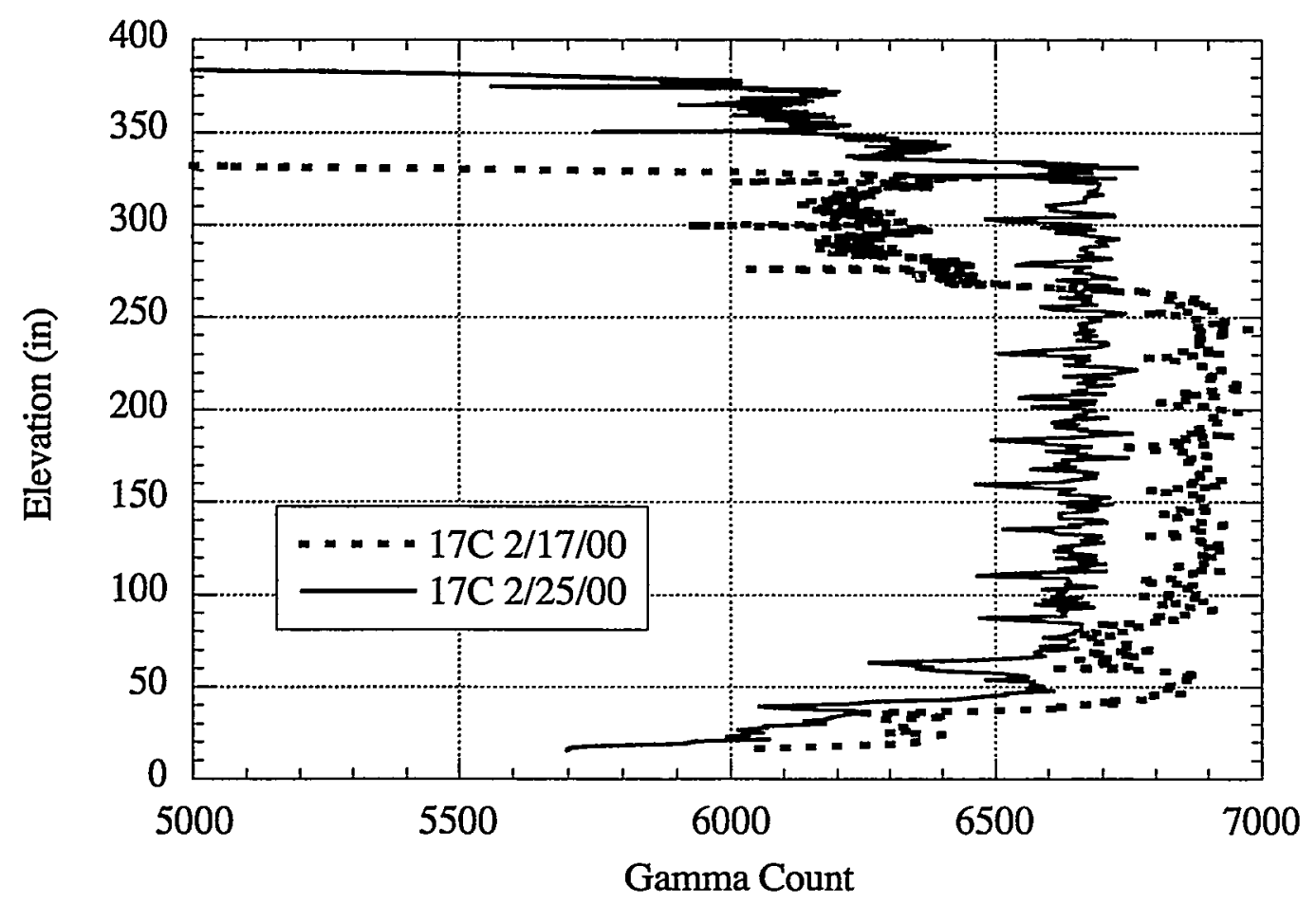

Figure 4.16. Gamma Profiles at 17B Before and After Dilutions 2c-e

\subsection{Neutron and Gamma Profiles During the Third Campaign}

Neutron and gamma profiles from risers $17 \mathrm{~B}$ and $17 \mathrm{C}$ that bracket the third campaign are shown in Figures 4.17 through 4.20. The transfer had little effect on the profiles except to lower the waste level. The results of the third back-dilution, which includes both top and low dilution, can be seen in the profiles shown in Figures 4.21 through 4.24. The high neutron count and low gamma count above about 330 inches on March 17 is evidence of excess water from the top dilution. The low neutron count and higher gamma count below 100 inches represents undiluted waste below the low dilution injection point at the base of the transfer pump. The final set of neutron profiles just before the start of the evaluation period in Figures 4.25 and 4.26 show that the entire waste column was well mixed above about 50 inches.

\subsection{Conclusions on Neutron and Gamma Data}

Because of the high gas fraction in the pre-dilution crust layer, the neutron and gamma probes were able to provide very useful details on the internal structure of the crust, changes that occurred during 1999, and its ultimate dissolution. Likewise, the contrast between the undiluted saturated salt solution and waster was sufficient for both systems to detect areas of more dilute waste and whether the mixer pump was reducing the stratification left after top dilution. Overall, the neutron and gamma data provided some of the most profound insights into the waste behavior and were some of the most valuable information available. 


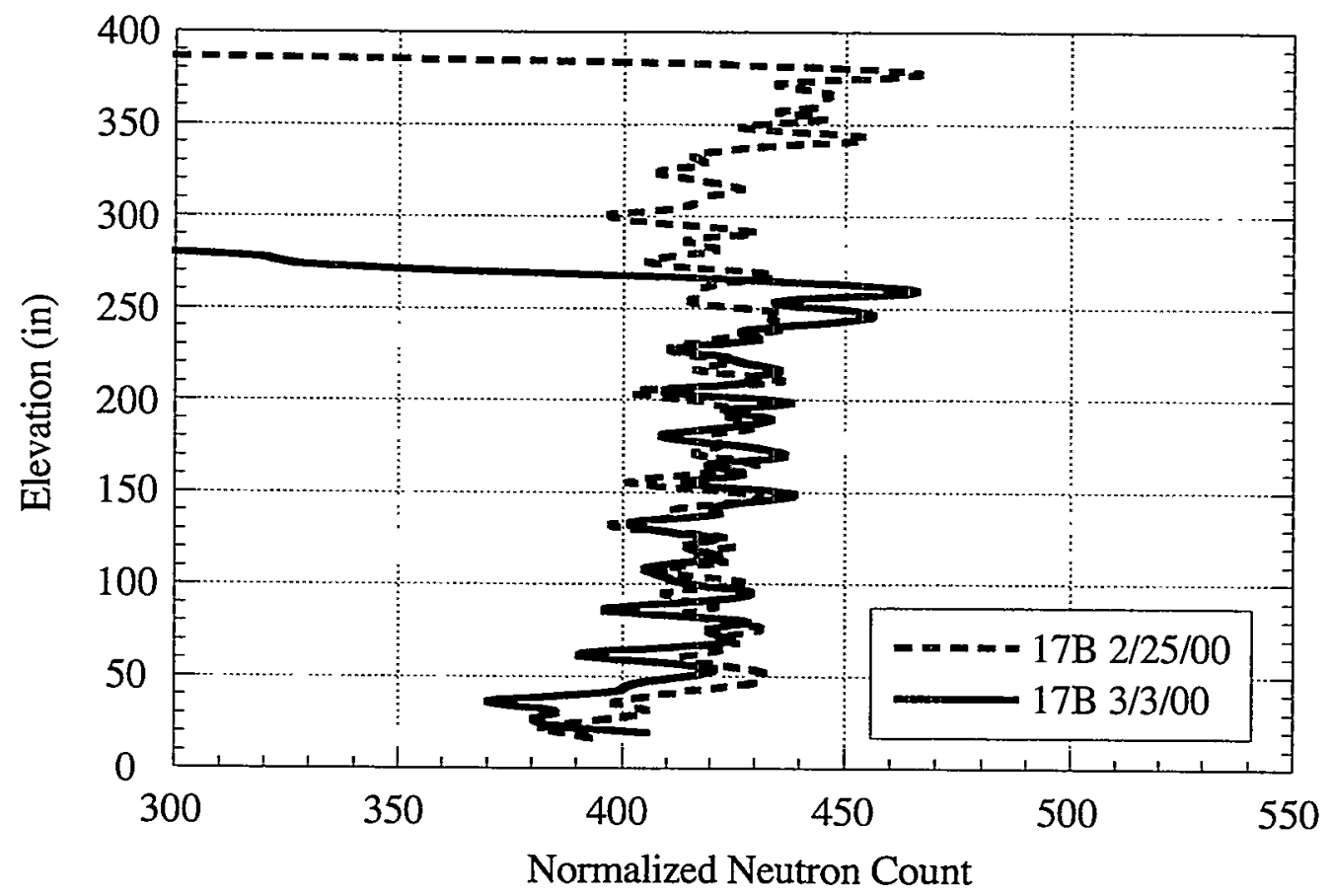

Figure 4.17. Neutron Profiles at 17B Before and After Transfers 3a-b

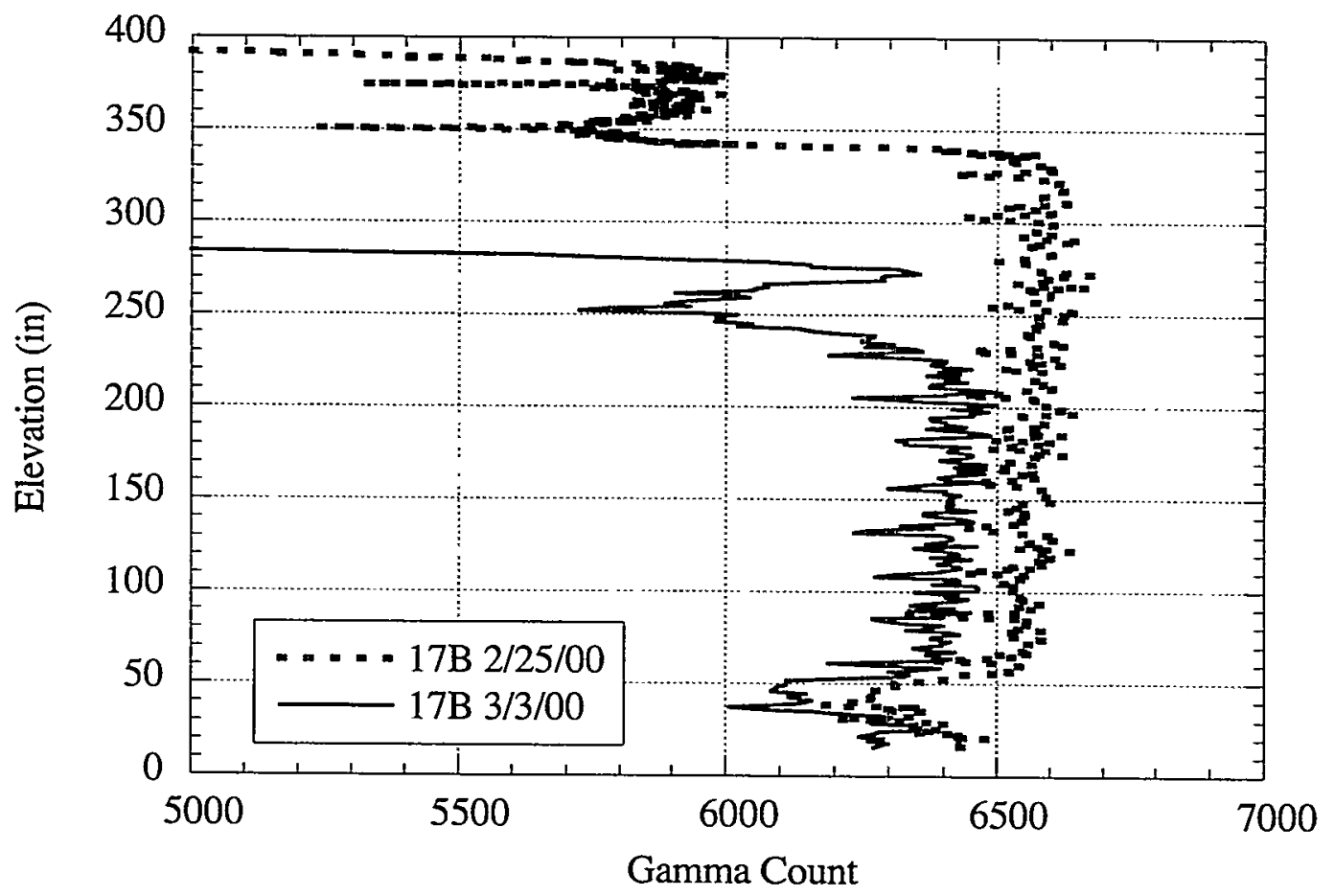

Figure 4.18. Gamma Profiles at 17B Before and After Transfers 3a-b 


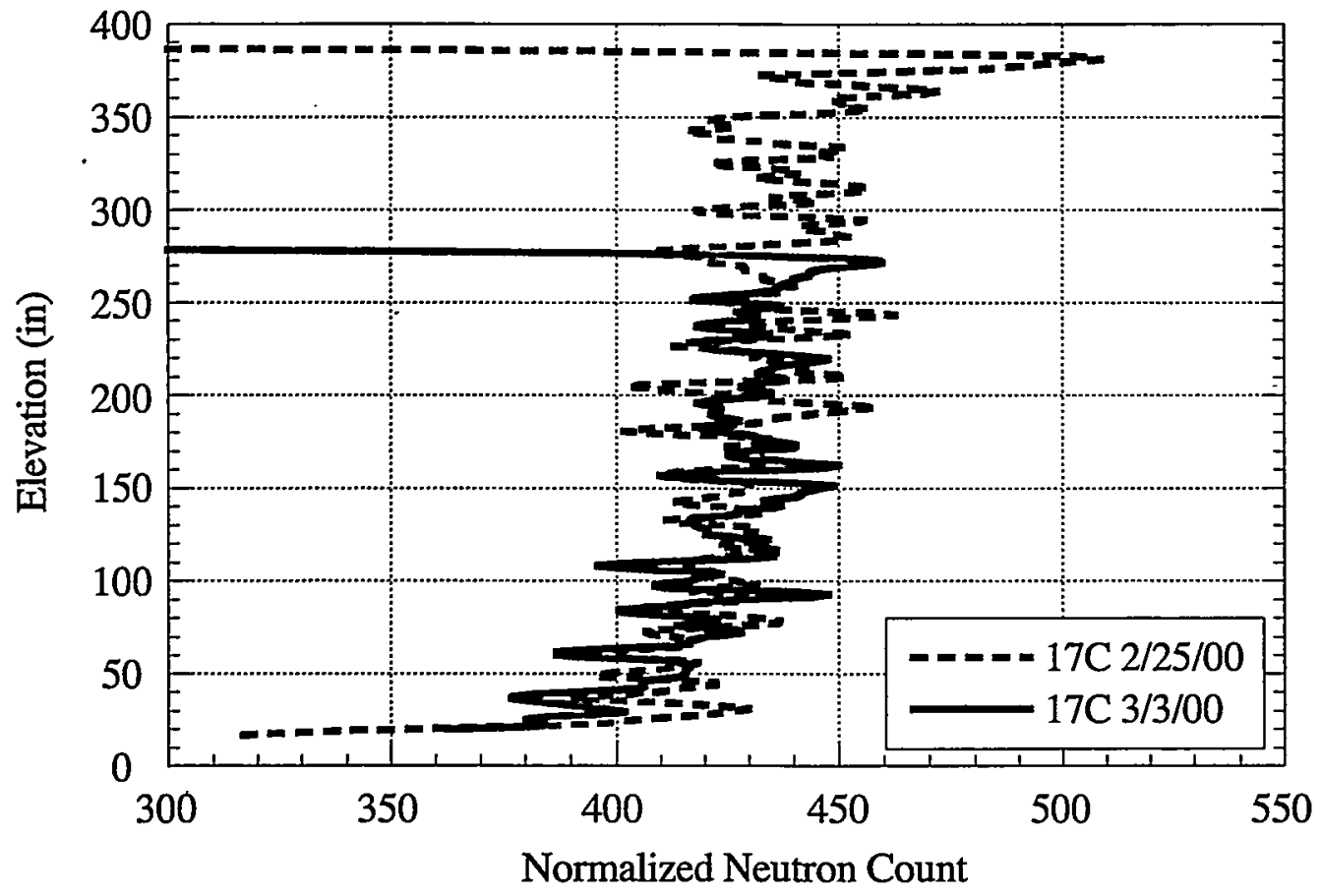

Figure 4.19. Neutron Profiles at $17 \mathrm{C}$ Before and After Transfers 3a-b

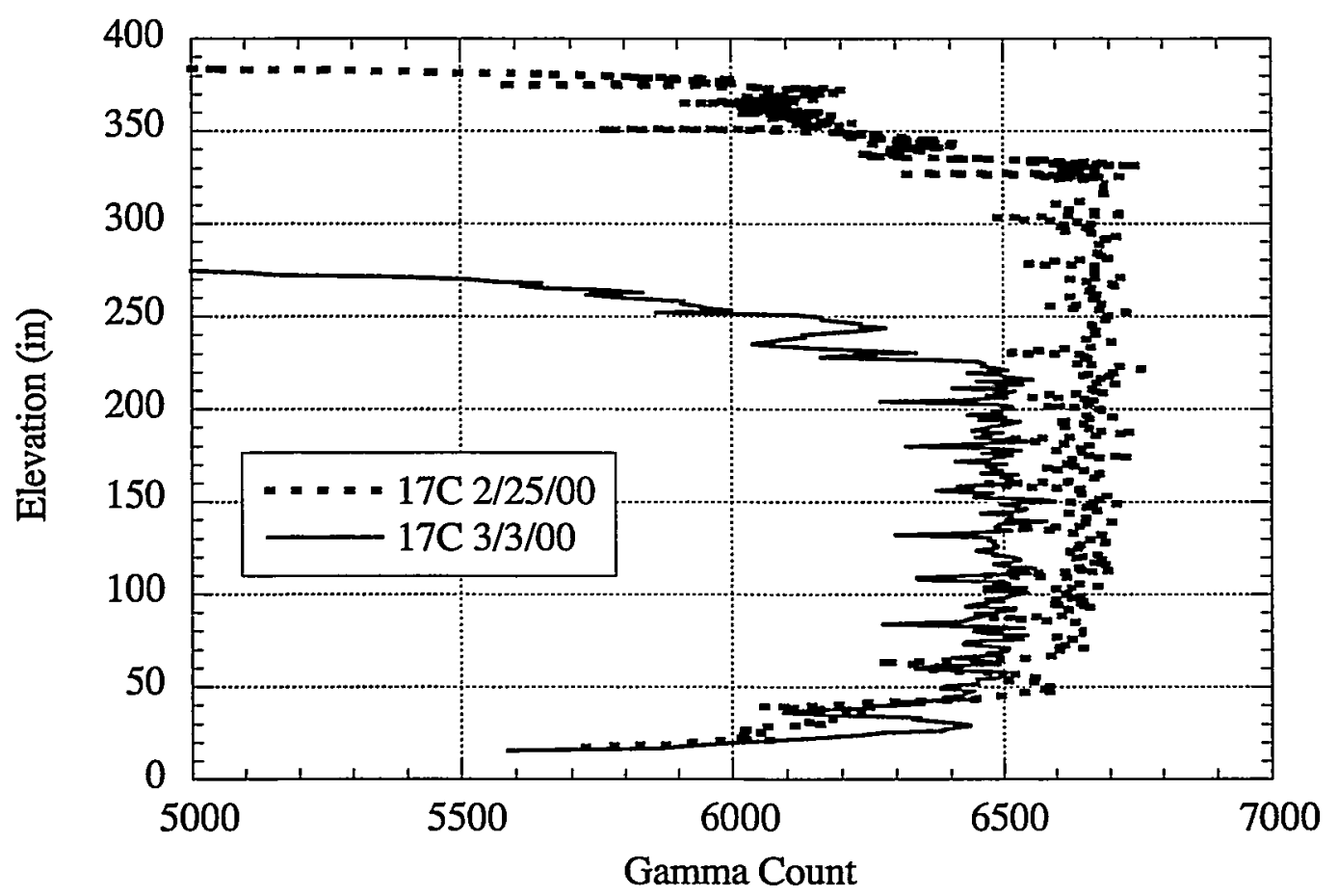

Figure 4.20. Gamma Profiles at $17 \mathrm{C}$ Before and After Transfers 3a-b 


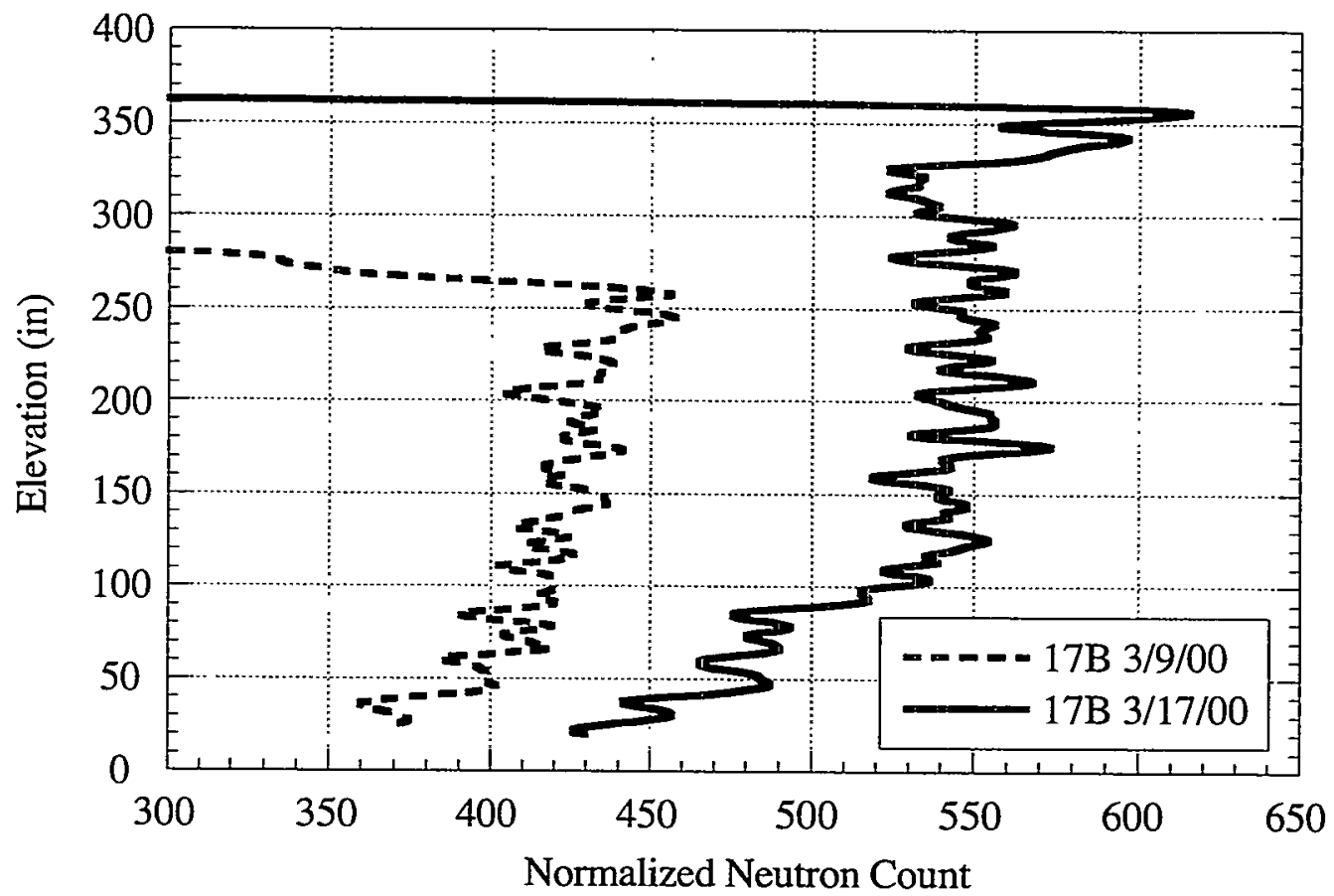

Figure 4.21. Neutron Profiles at 17B Before and After Dilutions 3c-f

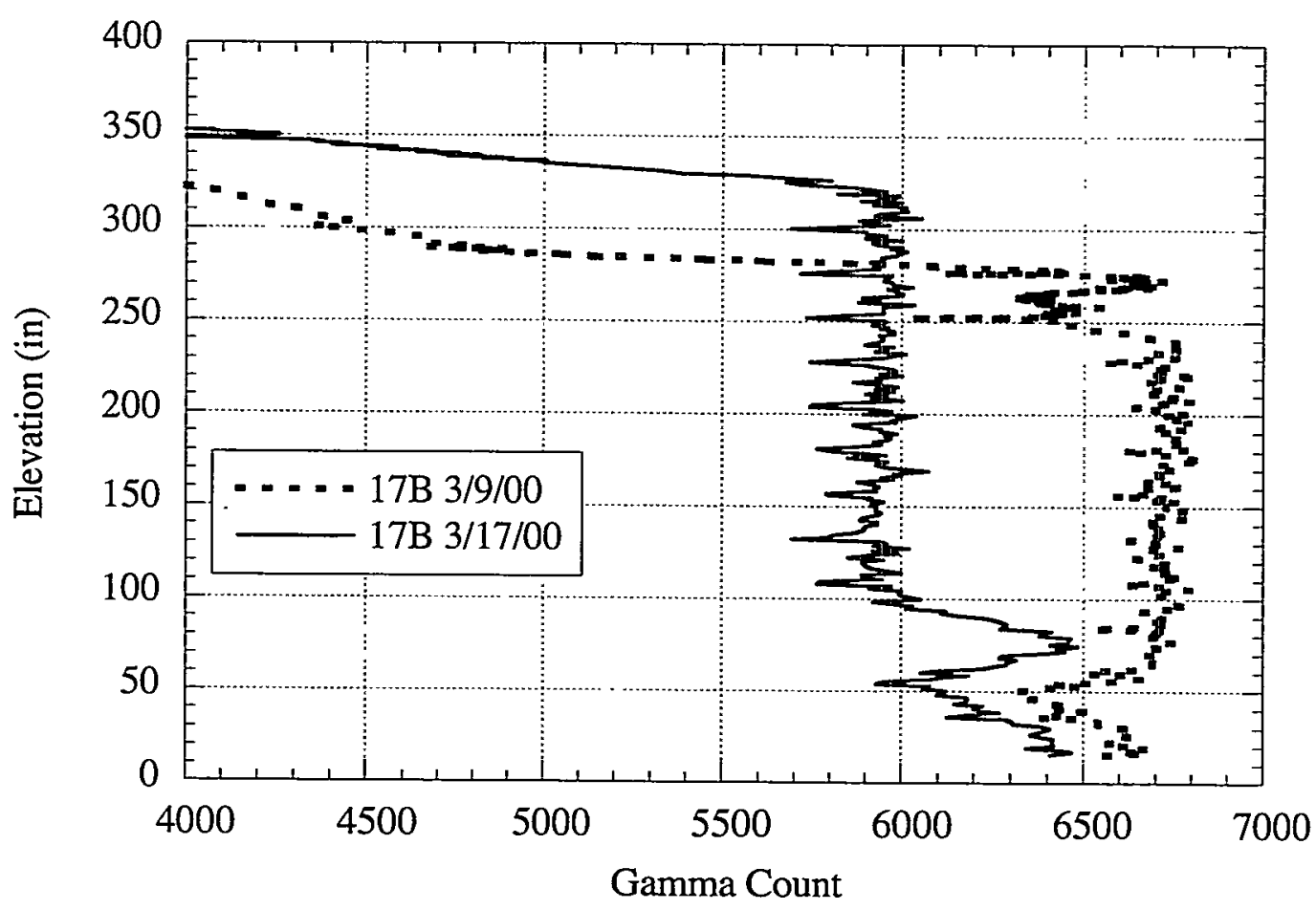

Figure 4.22. Gamma Profiles at 17B Before and After Dilutions 3c-f 


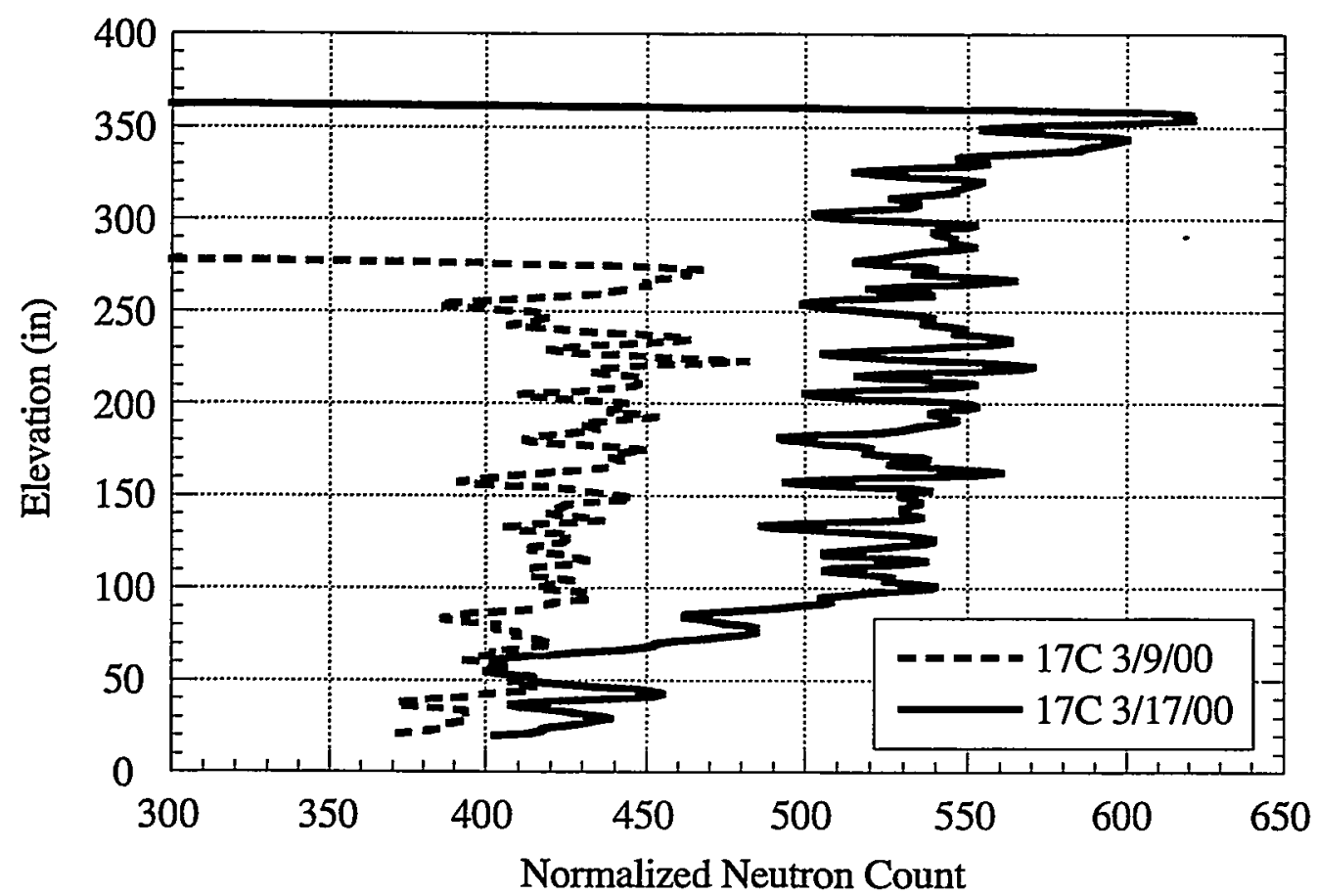

Figure 4.23. Neutron Profiles at $17 \mathrm{C}$ Before and After Dilutions 3c-f

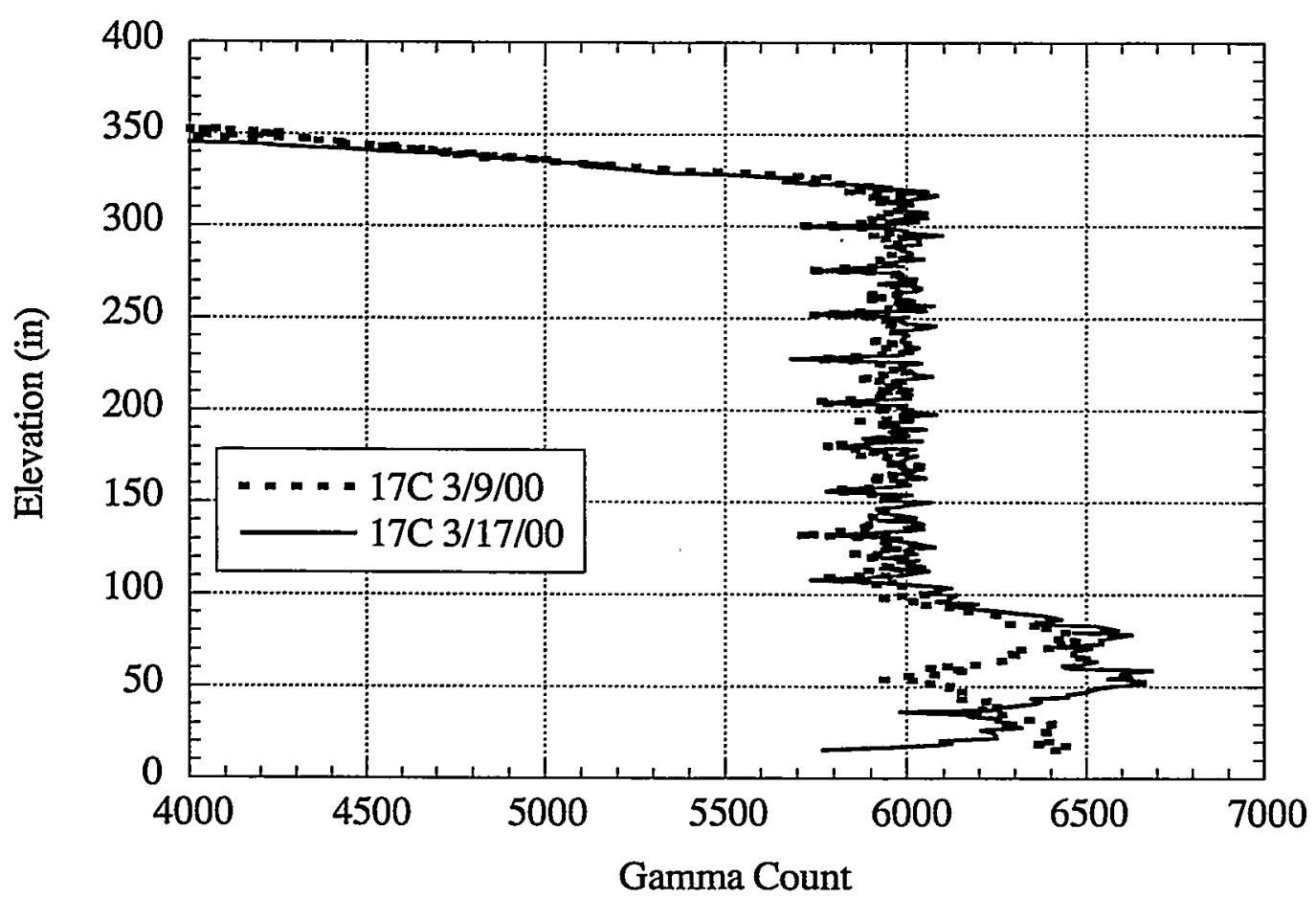

Figure 4.24. Gamma Profiles at 17C Before and After Dilutions 3c-f 


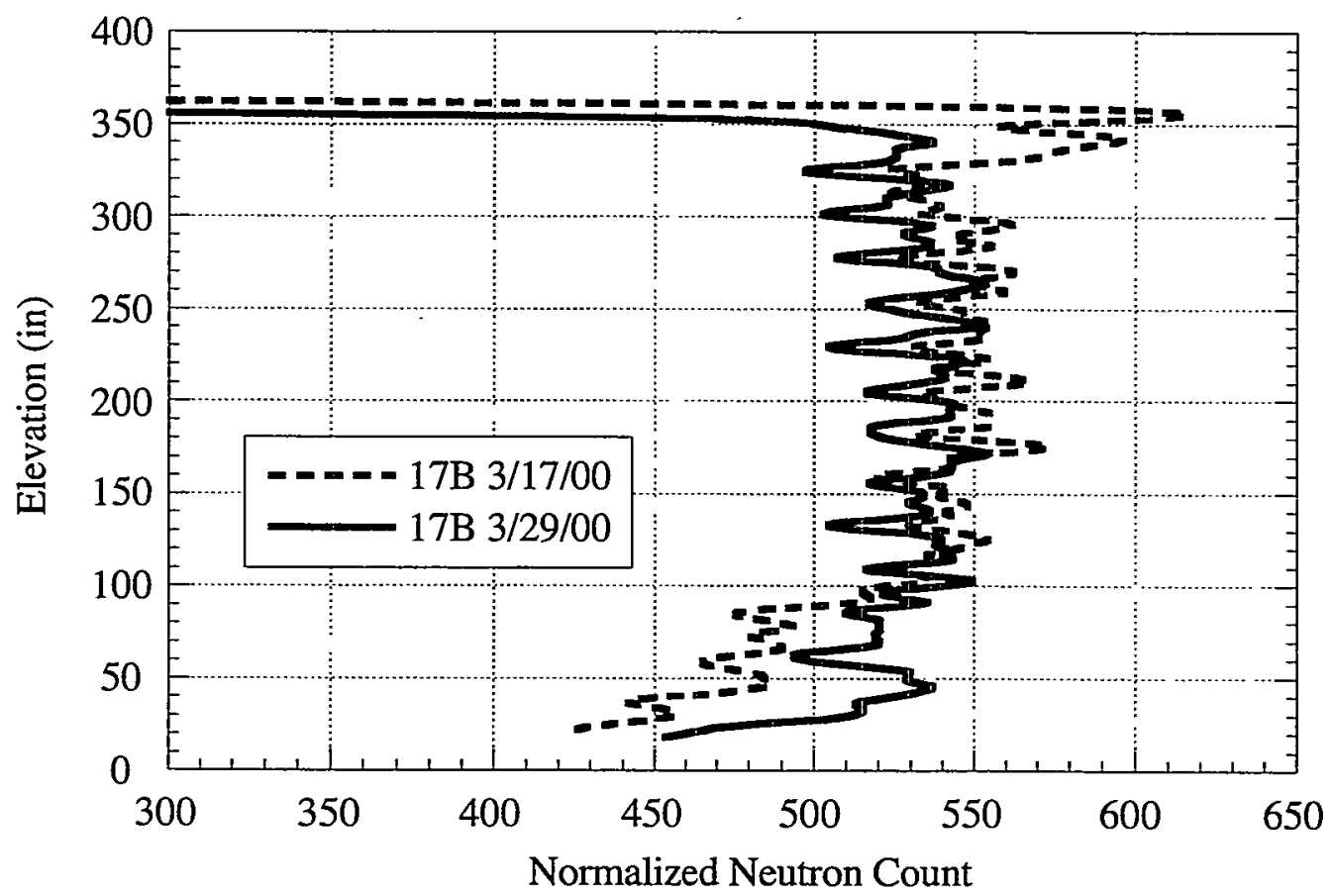

Figure 4.25. Neutron Profiles at 17B After the Third Campaign

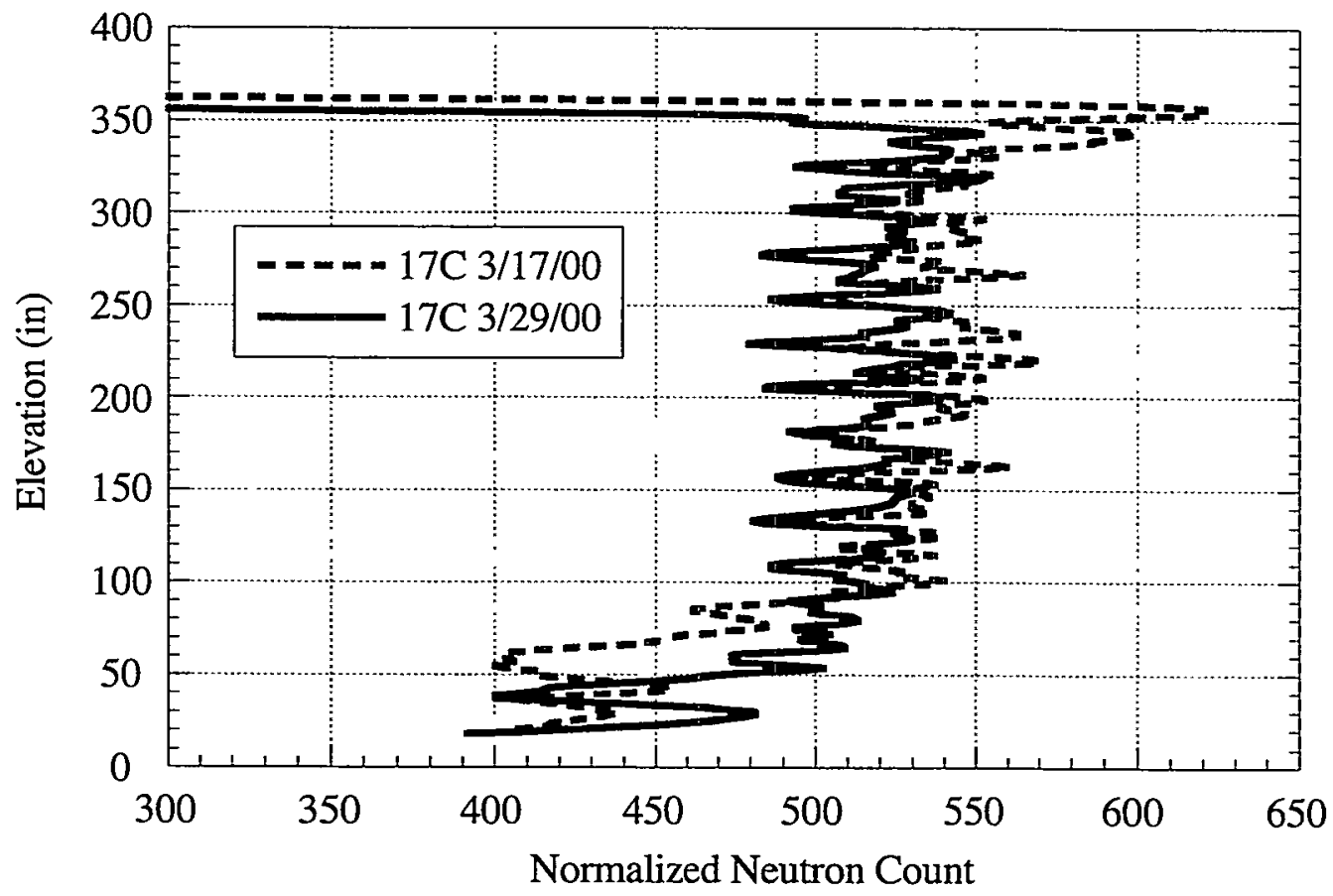

Figure 4.26. Neutron Profiles at $17 \mathrm{C}$ After the Third Campaign 


\subsection{Gas Concentrations and Releases}

The concentrations of hydrogen, nitrous oxide, and ammonia in both Tanks SY-101 and SY-102 as well as the ammonia concentration in the SY farm stack were monitored during each transfer and dilution because of controls to limit headspace flammability and worker health and safety issues with ammonia. The data collected this way also contributed significantly to understanding the processes involved.

Hydrogen is essentially insoluble and resides almost entirely in bubbles. It is also released with the bubbles as the solid-liquid matrix dissolves. At the other end of the spectrum, ammonia is extremely soluble and resides almost entirely in the liquid. Ammonia is released mainly by evaporation, although a small fraction is also released with bubbles of less soluble gas. Elevated ammonia levels are expected whenever free liquid or a wet waste surface is exposed. However, water rapidly absorbs ammonia and even a small water spray in the headspace or a water-diluted waste surface inhibits its release. Nitrous oxide is somewhat more soluble than hydrogen; its behavior has some of the characteristics of ammonia. Most of it is stored in bubbles, but some evaporative release (and inhibition of release by water) can also be observed.

Based on gas composition measurements with the RGS, the hydrogen fraction in SY-101 waste ranges from 0.26 to 0.45 (Mahoney et al. 1999). The gas trapped in the crust layer had a hydrogen fraction of about 0.38 while the mixed slurry was significantly leaner at around 0.30 . The volume average hydrogen fraction is 0.34 , which is taken as the best estimate. The concentration of nitrous oxide is more uniform at about 0.20 in both the crust and the mixed slurry. Thus the ratio of hydrogen to nitrous oxide is close to 2 in the crust and 1.5 or less in the slurry. This difference can sometimes be used to infer the source of the gas being released during a specific stage of remediation. However, this inference may be incorrect if the evaporative release of nitrous oxide is significant.

In SY-101 hydrogen concentration in the headspace is monitored by three gas chromatographs (GCs). GC3 is a low-range instrument designed for hydrogen concentrations below $400 \mathrm{ppm}$; GC2 is the high-range instrument that is considered accurate for concentrations above a few hundred ppm; and $\mathrm{GC} 1$ is designed to provide full-range coverage. However, since $\mathrm{GC1}$ was down or gave spurious readings at times, we found the best measurement of hydrogen concentration to be the maximum of the readings from GC2 and GC3. Nitrous oxide and ammonia concentrations in SY-101 are measured with a Fourier transform infrared spectrometer (FTIR), which is accurate over the full range of concentrations encountered.

SY-102 is fitted with an E+ version of the standard hydrogen monitoring system (SHMS). The SHMS-E+ uses a GC to monitor hydrogen, nitrous oxide, and methane and an infrared (IR) photo-acoustic cell to measure ammonia concentration (McCain 1999). An IR cell is also used to monitor ammonia in the SY farm stack. The stack receives flow from SY-101, SY-102, and SY-103 at flow rates of approximately $500 \mathrm{cfm}, 200 \mathrm{cfm}$ and $200 \mathrm{cfm}$, respectively.

Based on the retained gas fraction measurements with the void fraction instrument (VFI) and RGS, along with estimates of crust thickness and structure from neutron and gamma logs, the total gas volume stored in SY-101 prior to remediation was 15,000 \pm 2000 scf (Rassat et al. 2000). About 10,000 scf of this was stored in the crust layer, and 5,000 scf was assumed to be 
small bubbles suspended in the mixed slurry layer. During the 107 days from the start of the first transfer to the start of the mixer pump evaluation period, essentially all of this gas was released. About half of the stored gas was released during and after the large top dilution accomplished in the second campaign. Other significant releases occurred between the first and second campaigns and after the last campaign.

The stored gas bubble release and ammonia evaporation release for each main segment of the remediation sequence is summarized in Table 5.1. The total gas release in SY-101 is computed as the time integral of the product of hydrogen concentration and ventilation flow rate divided by the estimated fraction of hydrogen in the released gas. The stored gas release is taken as the total less the estimated cumulative gas generation. The gas generation rate is reduced as waste is removed to account for removal of the source term and the effects of cooling and dilution, as described in Section 3.4. The ammonia release is computed simply as the integral of the product of ammonia concentration and ventilation rate. The ammonia generation rate is small (about $6 \%$ of the total, 1/6 that of hydrogen) and is ignored in the calculation. Hydrogen release in SY-102 is assumed to be bubbles transferred from SY-101 that contain $28 \%$ hydrogen based on RGS measurements in the mixed slurry layer (Mahoney et al. 1999).

The gas releases are described in detail for each campaign in Sections 5.1 through 5.3. Transient hydrogen, nitrous oxide, and ammonia concentrations in SY-101 and SY-102 and the ratio of hydrogen to nitrous oxide in SY-101 are presented as well as the SY farm stack ammonia concentration. Section 5.4 provides a summary of gas release behavior.

Table 5.1. Gas Release Volumes During Remediation Campaigns

\begin{tabular}{|c|c|c|c|}
\hline \multirow[b]{2}{*}{ Remediation Period } & \multicolumn{3}{|c|}{ Gas Release (scf) } \\
\hline & $\begin{array}{c}\text { SY-101 } \\
\text { bubbles }^{(a)}\end{array}$ & $\begin{array}{c}\text { SY-101 } \\
\text { ammonia }^{(b)}\end{array}$ & $\begin{array}{c}\text { SY-102 } \\
\text { bubbles }^{(c)}\end{array}$ \\
\hline First Campaign & 980 & 220 & 220 \\
\hline Between $1^{\text {st }}$ and $2^{\text {nd }}$ Campaigns & 1,700 & 3,000 & \\
\hline $\begin{array}{l}\text { Second Campaign: } \\
\text { Transfer } 2 \mathrm{a} \text { and Top Dilution } 2 \mathrm{~b}\end{array}$ & 3,000 & 750 & 200 \\
\hline Between Top Dilution $2 \mathrm{~b}$ and Low Dilution $2 \mathrm{c}$ & 4,400 & 4,500 & \\
\hline Second Campaign: Dilutions 2c-e & 370 & 710 & \\
\hline Between $2^{\text {nd }}$ and $3^{\text {rd }}$ Campaigns & 390 & 550 & \\
\hline Third Campaign: Transfers 3a-b & 310 & 240 & 130 \\
\hline Between Transfer $3 b$ and Low Dilution 3c & 400 & 1000 & \\
\hline Third Campaign: Dilutions 3c-f & 600 & 190 & \\
\hline After $3^{\text {rd }}$ Campaign & 2,500 & 2,200 & \\
\hline TOTAL & 14,650 & 13,400 & 550 \\
\hline \multicolumn{4}{|c|}{$\begin{array}{l}\text { (a) Calculated from net hydrogen release assuming released gas is } 34 \% \text { hydrogen. } \\
\text { (b) Ammonia release calculation ignores ammonia generation. } \\
\text { (c) Calculated from hydrogen release in SY-102 assuming } 28 \% \text { hydrogen. }\end{array}$} \\
\hline
\end{tabular}




\subsection{Gas Release During the First Campaign}

Figure 5.1 shows the behavior of hydrogen, ammonia, and nitrous oxide in the SY-101 headspace during the first campaign. Hydrogen and nitrous oxide concentrations rose steeply for the first eight hours after the transfer began, while ammonia increased only gradually. After eight hours, hydrogen held steady, nitrous oxide increased gradually, and the increase in ammonia accelerated, apparently as a result of evaporation. The concentrations of all three gases dropped sharply immediately upon cessation of transfer, though ammonia declined less rapidly than the more insoluble gases.

The somewhat elevated gas concentrations during transfer were unexpected. We believed that the crust would descend smoothly and uniformly without being disturbed in a way that would release gas. Because hydrogen held approximately constant while ammonia accelerated, the mechanism that caused the release apparently involved a constant rate of bubble release and a steady increase in the wetted waste area exposed. This is consistent with a ring of wet waste adhering to the wall being progressively exposed and disturbed at a constant rate by the falling waste level. Once transfer ended, the disturbance stopped and ventilation rapidly reduced the concentrations of all three gases. An attached ring of waste is consistent with the implications of the video evidence shown in Section 2.2 and the mismatch of transfer flow and waste level drop described in Sections 3.1 and 3.2.

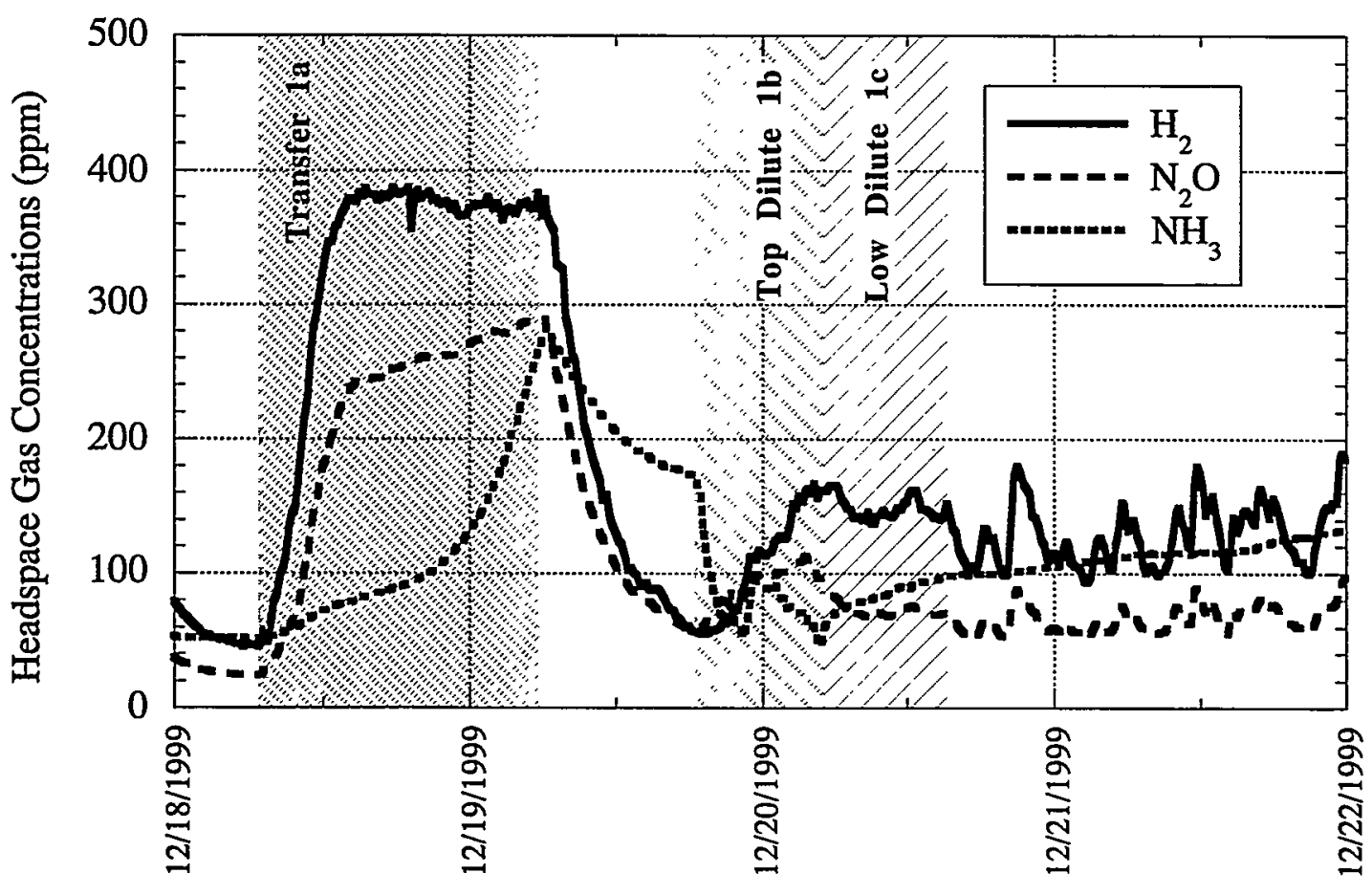

Figure 5.1. SY-101 Headspace Concentrations During First Campaign 
The water spray attendant with top dilution $1 \mathrm{~b}$ caused an abrupt decrease in the ammonia concentration as the water scrubbed ammonia from the headspace atmosphere. Ammonia began to rise slowly once the scrubbing effect of top dilution was removed. Dissolution of the portion of the crust above the original liquid level that contained little retained gas caused a minimal rise in hydrogen and nitrous oxide concentrations, as expected.

The transition to low dilution $1 \mathrm{c}$ caused hydrogen and nitrous oxide concentrations to decrease slightly and then hold roughly constant at concentrations about double the original background, an unexpectedly low release rate. The gas in the mixed slurry was assumed to be retained as small bubbles attached to particles. As the particles dissolved, we expected the attached bubbles to release. The lack of gas release during low dilution implied that either little dissolution occurred, bubbles were not retained by attachment to particles, or little gas was present in the first place.

Figure 5.2 shows the $\mathrm{H}_{2} / \mathrm{N}_{2} \mathrm{O}$ ratio during and shortly after the first campaign. Before and after transfer 1a the ratio was around 2, typical of the gas mixture found in the crust layer by the RGS. During transfer, the ratio steadily decreased. This is interpreted as a result of evaporation of $\mathrm{N}_{2} \mathrm{O}$ rather than release of gas from the mixed slurry where the ratio is lower. When $\mathrm{N}_{2} \mathrm{O}$ evaporation stopped as water covered the waste surface during top dilution $1 \mathrm{~b}$, the ratio returned to about 2 .

A number of substantial hydrogen releases (none of which caused headspace hydrogen concentrations to exceed $400 \mathrm{ppm}$ ) occurred during the month after the first campaign, as shown in Figure 5.3. Many of these releases followed pump runs; others (which in most cases were

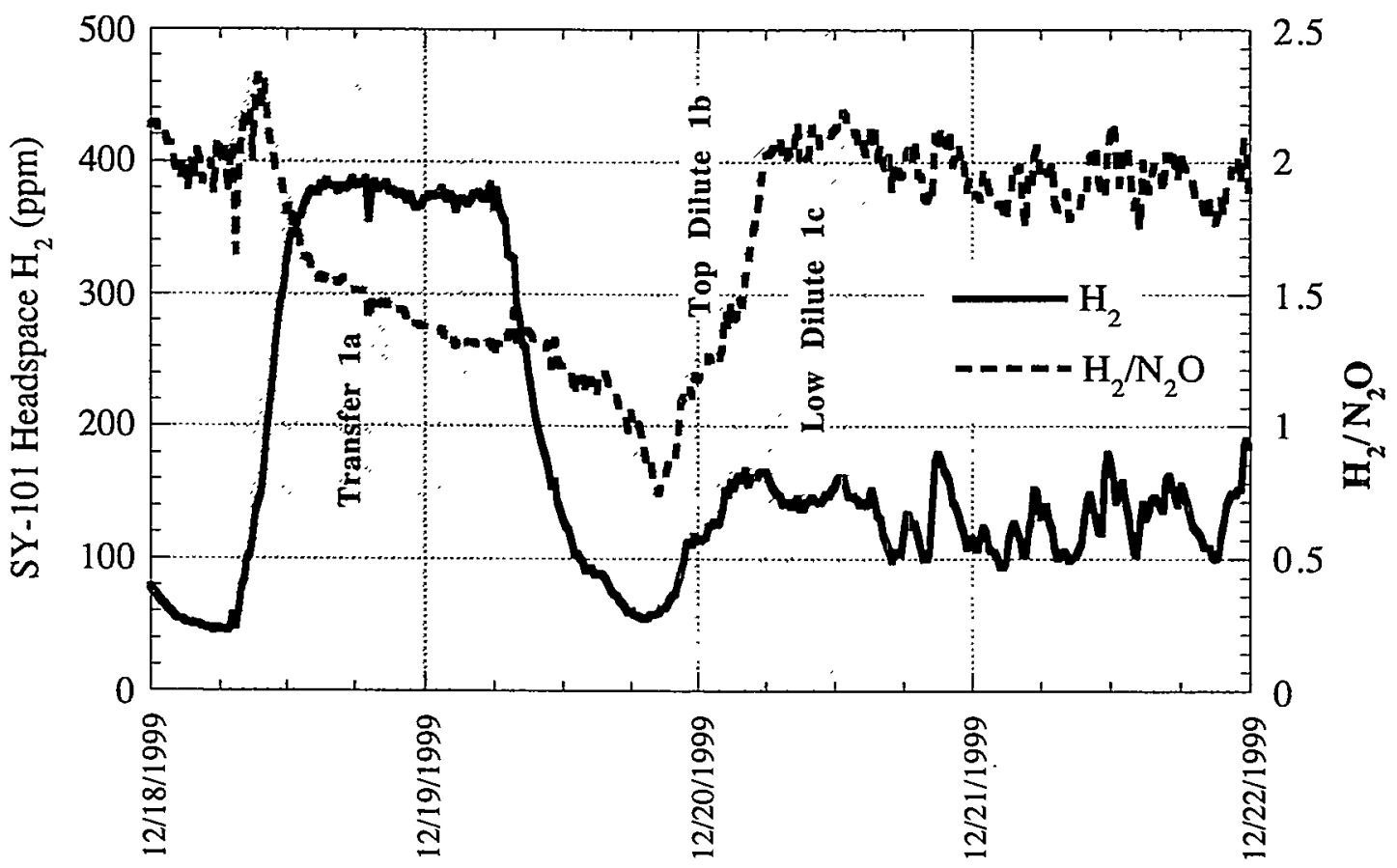

Figure 5.2. Hydrogen/Nitrous Oxide Ratio During the First Campaign 

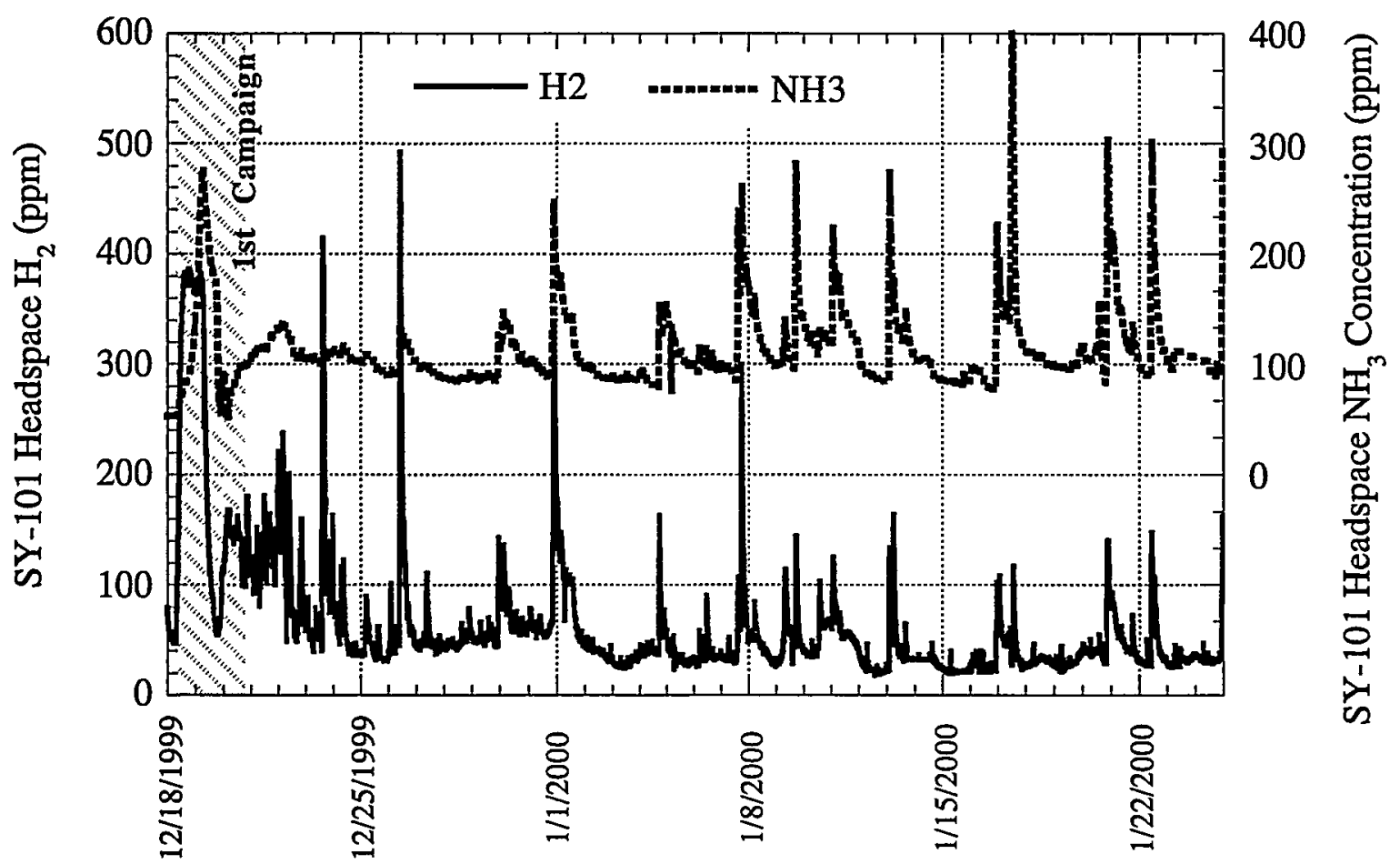

Figure 5.3. SY-101 Hydrogen and Ammonia Between the First and Second Campaigns

smaller) were spontaneous and apparently resulted from bubble slurry flows as described in Section 2.1. Both spontaneous releases and pump runs also produced ammonia spikes, which were not seen before the campaign. These comparatively large ammonia releases, and the increase in background ammonia, may indicate an opening up of passages through the crust.

Figure 5.4 shows the hydrogen, ammonia, and nitrous oxide concentrations in the SY-102 headspace during and shortly after the first campaign. The concentrations of all three gases rose rapidly. Hydrogen and nitrous oxide peaked and then declined after about 10 hours of transfer. This decrease in hydrogen concentration is not, at first glance, consistent with the assumption that retained gas came over from SY-101 as small bubbles to be released in SY-102 at a constant rate. However, it is possible that the reduction in release rate is a result of the increasing bubble transit time due to the increasing submergence of the drop leg in SY-102. It is also noteworthy that the $\mathrm{H}_{2} / \mathrm{N}_{2} \mathrm{O}$ ratio was about 0.6 at the time of peak concentration, much lower than values measured in SY-101 by RGS, probably due to evaporation of dissolved nitrous oxide.

The ammonia concentration rose steadily, almost linearly for the last 18 hours, throughout the transfer. This is believed to have been caused by ammonia capture by bubbles of air entrained by the siphon break in the drop leg through which waste entered SY-102 (see Section 6 and Estey 2000). Once the transfer stopped, this air sparging stopped and the ammonia release returned to evaporation alone, reducing the concentration to $80 \mathrm{ppm}$. The SY farm stack ammonia concentration (supplied mostly by SY-102) peaked at about $700 \mathrm{ppm}$ during the first transfer. 


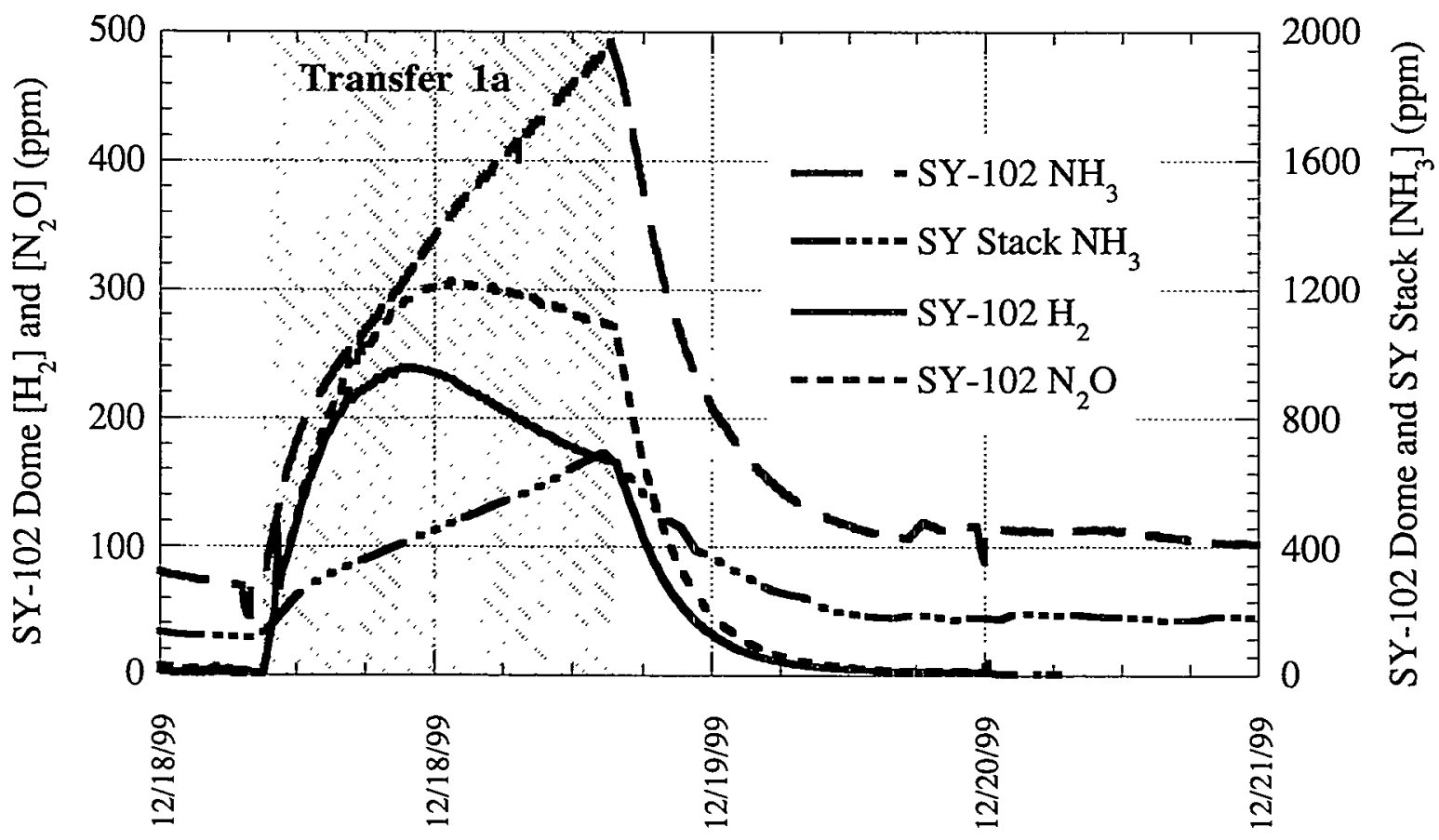

Figure 5.4. SY-102 Headspace Gas Concentrations During First Campaign

\subsection{Gas Release During the Second Campaign}

The two stages of the second campaign were markedly different in gas release character. During and after top dilution $2 \mathrm{~b}$, large releases occurred as the bulk of the thick floating crust dissolved. These were the largest gas releases seen since the mixer pump was installed. In low dilutions $2 \mathrm{c}-\mathrm{d}$ and top dilution $2 \mathrm{e}$, releases were modest because the most of the gas had already been released. Between the two stages the background ammonia concentration was the highest recorded except during pre-mixer pump GREs.

\subsubsection{Second Transfer and Top Dilution}

Figure 5.5 shows the behavior of the three gases of interest in the SY-101 headspace during the first stage of second campaign. During transfer $2 a$ the hydrogen concentration behaved in much the same way as in the first transfer: rising quickly and then remaining essentially constant. Nitrous oxide behaved like hydrogen, without the signs of evaporative release that appeared during the first transfer. Ammonia rose for a little more than a day, then became constant the following day.

During and after top dilution $2 \mathrm{~b}$, there were a number of spontaneous gas releases accompanied by bubble slurry flows resulting from crust dissolution (see Section 2.2). The peak hydrogen concentration reached $2000 \mathrm{ppm}$, and nitrous oxide exceeded $1000 \mathrm{ppm}$. During top dilution, ammonia releases were held down by water spray scrubbing and, after top dilution. 


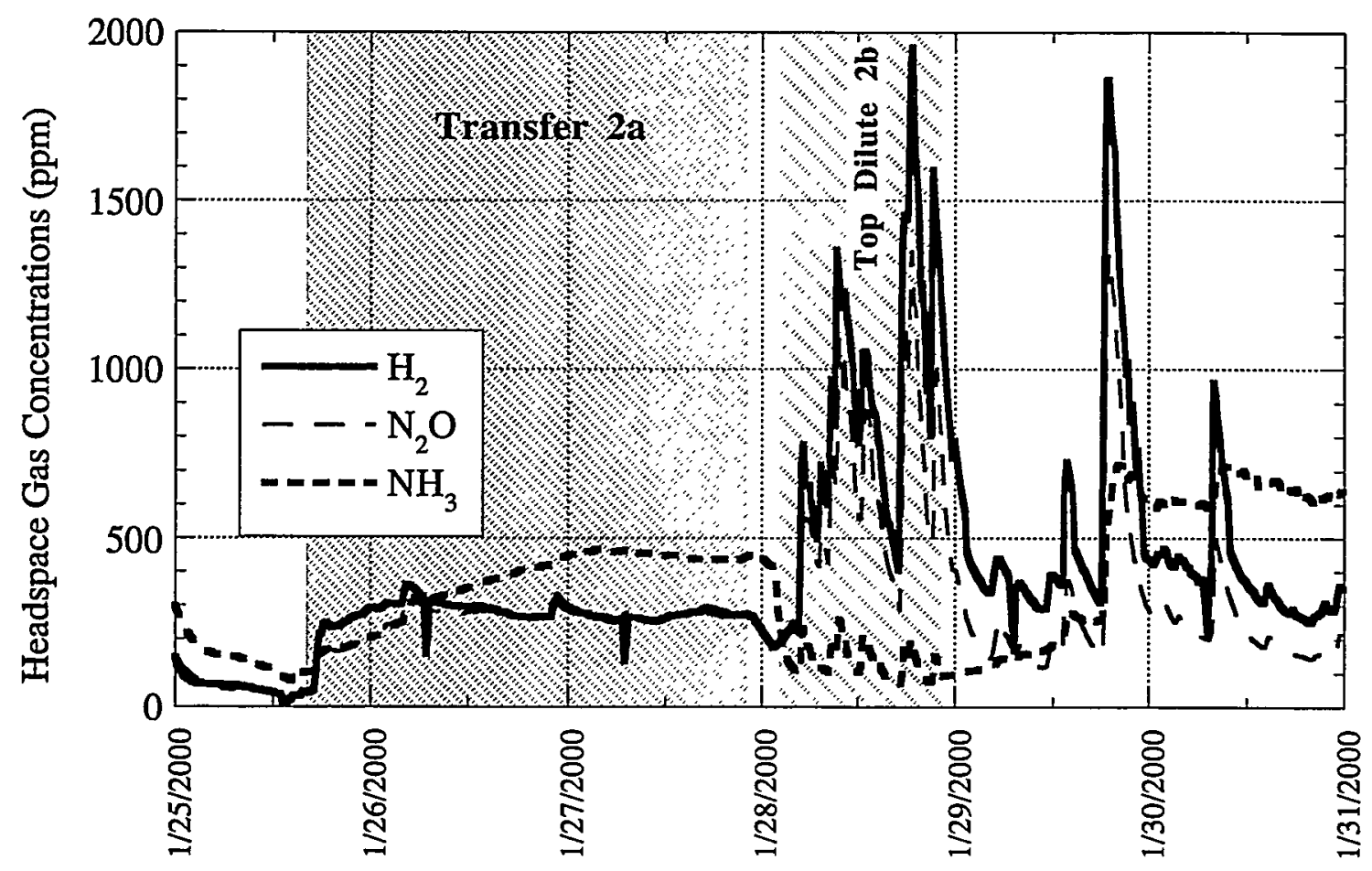

Figure 5.5. SY-101 Headspace Gas Concentrations During Transfer 2a and Top Dilute $2 b$

ceased, by the covering water pool. Late on January 29 , the day after top dilution $2 b$, the remains of the crust apparently rose through the dilute layer, bringing a more concentrated ammonia solution with them. This caused the ammonia concentration to rise rapidly to a steady $600 \mathrm{ppm}$, where it remained for about the next four days.

During transfer $2 \mathrm{a}$, the $\mathrm{H}_{2} / \mathrm{N}_{2} \mathrm{O}$ ratio in the SY-101 headspace was fairly constant at 1.0 to 1.4, the lower end of the RGS-measured range for retained gas, as shown in Figure 5.6. As during top dilution $1 \mathrm{~b}$, the top dilution $2 \mathrm{~b}$ caused the ratio to increase steadily to about 2.0 . The $\mathrm{H}_{2} / \mathrm{N}_{2} \mathrm{O}$ ratio remained between 1.5 and 2.5 for the next several days, consistent with the extensive gas release from the crust as it continued to dissolve.

Figure 5.7 shows the hydrogen, ammonia, and nitrous oxide concentrations in the SY-102 headspace during the second transfer. The concentrations of all three gases rose rapidly during transfer, following trends roughly similar to those of the first transfer. The $\mathrm{H}_{2} / \mathrm{N}_{2} \mathrm{O}$ ratio in SY-102 was between 0.1 and 0.3 during much of the second transfer, much lower than the 0.6-0.7 observed during the first transfer. The change indicates that more of the SY-102 releases came from evaporation and less from retained gas during the second transfer. The increase in the ammonia concentration late on January 27 is believed to be an instrument malfunction because no corresponding increase was observed at the stack. The small increase in ammonia beginning January 29 corresponds to a resumption in salt-well pumping. 


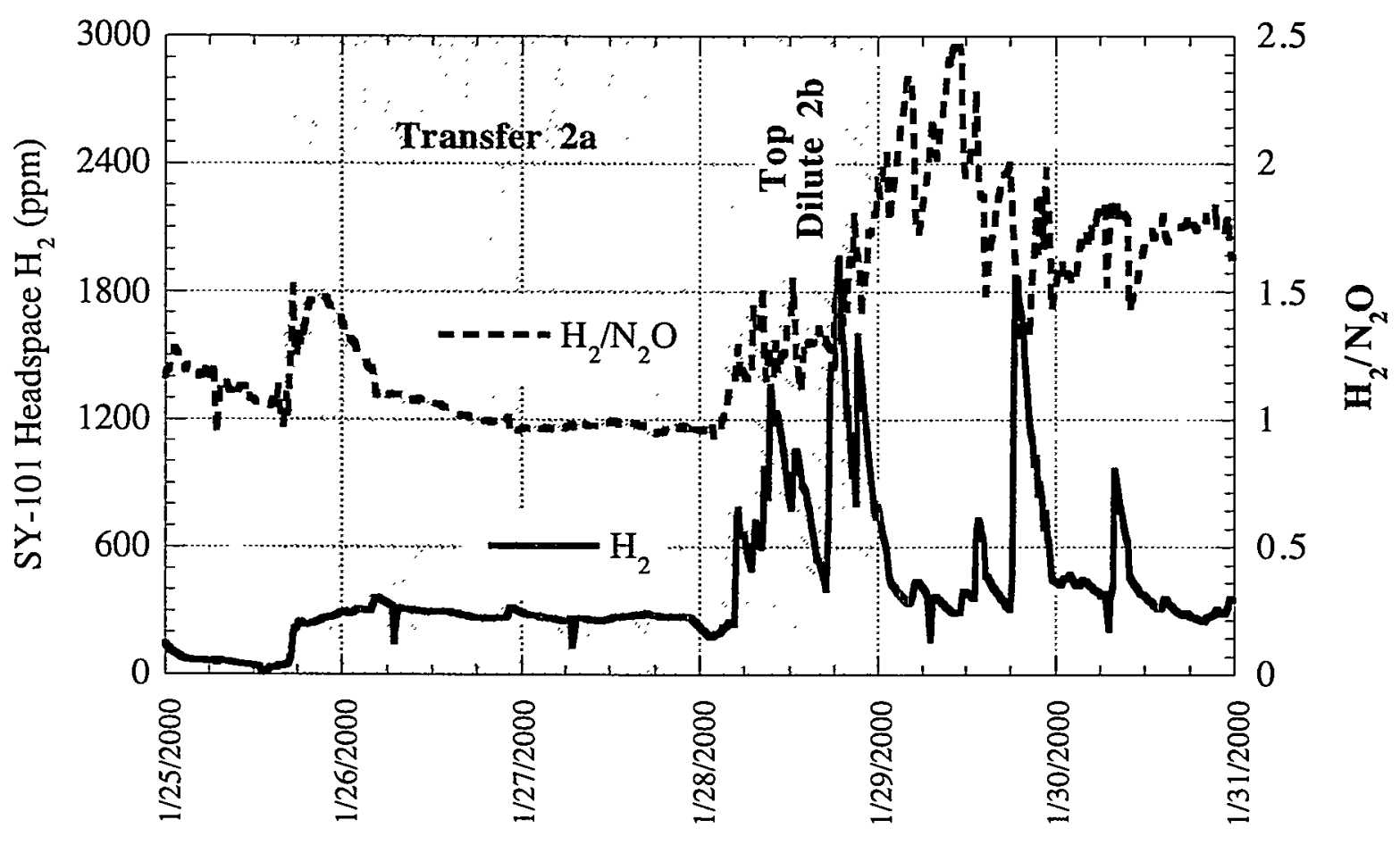

Figure 5.6. Hydrogen/Nitrous Oxide Ratio During Transfer 2a and Top Dilute 2b

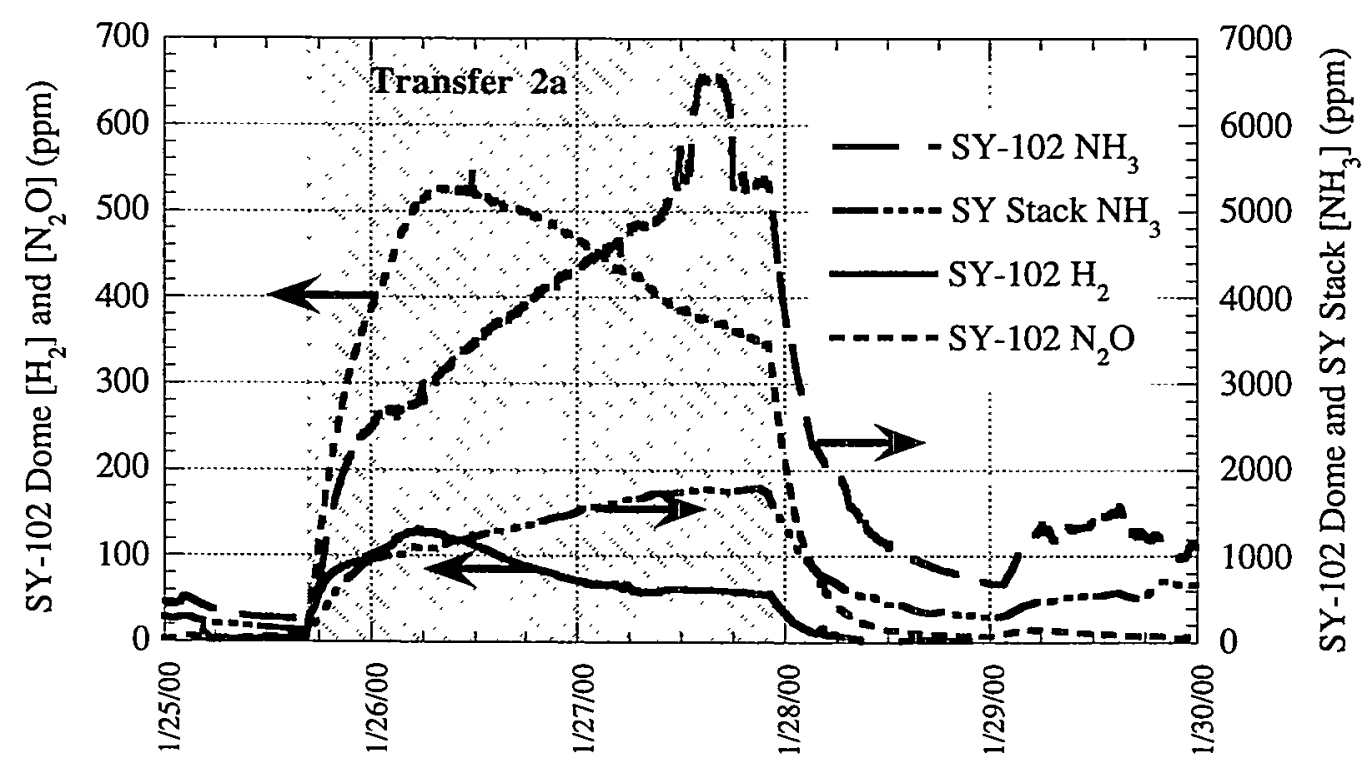

Figure 5.7. SY-102 Headspace Concentrations During Second Campaign 
Almost a month passed between top dilution $2 \mathrm{~b}$ and low dilution $2 \mathrm{c}$. Figure 5.8 shows the SY-101 hydrogen, nitrous oxide, and ammonia concentrations and the $\mathrm{H}_{2} / \mathrm{N}_{2} \mathrm{O}$ ratio between $2 \mathrm{~b}$ and 2c. Large gas releases ceased after February 1. Mixer pump runs produced small hydrogen and ammonia releases, both of which declined after the first week. The ambient ammonia concentration decreased from $600 \mathrm{ppm}$ to a little over $200 \mathrm{ppm}$ in the first week, probably from the depletion of ammonia in and the inhibiting effect of the "scum" layer of foam and crust remnants that formed in the few days after top dilution $2 \mathrm{~b}$. The $\mathrm{H}_{2} / \mathrm{N}_{2} \mathrm{O}$ ratio declined steadily to $1.0-1.2$ at the end of February.

\subsubsection{Second Low Dilution}

Low dilutions $2 \mathrm{c}$ and $2 \mathrm{~d}$ were accomplished about a day apart, causing similar gas releases. The gas concentrations in SY-101 are shown in Figure 5.9 and the $\mathrm{H}_{2} / \mathrm{N}_{2} \mathrm{O}$ ratio in Figure 5.10. The SY-101 ammonia concentration increased almost linearly throughout both low dilutions, peaking at just over $600 \mathrm{ppm}$ in $2 \mathrm{c}$ and about $550 \mathrm{ppm}$ in $2 \mathrm{~d}$. After low dilution $2 \mathrm{c}$, ammonia decayed exponentially. Top dilution $2 \mathrm{e}$ very quickly scrubbed ammonia from the headspace, but the concentration recovered immediately afterward. Apparently the top dilution volume was not sufficient to form a dilute cover layer that would have suppressed ammonia evaporation. The rise in ammonia during low dilution may be due to disturbance of the now soft and mobile "crust" by the plume of diluted liquid rising from the base of the transfer pump.

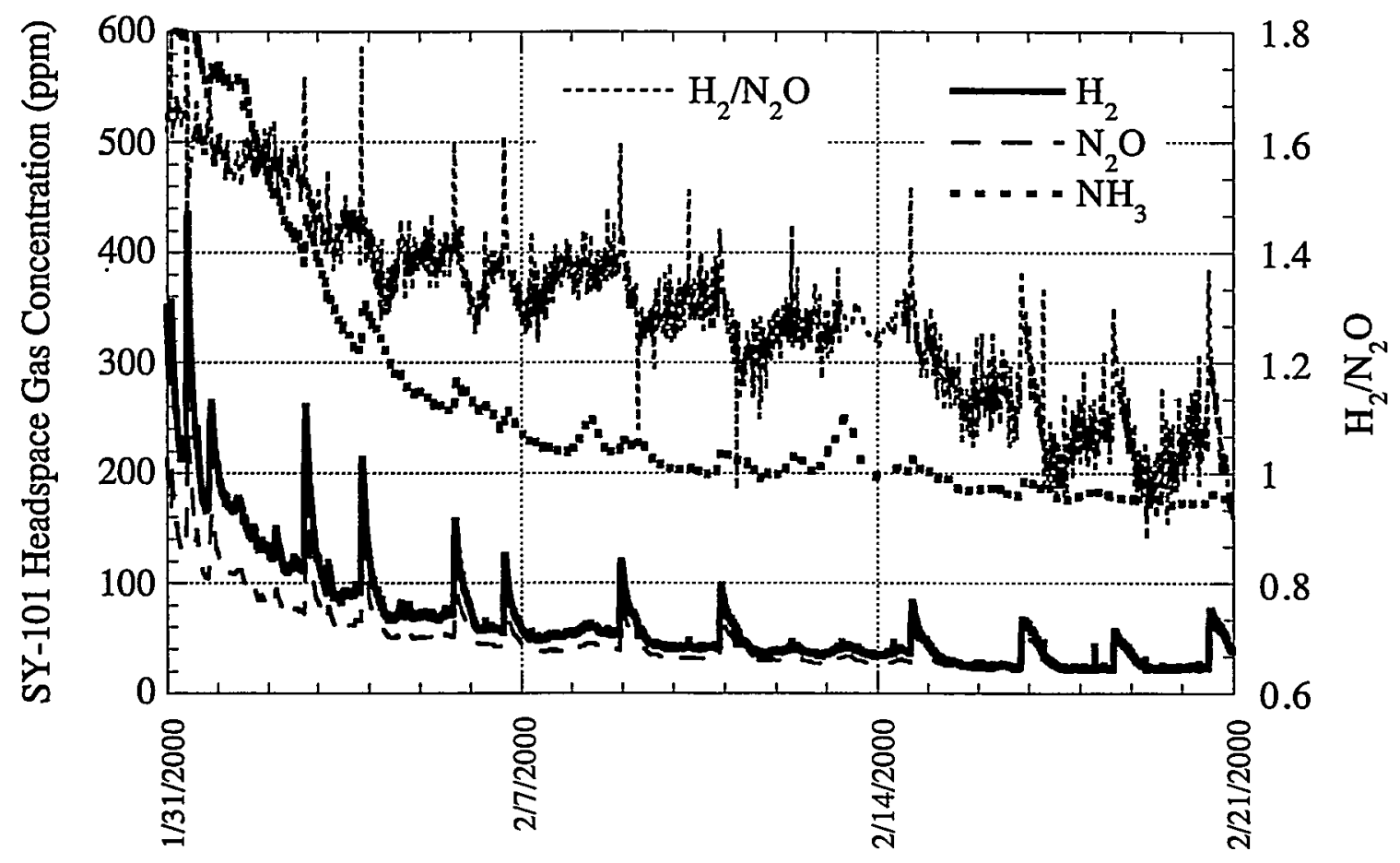

Figure 5.8. SY-101 Gas Concentration and $\mathrm{H}_{2} / \mathrm{N}_{2} \mathrm{O}$ Ratio After the Second Campaign 


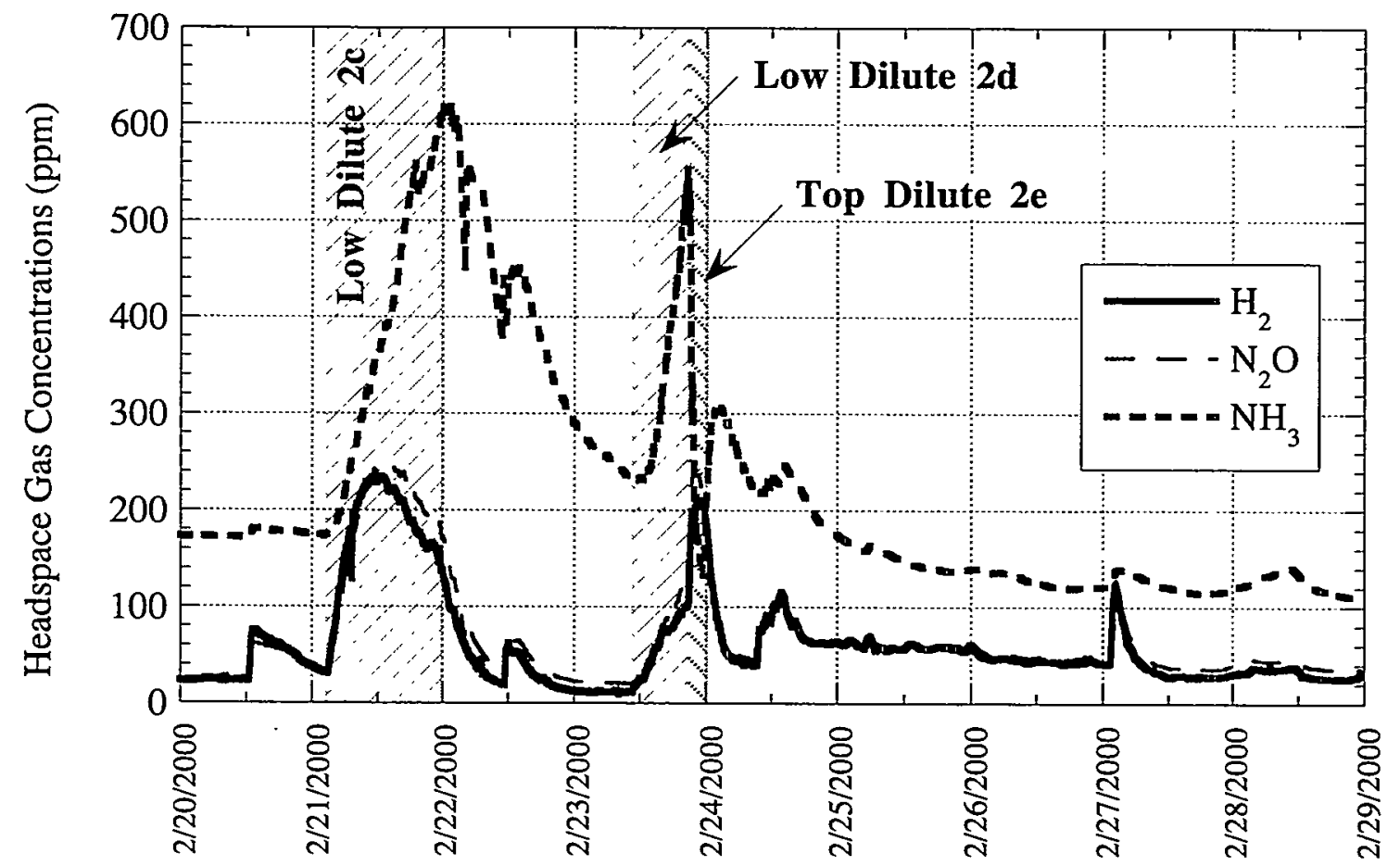

Figure 5.9. SY-101 Gas Concentrations During Dilutions $2 c-e$

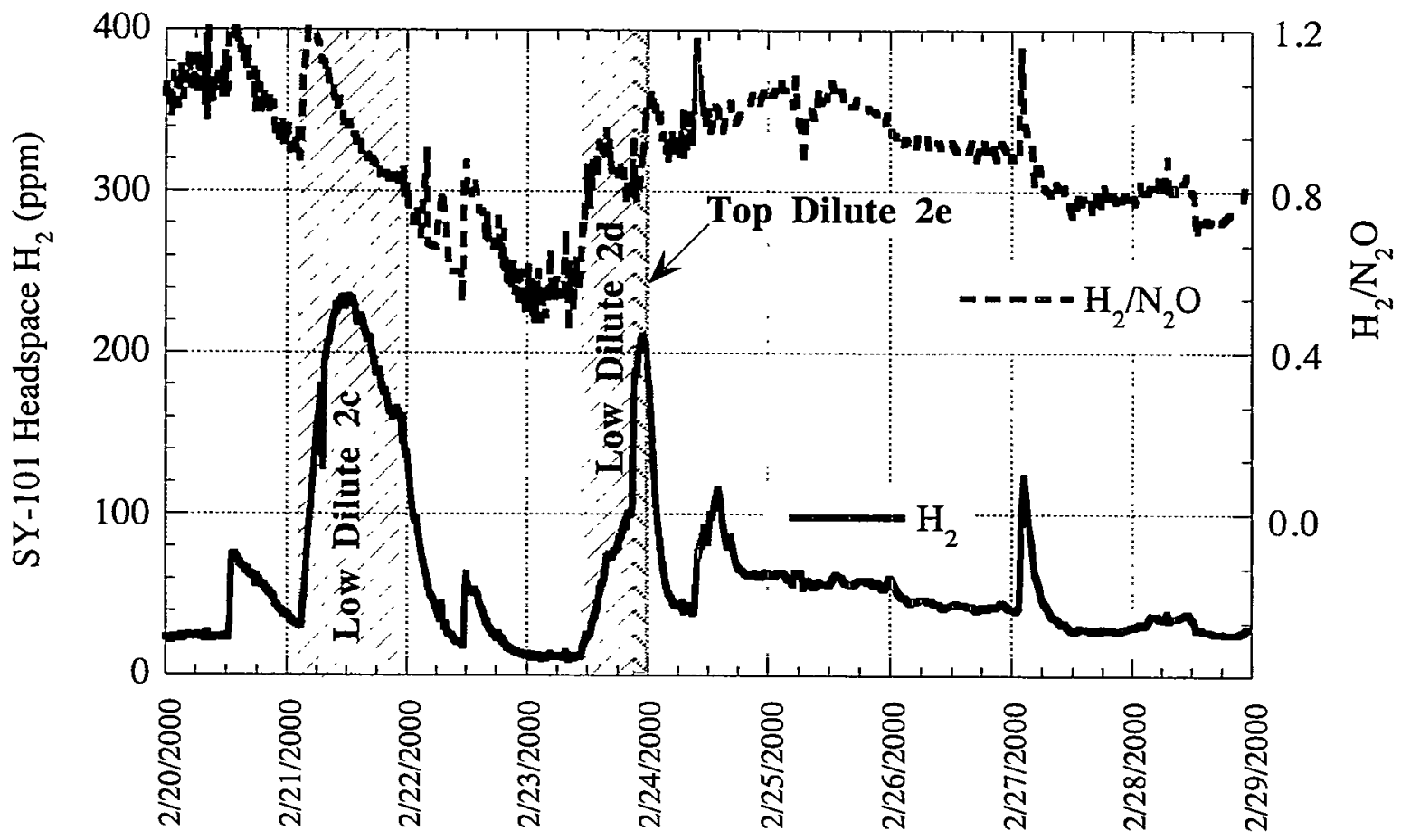

Figure 5.10. $\mathrm{SY}-101 \mathrm{H}_{2} / \mathrm{N}_{2} \mathrm{O}$ Ratio During Dilutions $2 \mathrm{c}-\mathrm{e}$ 
The hydrogen concentration rose significantly during low dilution, though it fell quickly to background between the two steps. The $\mathrm{H}_{2} / \mathrm{N}_{2} \mathrm{O}$ ratio increased briefly at the start of low dilution $2 \mathrm{c}$ but then dropped steadily to about 0.5 prior to $2 \mathrm{~d}$ (Figure 5.10). The hydrogen release could be attributed either to small bubbles in the mixed slurry finally being released, which is consistent with the low $\mathrm{H}_{2} / \mathrm{N}_{2} \mathrm{O}$ ratio, or by some additional dissolution of crust remnants. Crust remnant dissolution kept the hydrogen background concentration somewhat elevated for several days after the top dilution.

\subsection{Gas Releases During the Third Campaign}

The third and final campaign finished the dissolution of readily soluble solids and release of retained gas from SY-101 in preparation for the mixer pump evaluation period. Transfers $3 a-b$ brought the waste level down to 280 inches, the lowest yet attained. The transfer was done in two steps to avoid exceeding the limit of $100 \mathrm{lbm}$ per day of ammonia release. Back-dilution occurred ten days later with alternating large low dilutions ( $3 \mathrm{c}$ and $3 \mathrm{e}$ ) and smaller top dilutions ( $3 \mathrm{~d}$ and $3 \mathrm{f}$ ). Gas releases were relatively small and consistent with prior experience. A new feature of gas release behavior after the third campaign, however, was the series of modified mixer pump "tank sweeps," each with up to four 25 -minute runs at 1,000 rpm per day (in place of the programmed tank sweep of six 30 -minute runs at $750 \mathrm{rpm}$ ) for two weeks after the campaign.

Figure 5.11 shows the gas concentrations and $\mathrm{H}_{2} / \mathrm{N}_{2} \mathrm{O}$ ratio for transfers $3 \mathrm{a}-\mathrm{b}$ and a week afterward. Gas release was minimal during transfer $3 \mathrm{a}$ with hydrogen peaking at only $80 \mathrm{ppm}$ at the end. As new areas of the tank wall and mixer pump column were exposed during the second transfer step, however, both hydrogen and ammonia rose rapidly. Even after the large backdilutions of the second campaign, a thin layer of waste remained attached to the wall (see Section 2.3) that apparently released gas when exposed. The high ammonia spike late on March 6 is the result of a mixer pump run that was aborted after five minutes. The low waste level had exposed the vent hole on the flush ring. The resulting spray of waste into the headspace caused the high ammonia level.

The gas concentrations in SY-102 and SY-farm stack ammonia concentrations during the third transfer are shown in Figure 5.12. The ammonia concentrations followed the trends of the second transfer with a rapid rise to very high levels. SY-102 ammonia peaked at over 7,000 ppm during both transfer steps, while the SY-farm stack hit $2,000 \mathrm{ppm}$. During the second transfer ammonia reached $5,400 \mathrm{ppm}$ in SY-102 and $1,700 \mathrm{ppm}$ at the stack. The nitrous oxide concentration in SY-102 peaked at $700 \mathrm{ppm}$, compared with just over $500 \mathrm{ppm}$ in the second transfer. Hydrogen remained below $100 \mathrm{ppm}$ in both steps, somewhat lower than the $130 \mathrm{ppm}$ of the second transfer.

The higher ammonia and nitrous oxide concentrations during the third campaign were probably due to several factors. One was the use of a 0.33:1 in-line dilution ratio compared with $0.80: 1$ in the second campaign. The lower dilution provided less water to absorb ammonia in the line. The total flow rate was also higher in the third transfer, $200 \mathrm{gpm}$ compared with $140 \mathrm{gpm}$ in the second transfer. Perhaps most important was the increased concentration of ammonia in SY-102 from the two previous transfers from SY-101. 


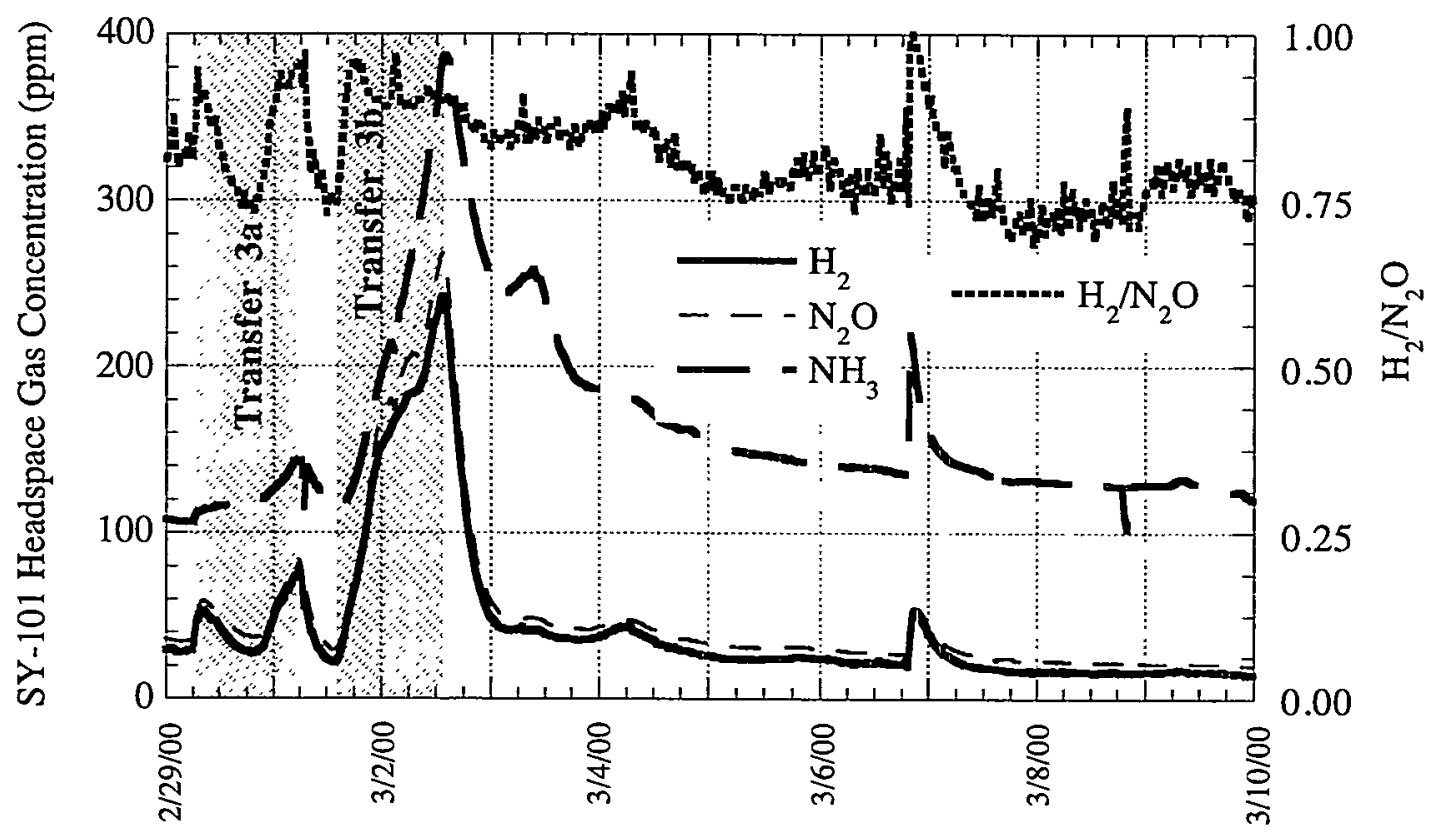

Figure 5.11. SY-101 Gas Concentrations and $\mathrm{H}_{2} / \mathrm{N}_{2} \mathrm{O}$ Ratio During Transfers 3a-b

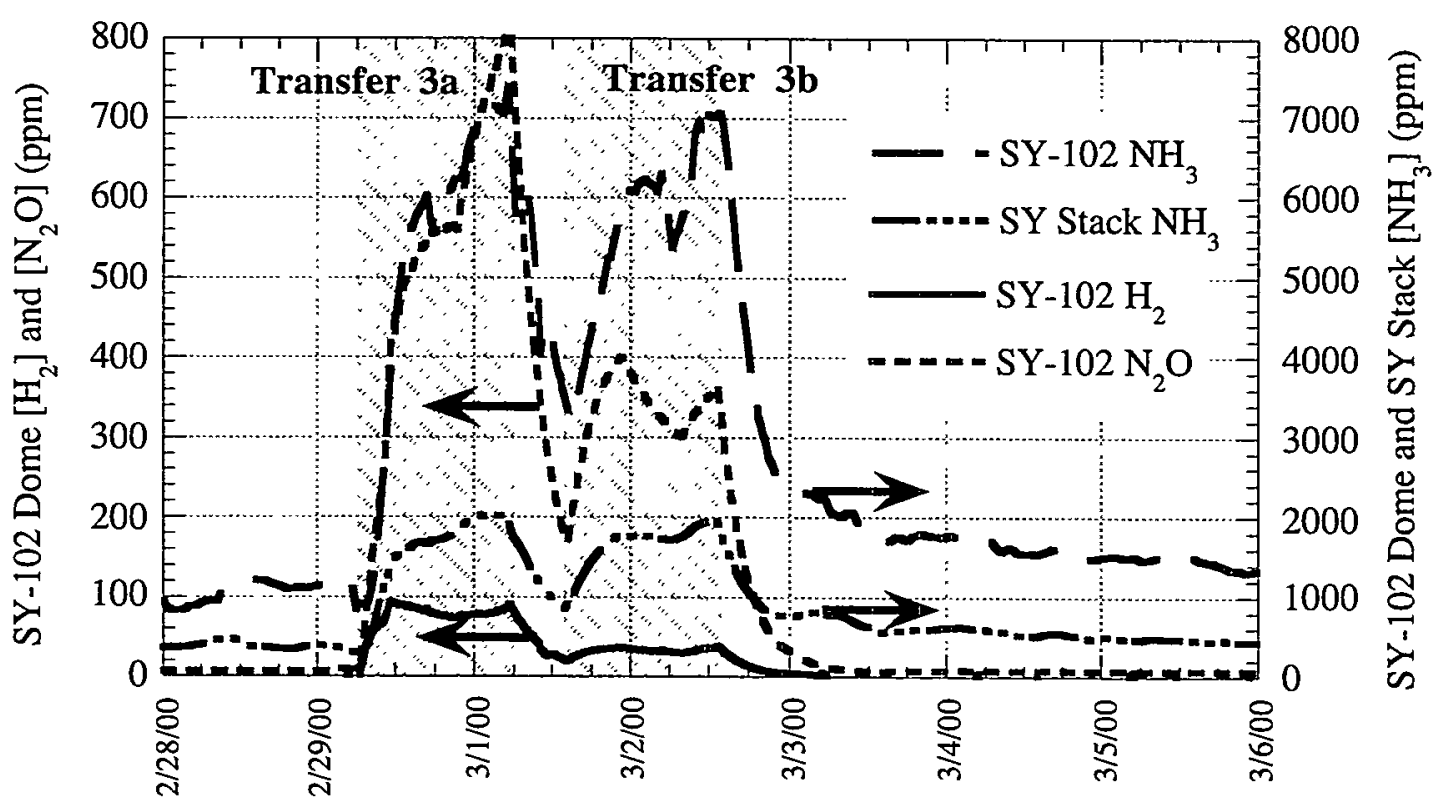

Figure 5.12. SY-102 Gas Concentrations During the Third Transfer 
The gas concentrations and $\mathrm{H}_{2} / \mathrm{N}_{2} \mathrm{O}$ ratio in SY-101 for the back-dilution period and for the two weeks afterward are shown in Figures 5.13 and 5.14, respectively. Ammonia rose with each low dilution but was scrubbed back out during each top dilution. The hydrogen concentration rose with each operation, significantly in the last top dilution, $3 \mathrm{f}$, to a peak of just over $400 \mathrm{ppm}$. The $\mathrm{H}_{2} / \mathrm{N}_{2} \mathrm{O}$ ratio increased with the hydrogen from 1.0 to over 2.0 at the end of top dilution $3 f$. This indicates that gas-retaining waste was being dissolved, possibly some of the material still attached to the tank wall. The new "crust" remained floating during dilution and probably did not dissolve very much. The hydrogen and nitrous oxide background releases remained elevated for almost a week, a sign that dissolution continued during that time. The aggressive pump sweeps also raised gas concentrations for almost half a day each. The combined result was to release 2,500 scf of gas, almost as much as during top dilution $2 \mathrm{~b}$.

\subsection{Summary of Gas Release Behavior}

Within the combined uncertainty of the measurement and prediction, all the gas retained in SY-101 was released during the three remediation campaigns plus the two-week period after the last dilution. The greatest gas release occurred during dissolution of the crust layer. Mixer pump operation also contributed to the total gas release, especially during the tank sweeps after the third campaign, and mixed the back-dilution water with the waste. The highest gas concentration was the 7,000 ppm ammonia that occurred in SY-102 during the third transfer. The highest hydrogen concentration was almost 3,000 ppm observed in SY-101 as a result of the bubble slurry flows during the second top dilution.

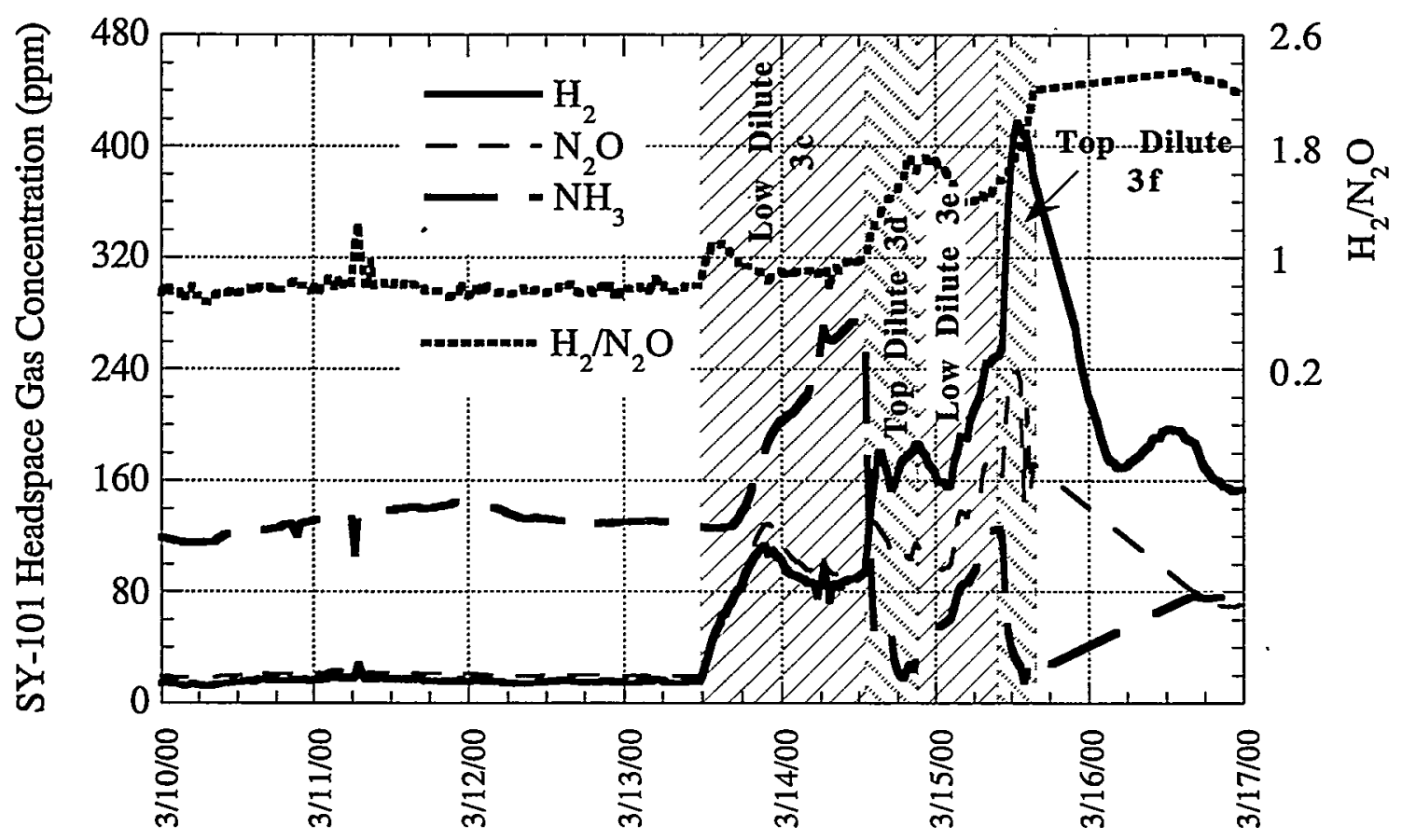

Figure 5.13. SY-101 Gas Concentrations and $\mathrm{H}_{2} / \mathrm{N}_{2} \mathrm{O}$ Ratio During Dilutions $3 \mathrm{c}-\mathrm{f}$ 


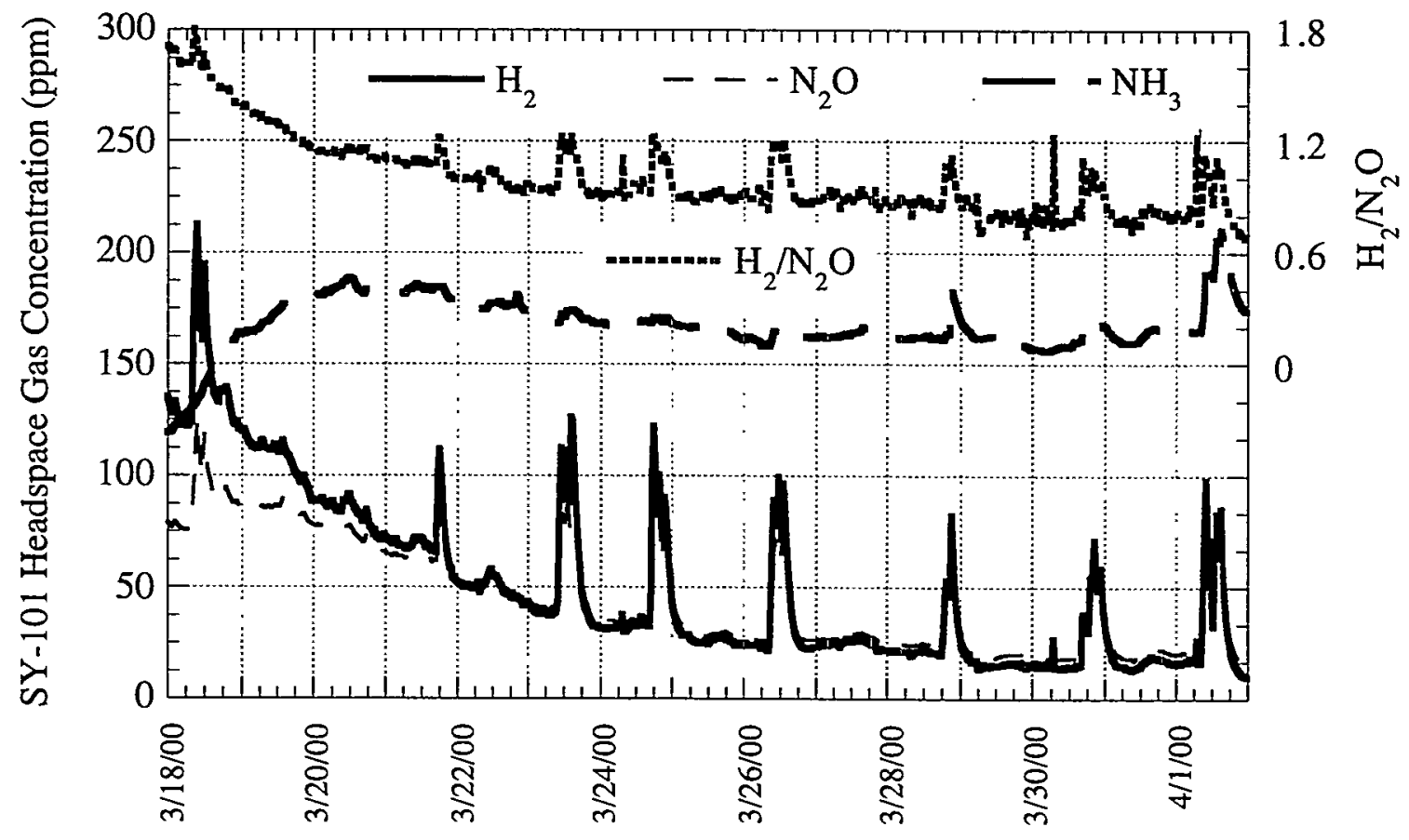

Figure 5.14. SY-101 Gas Concentrations and $\mathrm{H}_{2} / \mathrm{N}_{2} \mathrm{O}$ Ratio After the Third Campaign

Based on tank data and visual evidence, gas releases appeared to occur by the mechanisms that were predicted and analyzed. These mechanisms included, mainly during the second top dilution, bubble slurry flows, wasteberg capsize, crust sinking, and straight dissolution. But, also as predicted, these events occurred in only a small part of the crust and did not create hazardous concentrations. The "landslides" of attached crust from the tank walls caused comparatively little gas release. As expected, a foam or "scum" layer covered the waste surface after the crust layer dissolved. This reduced ammonia evaporation and controlled background ammonia concentrations in SY-101. 


\subsection{Temperatures}

The waste temperature data in SY-101 were useful in monitoring the effects of top dilution on the crust and of low diluent mixing in the slurry layer. In many cases, the temperature data gave the best overall picture of what was actually occurring in the tank. The temperature profile in SY-102 was used to assess whether solids transferred from SY-101 were accumulating on the bottom.

Temperature profiles have long been the primary source of information on the configuration of the waste in a tank. Thermal convection keeps the temperature uniform in a liquid. The temperature gradients arising from heat conduction in a nonconvective solids layer cause a linear or parabolic temperature profile. The elevation where the temperature profile changes shape identifies the layer boundaries. Since convection is also inhibited between, but not within, layers of different densities, the temperature profile also reveals stratification. Finally, because dilution water was usually colder (except in the first low dilution) than the waste, the temperature profile can also detect where the water-diluted liquid resides.

Temperatures in SY-101 are measured on two MITs. The MIT in riser 17C is on the southeast side of the tank close to the transfer pump and therefore is the first to feel the effects of top or low dilution (see Figure 1.1). The other MIT in riser 17B is about one tank radius from 17C on the north side of the tank. Each MIT has 22 thermocouples spaced 12-24 inches apart, with the lowest thermocouple four inches above the tank bottom. Data are recorded every 12 seconds by the DACS. Temperatures are monitored in SY-102 on a single thermocouple tree and are recorded manually once per day. There are 18 thermocouples spaced $24-48$ inches apart.

In SY-101, a validation probe consisting of a resistance temperature device (RTD) attached to a weight is periodically lowered down an internal tube in the MIT, which provides temperature readings every four inches. However, no validation probe data were available during the remediation sequence.

The waste temperature behavior during each of the three campaigns is discussed in Sections 6.1, 6.2 and 6.3, respectively. The changing temperature profiles in SY-102 are described in Section 6.4 to measure the depth of solids added by transfers from SY-101. Section 6.5 summarizes the temperature data.

\subsection{Temperature Behavior During the First Campaign}

In the first campaign, the behavior of the dilution water was of considerable interest. Top dilution water was predicted to penetrate through the "dry" crust freeboard and flow out radially across the tank over the heavier saturated salt solution at free liquid level. During this time, the water was also predicted to exert a buoyant force that would lift the crust almost as effectively as low dilution. Once the water had dissolved sufficient solids from the freeboard to form a mixture more dense than the crust but still lighter than the saturated salt solution below, it was expected to flow down through the crust and form a dilute layer between the crust base and saturated salt solution. Low dilution was expected to have little effect other than raising the 
crust. Before the first campaign it was not certain whether these expectations would be met or how fast the events would occur. The temperature data clearly showed that the dilution effects matched the predictions.

Figures 6.1 and 6.2 show the temperature transients during the first campaign for six thermocouples in the crust region at the MITs in $17 \mathrm{~B}$ and $17 \mathrm{C}$, respectively. The temperature decrease at 292 to 364 inches on 17B and 292 to 340 inches at $17 \mathrm{C}$ during the transfer results from the thermocouples being exposed to progressively cooler material as the crust descends. Note in Figure 6.1 that the temperature at 340 inches becomes equal to the initial temperature at $364^{\circ}$ inches at 11:00 PM on December 18, indicating the crust had descended 24 inches. This is almost exactly the level change measured visually on the 17B MIT at this time (see Figure 3.5). A similar match can be shown with the 316- and 340-inch thermocouples on 17B and the 292and 340-inch thermocouples on $17 \mathrm{C}$.

Just as the temperatures decreased when the crust descended during transfer, the temperatures increased as the crust was raised by back-dilution. Figures 6.1 and 6.2 show that, after a two-hour delay, top dilution $1 \mathrm{~b}$ lifted the crust, though not as strongly as low dilution $1 \mathrm{c}$.

Of particular interest is the sudden, dramatic temperature drop at the 292-inch thermocouple on $17 \mathrm{~B}$ and the 268 -inch thermocouple on $17 \mathrm{C}$ with the drop at $17 \mathrm{C}$ beginning about an hour before $17 \mathrm{~B}$. Because the top-dilution water was added at $80^{\circ} \mathrm{F}$, this is clear evidence that topdilution water had penetrated below the crust at this time. The equally steep temperature rise in

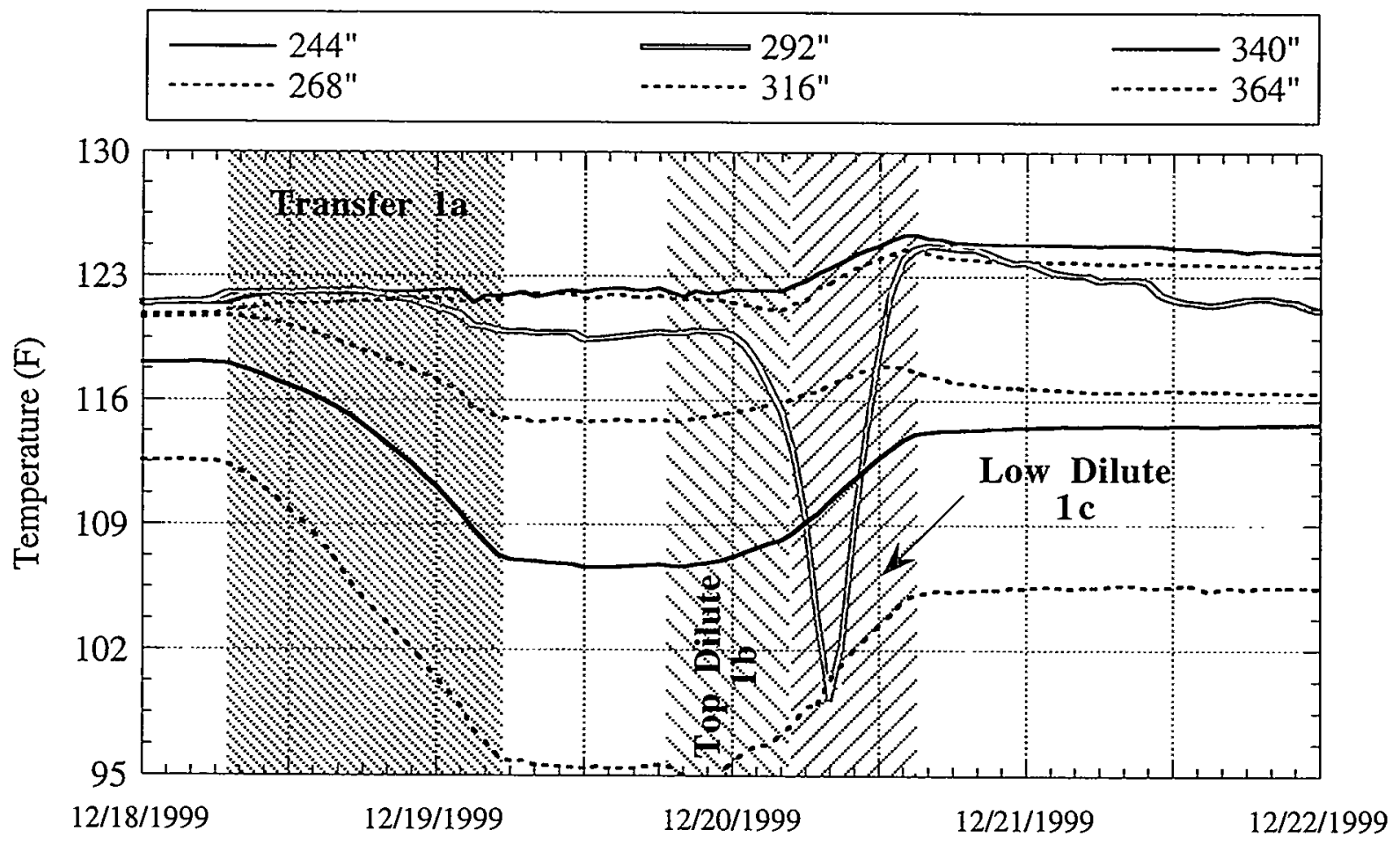

Figure 6.1. Crust Temperature at 17B During the First Campaign 


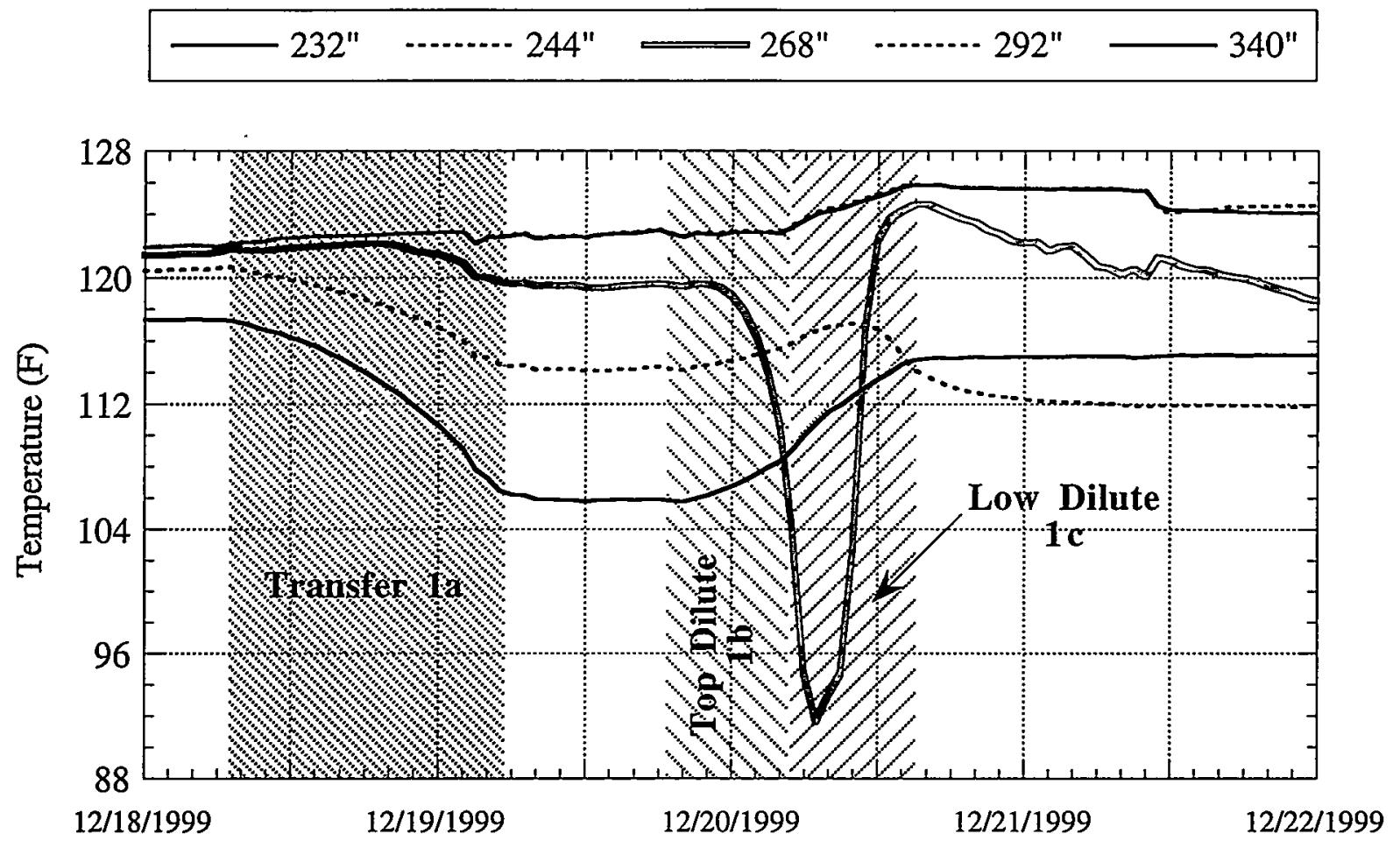

Figure 6.2. Crust Temperature at $17 \mathrm{C}$ During the First Campaign

the middle of low dilution $1 \mathrm{c}$ is simply a result of the cold, dilute mixture being lifted above the thermocouple. However, the small decreases in the temperatures at 316 inches on 17B and $292^{\circ}$ inches on $17 \mathrm{C}$ indicate the cold water layer was approaching those elevations at the end of low dilution.

Figures 6.3 and 6.4 present the temperature transient below the crust at $17 \mathrm{~B}$ and $17 \mathrm{C}$, respectively, for the same period as the first two figures. The most dramatic feature of these plots is the steep rise in temperature during low dilution of as much as $4^{\circ} \mathrm{F}$ above the initial values. Because the in-line dilution water was added at a maximum of $122^{\circ} \mathrm{F}$, very close to the existing slurry temperature, the increase is thought to have resulted from the heat of solution of solids in the mixed slurry or the dilution of the liquid in the slurry by water. The sudden temperature drops on December 21, 23 and 26 are the result of mixer pump runs. Each pump run brings the slurry temperatures closer together until they become essentially uniform between 100 and 244 inches after the third run.

The temperatures increased very uniformly above the low-dilution injection point at the 96-inch elevation. Apparently, the buoyant dilution water mixed completely with the waste above the injection point, as expected. The pump run on December 21, 1999 mixed the slurry above and below the water injection point, with some residual stratification. Note also the smaller temperature increase above 100 inches during the transfer. This may have been caused by heat of solution from a small bypass or leak of in-line dilution water. During transfer, the temperature of the waste stream after a 0.9:1 in-line dilution was $132^{\circ} \mathrm{F}$, also considerably higher than either the waste or water, which were both at about $122^{\circ} \mathrm{F}$. The bypass or leakage volume 
cannot be quantified precisely, but either condition would reduce the actual dilution ratio during transfer, removing slightly more waste and adding slightly more water than the values given in Table 1.1.

The heat of solution per mole of water added was calculated based on an hourly heat balance. The mixed slurry enthalpy based on the measured temperatures at riser 17B was compared to the enthalpy expected from sensible heat alone, based on known waste and water temperatures. Heat capacities of $4180 \mathrm{~J} / \mathrm{K} \mathrm{kg}$ for water, $2200 \mathrm{~J} / \mathrm{K} \mathrm{kg}$ for brine, and $1980 \mathrm{~J} / \mathrm{K} \mathrm{kg}$ for slurry were used. $^{\text {(a) }}$ The excess temperature was found to be $2^{\circ}$ to $3^{\circ} \mathrm{F}$.

The estimated heat of solution was very sensitive to the assumptions of how much topdilution water flowed under the crust and participated in dissolving slurry solids. The $17 \mathrm{C}$ temperature data could not be used because there was so much cold fluid from the top dilution. Estimates based on $17 \mathrm{~B}$ data ranged from 1 to $11 \mathrm{~kJ} /$ mole $\mathrm{H}_{2} \mathrm{O}$, with the higher values occurring earlier in dilution.

When calculations were made with the $\operatorname{ESP}^{\mathrm{a}}$ equilibrium model, the excess heat was calculated to be about $35 \mathrm{~kJ} / \mathrm{mol} \mathrm{H}_{2} \mathrm{O}$ for a $1: 1$ dilution of SY-101 waste. ${ }^{(b)}$ The largest

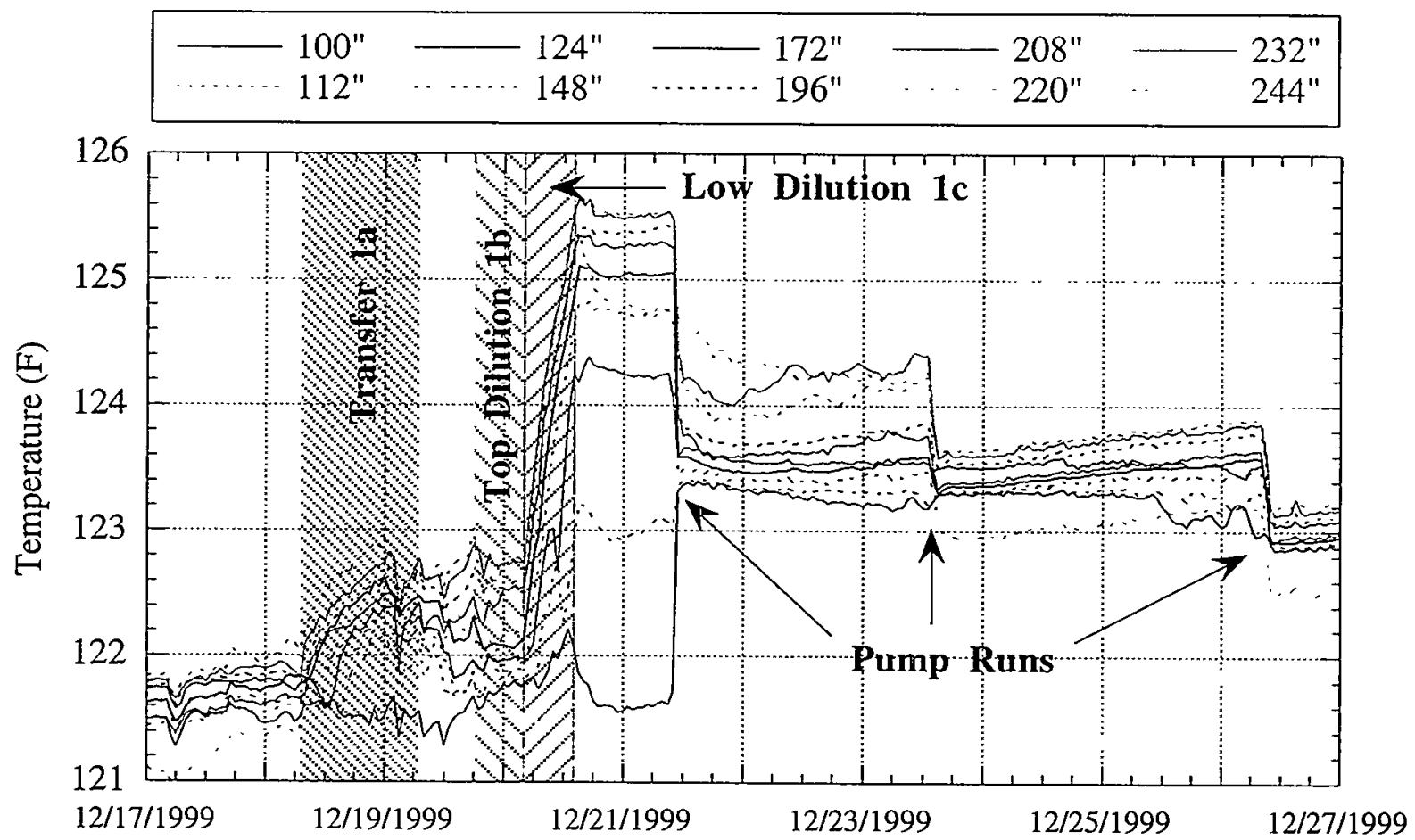

Figure 6.3. Mixed Slurry Temperature at 17B During the First Campaign

(a) The brine and slurry values were calculated from the algorithms in Section 10 of Mahoney and Trent (1995) using the known concentrations of dissolved and undissolved solids.

(b) Reynolds DA. 1999. Enthalpy Changes Expected from Dilution of Tank 241-SY-101 Waste. Letter 74B50-99-042 to N.W. Kirch, Lockheed-Martin Hanford Corp., Richland, Washington. 


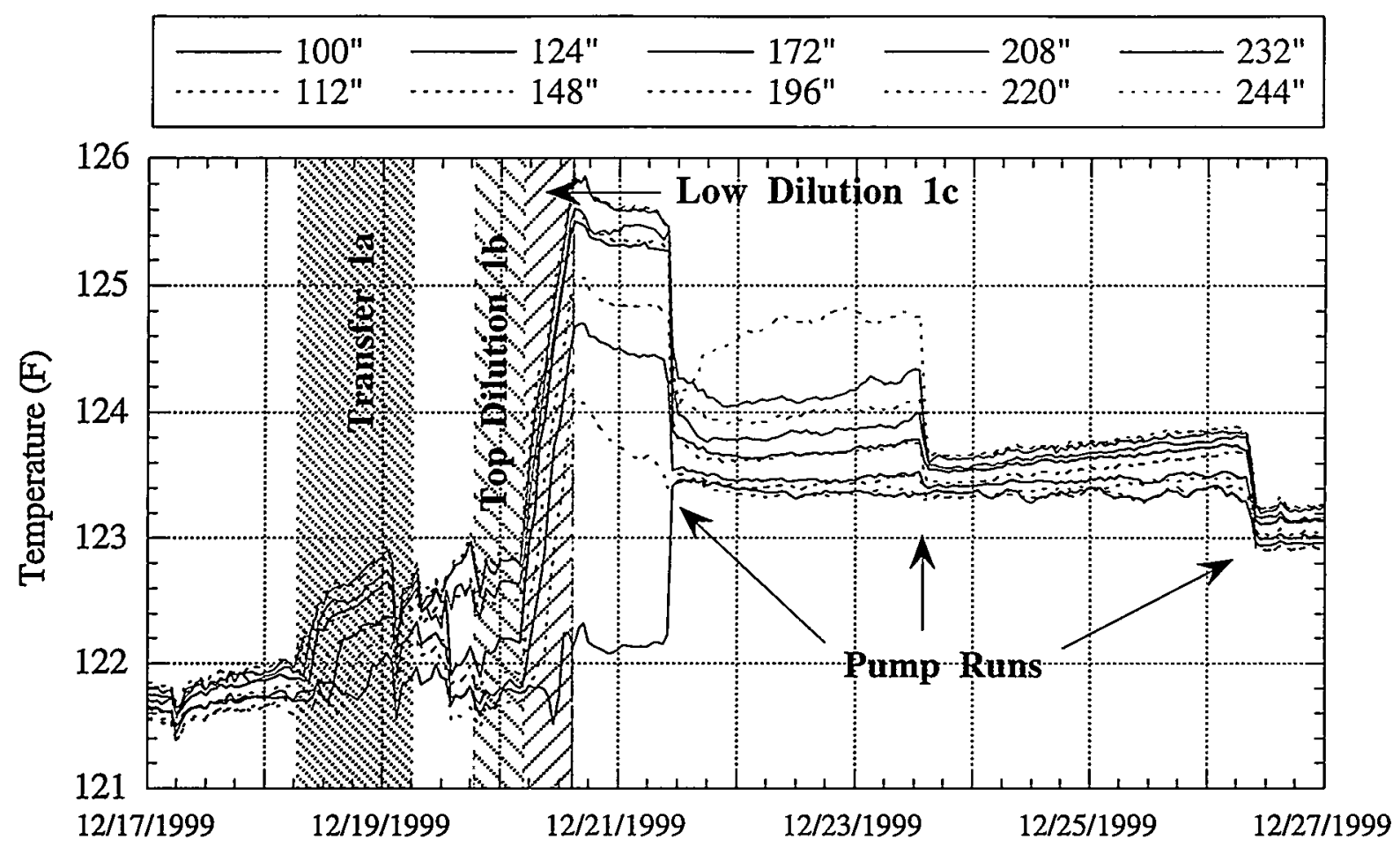

Figure 6.4. Mixed Slurry Temperature at 17C During the First Campaign

contributors to the exothermic heat of solution were aluminum hydroxides; the major constituents, sodium nitrite and nitrate, had endothermic heats of solution. Heat of dilution of the sodium hydroxide was probably not a contributor; at the relatively low concentration in SY-101, 2 to 3 M, sodium hydroxide dilution is endothermic (Perry and Chilton 1973).

Figures 6.5 and 6.6 depict the progress of temperature changes at riser $17 \mathrm{~B}$ and $17 \mathrm{C}$ as color contour plots with the temperature indicated by color. The $y$-axis is elevation and the $\mathrm{x}$-axis is time. The slope of the green band on the left of the plots indicates the lowering of the crust by waste transfer as discussed above. The rise of the crust due to back-dilution can also be seen. The green eye at top center of the plot shows the down flow of relatively cold top dilution water through the crust.

The white region in the right center of the plot is the effect of the heat of dilution as water was added during low dilution 1c. The abrupt cutoff of the white area is the result of the first full 25-minute mixer pump run after the campaign. Somewhat less evident is the presence of a cold layer under the crust that persisted after dilution. The thickening of the orange region (compared with pre-transfer conditions) indicates this lower temperature, dilute stratum left over from topdilution) in Figure 6.5. The dilute layer is much clearer at $17 \mathrm{C}$, as shown by the yellow-toorange layer from 290 to 340 inches on the right side of Figure 6.6. The cold layer was eventually absorbed into the mixed slurry in mid-January after several pump runs. 


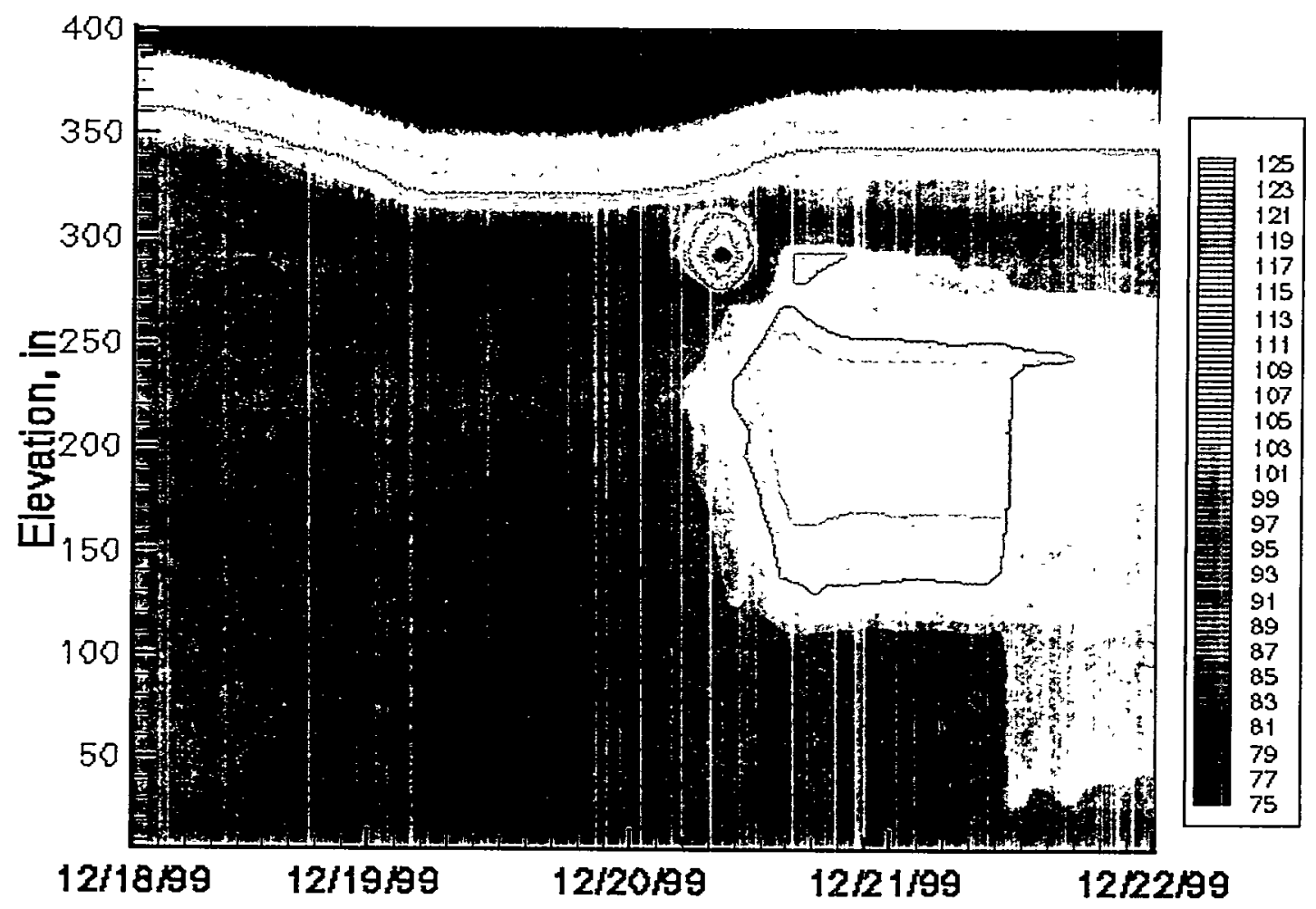

Figure 6.5. Temperature Profile History at 17B During the First Campaign

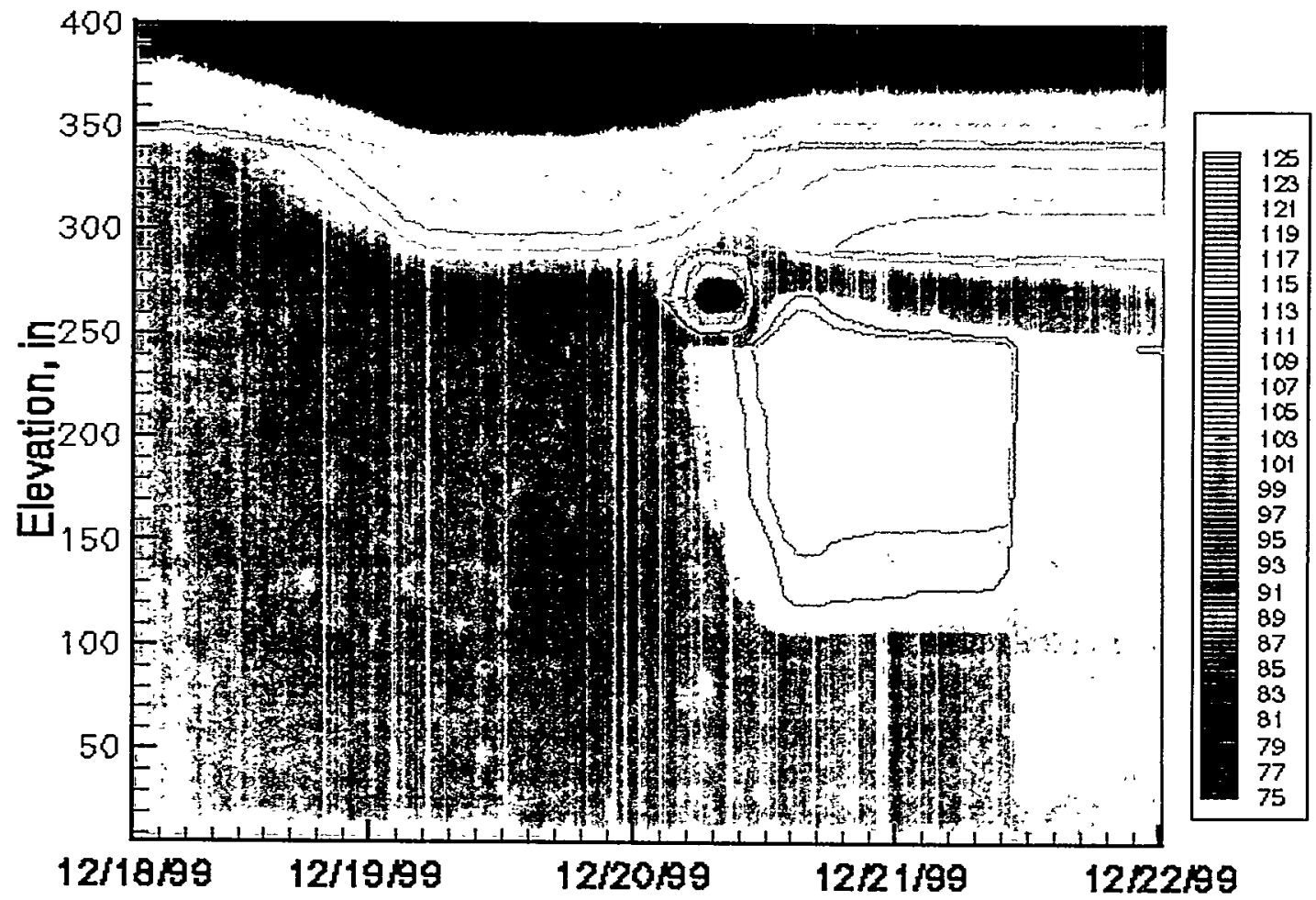

Figure 6.6. Temperature Profile History at $17 \mathrm{C}$ During the First Campaign 


\subsection{Temperature Behavior During the Second Campaign}

The temperature data for the first part of the second campaign reveals the dynamics of crust dissolution during top dilution $2 \mathrm{~b}$. During the top dilution, crust sinking, "wasteberg" capsize, and "landslides" of attached waste from the tank wall can be identified in the temperature histories. During dilutions $2 \mathrm{c}-\mathrm{e}$, cooling and mixing of the waste are the main events. Section 6.2.1 describes the transfer (2a) and top dilution (2b), and Section 6.2.2 discusses the following low dilutions (2c-d) and small top dilution (2e) performed a month later.

\subsubsection{Second Transfer and Top Dilution}

The temperature histories of the upper half of the waste column at $17 \mathrm{~B}$ and $17 \mathrm{C}$ during the second transfer $2 \mathrm{a}$ and top dilution $2 \mathrm{~b}$ are shown in Figures 6.7 and 6.8 , respectively. The temperatures decreased smoothly during the transfer as each thermocouple was exposed to progressively cooler waste just as in the first transfer. At 17B, temperatures increased as the crust began to rise with top dilution but fell back during the afternoon of January 28. Bubble slurry flows and notable gas releases began about this time (see Section 2.2 and Figure 5.5).

Just before top dilution ended, a large section of crust in the vicinity of 17B apparently turned over abruptly and sank. This is shown in Figure 6.7 by the sudden reversal of temperatures at 292 inches and 196 inches (and those in between). This event was also accompanied by a considerable gas release and appearance of bubble slurry on the surface (see Figure 5.5). The upper and lower temperatures reversed again on the morning of January 30, apparently as some of the remains of the crust floated again. Another noteworthy gas release occurred just after noon, accompanied by a rapid increase in the ammonia concentration as a more concentrated solution came to the surface (see Figure 5.5).

At $17 \mathrm{C}$, it appears that the crust also submerged but more gently and without turning over. This occurred early in the second top dilution, as shown in Figure 6.8 by the steep temperature drop, first at 244 and 232 inches and then at 220 and 208 inches about an hour later. This was followed by a smaller drop at 196 inches. Shortly afterward the temperatures at 244 and 268 inches increased, possibly indicating warmer fluid rising from below.

Figure 6.9 shows a plot of the temperature histories in the lower part of the tank during transfer $2 \mathrm{a}$ and top dilution $2 \mathrm{~b}$. The "landslide" of waste from the wall early in top dilution is particularly dramatic. The in-tank video showed a large splash across the tank originating from the southeast tank wall adjacent to $17 \mathrm{C}$. The waste apparently flowed down the wall and across the tank bottom on top of the existing settled layer. The colder material suddenly reduced the temperature on the 28 -inch thermocouple at $17 \mathrm{C}$. The thermocouples immediately above and below began a cooling trend. A similar temperature drop occurred near the end of top dilution at the 76-inch thermocouple. However, the rapid recovery of the temperature and minor effect on adjacent thermocouples probably indicates a different phenomenon. Landslides that may have occurred at 17B did not affect the thermocouples. 


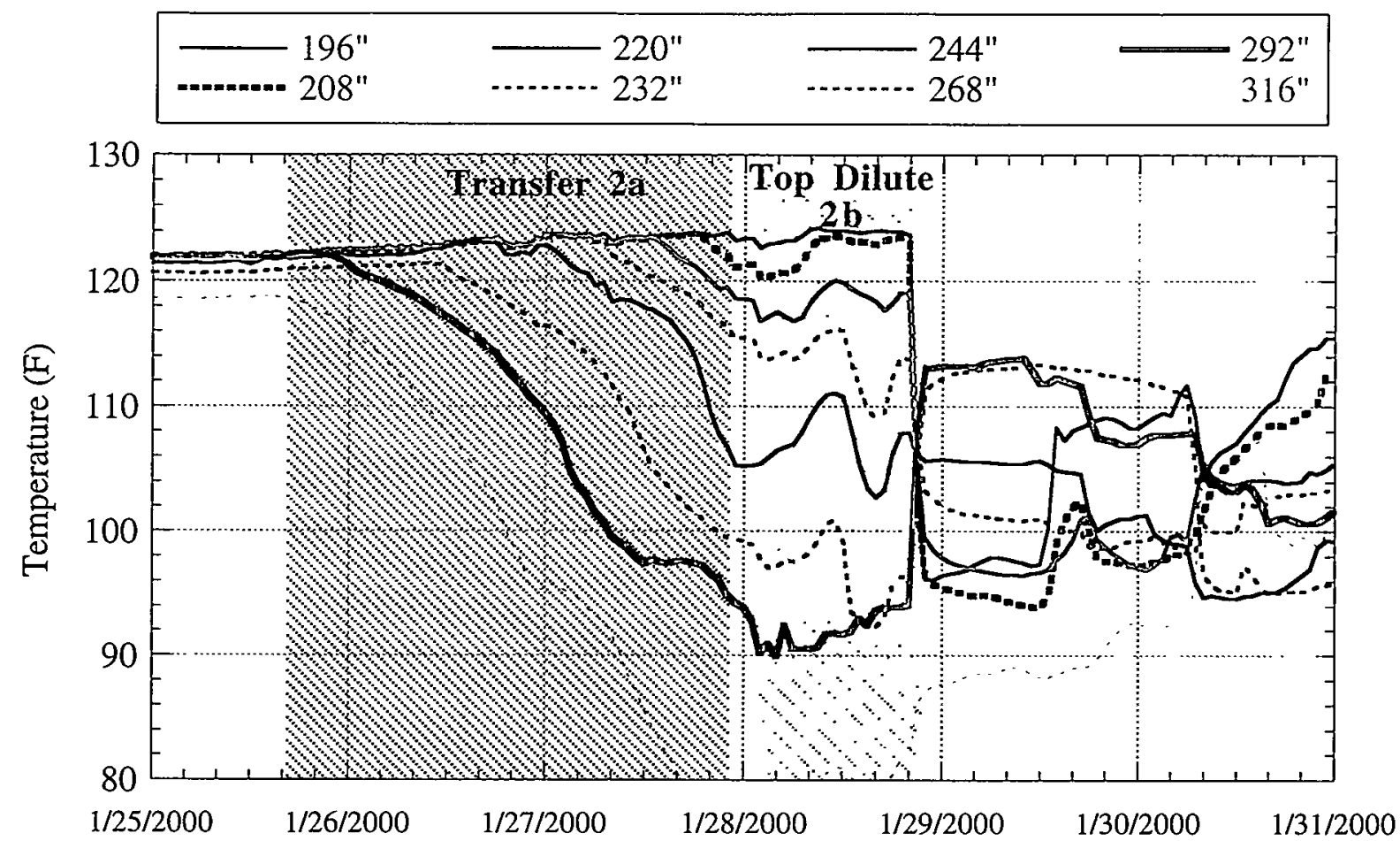

Figure 6.7. Upper Temperatures at 17B During Transfer $2 \mathrm{a}$ and Top Dilution $2 \mathrm{~b}$

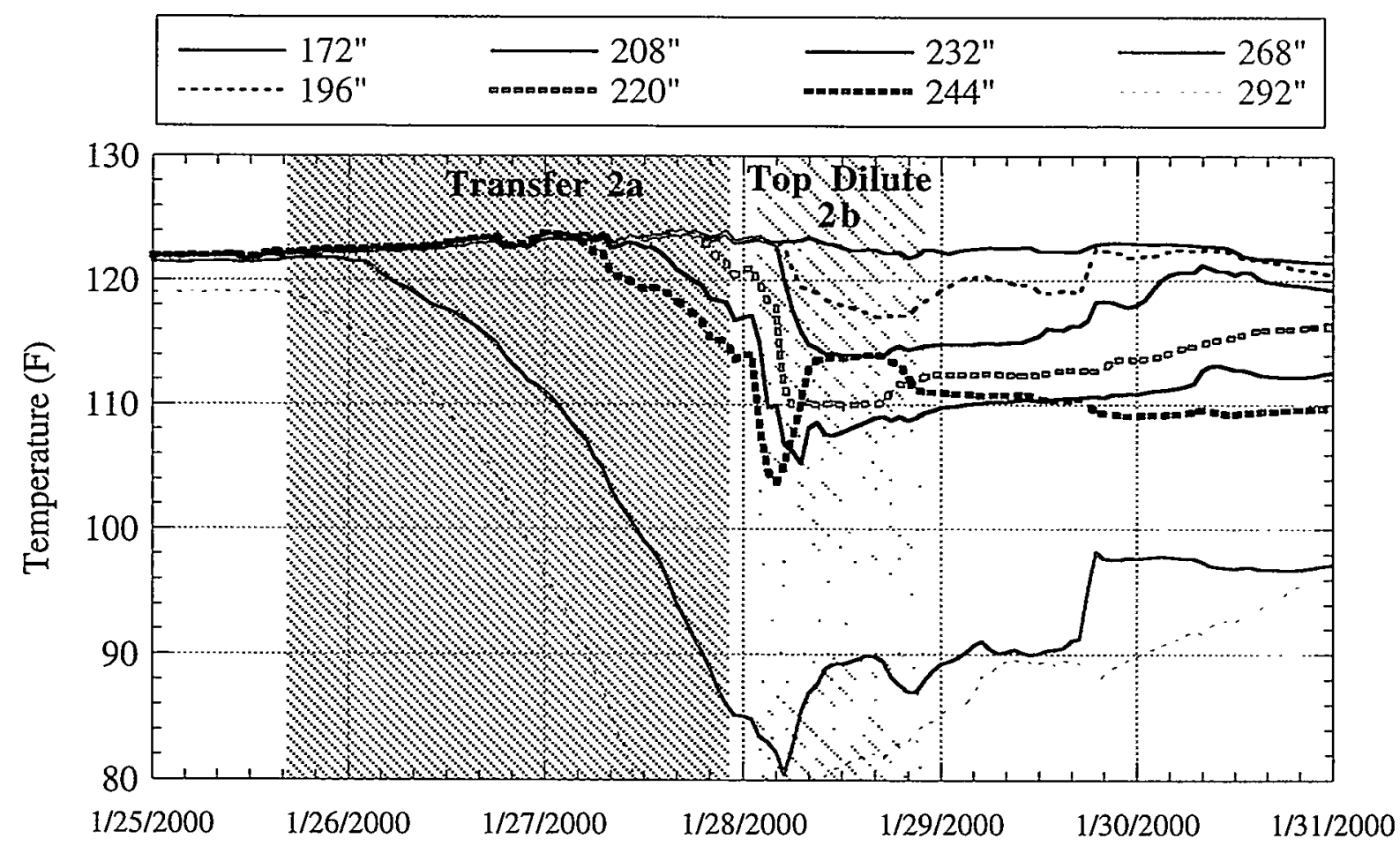

Figure 6.8. Upper Temperature at $17 \mathrm{C}$ During Transfer $2 \mathrm{a}$ and Top Dilution $2 \mathrm{~b}$ 


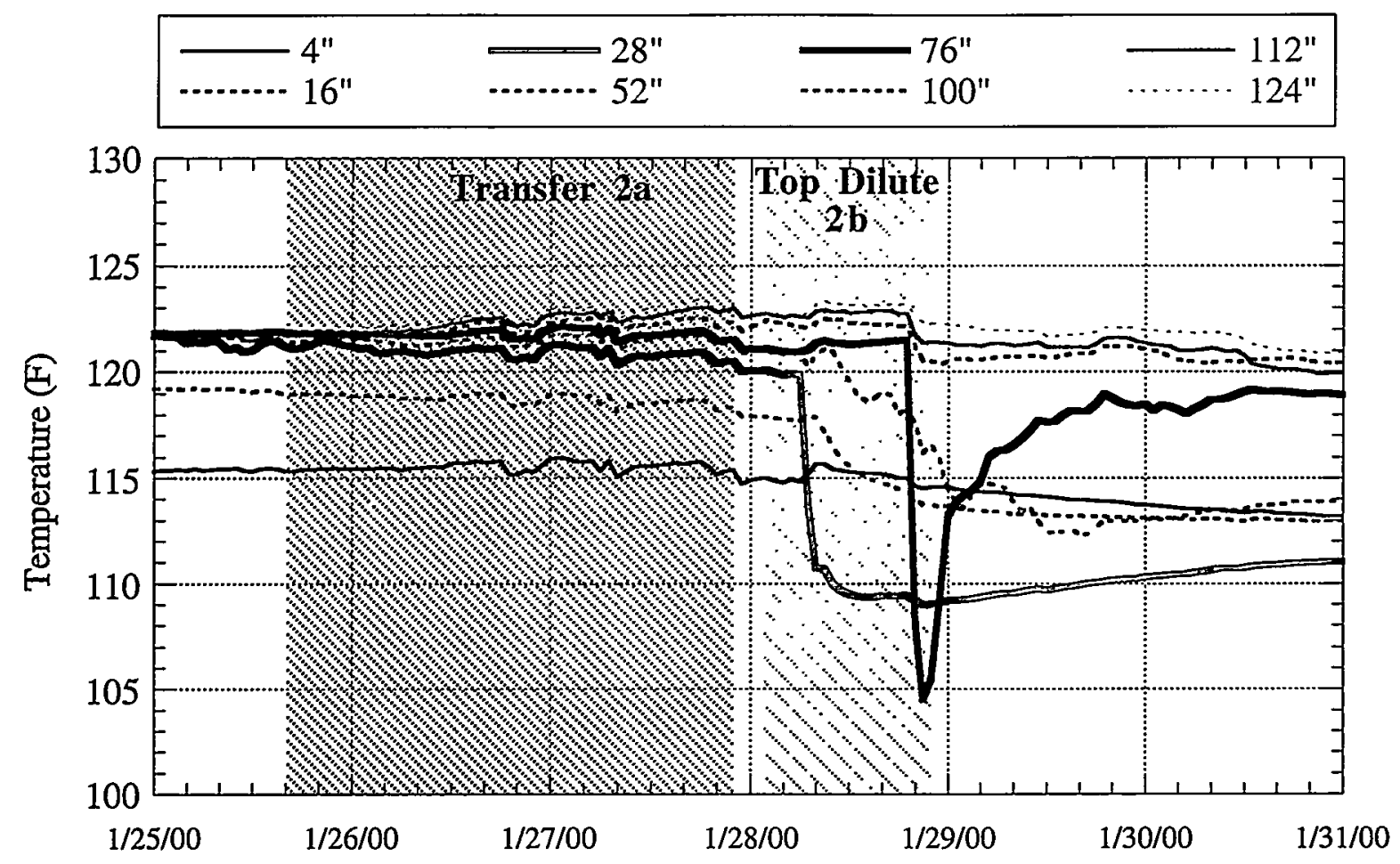

Figure 6.9. Lower Temperatures at $17 \mathrm{C}$ During Transfer $2 \mathrm{a}$ and Top Dilution $2 \mathrm{~b}$

Figures 6.10 and 6.11 show the temperature profiles as color contours at $17 \mathrm{~B}$ and $17 \mathrm{C}$, respectively, during and after the second transfer and top dilution. The slight heating above about 100 inches during the transfer is attributed to the heat of solution of a small bypass or leakage of in-line dilution water. The local crust-sinking event at $17 \mathrm{~B}$ is clearly visible as an abrupt exchange of green and red areas. The submerged cool material extended from about 190 to 240 inches elevation, consistent with the apparent submerged crust between 220 and $290^{\circ}$ inches that was visible in the neutron scan from January 29 (see Figure 4.5). The crust reflotation on January 30 is also visible as the disappearance of the red area in the crust.

The less dramatic crust sinking at $17 \mathrm{C}$ can also be seen as the appearance of the thicker yellow region below the crust in Figure 6.11. The thickening green layer on top of the crust is apparently a deepening layer of water, consistent with the neutron log of January 29 (see Figures ${ }^{\circ} 4.5$ and 4.7). The yellow streak on the tank bottom midway across the figure matches the landslide event whose effects persisted for several days. The small eye above the landslide remnants late on January 28 represents the abrupt temperature drop at the 76-inch level discussed above. The cooling in this region did not persist, and the event is as yet unexplained.

Figures 6.12 and 6.13 show the long-term relaxation and mixing at $17 \mathrm{~B}$ and $17 \mathrm{C}$, respectively, that occurred in the month between top dilution $2 \mathrm{~b}$ and low dilution $2 \mathrm{c}$. The coolest layer on top of the waste became thinner as crust dissolved and the dilute liquid was mixed. The temperature profiles also show that the landslide remnants on the bottom at $17 \mathrm{C}$ were not cleared until February 4. 


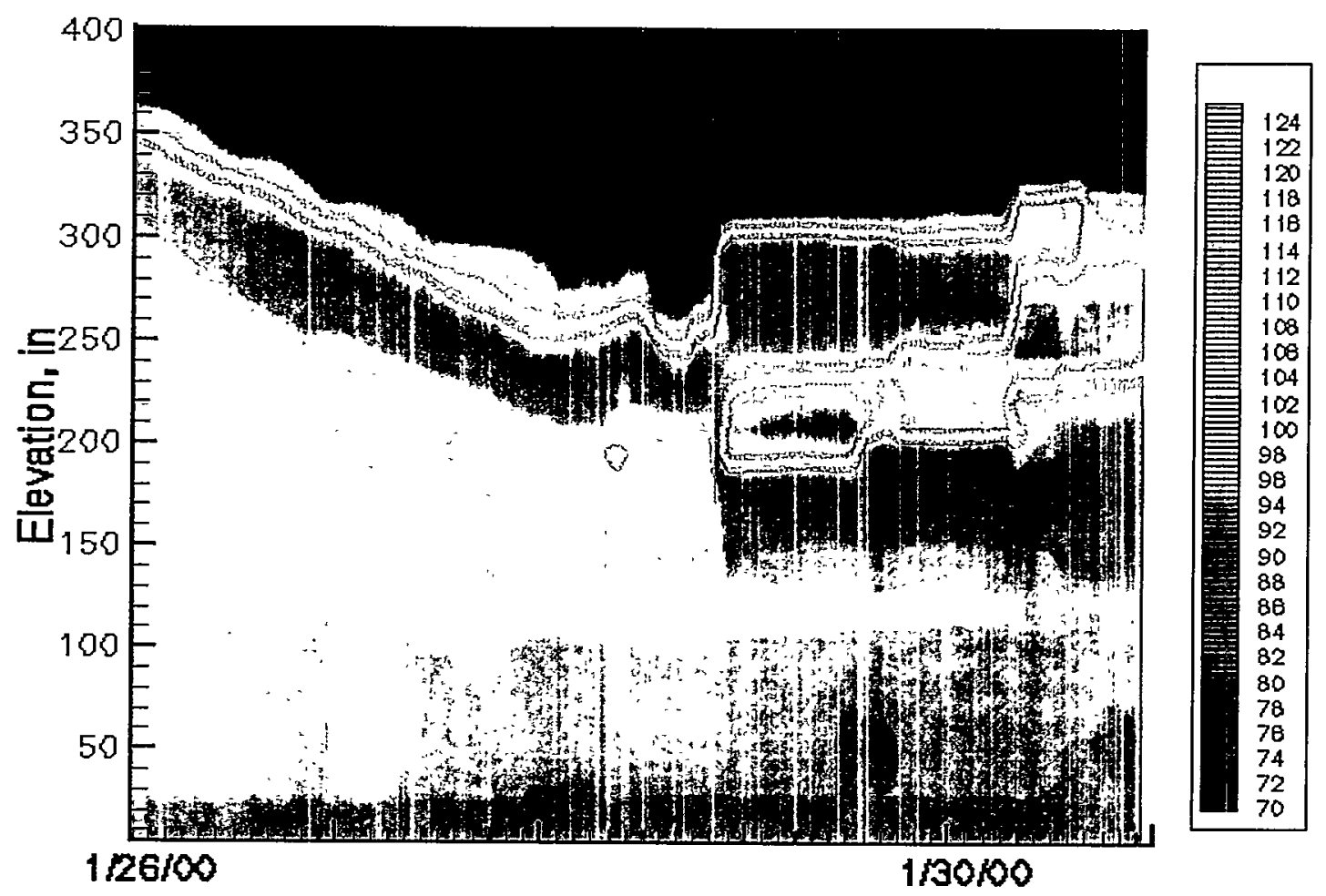

Figure 6.10. Temperature Profile at 17B During Transfer 2a and Top Dilution $2 b$

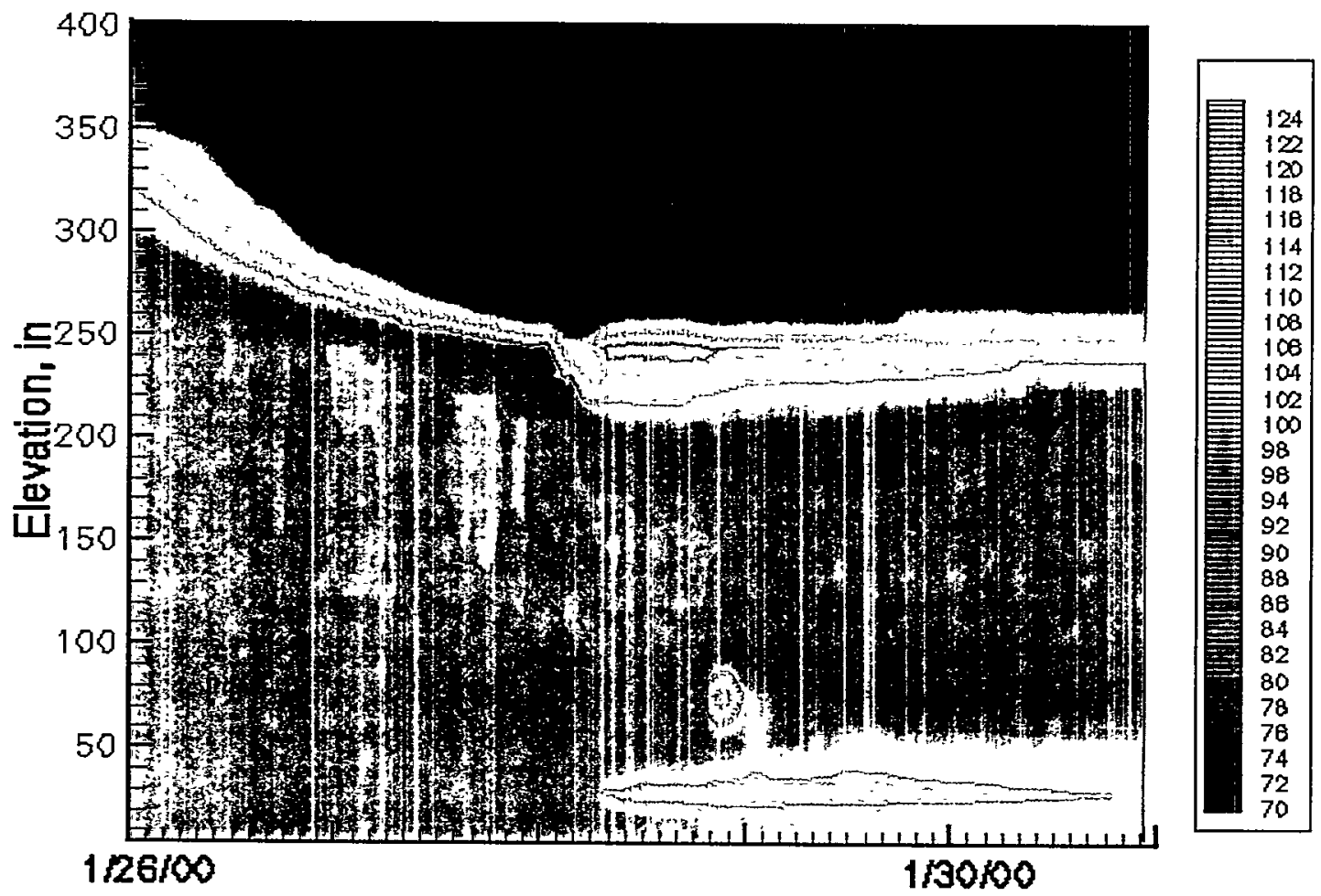

Figure 6.11. Temperature Profile at $17 \mathrm{C}$ During Transfer $2 \mathrm{a}$ and Top Dilution $2 \mathrm{~b}$ 


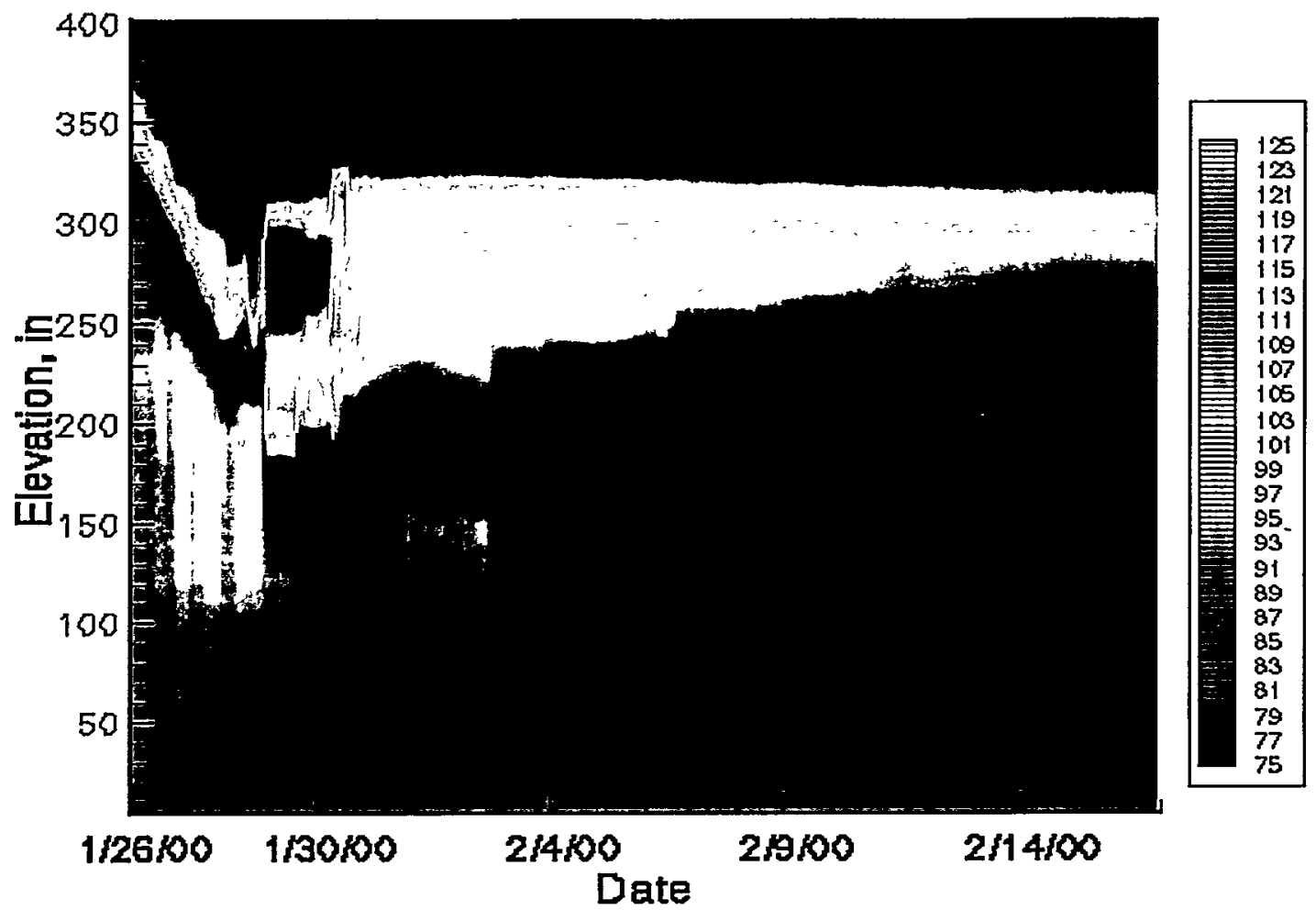

Figure 6.12. Temperature Profiles at 17B During and After Top Dilution 2b

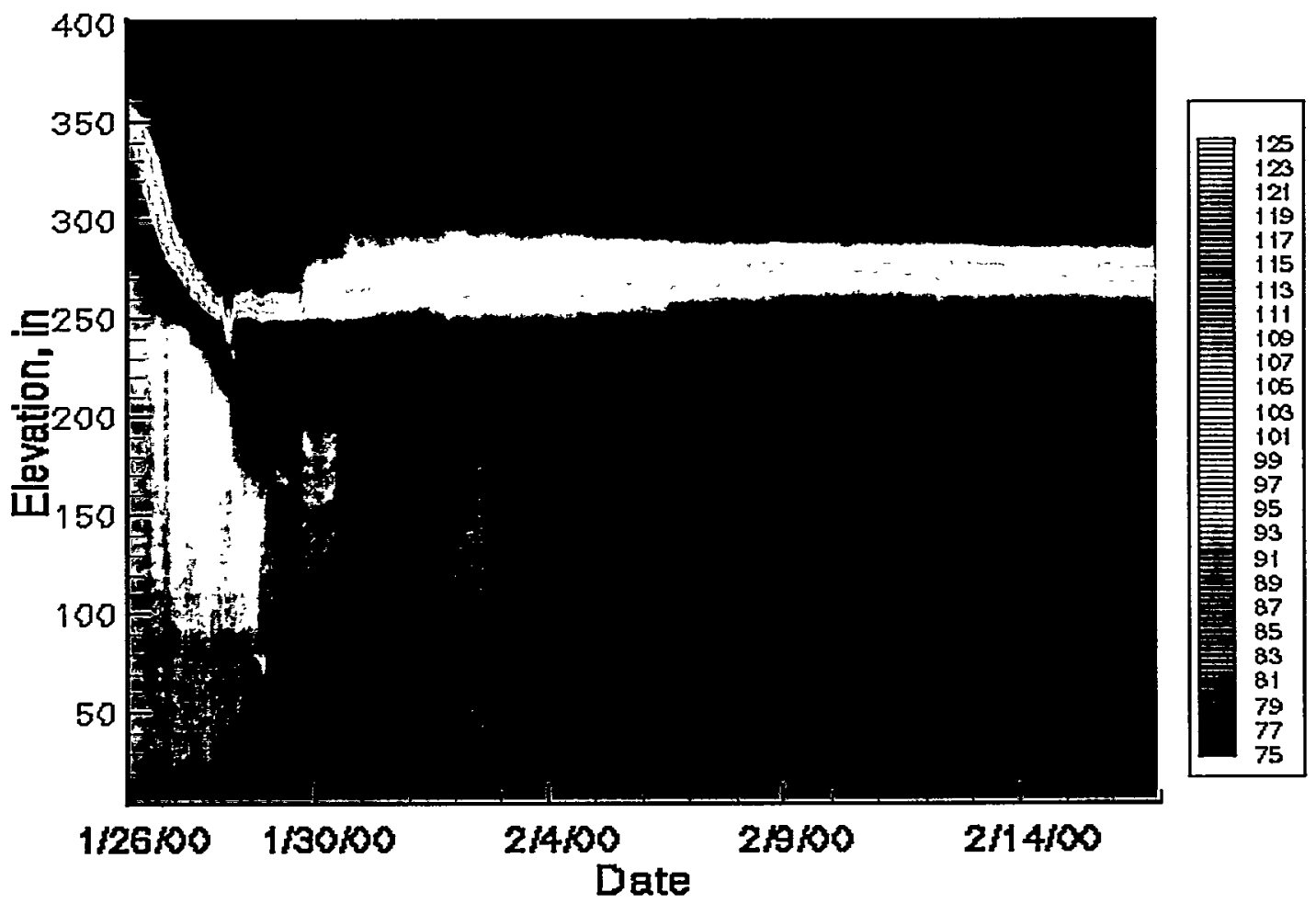

Figure 6.13. Temperature Profile at 17C During and After Top Dilution 2b 


\subsubsection{Second Low and Top Dilution}

The aftermath of crust dissolution from top dilution $2 \mathrm{~b}$ left the upper part of the tank quite stratified in both density and temperature. The neutron and gamma scans for the first half of February show one or more dilute layers of crust remnants and debris above about 260 inches in both risers (see Figures 4.9 through 4.12). This is also visible in the temperature histories of the upper portion of the tank just before the second low dilution, as shown in Figures 6.14 and 6.15 at $17 \mathrm{~B}$ and $17 \mathrm{C}$, respectively. The temperature histories for the bottom half of the tank at $17 \mathrm{~B}$ and $17 \mathrm{C}$ for the same period are shown in Figures 6.16 and 6.17, respectively. The temperatures in this region are quite uniform above 28 inches.

The main trend of the latter half of the second campaign is one of cooling. Both the low dilution and top dilution water was added at about $50^{\circ} \mathrm{F}$ with the goal of advancing the tank more quickly to its eventual cooler steady state. The cooling of the mixed region below the upper dilute layers during low dilution $2 \mathrm{c}$ is clearly seen in Figures 6.14 and 6.15 as a linear temperature decrease at the 232-, 244-, and 268-inch thermocouples with some higher ones joining the trend as the waste level rose. Thermocouples exposed to the apparently nonconvective dilute layer showed a nearly linear temperature increase during low dilution, as did the original crust during the first campaign. The thermocouples above 100 inches in Figures ${ }^{\circ} 6.16$ and 6.17 also show the cooling trend as $50^{\circ} \mathrm{F}$ low dilution water mixes with the waste.

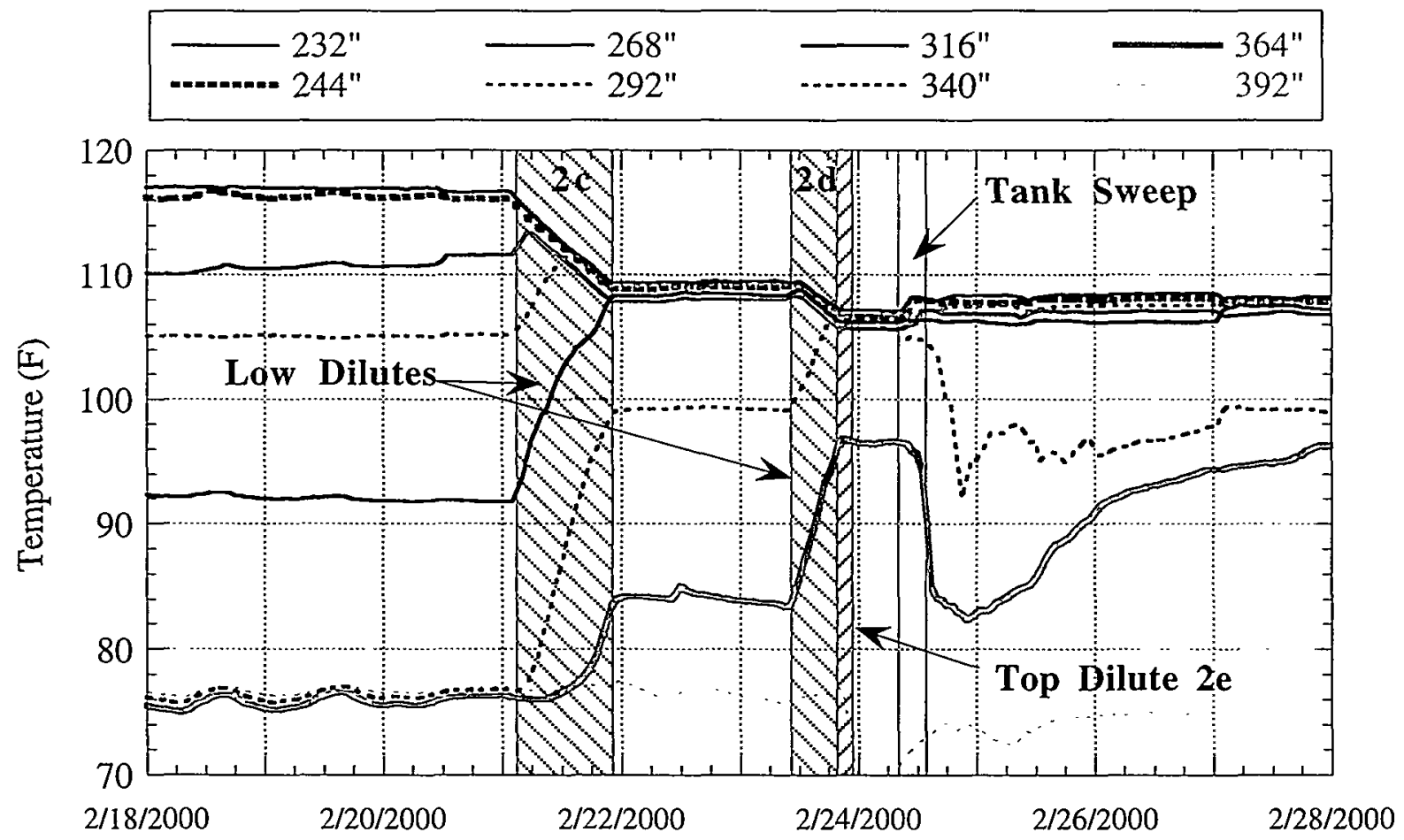

Figure 6.14. Crust Temperatures at 17B During Dilutions 2c-e 


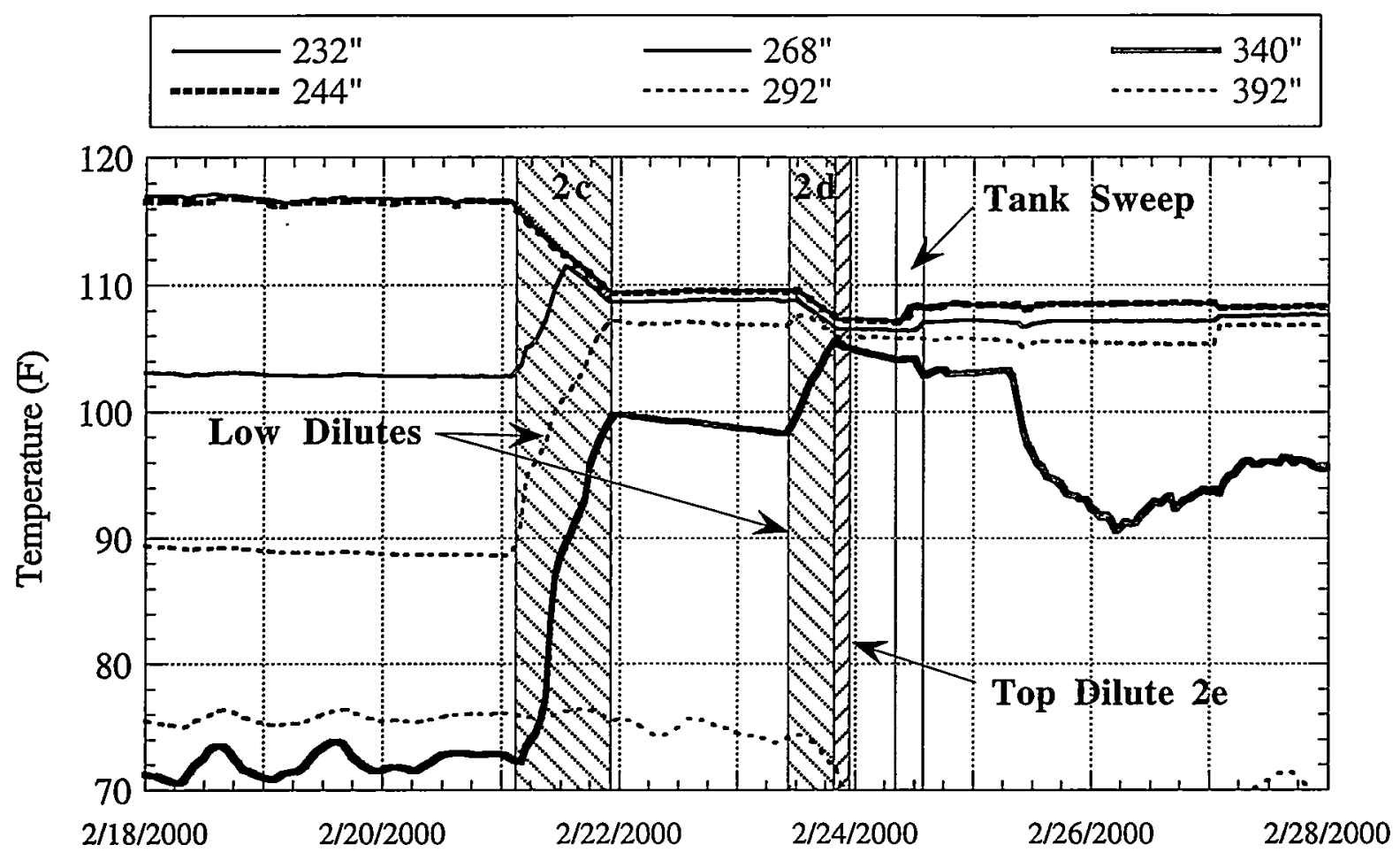

Figure 6.15. Crust Temperatures at 17C During Dilutions 2c-e

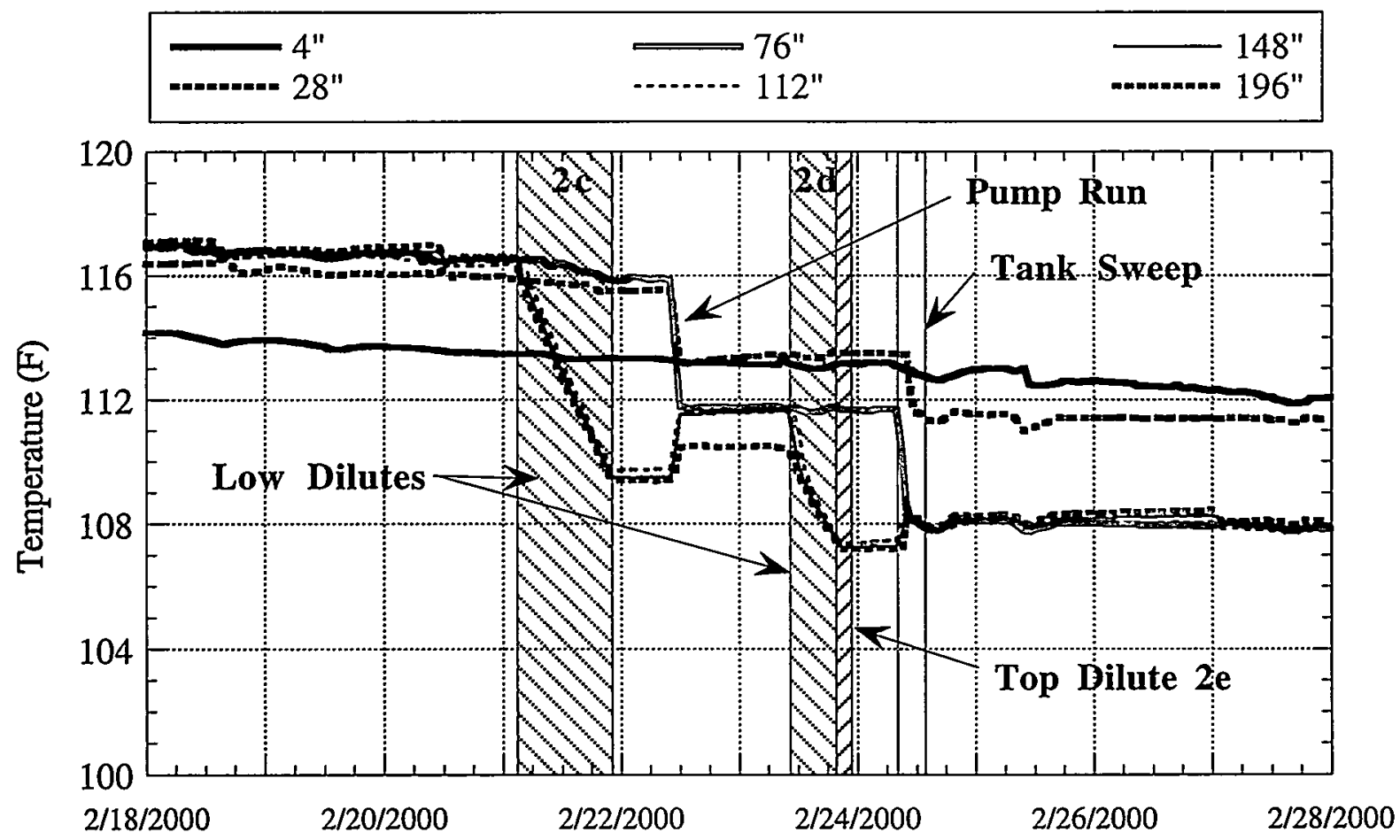

Figure 6.16. Mixed Slurry Temperatures at 17B During Dilutions 2c-e 


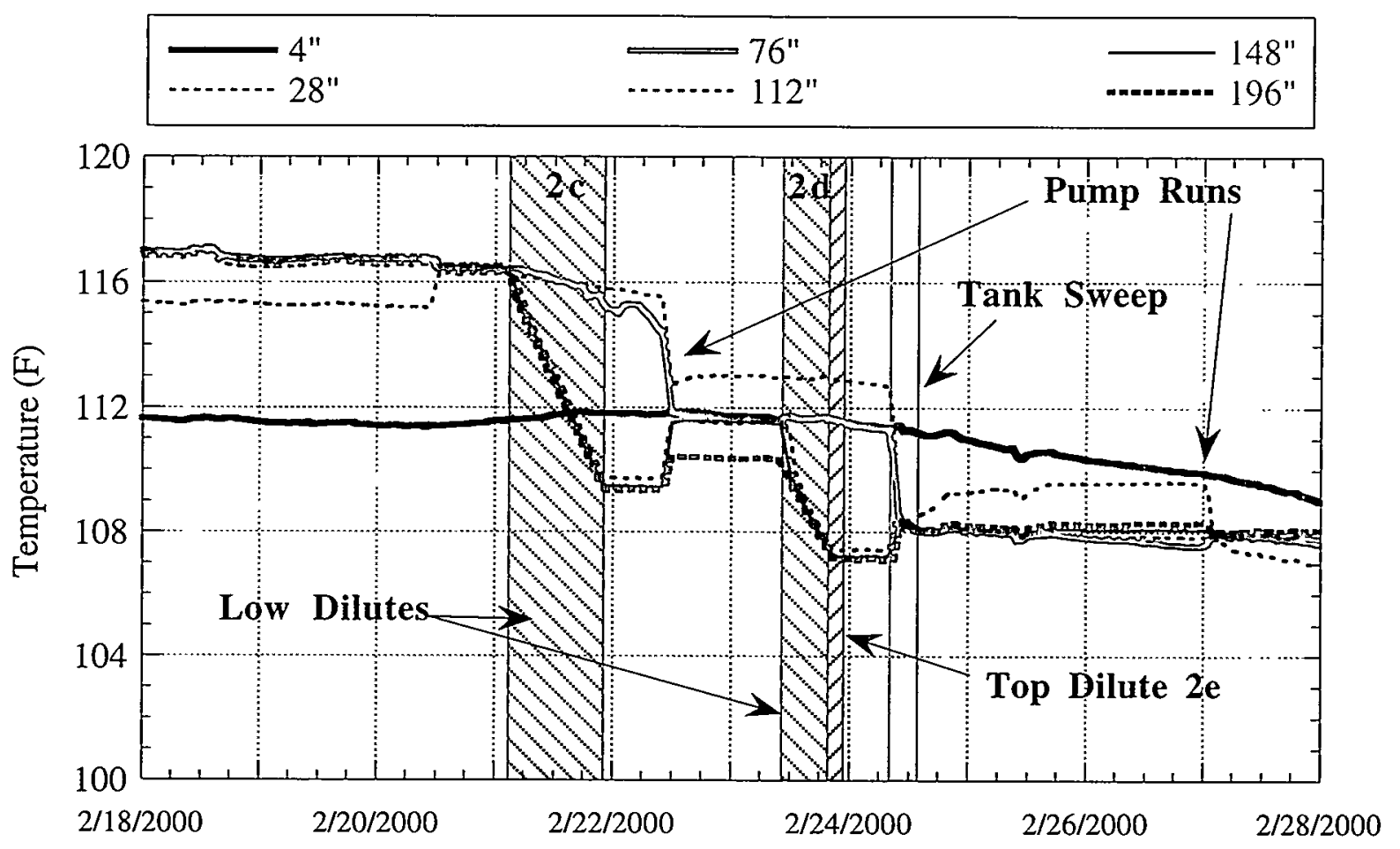

Figure 6.17. Mixed Slurry Temperatures at $17 \mathrm{C}$ During Dilutions 2c-e

The low temperature of the low dilution water was sufficient to overcome the heat of solution. The temperature above the 100 -inch level decreased from $116^{\circ}$ to $109^{\circ} \mathrm{F}$ during the dilution 2c (see 112- to 196-inch thermocouples in Figure 6.16). However, an energy balance based only on mixing indicates that the temperature should have fallen to $100^{\circ} \mathrm{F}$. The smaller temperature drop can be attributed to the heat of solution.

Similar trends continued in dilution $2 \mathrm{~d}$ on February 23 that reduced the difference between the warm mixed slurry and the cool upper layers significantly. On the bottom, the 4-inch thermocouples became the warmest in the tank. A three-hour tank sweep performed February 24 appears to have caused the temperatures to diverge. The sudden temperature drops on the 340and 364-inch thermocouples at $17 \mathrm{~B}$ and the 340 -inch thermocouple at $17 \mathrm{C}$ have not been explained. It is possible that the temperature drops represent remnants of the original crust moving away or dissolving from around the MITs, suddenly exposing the thermocouples to colder liquid.

\subsection{Temperature Behavior During the Third Campaign}

During the third campaign, the waste was further cooled and the mixed slurry was further diluted. At the end of top back dilute $3 f$, the waste was still significantly stratified. The region below the transfer pump inlet was more concentrated, and a more dilute layer lay on top. This condition existed ever since the large top dilution at the end of January. Aggressive 1,000-rpm tank sweeps following the third campaign, however, removed most of the stratification. 
Figures 6.18 and 6.19 show temperature histories at $17 \mathrm{~B}$ and $17 \mathrm{C}$, respectively, that represent the entire waste column during the third campaign. The two-step transfer proceeded uneventfully. The 340-inch thermocouple is uncovered after transfer 3a, and the 268-inch thermocouple was almost uncovered as transfer $3 \mathrm{~b}$ lowered the waste level to 280 inches. Again, $50^{\circ} \mathrm{F}$ water was used for dilutions $3 \mathrm{c}$ through $3 \mathrm{f}$, which lowered the temperature above the transfer pump inlet to almost $90^{\circ} \mathrm{F}$. Spray cooling during top dilution also reduced the headspace temperature below $70^{\circ} \mathrm{F}$, as shown by the 340 -inch thermocouples at $17 \mathrm{~B}$ and $17 \mathrm{C}$.

Though the temperatures decreased during low dilution, the heat of solution had the same effect as it did at the end of the second campaign in keeping the waste warmer than predicted by mixing only. During low dilution $3 \mathrm{c}$, the temperature between the upper dilute layer at $250^{\circ}$ inches and the base of the transfer pump at 100 inches decreased from $108^{\circ}$ to $96^{\circ} \mathrm{F}$ (see the 148- and 208-inch thermocouples in Figure 6.18). An energy balance with 127,000 gallons of water added at $50^{\circ} \mathrm{F}$ predicts the temperature should have dropped to $90^{\circ} \mathrm{F}$.

The temperature history at both MITs for the period from the end of the third campaign to the start of the mixer pump evaluation period is shown in Figures 6.20 and 6.21. Both figures give essentially the same picture of progressive reduction in the stratification by the mixer pump tank sweeps on March 17, 23, 24, 26, 30, and April 1. Each sweep made four runs of 25 minutes each at $1,000 \mathrm{rpm}$ with the jets rotated 30 degrees each time. Three runs were made on March 18 and 28 and one on March 21. By April 2, all of the waste above about 50 inches had a uniform temperature of $96^{\circ} \mathrm{F}$. The temperatures at 4 inches remained above $100^{\circ} \mathrm{F}$, but the slope showed it would soon join the others. The neutron and gamma profiles for March 29 confirmed the tank was well mixed except for the bottom 50 inches (see Figures 4.25 and 4.26).

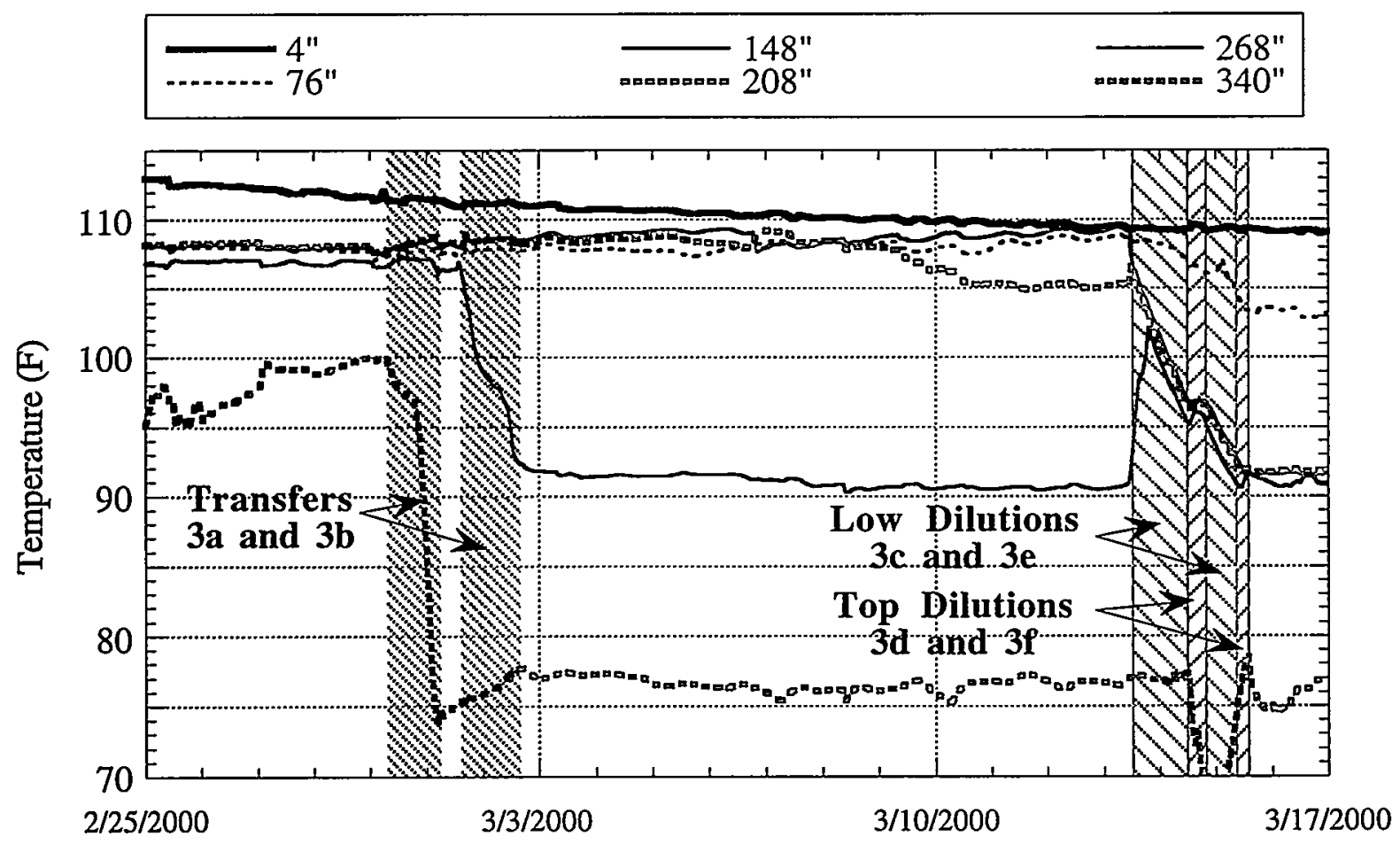

Figure 6.18. Temperatures at 17B During the Third Campaign 


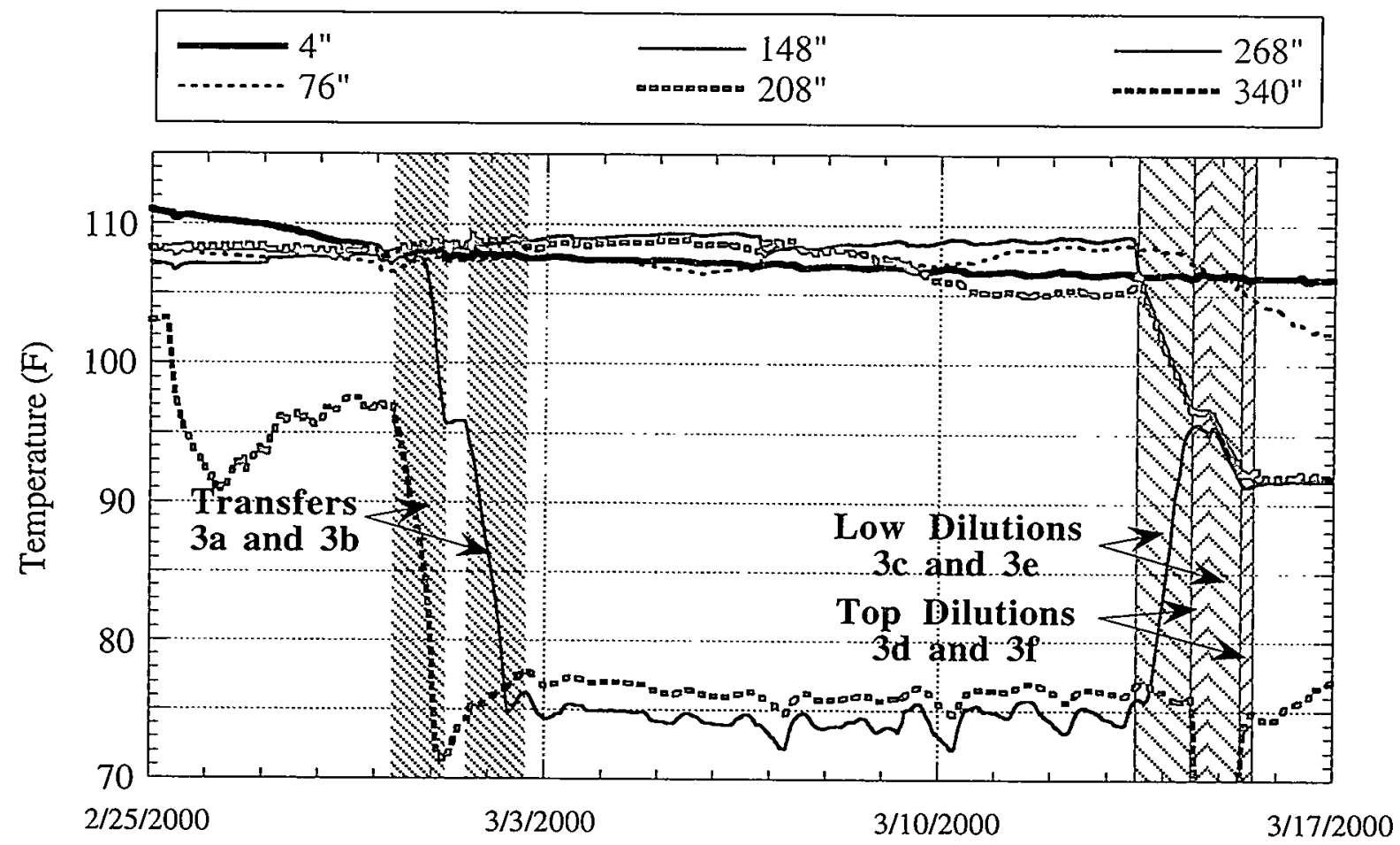

Figure 6.19. Temperatures at $17 \mathrm{C}$ During the Third Campaign

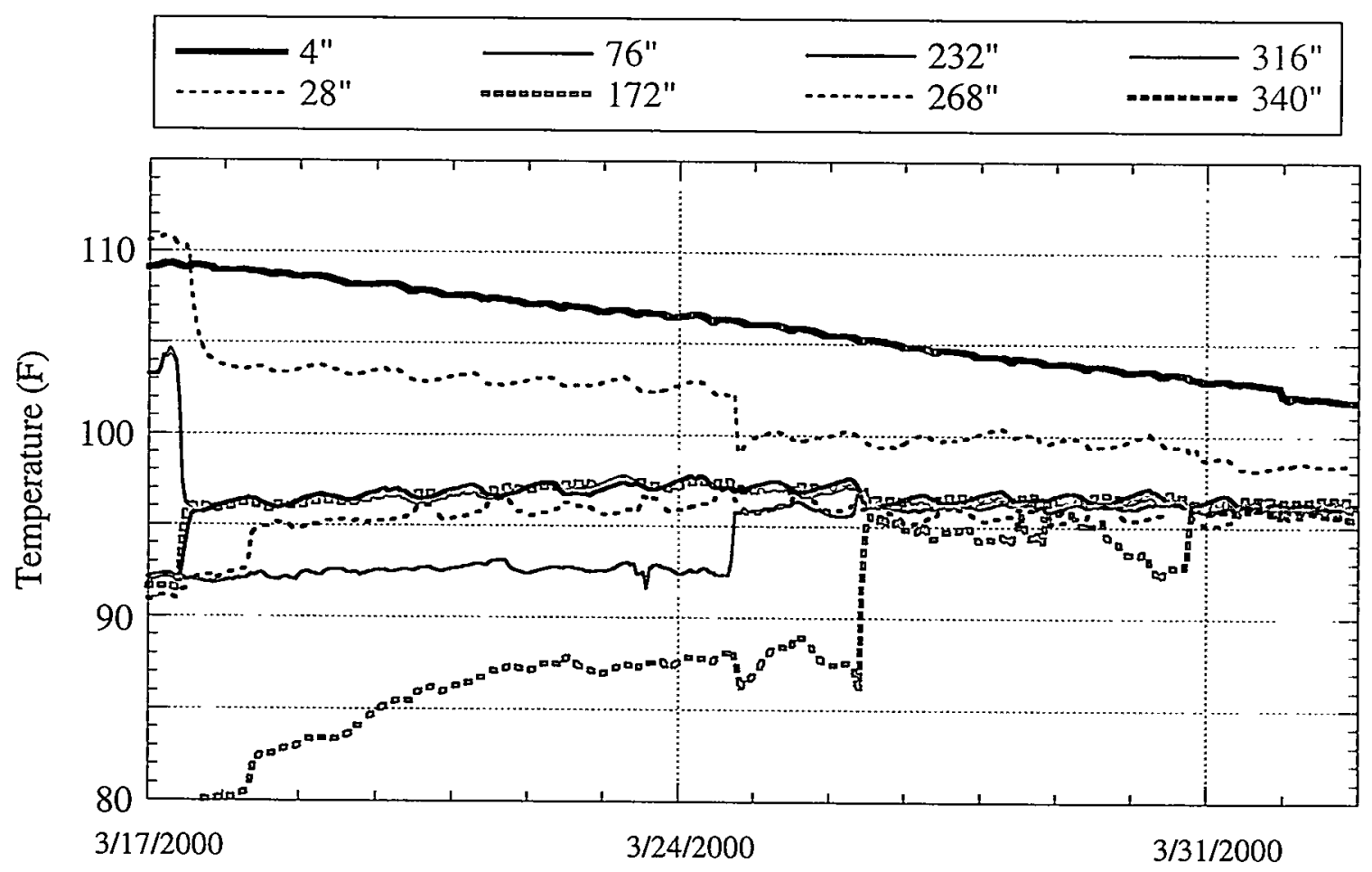

Figure 6.20. Temperature at 17B After the Third Campaign 


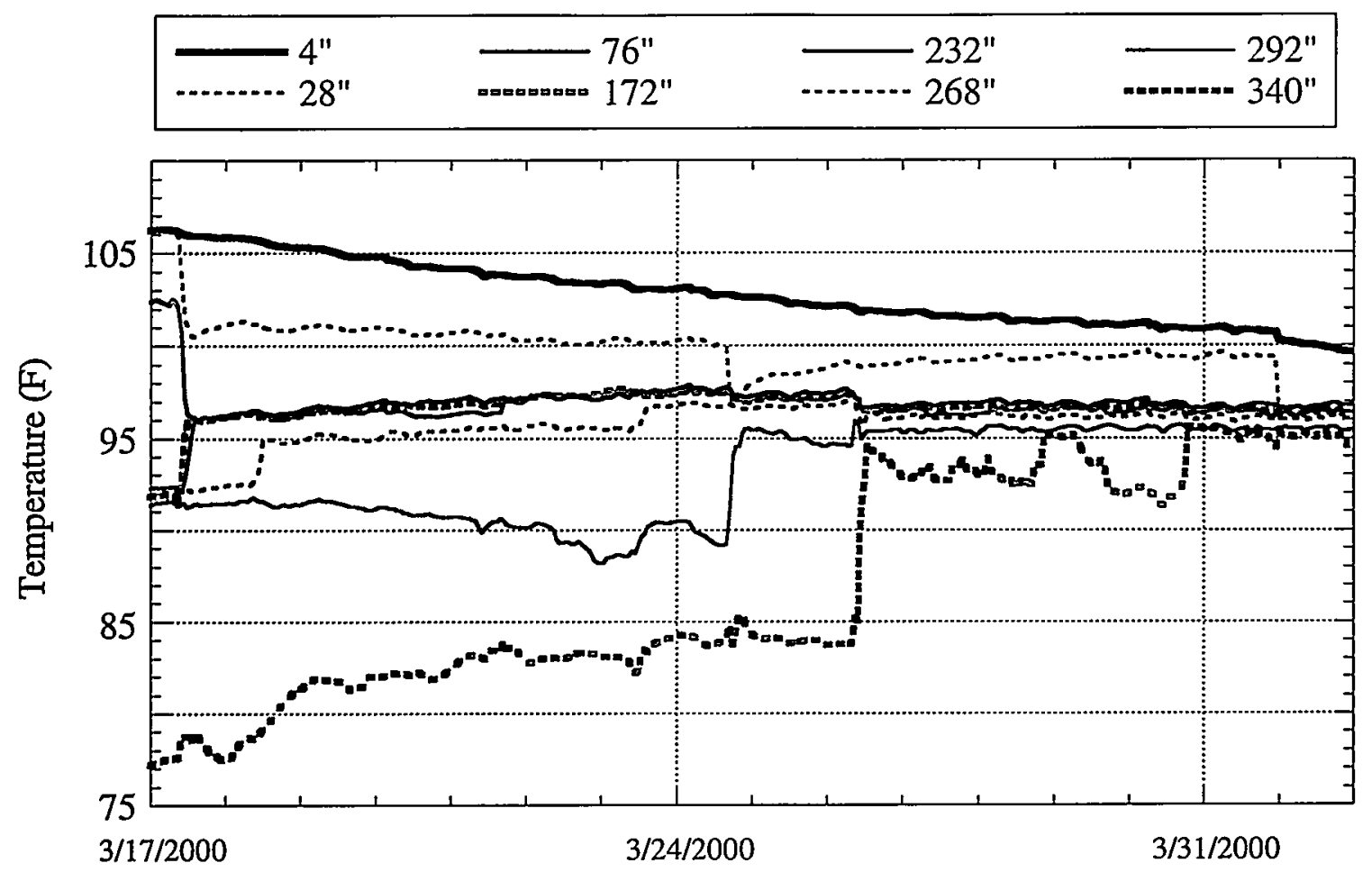

Figure 6.21. Temperatures at $17 \mathrm{C}$ After the Third Campaign

\subsection{Temperature Profiles in SY-102}

The temperature profiles measured in SY-102 are shown in Figure 6.22 for each of the three transfers from SY-101 performed during the remediation sequence. Each pair of curves, December 17 and 20, January 24 and 28, and February 28 and March 3, represents the temperature profiles before and after the first, second, and third transfers, respectively. The last pair of curves, March 31 and April 26, shows the long-term effects of the transfers almost two months after the last transfer. The profiles for January 24, February 28, and March 31 occur a short time after cross-site transfers removed waste from SY-102 to the Hanford 200 East Area.

An important issue during remediation of SY-101 was the accumulation of undissolved solids in SY-102 that might have the potential of retaining gas and causing future BD GREs. The initial state, indicated by the December 17 profile, shows the initial settled solids layer to be about 25 inches thick. The January 24 profile after the first campaign could be interpreted to indicate a nonconvective layer up to 100 inches deep. Similarly, the March 3 profile after the third transfer could show a 75-inch nonconvective layer. However, these profiles are evidently the result of transient density gradients due to settling or mixing because the March 31 and April 26 profiles clearly show that the settled solids are no more than 50 inches deep. The solids layer depth predicted based on SY-101 waste dilution tests was 44 inches. No significant gas retention was expected (Wells et al. 2000). 


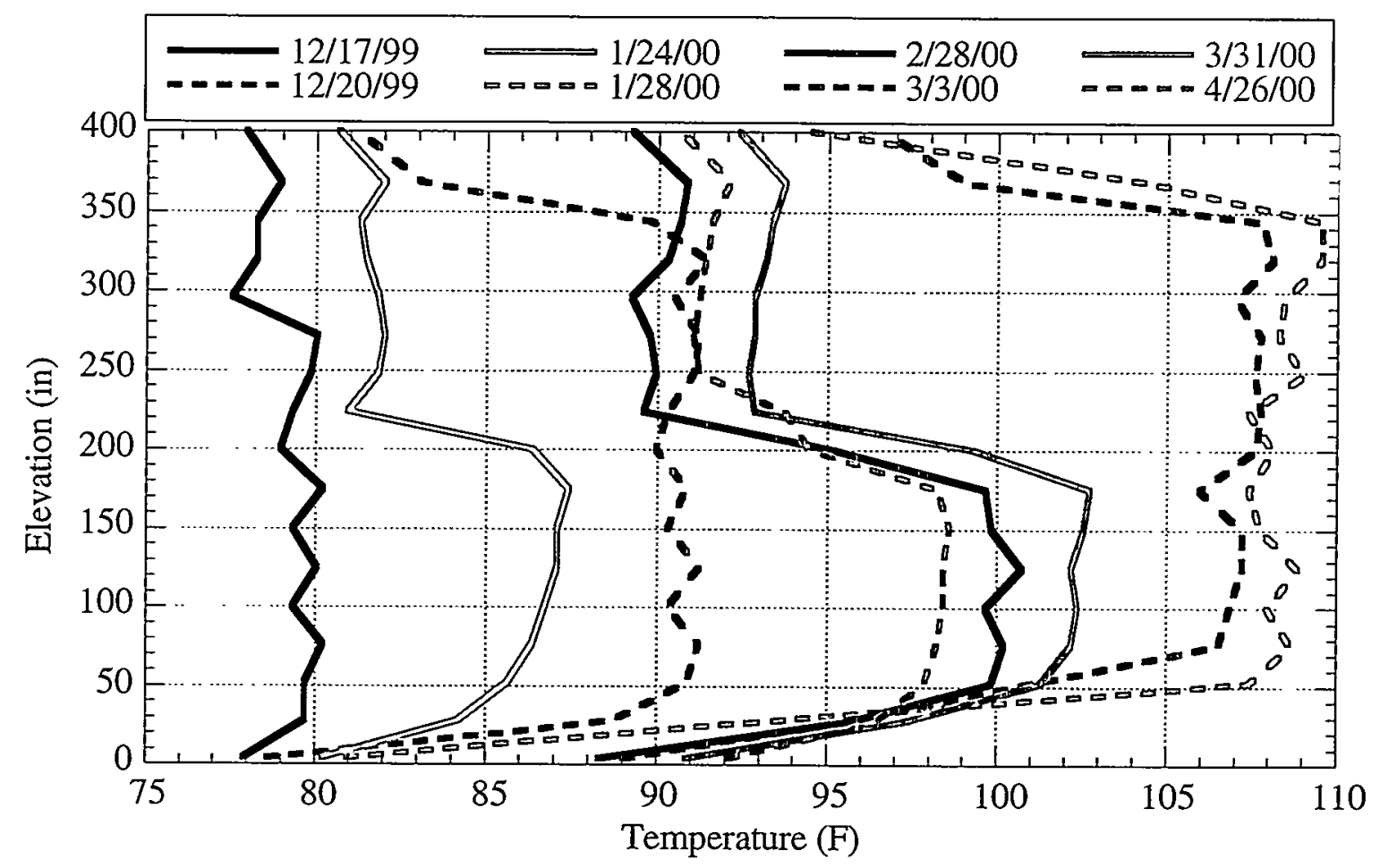

Figure 6.22. SY-102 Temperature Profiles

\subsection{Summary of Temperature Behavior}

Temperature data in SY-101 and SY-102 provided important insights on waste behavior that were not available from any other source. Combined with other observations, the evolution of temperature profiles gave us an almost three-dimensional picture of what was happening in the tank in response to transfers, top dilution, low dilution, and mixer pump operation between campaigns. This information confirmed our predictions and provided a sound technical basis for continuing the remediation sequences. Specifically, the temperature data revealed and described the following phenomena:

- Movement of dilute liquid through the crust during the first top dilution

- Lifting of the crust by top dilution as well as low dilution

- Efficient mixing of low dilution water with waste above the injection point

- Heat of solution/dilution causing a significant temperature rise (or smaller temperature drop) during low dilution

- Possible bypass or leak of in-line dilution water during transfer, causing a small temperature rise, also from heat of solution/dilution.

- The dynamics of crust dissolution and gas release including sinking, capsize, and landslides of waste attached to the wall

- Buildup of a persistent dilute layer at the waste surface and a concentrated layer on the tank bottom and progress of mixer pump operation in reducing them

- Solids settling and small nonconvective layer depth in SY-102 
The temperature data also confirmed neutron and gamma probe information showing that the original thick gas-retaining crust layer no longer existed after the second campaign and that little trace remained of any crust after the third campaign. During the mixer pump evaluation period, temperature profiles are also being monitored to determine the eventual depth of the nonconvective layer in SY-101, which is one of the most important parameters to confirm that the tank will not return to BD GREs. 


\subsection{Mixer Pump Performance}

Part of SY-101 data monitoring has been to review mixer pump operating parameters. Prior to remediation, mixer pump monitoring focused primarily on tracking the density of the slurry being pumped to determine the ambient void fraction below the crust layer. After transfer and back-dilution began, monitoring also focused on the slurry density to confirm the effects of dilution and to detect potential ingestion of voids or solids from the base of the crust after transfers. Thermocouple response when the pump jets were aimed at the MITs in 17B and 17C also provided insights on the mixing process between campaigns.

Section 7.1 discusses the SY-101 mixer pump parameters. The evidence of thermocouple uncovery is shown in Section 7.2.

\subsection{Mixer Pump}

The mixer pump was run on approximately its normal schedule throughout the three campaigns except for the actual transfers and back-dilutions. There were concerns that the mixer pump performance might degrade by ingesting gas or additional solids as the base of the crust was lowered after dilution. Accordingly, pump performance parameters were monitored carefully, especially on the first few runs following a transfer. Data were acquired every 6 or 10 seconds over each pump run at $1,000 \mathrm{rpm}$ and were averaged over the run duration (usually 25 minutes). The parameters of importance included the following:

- The pump power demand (calculated by multiplying the product of current and voltage by the square root of 3 to account for three-phase power)

- The pump volute pressure (the part of the pressure that results from flow, subtracting the static head)

- The pressure drop along the discharge line (volute pressure minus the average of the two nozzle pressures, subtracting the static head)

- The pump motor oil temperature.

Figure 7.1 shows the run-average volute pressure and power for every run performed during all three remediation campaigns that was longer than 20 minutes at $1,000 \mathrm{rpm}$. Figure 7.2 shows the run-average discharge line pressure drop and inlet temperature for these runs. Note that after the third campaign tank sweeps were performed with four 25-minute, 1,000-rpm runs in one day; hence the increased density of the data points. Table 7.1 summarizes the changes in the runaveraged pump power demand, volute pressure, and discharge line pressure drop.

The power, volute pressure, and discharge line pressure drop should all be proportional to density. Therefore, each should decrease by about the same fraction after each campaign. However, as the figures and table show, this occurred only after the third campaign. After the first campaign the power and volute pressure decreased by similar fractions, but the pressure

drop decreased much more. In the second campaign both pressures decrease more than the power, and the pressure drop decreased much more than the volute pressure. 


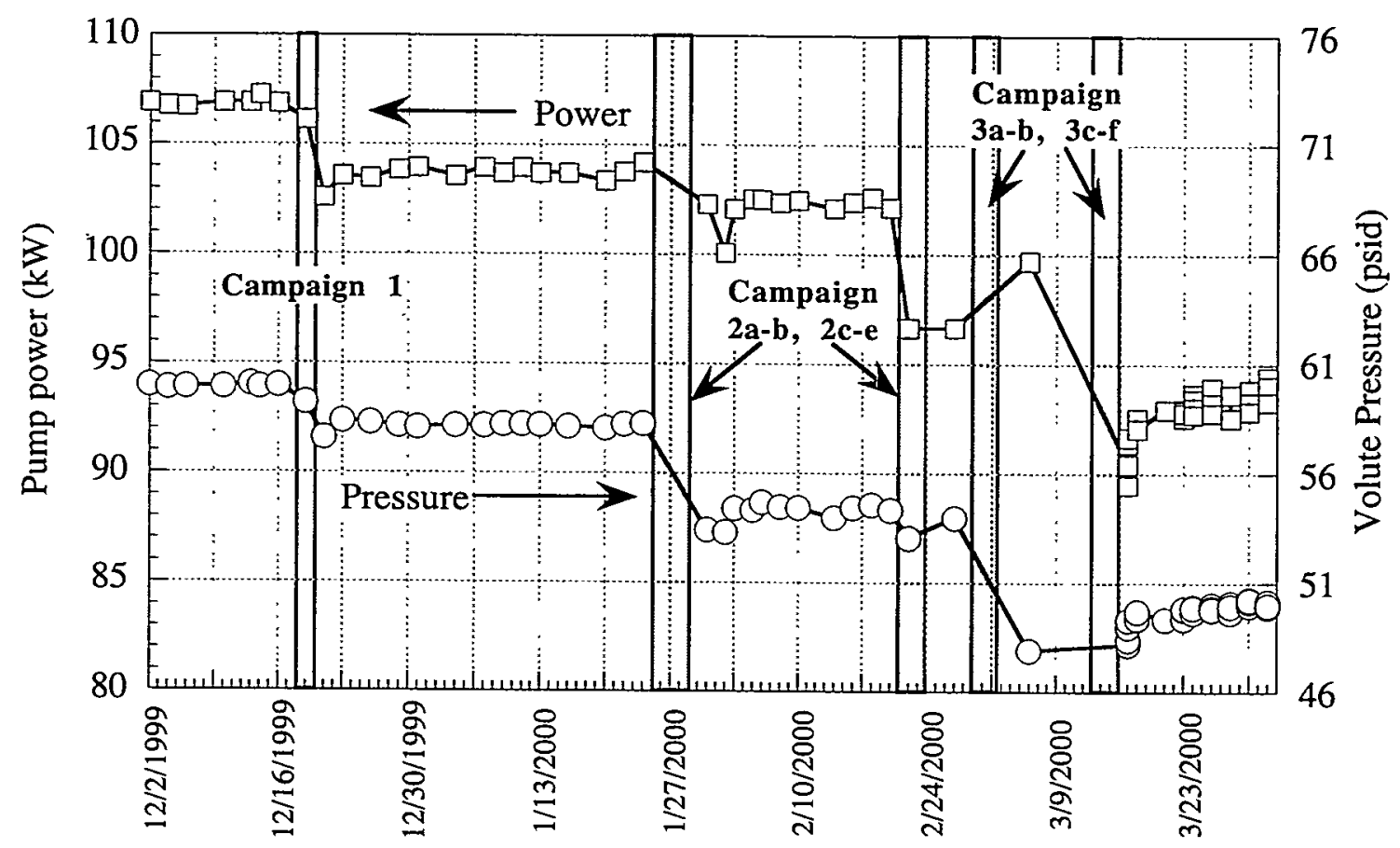

Figure 7.1. Run-Average Power and Volute Pressure for All Campaigns

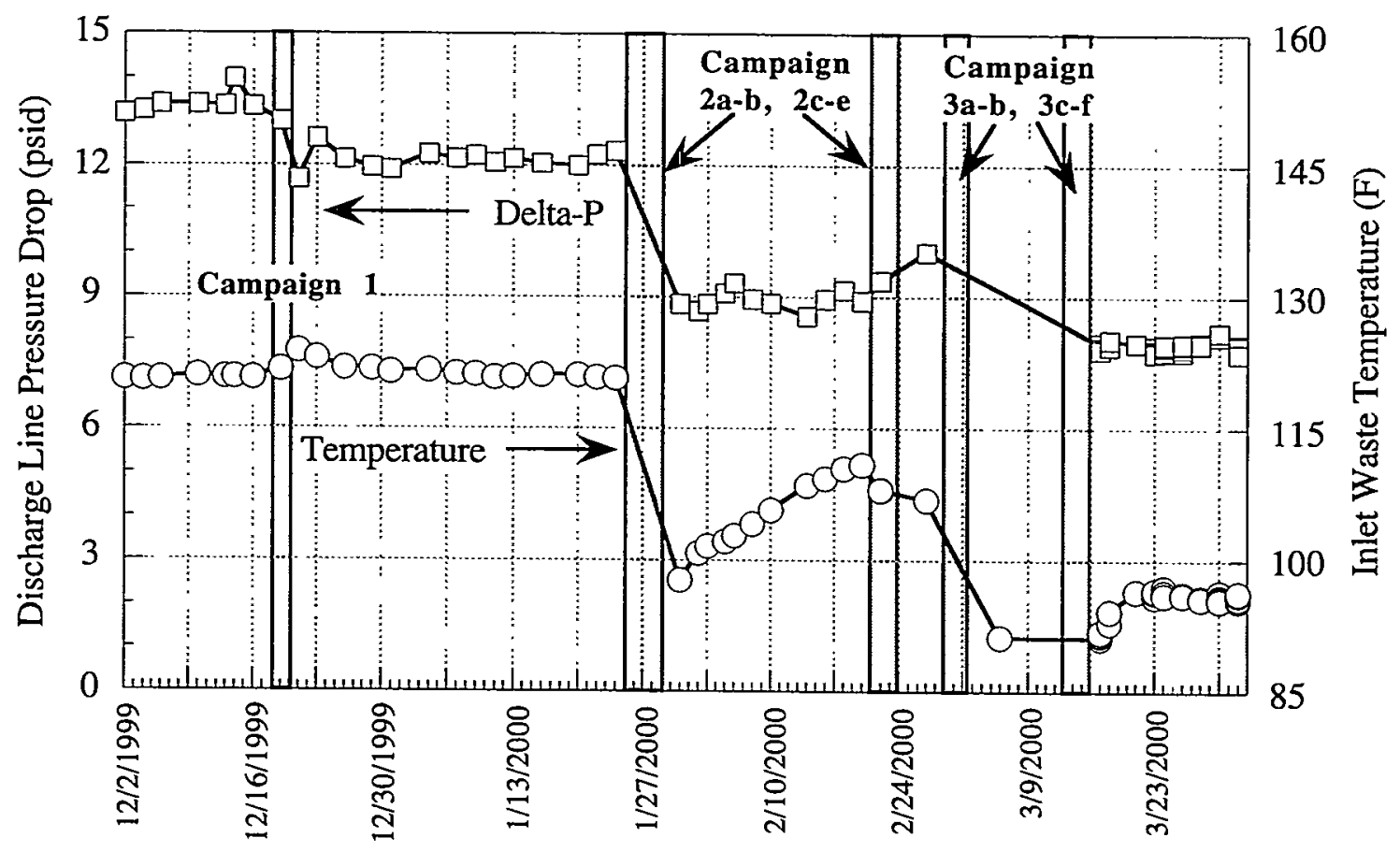

Figure 7.2. Run-Average Discharge Line Pressure Drop and Inlet Waste Temperature 
Table 7.1. Remediation Campaigns' Effects on Mixer Pump Parameters

\begin{tabular}{|c|c|c|c|c|c|c|}
\hline & \multicolumn{2}{|c|}{ Power } & \multicolumn{2}{|c|}{ Volute Pressure } & \multicolumn{2}{|c|}{ Discharge Line $\Delta \mathbf{P}$} \\
\hline & $\mathbf{k W}$ & change & psid & change & psid & change \\
\hline \multicolumn{7}{|l|}{ First Campaign } \\
\hline Average before $1^{\text {st }}$ campaign & 106.9 & & 59.9 & & 13.4 & \\
\hline Minimum shortly after $1^{\text {st }}$ & 102.6 & $-4 \%$ & 57.6 & $-4 \%$ & 11.7 & $-13 \%$ \\
\hline Average after $1^{\text {st }}$ campaign & 103.7 & $-3 \%$ & 58.2 & $-3 \%$ & 12.1 & $-9 \%$ \\
\hline \multicolumn{7}{|l|}{ Second Campaign } \\
\hline Average before $2^{\text {nd }}$ campaign & 103.7 & & 58.2 & & 12.1 & \\
\hline Minimum shortly after $2^{\text {nd }}$ & 100.1 & $-4 \%$ & 53.3 & $-8 \%$ & 8.7 & $-28 \%$ \\
\hline Average after $2^{\text {nd }}$ campaign & 102.4 & $-1 \%$ & 54.4 & $-7 \%$ & 8.9 & $-27 \%$ \\
\hline \multicolumn{7}{|l|}{ Third Campaign } \\
\hline Average before $3^{\text {rd }}$ campaign & 102.4 & & 54.4 & & 8.9 & \\
\hline Minimum shortly after $3^{\text {rd }}$ & 89.5 & $-13 \%$ & 48.2 & $-11 \%$ & 7.7 & $-14 \%$ \\
\hline Average after $3^{\text {rd }}$ campaign & 92.5 & $-10 \%$ & 49.5 & $-9 \%$ & 7.9 & $-12 \%$ \\
\hline Overall Change & & $-14 \%$ & & $-17 \%$ & & $-41 \%$ \\
\hline
\end{tabular}

The initial density of the degassed slurry was estimated at $1620 \mathrm{~kg} / \mathrm{m}^{3}$. Based on laboratory dilution data on SY-101 core sample material, the slurry density after the first campaign was predicted to be $1572 \mathrm{~kg} / \mathrm{m}^{3}$. The change of $-3.0 \%$ matches the change in pressure and volute pressure in Table 7.1. The densities predicted after the second and third campaigns are $1480 \mathrm{~kg} / \mathrm{m}^{3}$ and $1394 \mathrm{~kg} / \mathrm{m}^{3}$, respectively. The density decreases $5.6 \%$ between the first and second campaigns and 5.8\% between the second and third. These changes match the change in volute pressure between the first and second campaigns but not between the second and third. The changes in power and pressure drop don't match the density in the last two campaigns.

The reason for the inconsistent changes in the three parameters relative to the density is unknown. The ambient void in the slurry can only be estimated for the pre-remediation state and probably decreased with each campaign. A decrease in void would tend to reduce the density change, which apparently did not occur. Viscosity should also have been decreased as suspended solids dissolved and the liquid diluted. A decrease in viscosity for the same pump speed would decrease the power demand, increase the head, and decrease the discharge line pressure drop. This could explain why the relative change in discharge pressure drop is much higher than the other parameters in the last two campaigns, but it does not explain the relationship between the power and volute pressure changes.

Suffice it to say that the changes in mixer pump parameters are consistent with the effects of dilution of the liquid and dissolution of the suspended solids. After the three remediation campaigns, the mixer pump is running at the same speed with $14 \%$ less power, $17 \%$ lower volute pressure, and $41 \%$ lower discharge pressure drop. The fluid is simply much easier to pump.

The pump oil temperature transients before and after each campaign are compared in Figure 7.3. The most significant change was the drop in the initial oil temperature. The result is that at least four 25 -minute runs at $1,000 \mathrm{rpm}$ could be made in the same day after the third 


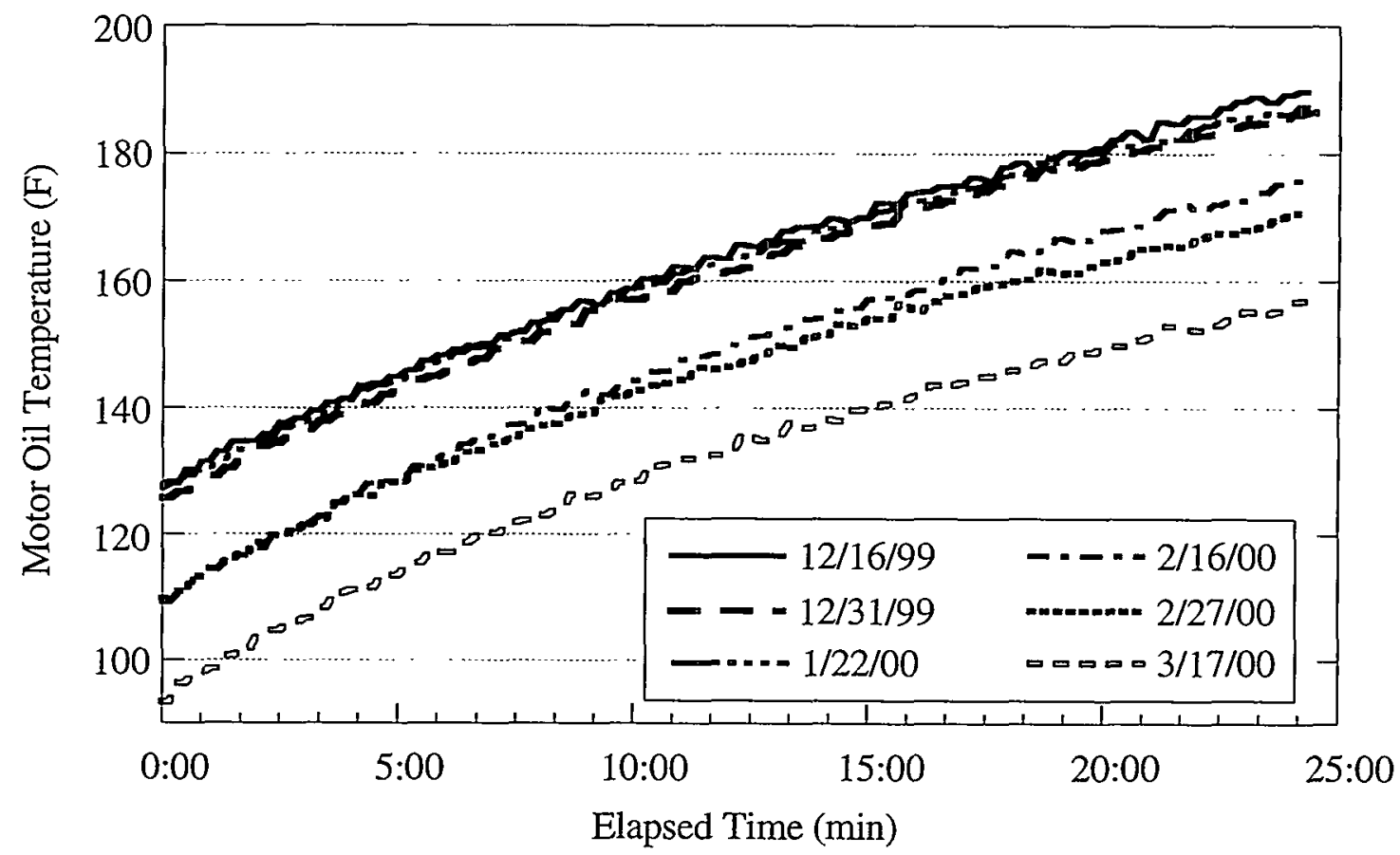

Figure 7.3. Pump Oil Temperature Transients Through All Remediation Campaigns

campaign without exceeding the temperature limit. The rate of temperature increase for the last half of each run decreased steadily in proportion to the pump power, as expected. The oil temperature rise rate decreased 16\% between December 16 and March 17, which approximates the $14 \%$ decrease in pump power.

\subsection{Thermocouple Uncovery Data}

Thermocouple response has been used for many years to confirm that the mixer pump jet mobilizes the lower levels of the waste at outer radii. The waste temperature in the lower two meters of waste is reduced several degrees below the bulk mixed slurry temperature by heat conduction through the primary floor of the tank to the cooling channels below. As the mixer pump jet disturbs this cooler material, the thermocouples exposed to the jet show a sudden temperature rise. This behavior is termed "uncovery" from the conceptual model of thermocouples buried in waste being suddenly uncovered hydraulically. The thermocouples generally "uncover" from top to bottom in sequence a few minutes apart.

A typical uncovery transient at 17B is shown in Figure 7.4. In this and in each subsequent uncovery plot, the mixer pump run begins five minutes after the initial time shown. Even though this mixer pump run on December 26 followed the first campaign, it represents typical behavior prior to remediation because of the limited effect of small low dilution 1c. The four-inch thermocouple uncovers about six minutes after the 28 -inch thermocouple, which uncovers essentially as soon as the pump starts. The top thermocouple doesn't change because it is 


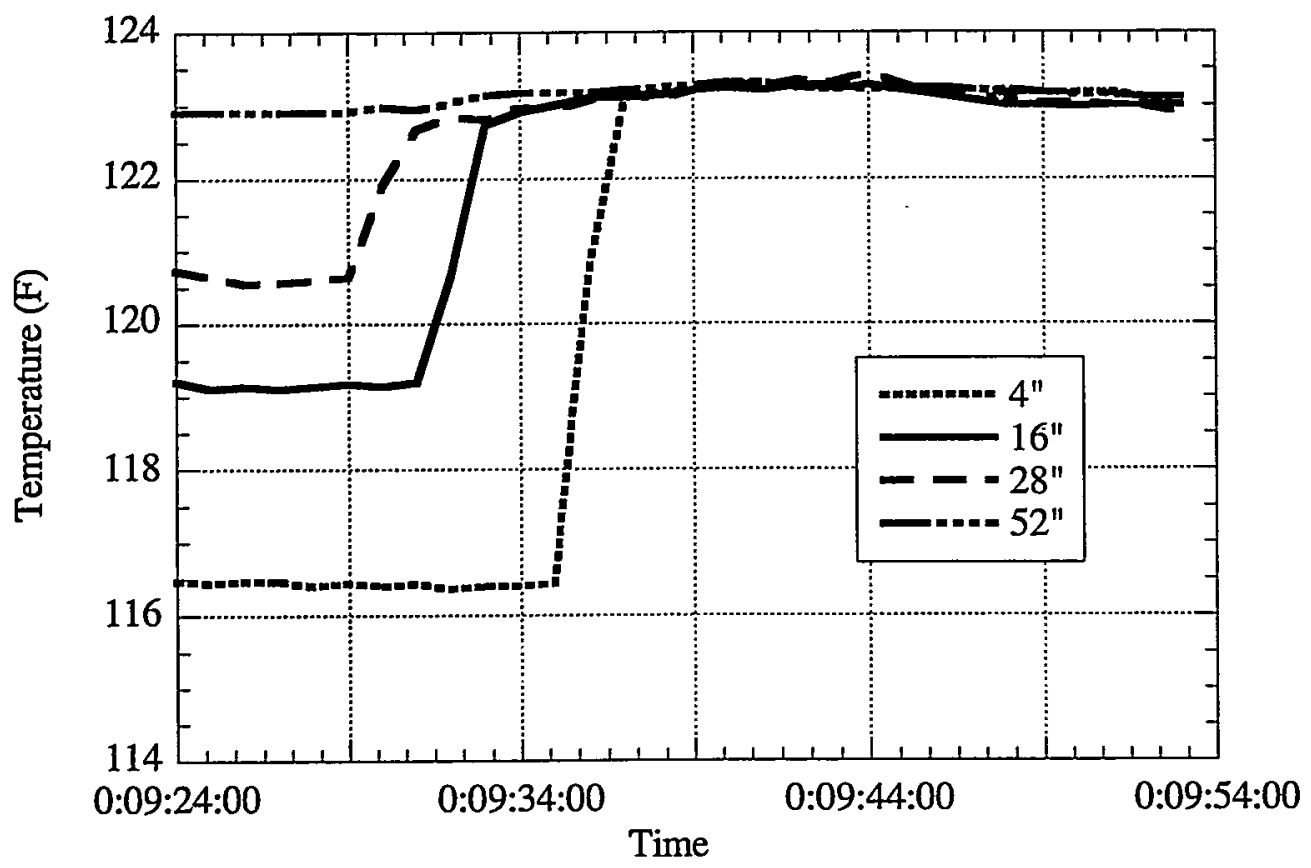

Figure 7.4. Thermocouple Uncovery Transient at 17B December 26, 1999

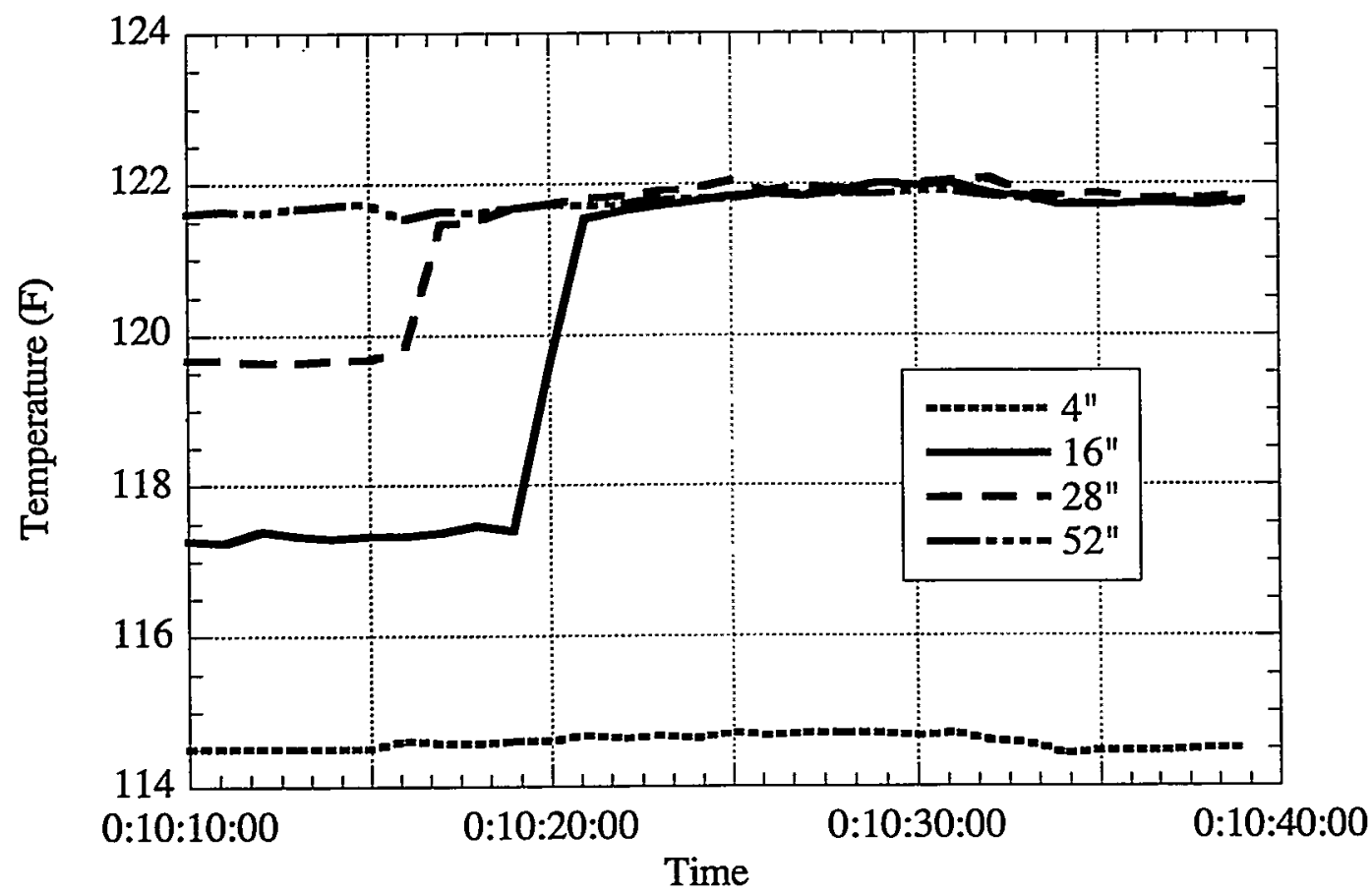

Figure 7.5. Thermocouple Uncovery Transient at $17 \mathrm{C}$ January 22, 2000 
already at the bulk temperature. The corresponding baseline behavior at $17 \mathrm{C}$ is shown in Figure 7.5, taken from a run on January 22. The thermocouples uncover a few minutes later than at $17 \mathrm{~B}$. The bottom one is not affected. This difference may be due to a local obstruction in the

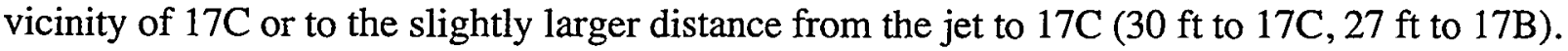

Several mixer pump runs after the second transfer and top dilution produced thermocouple responses similar to those shown in Figures 7.4 and 7.5. The large volume of cold water added in the second low dilution, however, reversed the response. Figures 7.6 and 7.7 show the thermocouple uncovery transients at $17 \mathrm{C}$ on February 24 and 27, respectively. Note that the lowest temperature is at the 54-inch level and that uncovery results in a temperature decrease - just the inverse of the earlier behavior. The run on February 24 was part of a "tank sweep" at $750 \mathrm{rpm}$, while the run on February 27 was at the normal speed of $1,000 \mathrm{rpm}$.

Because the mixer pump inlet is at the 230 -inch elevation, it draws in fluid that has had the full effect of any low dilution injected at the base of the transfer pump at 100 inches. The fluid in the jet exiting the nozzles is therefore much less dense than the surrounding fluid. The effect of buoyancy is to prevent the jet from penetrating as far as it had before dilution. This can be seen in the somewhat longer times to uncovery of the 16- and 28-inch thermocouples in Figure 7.7 compared with the times in Figure 7.5.

After the large low dilutions of the third campaign, the temperature inversion on the tank bottom is even more pronounced. Figures 7.8 and 7.9 show the thermocouple responses at 17B and 17C, respectively, on March 17. These plots represent two of four 25-minute, 1,000-rpm

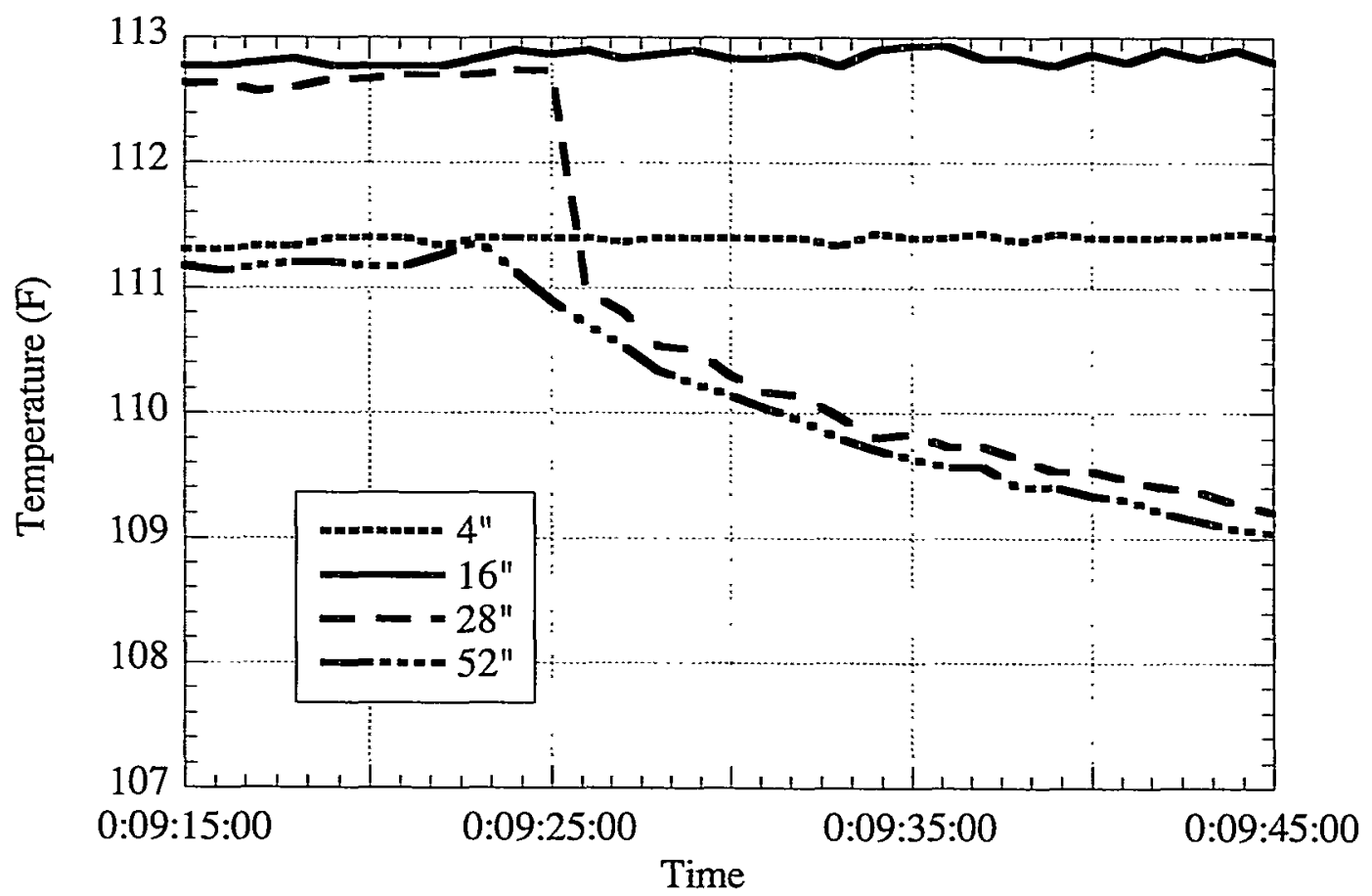

Figure 7.6. Thermocouple Uncovery Transient at 17C, February 24,2000 


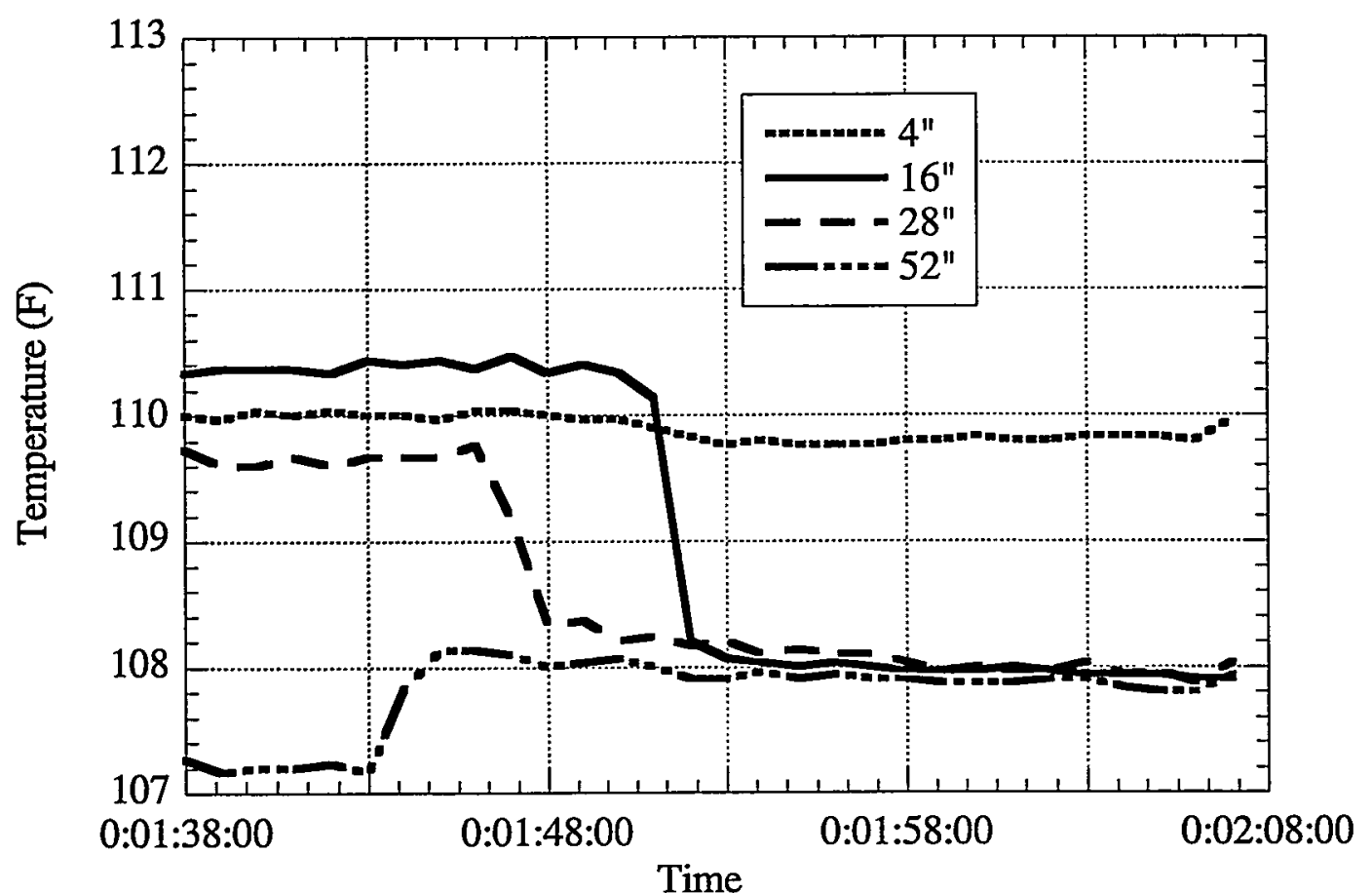

Figure 7.7. Thermocouple Uncovery Transient at 17C, February 27, 2000

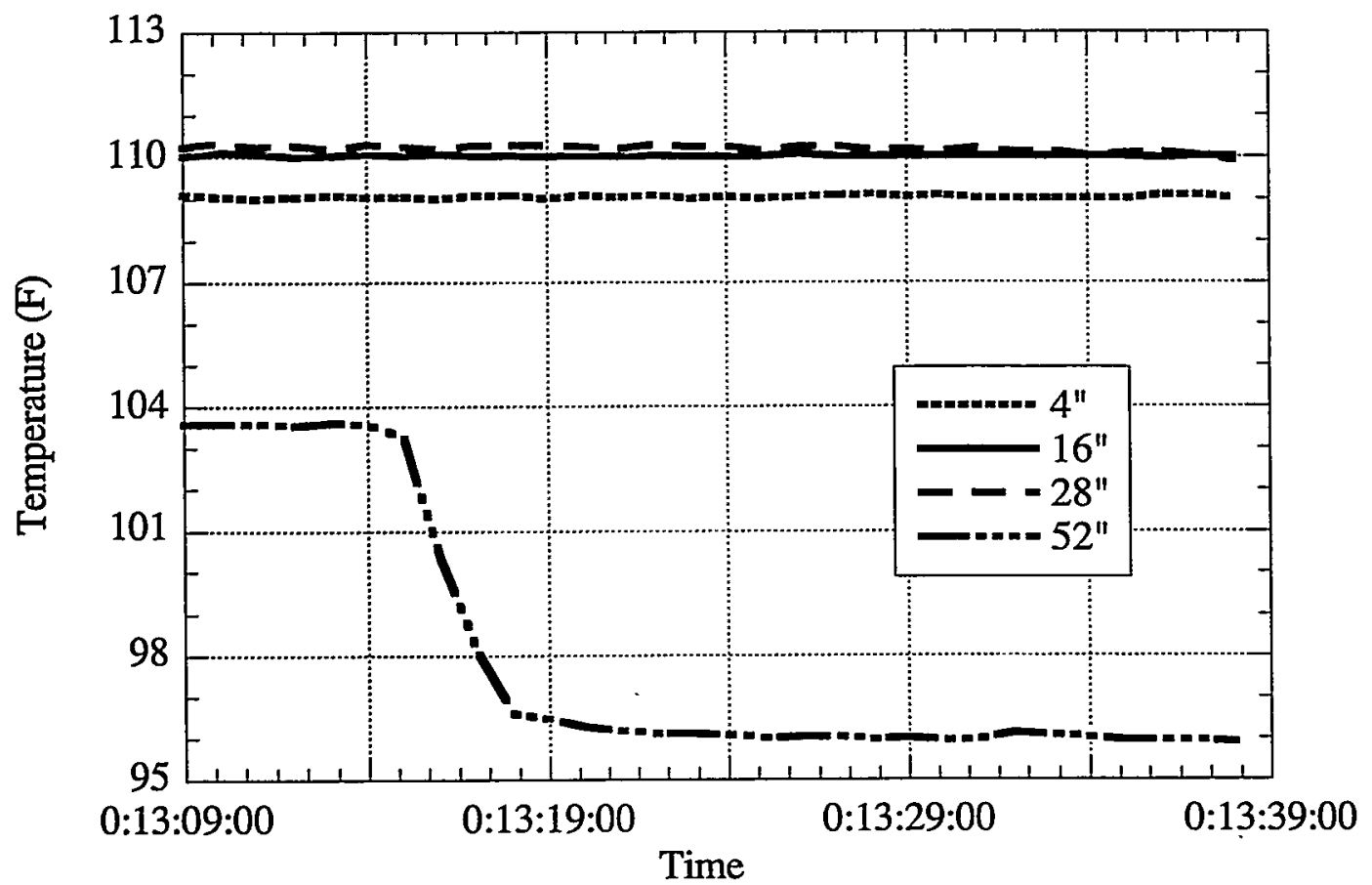

Figure 7.8. Thermocouple Uncovery Transient at 17B, March 17, 2000 


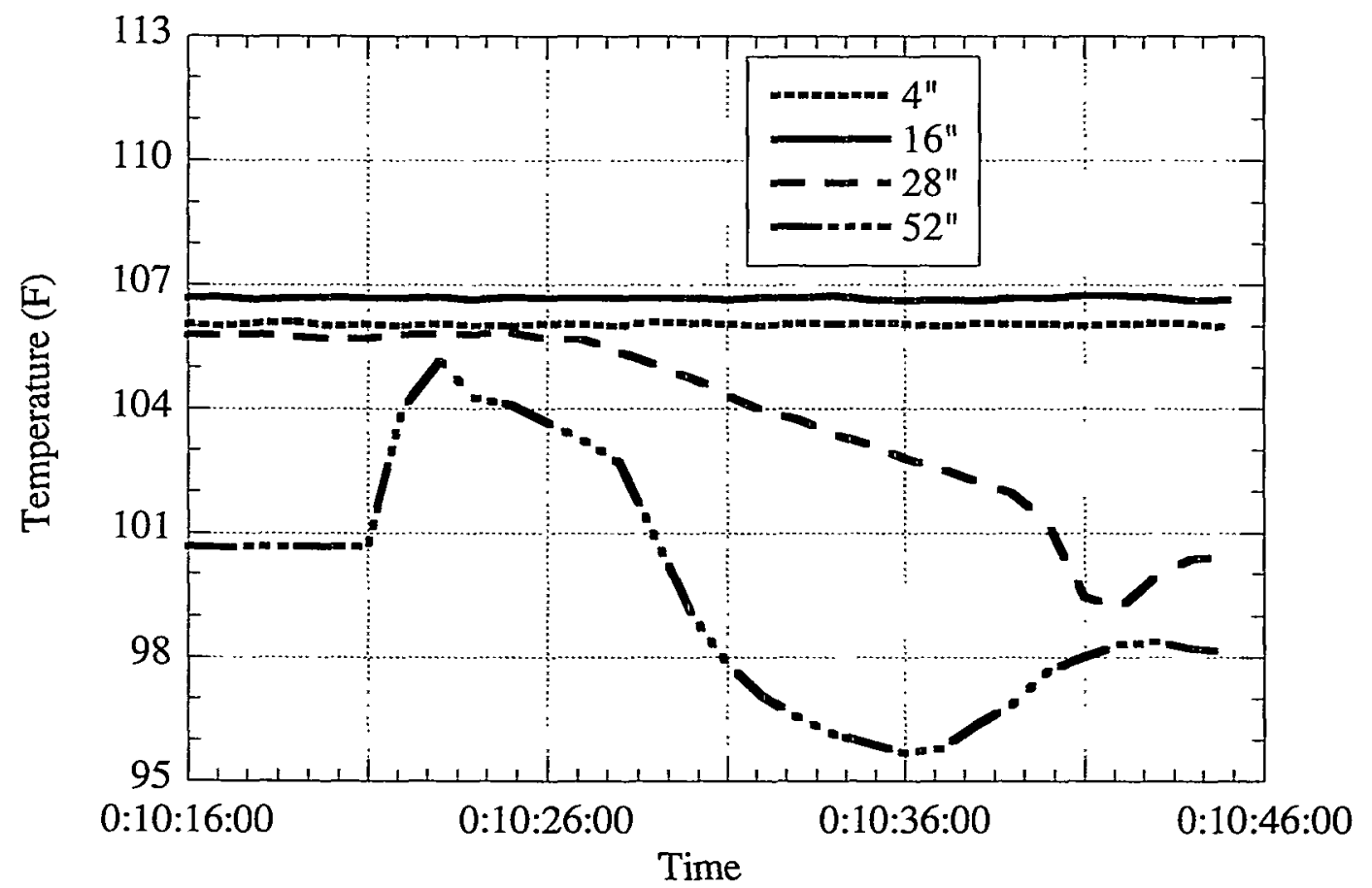

Figure 7.9. Thermocouple Uncovery Transient at 17C, March 17, 2000

runs made on that day with the jets aimed at $30,63,95$, and 123 degrees, respectively. Thus the run shown in Figure 7.9 actually took place three hours earlier than the one seen in Figure 7.8. The buoyancy effect is very strong. The jet affected only the 54-inch thermocouple on 17B (Figure 7.8) and was not able to cleanly uncover either the 54-inch or the 28-inch thermocouples on 17C (Figure 7.9).

Figure 7.10 shows the thermocouple response at 17B on March 24. This was the third of four runs on this date. The first run was aimed at $17 \mathrm{C}$, which shows an essentially identical response. A week of mixing has brought the 54-inch thermocouple to the mixed slurry temperature, and the lower density difference allows a clean uncovery of the 28 -inch thermocouple. Cooling of the bottom layer and improved jet penetration can be seen in the response one week later at 17C (April 1) shown in Figure 7.11. Here, the 16-inch thermocouple is beginning to respond during the last half of the pump run.

The thermocouple uncovery response displayed in Figure 7.11 along with neutron and gamma profiles clearly showed that the waste was well mixed from about 28 inches to the surface at 355 inches. Based on these data, the project concluded that the mixer pump evaluation period could begin. 


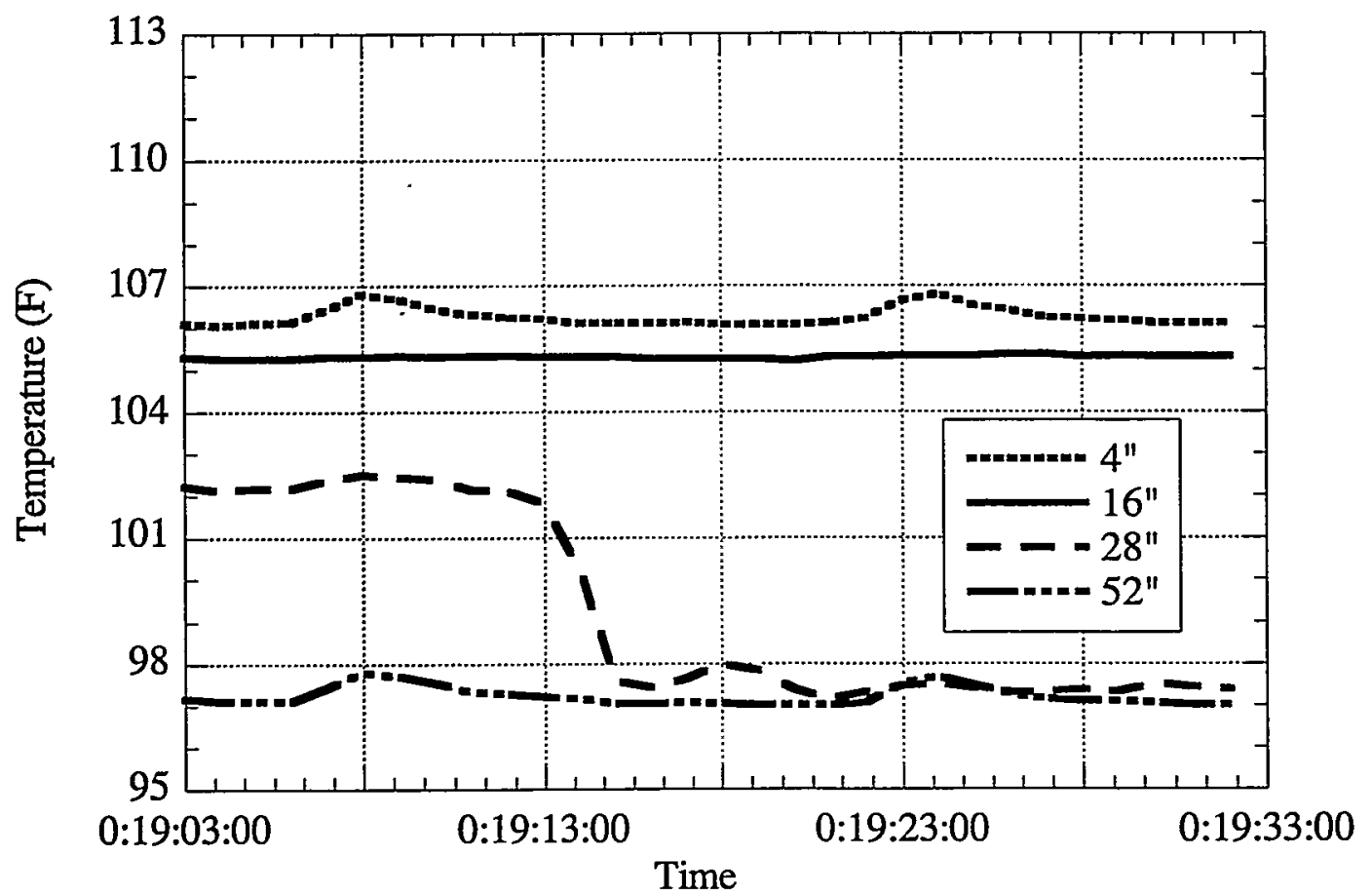

Figure 7.10. Thermocouple Uncovery Transient at 17B, March 24, 2000

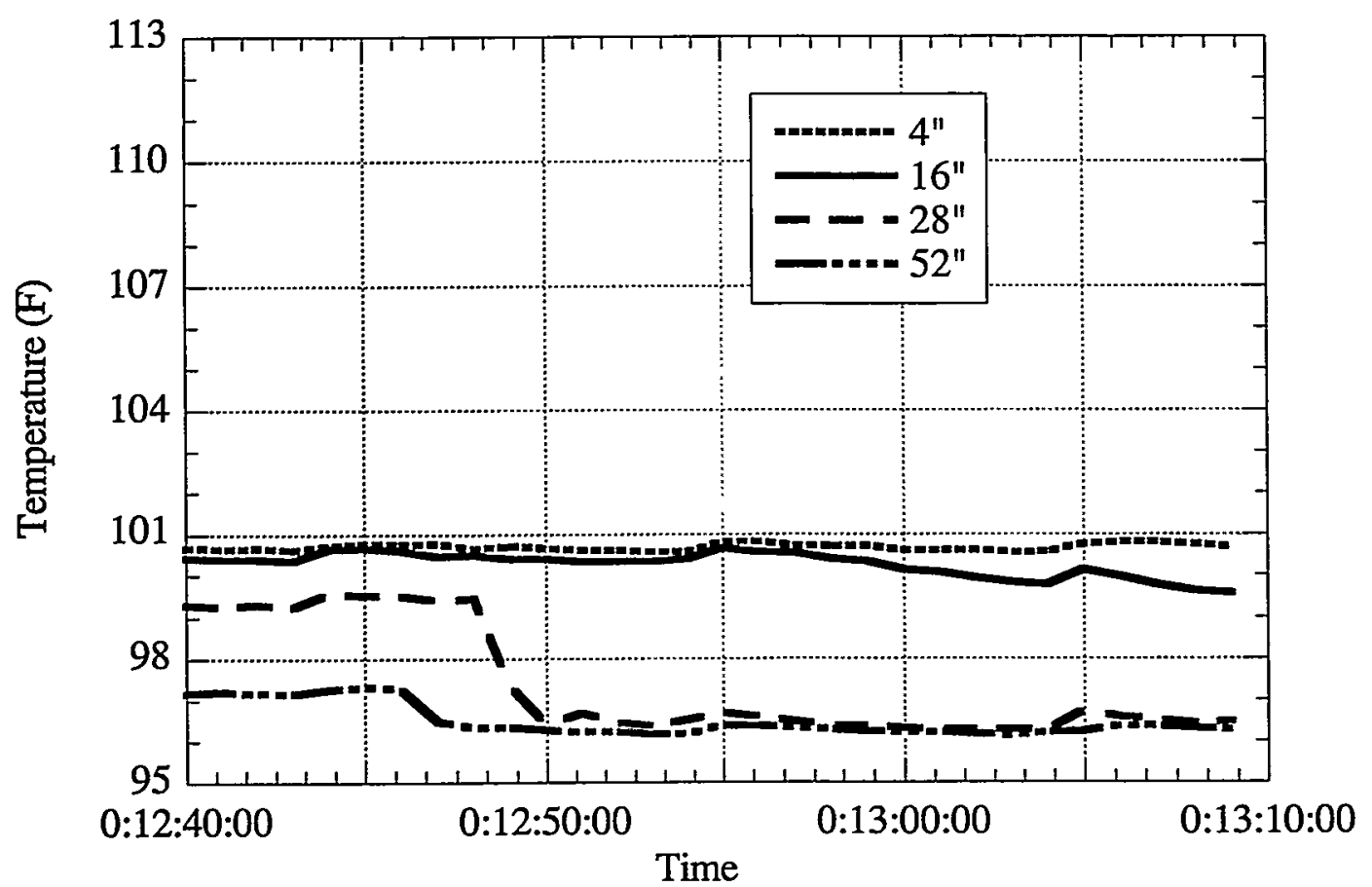

Figure 7.11. Thermocouple Uncovery Transient at 17C, April 1, 2000 


\subsection{Transfer System Performance}

The transfer pump was run in real waste for the first time during SY-101 remediation, and its performance was even more stable and dependable than anticipated. The transfers of waste from SY-101 to SY-102 were the first application of the New Generation Transfer Pump design with actual Hanford tank waste. The performance of the transfer pump and in-line dilution system was very reliable and stable throughout all campaigns. The operators were able to adjust the waste and water flows precisely. Total waste plus water flows ranged from 100 gpm to over 200 gpm. In-line dilution was initially set at about $0.9: 1$ on the first transfer but was reduced to $0.35: 1$ on the last transfer. However, the water added to the tank during back-dilutions maintained an overall dilution of about $0.9: 1$ in the mixture transferred to SY-102. Figures 8.1 through 8.4 show the waste flow, in-line dilution water flow, and resulting dilution ratio history for transfers 1a, 2a, 3a and 3b. Table 8.1 lists the values of these parameters and the averages for periods of different flows during each transfer.

The first transfer began with the waste flow adjusted to 62 gpm with a 60 -gpm water flow, for a dilution ratio of $0.97: 1$. After about six hours the waste flow was increased to $65 \mathrm{gpm}$, and a little over an hour later to almost $70 \mathrm{gpm}$. The water flow was held constant, so the dilution ratio decreased to $0.92: 1$ and $0.87: 1$, respectively. The waste flow decreased gradually to about $68 \mathrm{gpm}$ at the end of the transfer. The average waste and water flows for the first transfer were 66.8 and 59.9 , for an average dilution ratio of $0.90: 1$. The total flow of waste plus dilution water averaged about $128 \mathrm{gpm}$.

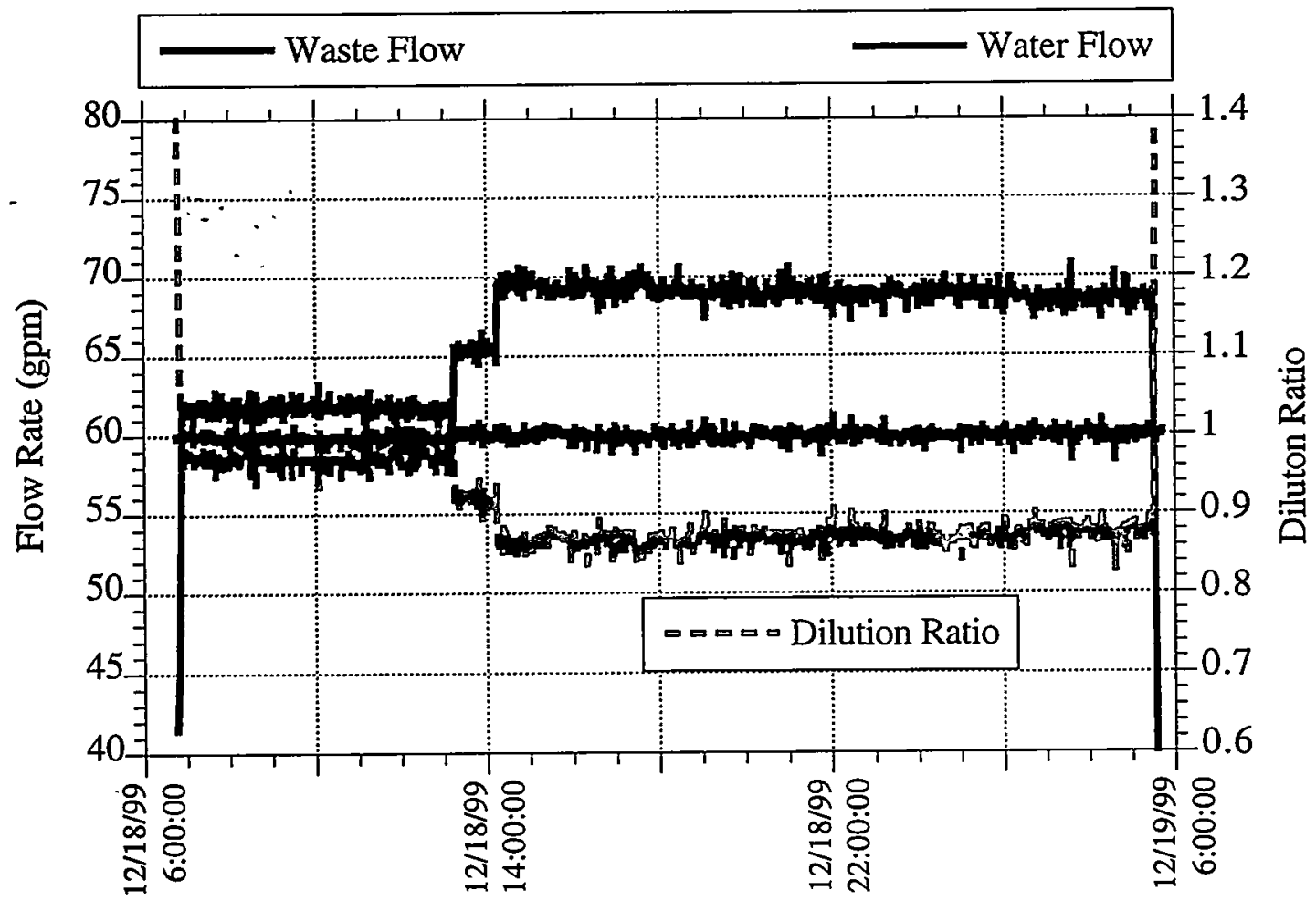

Figure 8.1. Waste Flow, Water Flow, and Dilution Ratio for the First Transfer 


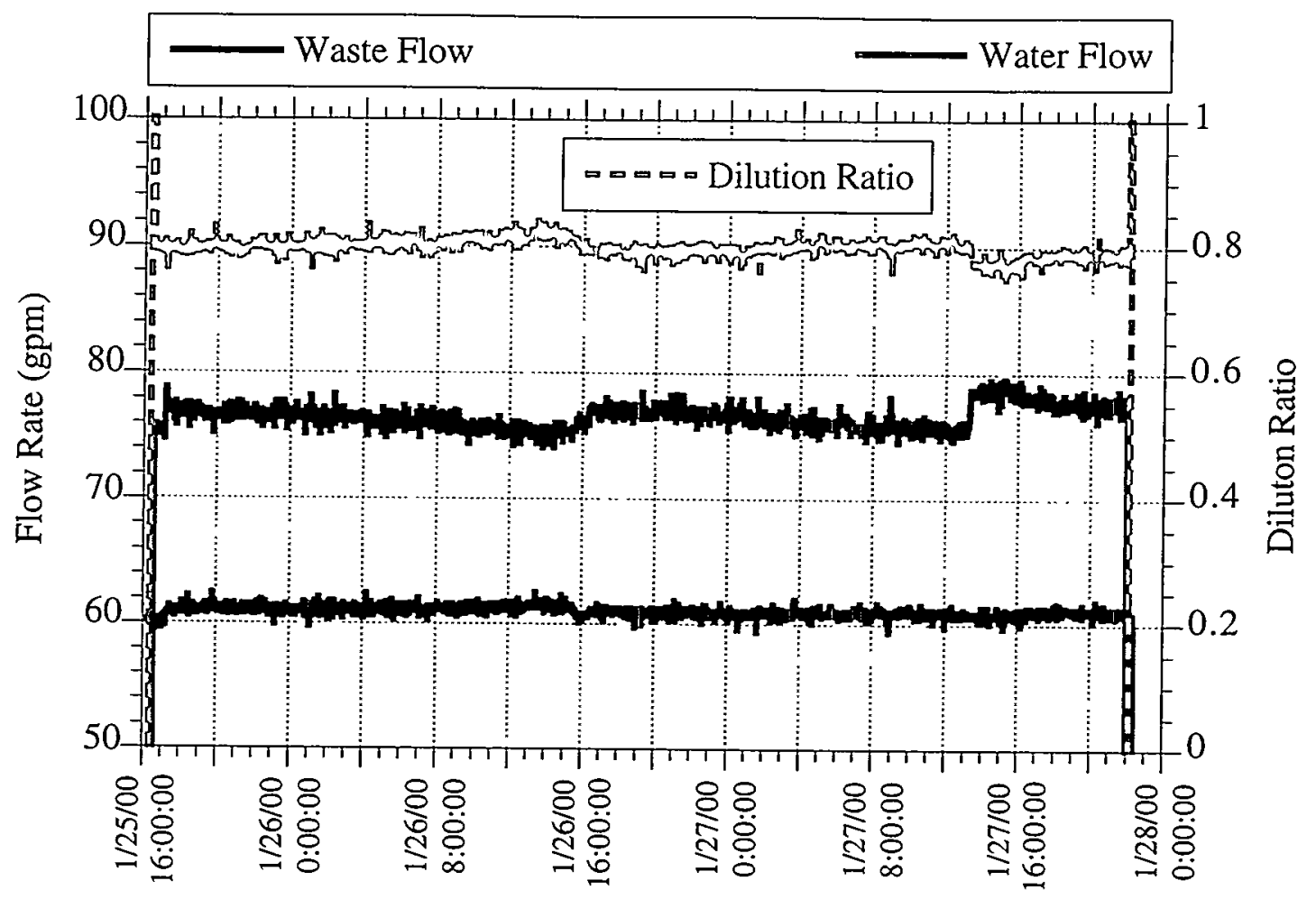

Figure 8.2. Waste Flow, Water Flow, and Dilution Ratio for the Second Transfer

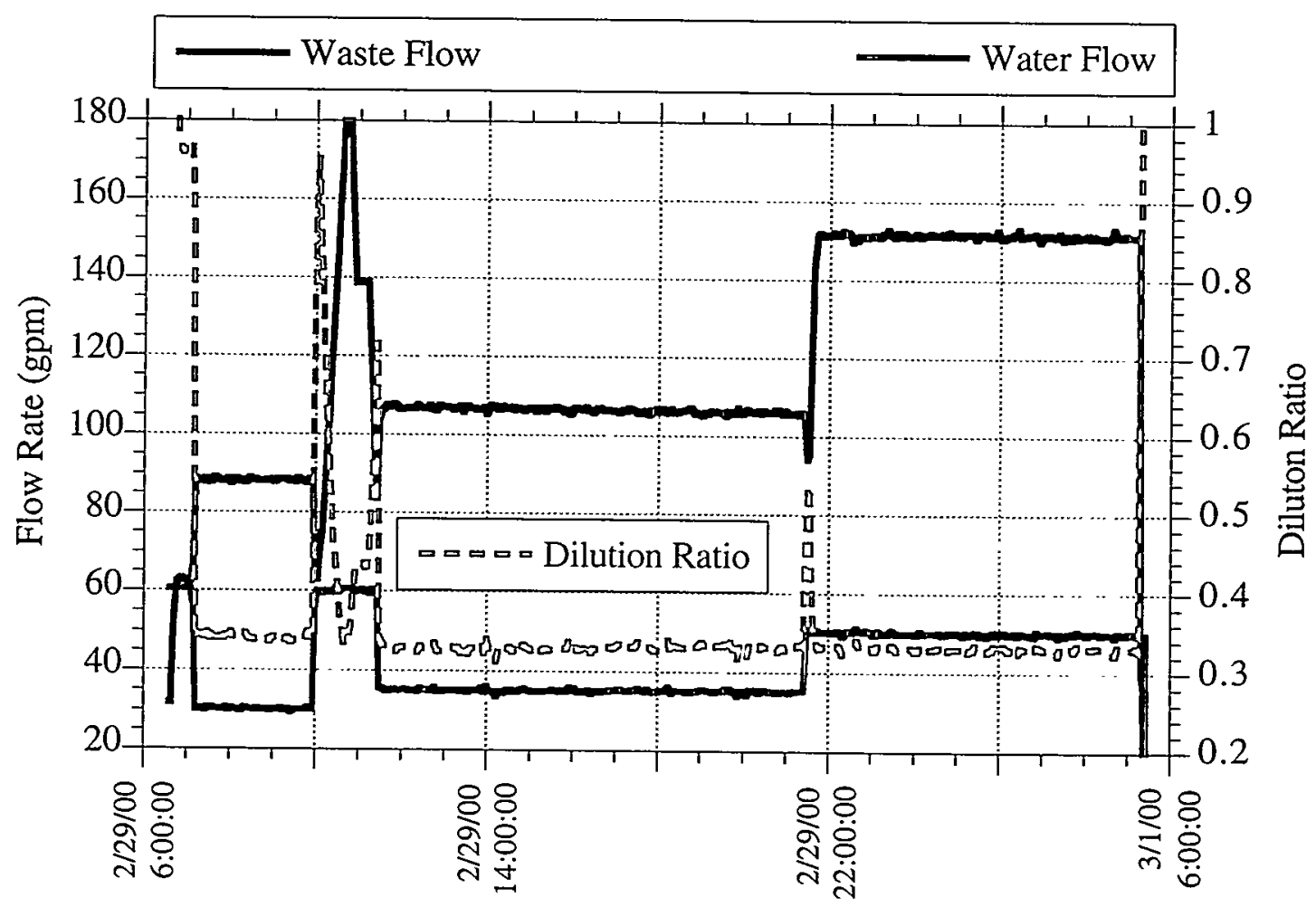

Figure 8.3. Waste Flow, Water Flow, and Dilution Ratio for Transfer 3a 


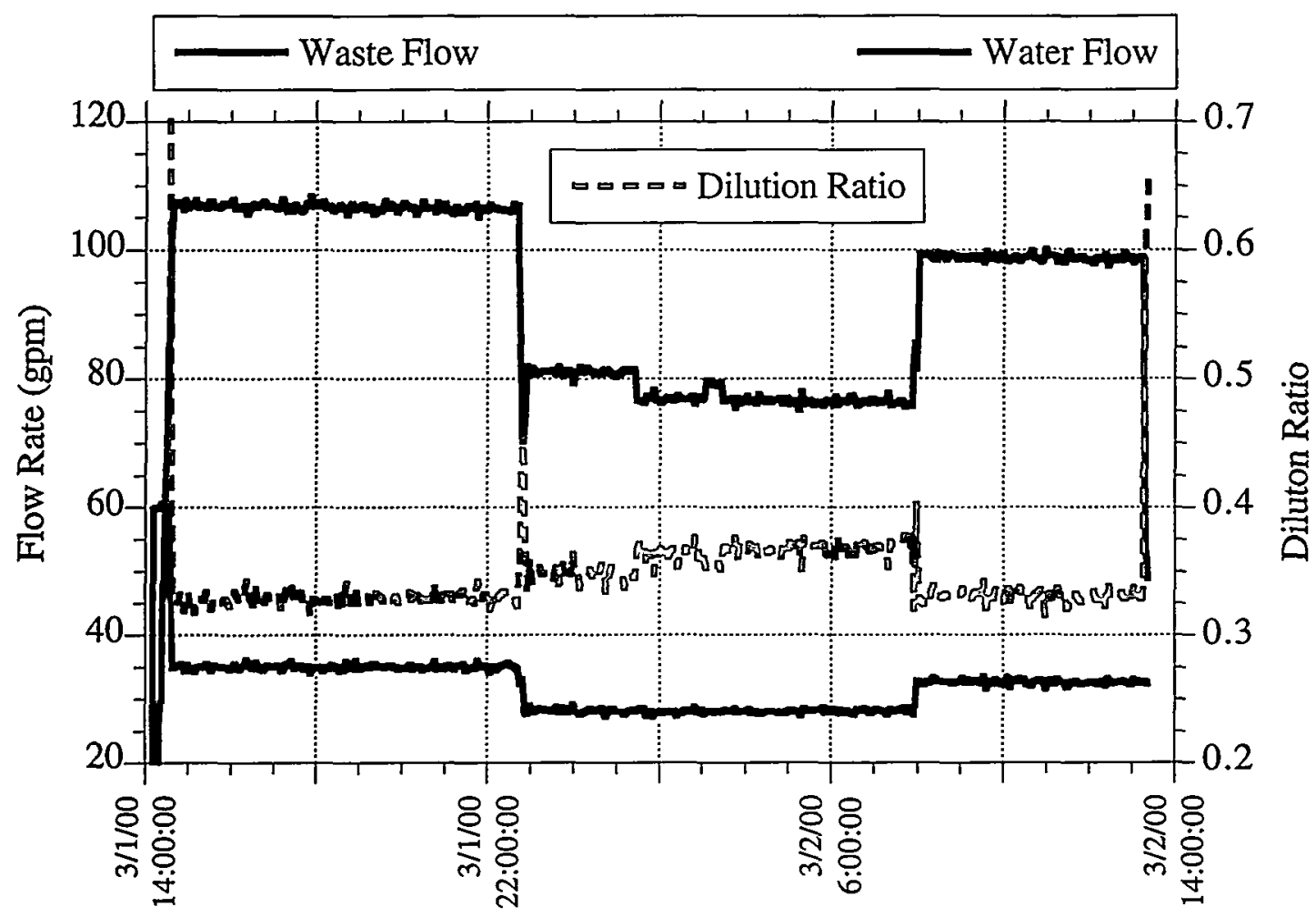

Figure 8.4. Waste Flow, Water Flow, and Dilution Ratio for Transfer $3 b$

Only small adjustments were made in the flows during the second transfer to compensate for the gradually decreasing waste flow as the level in SY-101 dropped and the level in SY-102 rose. The transfer started out at a waste flow of $77 \mathrm{gpm}$ with a $61 \mathrm{gpm}$ water flow, for a dilution ratio of 0.80 . About 24 hours later, the waste flow had decayed to about $75 \mathrm{gpm}$ and was reset back to $77 \mathrm{gpm}$. After 21 hours, the waste flow had again decreased to $75 \mathrm{gpm}$ and was raised back to $78 \mathrm{gpm}$. The water flow rate held almost constant during the entire transfer, averaging $61 \mathrm{gpm}$. The average waste flow was $76.3 \mathrm{gpm}$, and the dilution ratio was $0.80: 1$. The total waste mixture flow during the second transfer was about $140 \mathrm{gpm}$.

Transfer 3a began with an $86.7 \mathrm{gpm}$ waste flow and a $32.7 \mathrm{gpm}$ water flow, for a dilution ratio of $0.38: 1$. Three hours later the waste flow was ramped up to $143 \mathrm{gpm}$ with a water flow of $60 \mathrm{gpm}$. During the ramp-up, the total flow was over $240 \mathrm{gpm}$ for about 10 minutes. After about an hour, the waste flow was reduced to $107 \mathrm{gpm}$ with a water flow of $36 \mathrm{gpm}$ and held for the next 10 hours. At this point, the total flow was raised to a nominal $200 \mathrm{gpm}$ again with a waste flow of $150 \mathrm{gpm}$ and $50 \mathrm{gpm}$ of dilution water. The average waste and water flows for transfer $3 \mathrm{a}$ were $119 \mathrm{gpm}$ and $40 \mathrm{gpm}$, respectively, with a dilution ratio of 0.35:1.

The last transfer, $3 \mathrm{~b}$, began at a nominal $140 \mathrm{gpm}$ total flow, $107 \mathrm{gpm}$ waste and $35 \mathrm{gpm}$ water, with a dilution ratio of 0.33 . The waste flow was reduced to about $80 \mathrm{gpm}$ and the water flow to $28 \mathrm{gpm}$ after about eight hours to control the rate of ammonia release from the SY far stack. After maintaining this lower flow for about nine hours, the total flow was raised to a nominal $132 \mathrm{gpm}$ with $99 \mathrm{gpm}$ of waste and $33 \mathrm{gpm}$ of water. The average waste and water flows for transfer $3 \mathrm{~b}$ were $92.2 \mathrm{gpm}$ and $32 \mathrm{gpm}$, respectively, with a dilution ratio of 0.35 . 
Table 8.1. Transfer Flows and Dilution Ratio Summary

\begin{tabular}{|c|c|c|c|c|c|}
\hline Transfer & $\begin{array}{c}\text { Start Date and } \\
\text { Time } \\
\end{array}$ & $\begin{array}{c}\text { End Date and } \\
\text { Time }\end{array}$ & $\begin{array}{c}\text { Waste Flow } \\
\text { (gal) }\end{array}$ & $\begin{array}{c}\text { Water Flow } \\
\text { (gal) }\end{array}$ & $\begin{array}{c}\text { Dilution } \\
\text { Ratio }\end{array}$ \\
\hline \multirow[t]{6}{*}{$1 a$} & $12 / 180645$ & $12 / 180652$ & \multicolumn{3}{|c|}{ Startup } \\
\hline & $12 / 180645$ & $12 / 181315$ & 61.8 & 59.8 & 0.969 \\
\hline & $12 / 181315$ & $12 / 181415$ & 65.4 & 60 & 0.918 \\
\hline & $12 / 181415$ & $12 / 190530$ & 68.9 & 59.9 & 0.869 \\
\hline & $12 / 190530$ & $12 / 190545$ & \multicolumn{3}{|c|}{ Shutdown } \\
\hline & Average & & 66.8 & 59.9 & $0.902^{(a)}$ \\
\hline \multirow[t]{6}{*}{$2 a$} & $1 / 251622$ & $1 / 251637$ & \multicolumn{3}{|c|}{ Startup } \\
\hline & $1 / 251637$ & $1 / 261524$ & 76.2 & 61.1 & 0.803 \\
\hline & $1 / 261524$ & $1 / 271320$ & 76.3 & 60.9 & 0.798 \\
\hline & $1 / 271320$ & $1 / 272200$ & 78.0 & 60.9 & 0.781 \\
\hline & $1 / 272200$ & $1 / 272207$ & \multicolumn{3}{|c|}{ Shutdown } \\
\hline & Average & & 76.3 & 61.0 & $0.800^{(a)}$ \\
\hline \multirow[t]{7}{*}{$3 a$} & $2 / 290635$ & $2 / 290712$ & \multicolumn{3}{|c|}{ Startup } \\
\hline & $2 / 290712$ & $2 / 291012$ & 86.7 & 32.7 & 0.377 \\
\hline & $2 / 291012$ & $2 / 291119$ & 143.0 & 60.2 & 0.421 \\
\hline & $2 / 291119$ & $2 / 292132$ & 106.1 & 35.6 & 0.336 \\
\hline & $2 / 292132$ & $3 / 10516$ & 151.1 & 49.9 & 0.331 \\
\hline & $3 / 10516$ & $3 / 10523$ & \multicolumn{3}{|c|}{ Shutdown } \\
\hline & Average & & 119.0 & 40.1 & $0.352^{(\mathrm{a})}$ \\
\hline \multirow[t]{6}{*}{$3 b$} & $3 / 11418$ & $3 / 11439$ & \multicolumn{3}{|c|}{ Startup } \\
\hline & $3 / 1 \quad 1439$ & $3 / 12242$ & 106.6 & 35.0 & 0.328 \\
\hline & $3 / 12242$ & $3 / 20759$ & 78.0 & 28.1 & 0.360 \\
\hline & $3 / 20759$ & $3 / 21316$ & 98.8 & 32.6 & 0.330 \\
\hline & $3 / 21316$ & $3 / 21326$ & \multicolumn{3}{|c|}{ Shutdown } \\
\hline & Average & & 92.2 & 32.0 & $0.347^{(\mathrm{a})}$ \\
\hline
\end{tabular}

Transfer pump performance can be illustrated by the relationship between pump power and the output pressure and flow rate. The total flow rate (waste plus in-line dilution water) and pump pressure (measured on the outlet line in the PPP) during transfer 3a are plotted against pump motor current (approximate measure of power) in Figure 8.5. The plot represents the first six hours of transfer $3 a$ when the transfer flows were varied over the widest range. Since in-line dilution flow is independent of waste flow, the dilution ratio varied between 0.3:1 and 1:1 during this period. The density of the fluid being pumped varying accordingly and probably made the slight hysteresis that is visible mainly in the pressure. The "knots" on the plot show periods of steady operation. 


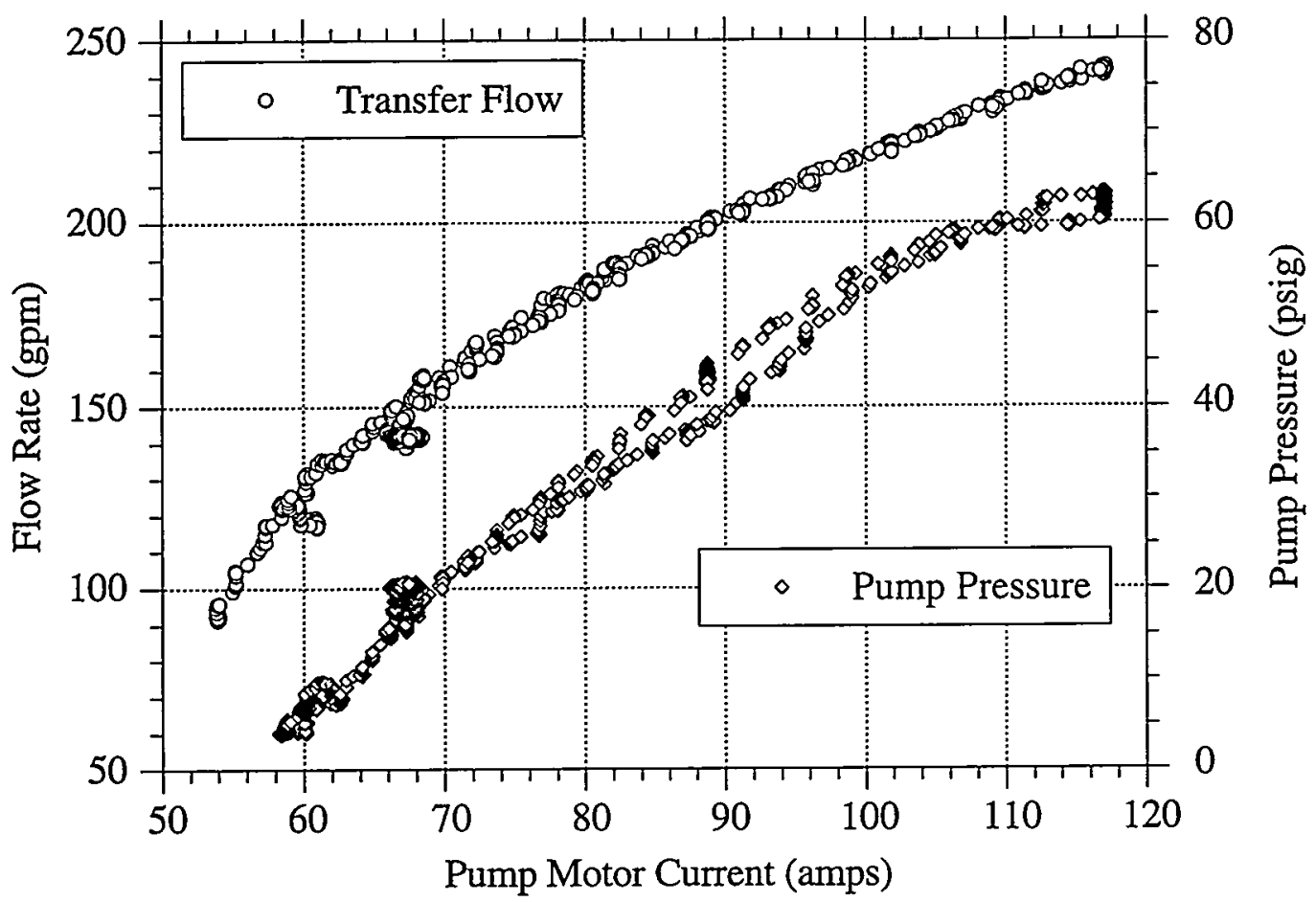

Figure 8.5. Transfer Pump Performance During Transfer 3a

Pump performance during the first transfer is compared to that of transfer 3a in Figure 8.6. While the two transfers follow almost identical trends within the "noise" of the data, the flow during the first transfer was slightly lower and the pressure slightly higher than during the third transfer. This is probably the result of a higher fluid density and the smaller difference between initial waste levels in SY-101 and SY-102 in the first transfer. ${ }^{(a)}$ The flow rate during transfer 3a is also plotted versus percent maximum pump speed in Figure 8.7. ${ }^{(b)}$ The flow rate increases linearly with pump speed except at the lowest rpm.

During design of the transfer system and planning its operation, several potential problems were postulated that might have degraded system performance. The major ones are summarized and refuted in the following list:

- There was some concern that the high-performance pump might have difficulty moving a liquid-solid-gas slurry with as high a density $(1.6 \mathrm{~g} / \mathrm{mL})$ as SY-101 waste, even with a 1:1 in-line dilution. No difficulties were encountered with the pump at any time during any transfer.

- With a fixed flow of pre-impeller dilution water, the fluid density increases with flow rate, which makes pressure drop and mass flow difficult to calculate. The concern was that the system could enter some adverse unpredicted mode that might damage the pump. The pump was quite stable and controllable throughout.

(a) The anti-siphon break in SY-102 is not complete at nominal waste flows.

(b) DSI from JR Buchanan to CE Hanson, CHGI, March 8, 2000, subject: NGTP Performance Data. 


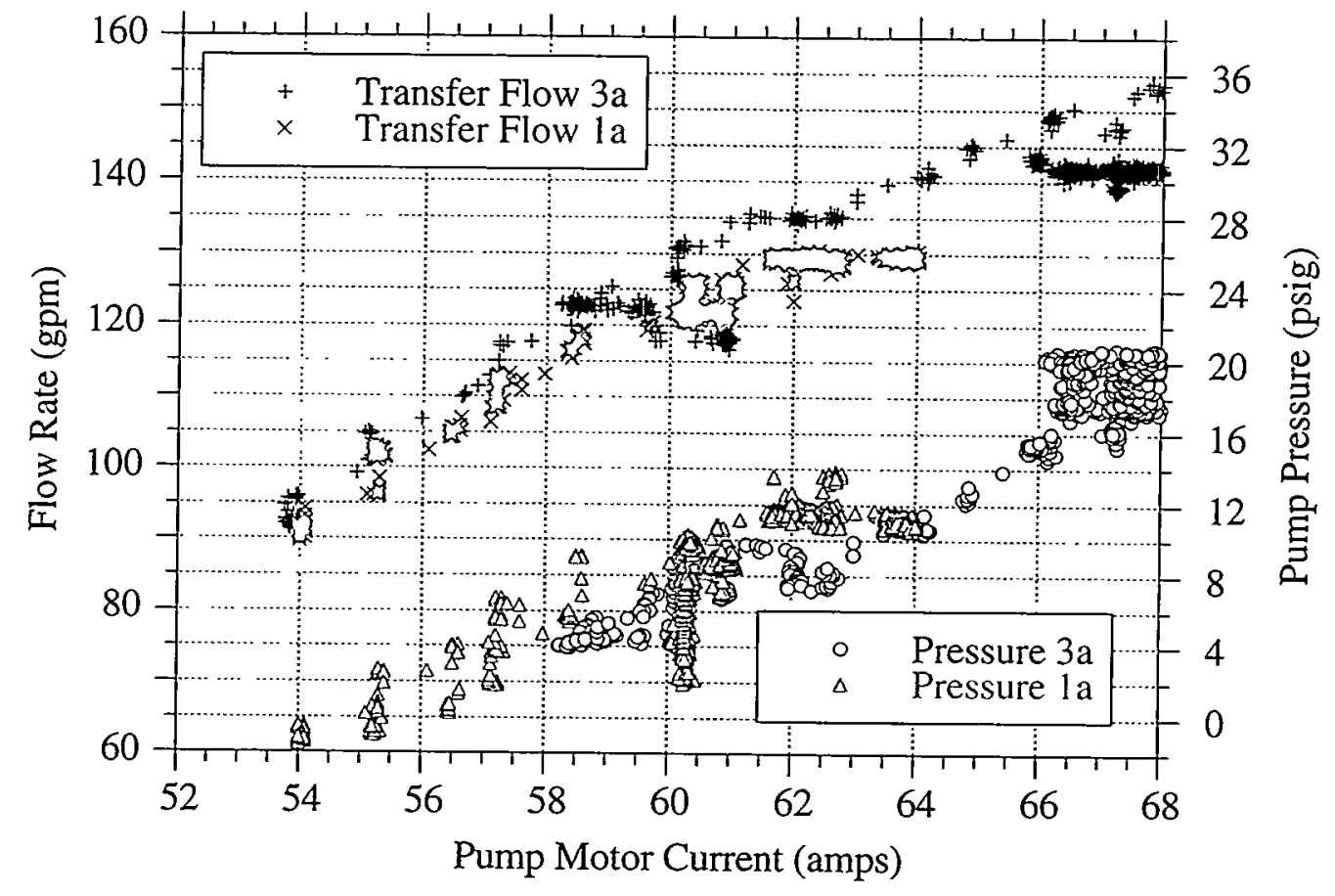

Figure 8.6. Comparison of Transfer Pump Performance Between Transfers 1a and 3a

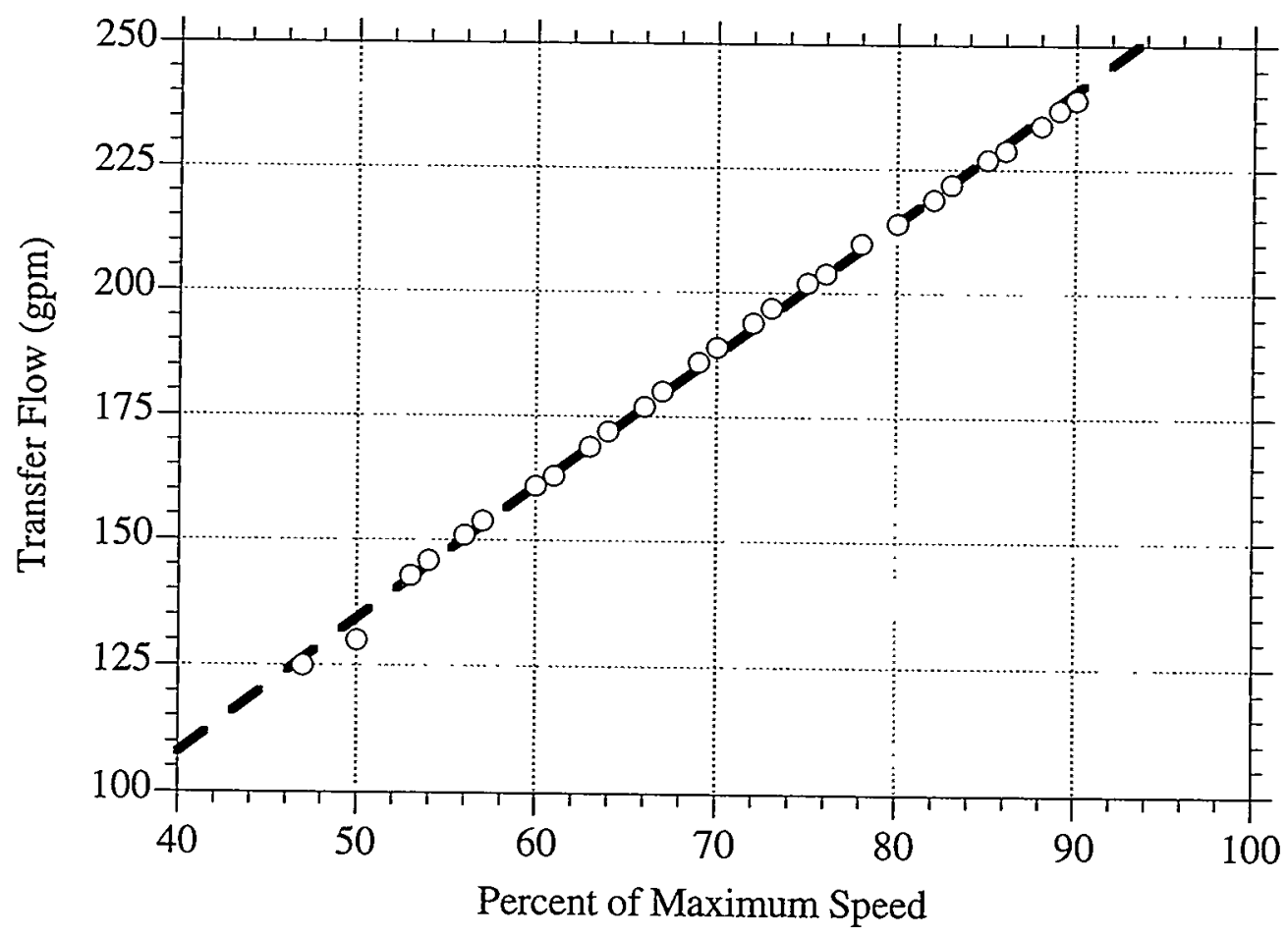

Figure 8.7. Transfer Flow Versus Percent Speed for Transfer 3a 
- Because the transfer flow path from SY-101 to SY-102 was essentially an inverted U-tube, there was concern that a siphoning instability might occur at startup and siphoning might occur under some conditions at shutdown, even with the anti-siphon break in SY-102. Motor current, flow, and pressure increases were steady and stable during startup, and the flow stopped cleaning when the pump was de-energized.

- Because in-line dilution was introduced as a spray outside the inlet screen, and dilution flow was established before the transfer pump started, it was postulated that a large fraction of the dilution flow might bypass the pump. Flow and temperature measurements showed that, at most, only a very small bypass of in-line dilution water occurred.

- The mixed slurry in SY-101 contained a small, unknown volume of gas in the form of small bubbles. The effect of these bubbles on the pump and their behavior in the system was also unknown. Vapor binding in the impellers and gas collecting at high points in the system were concerns. There was no evidence of either effect during operation.

The transfer pump performance in the tank matched or exceeded that predicted during design and experienced during testing in water. The pump was stable, precisely controllable, and operated successfully at near its design limit for about ten minutes during transfer $3 \mathrm{~b}$. The only design problem was the apparent air entrainment in the SY-102 siphon break that was assumed to have caused the high ammonia releases during transfer (see Section 5). 


\subsection{Summary and Conclușion}

The three-month remediation process, from mid-December 1999 through mid-March 2000, converted Tank 241-SY-101 from a high potential hazard requiring constant attention and expense into a resource that can eventually be used for normal waste retrieval staging operations. Throughout the three campaigns, transfer and dilution procedures were accomplished smoothly and efficiently without any major difficulties or discovery of new hazards. The transfer pump and dilution system performed flawlessly, and the mixer pump continued to operate normally except for a few minor irritations that were easily corrected.

Because of the history of SY-101 and the perceived hazards involved with eradicating the crust and releasing the considerable volume of gas it contained, the transfer and back-dilution process was heavily analyzed before the fact (e.g., Rassat et al. 2000; Stewart et al. 2000; Wells et al. 2000). Predictions were made about how the crust would behave during transfer and dissolution. Analyses were performed on the potential for crust hang-up or deformation during transfer, where the top and low back-dilution water would go, whether the crust would sink during back-dilution, and the consequences of wasteberg capsize and bubble slurry flow gas releases. The possibility of mixer pump damage or degradation by ingesting material from the base of the crust was considered in detail as was the potential for hazardous ammonia release by evaporation from a crust-free surface. The potential for formation of a deep nonconvective layer in SY-102 leading to BD GREs was also assessed. Section 9.1 summarizes actual observations compared with the predictions and expectations of these analyses and assessments, and Section 9.2 describes the end state of the tank and its expected behavior.

\subsection{Summary of Observations Versus Predictions and Expectations}

Though the analyses showed that the hazards and consequences were either minor or could be controlled effectively, all the predictions and assumptions could only be confirmed by direct observation. In most cases, the observations and measurements were in qualitative and often quantitative agreement with predictions made before the transfer. The list below summarizes the findings that matched expectations:

- The crust descended smoothly and in direct proportion with transfer if a ring of waste was assumed to be attached to the tank wall. The apparent ring thickness was about 40 inches during the first transfer, 24 inches during the second, and 16 inches during the last part of the third transfer.

- Top back-dilution lifted the crust almost as promptly and positively as low backdilution except during the initial part of the second campaign, when gas releases and crust dissolution obscured the lifting effect.

- No significant gas releases occurred in SY-101 during any of the transfers, but high ammonia concentrations were observed in SY-102 during each transfer.

- Little gas release occurred during the first back-dilution as the original crust freeboard, which contained little gas, dissolved. 
- Relatively large gas releases (up to $2000 \mathrm{ppm}$ hydrogen in the SY-101 headspace) occurred during the second top dilution as sections of the crust broke up, capsized, and submerged, accompanied by bubble slurry flows. Relatively small portions of the crust participated in these events.

- Mixing of low-dilution water above the transfer pump injection point during bottom dilution was very thorough, as evidenced by the uniform temperatures above the 100-inch level.

- Effects of a heat of solution or dilution raised the bulk slurry temperature about $4^{\circ} \mathrm{F}$ during the first low dilution and reduced the temperature drop during the second and third low dilutions.

- The first campaign's top dilution (1b) reduced the crust thickness about as much as predicted and nonuniformly as expected.

- Water from the first top-dilution (1b) flowed under the upper surface of the crust and across almost the entire tank, though islands were always visible. It did not show any symptoms of boring a hole through the crust.

- After the density of the diluent mixture increased sufficiently by dissolution of solids, the diluent readily flowed through the crust as the crust rose up through it.

- The overlying unsaturated liquid layer produced by top-dilution $2 \mathrm{~b}$ became nearly imperceptible to the neutron probe over the course of a month, with regular mixer pump runs and continued dissolution of the crust debris.

- Transfer pump operation was exceptionally stable and precisely controllable (no siphoning) in both campaigns.

- Mixer pump runs after each campaign showed reduced power consumption, volute pressure, and discharge line pressure drop, with no major operational anomalies.

- The flow of top dilution water quickly scrubbed much of the ammonia from the SY-101 headspace. The dilute layer that formed on the surface also inhibited ammonia evaporation.

- The depth of settled solids in SY-102 increased but by no more than 25 inches, as predicted.

- The original SY-101 crust was replaced by a thin, white, foamy "scum" that now covers the entire waste surface. No clean liquid surface formed.

These other observations were unexpected, though they did not suggest difficulties or new hazards with further transfer and dilution steps. The most significant of these are

- An irregular ring of waste unexpectedly remained attached to the wall, possibly all the way to tank bottom. However, the maximum ring thickness of $\sim 1 \mathrm{~m}$ matched the maximum value predicted based on the estimated strength of the waste.

- Strains on the 17C MIT and mixer pump column indicated some transverse loading during the first and second campaigns.

- The second top dilution entirely submerged the crust and caused detachment of the ring of waste stuck to the tank walls above the waste surface. This resulted in "landslides" of waste from the walls onto the surface and across the tank bottom. 
- Density stratification in SY-102 apparently inhibited convection, causing the appearance of a false nonconvective layer in the temperature profile after each transfer. Later evolution of the temperature profile showed these were false indications.

- Mixer pump power, volute pressure, and discharge pressure drop decreased nonuniformly and by a larger factor than the decrease in mixed slurry density.

- Very little, if any, gas was released from the mixed slurry during low back-dilution in the first two campaigns.

- Gas release during the first transfer was higher than expected; it increased promptly when transfer started, and decreased promptly when transfer ended.

\subsection{Results of Remediation}

The three remediation campaigns achieved the intended goals. The surface level rise issue was solved, and the threat of the waste level exceeding the tank capacity was removed. The first campaign solved the immediate waste level problem by dissolving the upper part of the crust. It also confirmed (and slightly adjusted) our expectations of the behavior of the waste during transfer, top dilution, and low dilution and exercised all aspects of the transfer system. The second campaign removed the hazard that had developed over several years of level growth by destroying the crust and releasing most of the tank's stored gas. The third campaign eliminated the waste's ability to retain a significant volume of gas by dissolving the bulk of the remaining soluble solids and diluting the rest of the waste to the desired point.

On April 3, 2000, SY-101 entered a period of evaluation without mixer pump runs to confirm that the desired end state has actually been achieved. The tank is predicted to contain a relatively shallow nonconvective layer with a much-reduced gas generation rate that will not retain a volume of gas that could lead to return to BD GREs. The amount of dilution required to accomplish this was determined from all the available models and criteria that have been developed over several years to assess whether a tank is subject to BD GREs.

These models and criteria distinguish tanks exhibiting BD GREs from other DSTs by comparing combinations of physical parameters, including convective and nonconvective layer density and depth, nonconvective layer strength, and gas generation rate. Specifically, three parameters or combinations of parameters are used to separate BD GRE tanks from non-BD GRE tanks:

1. Average SpG: Based on experience from evaporator operations, the average specific gravity of the waste in the tank is used to separate BD GRE and non-BD GRE tanks in the current waste compatibility criteria (Fowler et al. 1995).

2. $\mathrm{SpG}_{\mathrm{CL}} * \mathbf{H}_{\mathrm{NCL}}$ : The product of the convective layer specific gravity and the nonconvective layer depth was determined empirically to be a discriminator of BD GRE behavior (Estey and Guthrie 1996).

3. Buoyancy Ratio: This is a semi-empirical relation that estimates the average waste void fraction based on a balance of gas generation and background release (Meyer and Wells 
2000). The buoyancy ratio represents the average void fraction divided by the neutral buoyancy void fraction and is given by

$$
\mathrm{BR}=\frac{\mathrm{CH}_{\mathrm{NCL}}^{2}}{\rho_{\mathrm{NCL}}-\rho_{\mathrm{CL}}}\left(\frac{\mathrm{GT}}{\mathrm{P}}\right)^{1 / 3}
$$

where $\mathrm{C}$ is a constant, $\mathrm{H}_{\mathrm{NCL}}$ is the nonconvective layer depth, $\mathrm{G}$ is the molar gas generation rate per unit volume, $\mathrm{T}$ and $\mathrm{P}$ are the average NCL temperature and pressure, respectively, and $\rho_{\mathrm{NCL}}$ and $\rho_{\mathrm{CL}}$ are the layer densities. The neutral buoyancy void fraction is a function of the convective and nonconvective layer densities and is expressed as

$$
\alpha_{\mathrm{NB}}=1-\frac{\rho_{\mathrm{CL}}}{\rho_{\mathrm{NCL}}}
$$

A range of expected values of these three parameters for SY-101 after various volumes of transfer and back-dilution are compared with those for the other DSTs. Five sequential steps in the transfer and back-dilution process are evaluated as follows (see Table 1.2):
A initial, pre-mixer pump condition of 1992-93 when BD GREs were observed
B pre-dilution conditions of $12 / 99$ with $3-m$ crust
$\mathrm{C}$ after the first campaign (net $90 \mathrm{kgal}$ transfer and $62 \mathrm{kgal} \mathrm{back-dilution)}$
D after the second campaign (net $321 \mathrm{kgal}$ transfer and $291 \mathrm{kgal}$ back-dilution)
$\mathrm{E}$ after the third campaign (net $525 \mathrm{kgal}$ transfer and $434 \mathrm{kgal}$ back-dilution)

Cases C-E are the cumulative results of the three transfer and back-dilution campaigns. The waste configuration for each case is given in Table 9.1. These configurations represent the unmitigated (unmixed) waste configuration that would eventually exist if mixer operation were terminated and suspended solids allowed to settle. Physical parameters for SY-101 after transfer and back-dilution were estimated based on an analysis of the dilution data and conservation of mass. Uncertainties for SY-101 were determined with a Monte Carlo simulation on the transfer and back-dilution model. Uncertainties for the other tanks exhibiting BD GREs using Monte Carlo simulation based on the TWINS3 Best Basis Data Base (8/11/99) data. Uncertainties are not available in the data for tanks that do not exhibit BD GREs.

The gas generation rates listed for cases $\mathrm{C}-\mathrm{E}$ are computed based on dilution only and thus represent an upper bound. The columns labeled "CL" and "NCL" refer to the convective and nonconvective layers, respectively, and the last column is computed from Eq. (9.1). Essentially all of the soluble solids are dissolved after $291 \mathrm{kgal}$ of back-dilution (Case D). Further dilution reduced the gas generation rate and decreased the bulk specific gravity of the convective and nonconvective layers (Case $\mathrm{E}$ ).

The results are plotted in Figures 9.1-9.3. The buoyancy ratio is adjusted and $\mathrm{SpG}_{\mathrm{CL}}{ }^{*} \mathrm{H}_{\mathrm{NCL}}$ is normalized so the lowest value for BD GRE tanks is 1.0. In the figures, the squares represent conditions in SY-101, the triangles show tanks that exhibit BD GREs, and the diamonds indicate the top three non-BD GRE tanks. The vertical separation on the plots has no significance and is included only to improve clarity. 
Table 9.1. Effect of Transfer and Back-Dilution on SY-101 Waste Configuration

\begin{tabular}{|c|c|c|c|c|c|c|c|}
\hline \multirow{2}{*}{ Case } & \multicolumn{3}{|c|}{ Layer Thickness (in.) } & \multicolumn{2}{|c|}{ Specific Gravity } & \multirow[t]{2}{*}{$\begin{array}{c}\text { Gas } \\
\text { Generation } \\
\text { (scfd) }\end{array}$} & \multirow[t]{2}{*}{$\begin{array}{c}\text { Neutral } \\
\text { Buoyancy } \\
\text { Void } \\
\left(\alpha_{\mathrm{NB}}\right) \\
\end{array}$} \\
\hline & Crust & CL & NCL & $\mathrm{CL}$ & NCL & & \\
\hline$\overline{\mathrm{A}}$ & $39 \pm 3.5$ & $146 \pm 16$ & $230 \pm 16$ & $1.49 \pm 0.07$ & $1.70 \pm 0.05$ & $115 \pm 36$ & $0.13 \pm$ \\
\hline B & $122 \pm 11$ & $113 \pm 12$ & $185 \pm 13$ & $1.49 \pm 0.07$ & $1.70 \pm 0$ & $95 \pm 29$ & $0.13 \pm 0.02$ \\
\hline $\mathrm{C}$ & $100 \pm 6$ & $184 \pm 83$ & $119 \pm 81$ & $1.49 \pm 0.08$ & $1.70 \pm 0.09$ & $91 \pm 28$ & $0.13 \pm 0.03$ \\
\hline $\bar{D}$ & 0 & $279 \pm 36$ & $87 \pm 48$ & $1.43 \pm 0.06$ & $1.66 \pm 0.09$ & $63 \pm 19$ & $0.14 \pm 0.03$ \\
\hline$E$ & 0 & $270 \pm 29$ & $70 \pm 36$ & $1.34 \pm 0.05$ & $1.60 \pm 0.09$ & $44 \pm 13$ & $0.17 \pm 0.04$ \\
\hline
\end{tabular}

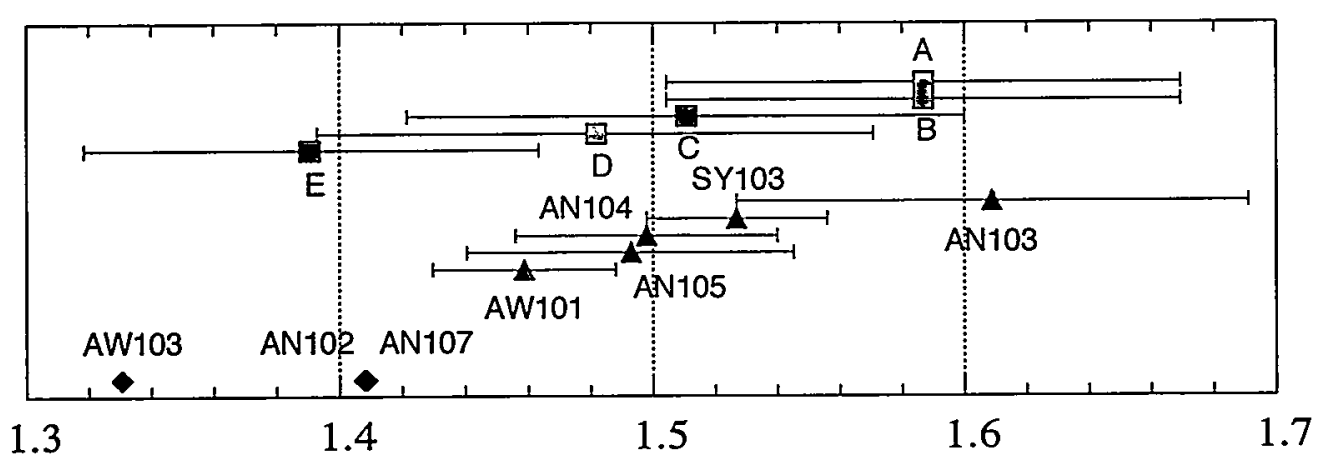

Figure 9.1. Average SpG

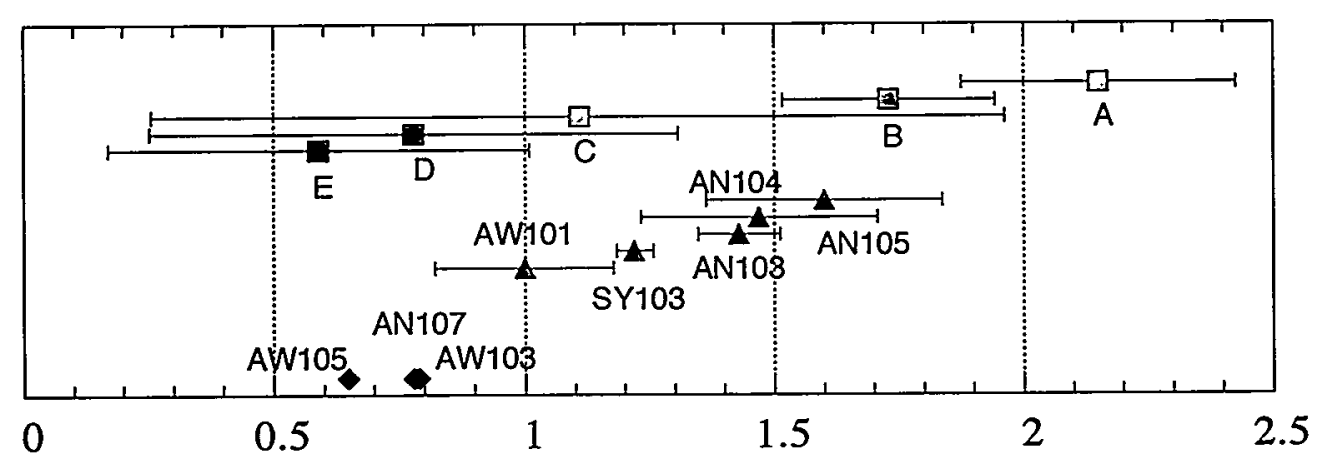

Figure 9.2. $\mathrm{SpG}_{\mathrm{CL}} * \mathrm{H}_{\mathrm{NCL}}$ (normalized) 


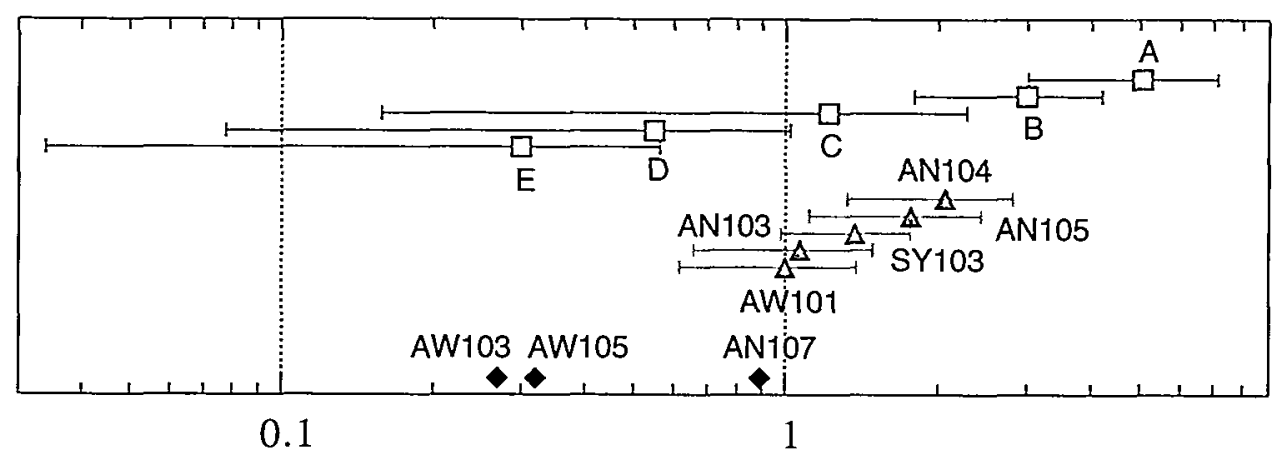

Figure 9.3. Buoyancy Ratio

The transfer and dilution volume that drives SY-101 into the company of non-BD GRE tanks using these parameters was the basis for the decision on the transfer and dilution volume that would accomplish remediation of gas retention in SY-101. From the comparisons shown in the figures, the project concludes that a 500-kgal transfer and approximately equal back-dilution was sufficient to drive SY-101 into the company of the non-BD-GRE tanks.

The mixer pump evaluation period will establish whether the predicted waste configuration and conditions described in Table 9.1 are attained after the suspended solids settle out without the mixer pump operating. Monitoring will also detect early signs of significant gas retention or other potentially hazardous conditions requiring return to mixer pump operations. However, no significant gas retention is expected, and the plan is to submit documentation to remove SY-101 from the FGWL and close the level-rise USQ in the fall of 2000 and return the tank to use. 


\subsection{References}

Barton WB. 1999. Maximum First Transfer and Dilution Volume for Tank 241-SY-101. RPP5344, Lockheed Martin Hanford Company, Richland, Washington.

Conner JM and GM Koreski. 1998. Quarterly Review of 241-SY-101 Data: October December, 1998. HNF-4039, Lockheed Martin Hanford Corp., Richland, Washington.

Conner JM and GM Koreski. 1999. Quarterly Review of 241-SY-101 Data: July-September, 1999. HNF-5265, Lockheed Martin Hanford Corp., Richland, Washington.

Estey SD. 2000. Process Control Plan for Tank 241-SY-101 Surface Level Rise Remediation. HNF-4264, Rev 3B. CH2M Hill Hanford Group, Inc., Richland, Washington.

Estey SD and.MD Guthrie. 1996. An Analysis of Parameters Describing Gas Retention/Release Behavior in Double-Shell Tank Waste. WHC-SD-WM-TI-755. Westinghouse Hanford Company, Richland, Washington.

Fowler KD. 1995. Tank Farm Waste Compatibility Program. WHC-SD-WM-OSD-015 Rev. 1, Westinghouse Hanford Company, Richland, Washington.

Hu TA. 1999. Empirical Rate Equation Model and Rate Calculations of Hydrogen Generation for Hanford Tank Waste. HNF-3851 Rev. 0, Lockheed Martin Hanford Corp., Richland, Washington.

Mahoney LA, ZI Antoniak, JM Bates, and ME Dahl. 1999. Retained Gas Sampling Results for the Flammable Gas Program. PNNL-13000, Pacific Northwest National Laboratory, Richland, Washington.

Mahoney LA and DS Trent. 1995. Correlation Models for Waste Tank Sludges and Slurries. PNL-10695, Pacific Northwest National Laboratory, Richland, Washington.

McCain DJ. 1999. Results of Vapor Space Monitoring of Flammable Gas Watch List Tanks. HNF-SD-WM-TI-797 Rev. 4, Fluor Daniel Hanford, Inc., Richland, Washington.

Meyer PA, ME Brewster, SA Bryan, G Chen, LR Pederson, CW Stewart and G Terrones. 1997. Gas Retention and Release Behavior in Hanford Double-Shell Waste Tanks. PNNL-11536 Rev.1, Pacific Northwest National Laboratory, Richland, Washington.

Meyer PA and BE Wells. February 2000. "Understanding Gas Release Events in Hanford Double-Shell Tanks." Proceedings of Waste Management 2000, Tucson, Arizona.

Perry RH and CH Chilton. 1973. Chemical Engineers' Handbook, Fifth Edition. McGraw-Hill Book Company, New York. 
Rassat SD, BE Wells, CW Stewart, JM Cuta, WL Kuhn, ZI Antoniak, KP Recknagle, G Terrones, JH Sukamto, VV Viswanathan, DP Mendoza. 2000. Dynamics of Crust and Gas Release in Tank 241-SY-101. PNNL-13112, Pacific Northwest National Laboratory, Richland, Washington.

Stewart CW, JM Alzheimer, G Chen, and PA Meyer. 1998. In Situ Void Fraction and Gas Volume in Hanford Tank 241-SY-101 as Measured with the Void Fraction Instrument. PNNL-12033, Pacific Northwest National Laboratory, Richland, Washington.

Stewart CW, SD Rassat, JH Sukamto, and JM Cuta. 1999. Buoyancy and Dissolution of the Floating Crust Layer in Tank 241-SY-101 During Transfer and Back-Dilution. PNNL-13040, Pacific Northwest National Laboratory, Richland, Washington.

Stewart CW, LA Mahoney, and WB Barton. 2000. Analysis of Several Hazardous Conditions for Large Transfer and Back-Dilution Sequences in Tank 241-SY-101. PNNL-13118, Pacific Northwest National Laboratory, Richland, Washington.

Sullivan HL. 1995. A Safety Assessment for Proposed Pump Mixing Operations to Mitigate Episodic Gas Releases in Tank 241-SY-101: Hanford Site, Richland, Washington. LA-UR-923196 Rev. 14, Los Alamos National Laboratory, Los Alamos, New Mexico.

Wells BE, PA Meyer, and G Chen. 2000. The Potential for Buoyant Displacement Gas Release Events in Tank 241-SY-101 after Waste Transfer from Tank 241-SY-101. PNNL-13202, Pacific Northwest National Laboratory, Richland, Washington. 


\section{Distribution}

No. of

Copies

Offsite

2 DOE Office of Scientific and

Technical Information

H Babad

2540 Cordoba $\mathrm{Ct}$.

Richland, WA 99352

WL Kubic

Los Alamos National Laboratory

PO Box 1663

Los Alamos, NM 87545
No. of

Copies

J. M. Conner R2-11

J. M. Grigsby R1-44

C. E. Hanson $\quad$ S7-70

G. D. Johnson R1-44

N. W. Kirch R2-11

L. J. Kripps R1-44

C. E. Leach R1-44

J.W. Lentsch R3-25

R. E. Raymond (5) $\quad$ S7-70

D. A. Reynolds R2-11

F. A. Schmorde T4-08

J. E. Van Beek S2-48

30 Pacific Northwest National Laboratory

12 DOE Office of River Protection

CA Groendyke (10) H6-60

DH Irby H6-60

J-S Shuen H6-60

22 PHMCTeam

W. B. Barton

R2-11

R. E. Bauer

S7-70

J. R. Biggs

S7-70

C. Carro

R1-44

R. J. Cash

R1-44

A. F. Choho
J. M. Bates

S. Q. Bennett

J. W. Brothers (10)

J. M. Cuta

P. A. Gauglitz

J. L. Huckaby

W. L. Kuhn

P. A. Meyer

L. A. Mahoney (3)

S. D. Rassat

C. W. Stewart (3)

B. E. Wells

Information Release (5)
K7-15

K7-90

K9-20

K7-15

K6-28

K7-15

K7-15

K7-15

K7-15

K6-28

K7-15

K7-15

K1-06 